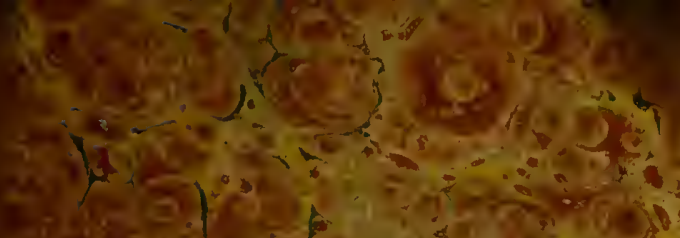

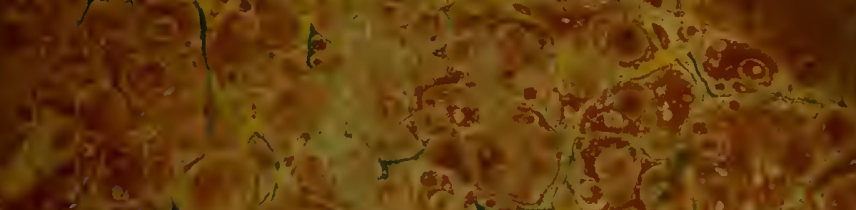

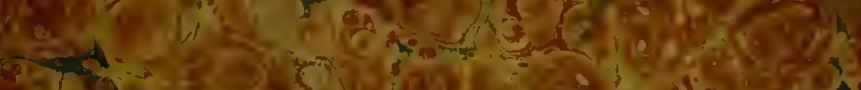

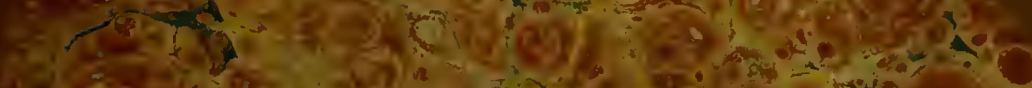

4.5.

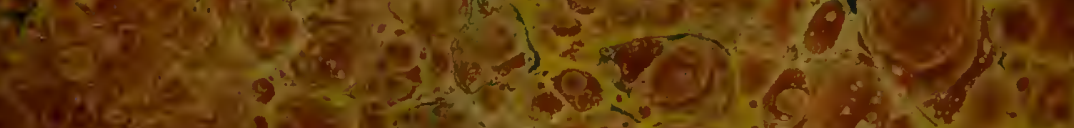

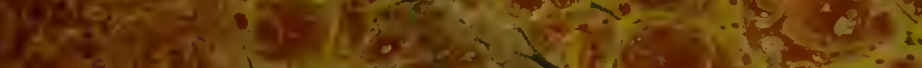

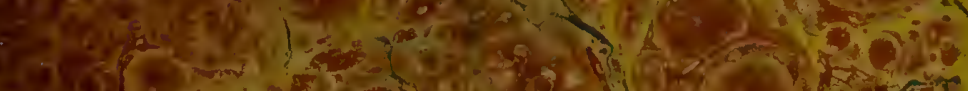
246)

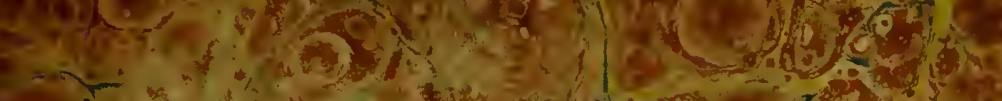

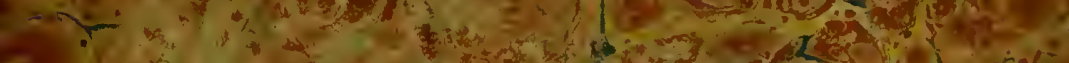

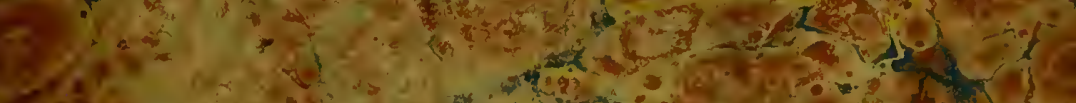

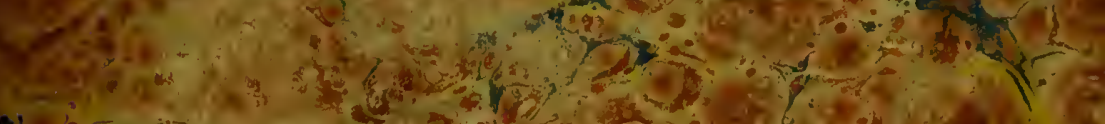

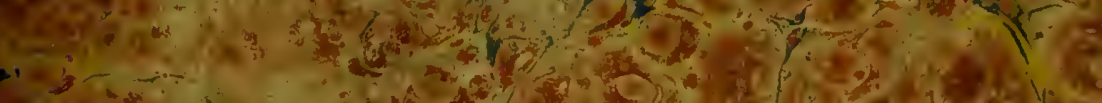

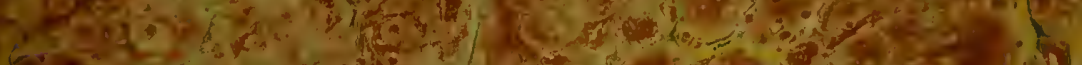

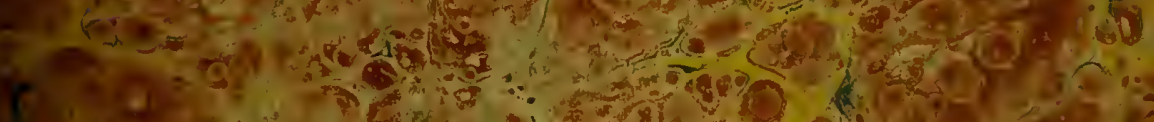

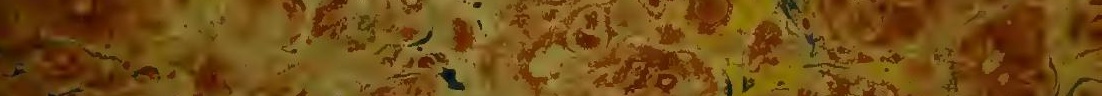

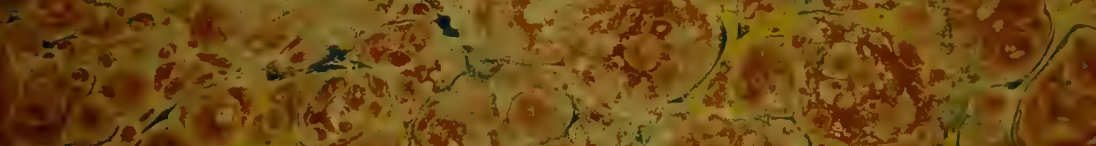

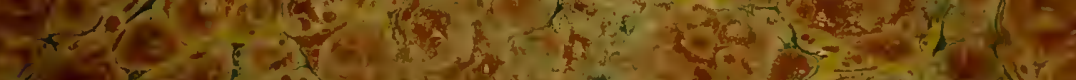

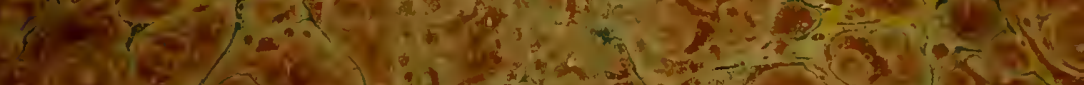

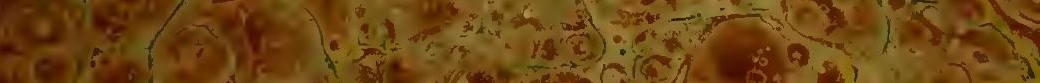

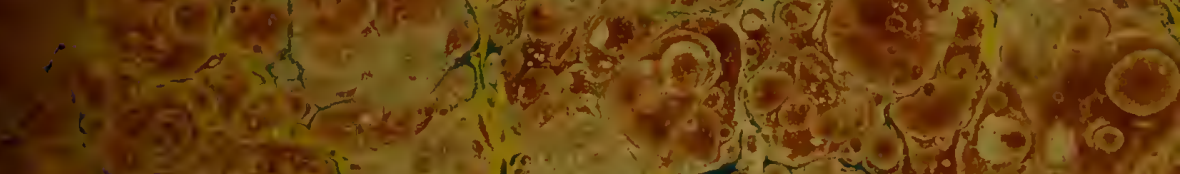

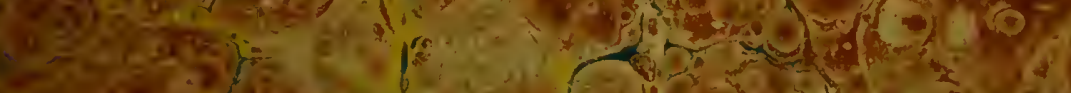

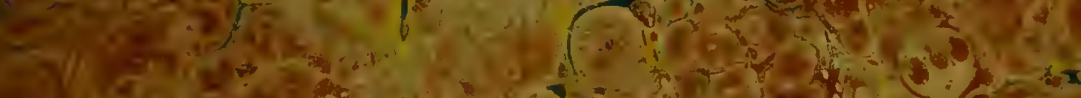

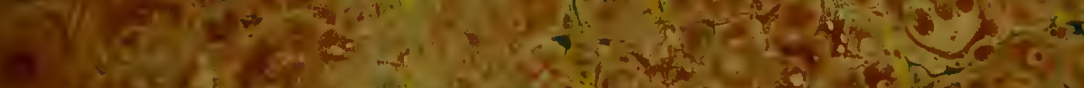

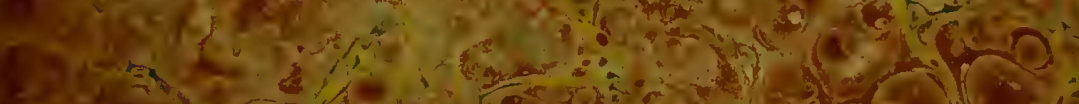

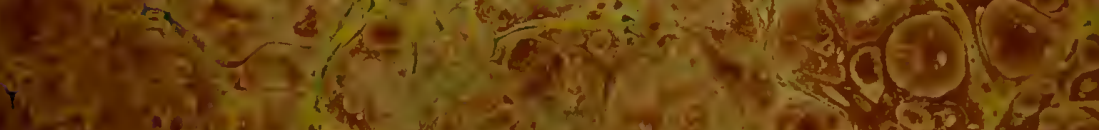

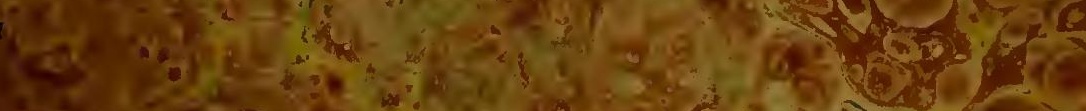

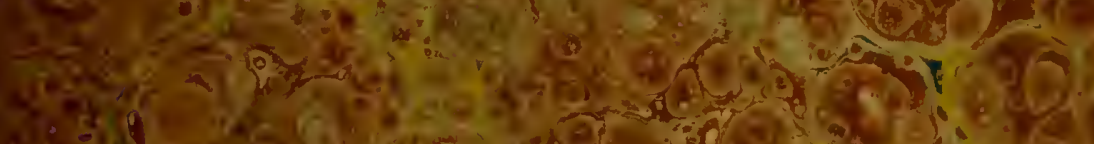
1)

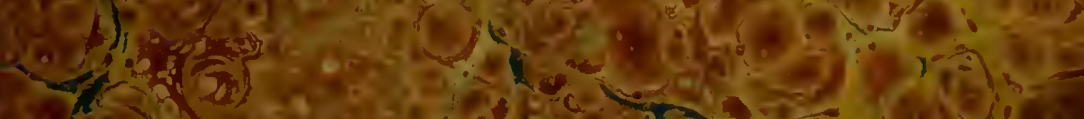

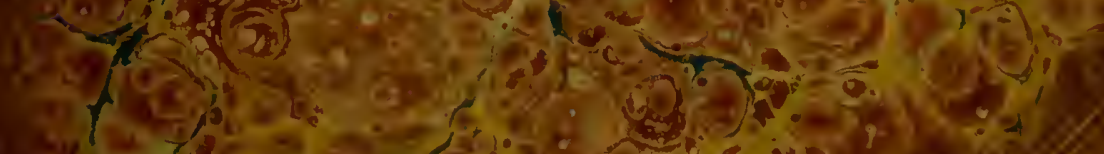

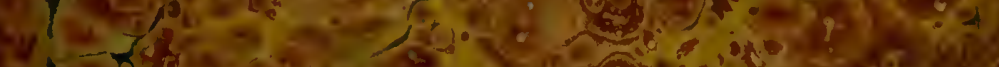

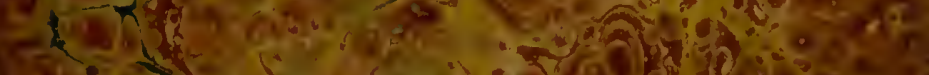

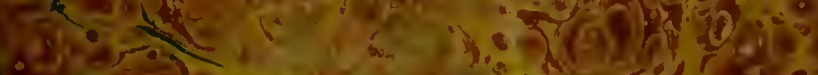

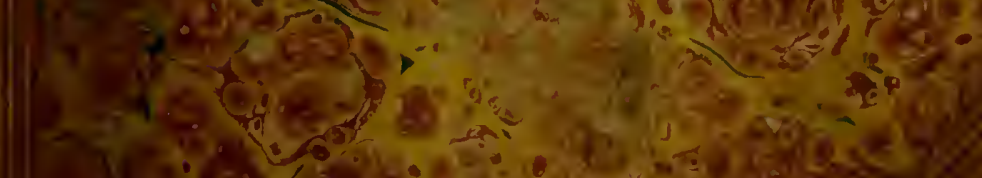

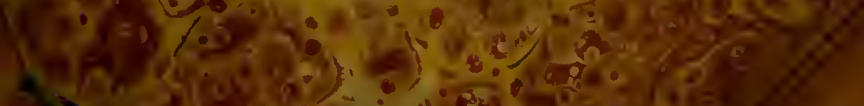




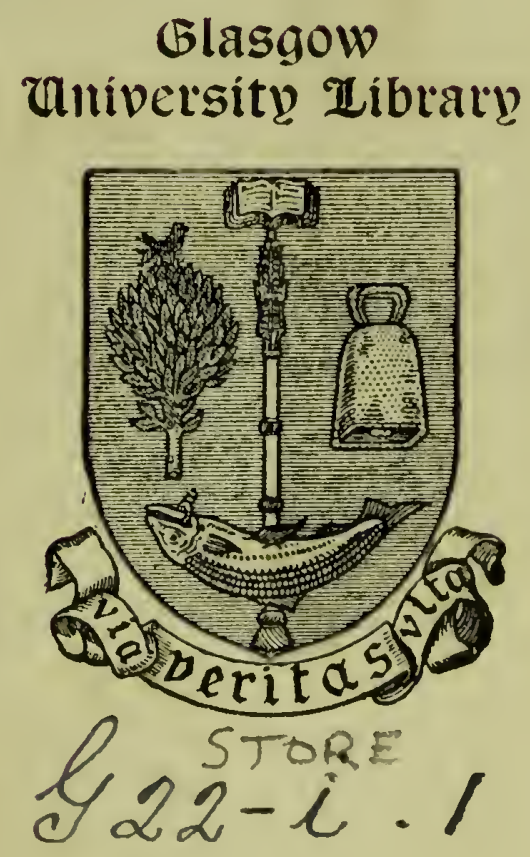

2. y. 12.30 

 \\ CARSSSI thenthom \\ cour}

. 



$$
.
$$


THE

\title{
VETERINARY SURGEON;
}

\author{
OR, \\ ffarriery
}

TAUGHT ON A NEW AND EASY PLAN,

BEING

\section{A TREATISE}

N ALL THE DISEASES AND ACCIDENTS TO WHICH THE HORSE IS LIABLE;

THE CAUSES AND SYMPTOMS OF EACH, AND THE MOST APPROVED REMEDIES EMPLOYED FOR THE CURE IN EVERY CASE;

WI TH

\section{INSTRUC'TIONS}

TO THE

SHOEING-SMITH, FARRIER, AND GROOM, HOW TO ACQUTRE

KNOWLEDGE IN THE ART OF FARRIERY, AND THE PREVENTION OF DISEASES.

PRECEDED BY

\section{A POPULAR DESCRIPTION}

OF THE

ANIMAL FUNCTIONS IN HEALTH, AND SHOWING THE PRINCIPLES ON WHICH THESE ARE TO BE RESTORED WHEN DISORDERED.

\section{BY JOHN HINDS,}

VETERINARY SURGEON.

\section{LONDON :}

PRINTED FOR SHERWOOD, GILBERT, AND FIPER, PATERNOSTER-ROW. 


\section{PREFACE.}

Whateven person would consult these pages with profit should previously read the first book with care; for in it he will find laid down the principles upon which all the subsequent details are founded, how the process of nature is carried on in health, and the cure is to be effected in every species of derangement. Indeed, he should study it !ard, if he would become proficient in " the Art of Farriery," and not rely implicitly upon other people's prescriptions for the cure of any alleged disorder, which have been composed for the most part without any such preparation.

From this neglect, also, symptoms of one disorder are confounded with those of another, when the proposed remedies cannot possibly effect the cure. If he be embued with the proper thirst after knowledge, lie his station in life about the horse what it may, he had best to comply with the advice strenuously urged at the very outset, to examine the internal parts of dead horses, as often as opportunity presents itself, which in the neighbourhood of large towns and hunts is frequent enough. For this is the manner in which I was myself mainly instructed; as well as by noting down 
whatever then appears worthy observation, connected with the previous disease of the deceased subject.

Such was my manner of proceeding for several years. And next about the present volume, how I came to write it, and what were my views in the manner of executing the task that was rather imposed upon me by the booksellers than sought after by me; and which was, in effect, occasioned by the nature and quantity of veterinary facts and observations 1 had a long time been in the habit of heaping together. But I had already been an author nearly a quarter of a century, having partly translated the Manual of La Fosse, at the request of another bookseller, Mr. Badcock, of Paternosterrow. I claim no credit for that performance, and have already stated my present opinion of its degree of usefulness, at pages 350 and 353. Proceeding with $\mathrm{my}$ "literary history," I may here add, that a few communications to the (old) Sporting Magazines, * to the Monthly Magazine, $\uparrow$ to the Weekly Dispatch newspaper, and other such publications, on topics connected with animal medicine, preceded the essays on the structure of the horse, which comprise the first book of this volume, and found place in a newer and much more brilliant publication. An accumulation of materials for these pages lay by me, with a latent hope of publication, when the mamnion of a "ten pound prize," for their insertion in the Annals of Sporting, and some cheering commendations that attended the appearance of those essays, from tine to time, induced me to finish

* For November and December, 1820, on "Fever in the foot," in refutation of Mr. Cherry, in which was described the successful treatment of a nag belonging to $\mathrm{Mr}$. Bowoley of Covent Garden.

$\uparrow$ Jan. 1821, \&cc. 
the design of a complete pocket manual for owners, grooms, and aspirants after the knowledge of horsemedicine, of every degree.

Like all other practitioners of the, old school, or rather no school, my late father had long amassed together and preserved, in an immense and shapeless volume, entitled his " Receipts," all the alleged remedies recommended as eligible and found good in crery variety of case : I believe he may have tried the efficacy of each, though I am now tolerably well convinced that some must have failed of complete success. Yet was the manuscript preserved like a family treasure; and, destined to fill my pockets at some distant day, its contents were secluded from vulgar eyes, though it contained nothing but prescriptions. As usual with all sinilar accumulations, the proper remedies were therein stated, without a word as to symptoms or those anomalous cases that frequently baffle the utmost skill; for the practice of medicine in any of its departments is but an imperfect science, even when we can ascertain the precise ailment under which the patient labours. This necessary preliminary is not always possible in veterinary practice: we, are more frequently baffled than assisted in our inquiries. Notwithstanding all this, my revered parent sustained a high character for successful practice; his close observation of the symptoms and attention to the operation of his physic, supplying the want of a "regular education," which no one farrier could at that time boast of : indeed, few of them could even copy their own receipts, which they preferred to carry in the memory. At a very early period I endeavoured to repair this apparent defect by study; with what success the reader may judge, and 
will endeavour in the next pages to make him com: prehend how my task has been executed.

The reputation of our name induced the boolseller just named to ask my father's opinion and mine (among others), of a certain mauuscript he held in his hand, which upon inspection turned out to be a treatise on the rationale of horse-medicine, with very plain direc. tions for ascertaining the true symptoms of diseases before attempting to apply any remedy, however estimable. As the expositions of the writer agreed mainly with our own ideas, it was impossible to withhold approbation. Finally, Mr. Badcock also consulted with $W$. S. Rickword of Moor-lane, and other veterinary surgeons of the college, and resolved upon the spirited publication of his new purchase, notwithstanding he had received the uncheering disapproval of Bracy Clark, of Smithfield, who gave for answer that " no one could learn the treatment of horses' diseases from printed books." Yet has Bracy Clark since then printed many books. The great success of the publication alluded to, which was James White's "Compendinu of the Veterinary Art," justified our opinion of its merits, and gratified my vanity at the early share I took in its promulgation, and the revision of many passages with a view to simplifying the terms (in particular); in which commendable quality, by the way, Mr. White is not deficient, though, in other respects, a lapse or two which have since fallen out, come under notice in the course of the following pages (viz. p. 104, 221, 295, and 401). No man can he perfect: how few among us know every thing that pertains to themselves?

Even at this last moment preceding the birth of my volume, I am not certain but I may be found similarly 
tripping-to have expressed myself obscurely, when I fancied my language most completely understandable by the meanest capacity; and I doubt that my familiar style may frequently appear vulgar to more polished eyes and ears than mine. But I take credit for having sedulously avoided the use of technical phrases, terms of science and learned dissertation, as well as the crime of over-refinement with which I have rebuked two cotemporaries, whose laughable sublimations are idealized at page 433 .

Candour and ability for the task are not always found combined with willingness, even among our best friends, to amend certain slips of the pen, or to curtail such exuberances as the more animated writers are liable to fall into; and I am free to aver, that the friendly assistance I have obtained in this respect, the nature of which may be inferred from the note at bottom of page 138, has not always seconded my plain meaning, nor adequately fulfilled my wishes, though I am grateful for these and every act of kindness. After all my care, repetitions have crept in, and owing to the length of time occupied in the composition, or rather the manner in which the various particles of information were collected together, and digested into form, great variety of style may be discovered, though unity of purpose, and the desire to instruct, pervades every page. The arrangement is at least obvious : the principles being taught in the first book, the details of practice follow in natural order in the second and third books, and seem to arise out of the preceding "observations on the animal system of the horse, as regards the origin of constitutional disorders." The references from the latter chapters to the former, operate as exercises 
witl those students who may have neglected to acquire and retain sufficient intimacy with the principles laid down in the pages so referred to.

The diseases of brute animals are few and simple, and easily cured when the symptoms can be distinctly traced up to their causes; for the remedy then consists in little more than putting the animal upon a direct contrary course to that which brought on the disorder (though not too rudely), and health follows. For example, heat, inflammation, fever, is the most general cause of constitutional derangement in the horse: in a state of nature, he seeks out and employs the remedy himself; when domesticated and pampered, or at least denied the use of green food, we judiciously set about reducing the heat by cooling medicines and factitious regimen, and the fever subsides. Again, liard work occasions lameness, rest restores the feet to their wonted state in incipient attacks, topical applications effect the remainder in bad cases.

For the same reasons few medicines are necessary in veterinary practice; but certain modifications of these add to their efficacy in particular cases; though the school in which I was first initiated, as well as the modern writers, White, and the Lawrences, quite overwhelm their reader's with the quantity and apparent contrariety of their prescriptions, that frequently possess no essential variation from others that may be applicable to a whole series of disorders.

Under such circumstances I have been extremely chary of puzzling the reader by merely altering the vehicle when the active material of the prescription had been already compounded for a similar disorder ; therefore I have aroided repetition of such (mostly purga- 
tives) by referring the reader to the page where these may be found. Notwithstanding the apparent difficulty of this mode, yet has it certain advantages that outweigh the trouble, and compensate for the moments thus expended. During my noviciate, and long intercourse with persons employed about the horse, in almost every capacity, I noticed that all those who consulted the books respecting any actual disorder, did little more than turn to the prescription which was recommended in their particular case, and it was made up and given to the animal without once more reading over and comparing " the symptoms," and notwithstanding they already had the same medicine upon the shelf. By this blind manner of proceeding, they did but adhere more closely to the old system of their "books of reeeipts," to the entire neglect of the anomalous symptoms, and risked the mistaking of one disease for another, in many cases. To compel the inquirer to study his case before he applies the remedy, I at one time thought of adopting the method of La Fosse, and others, who have thrown their prescriptions all together, and referred to each numerically; but, after due consideration, I adopted the middle course, and simply avoided repetition in this respect, as that which best suited with my views of instruction. In some cases, the remedy is mentioned in geveral terms only; for example, at page 348 , I said, " blistering ointment may be applied," \&c. The reader will of course, in this and all similar cases, consult the INDEx; and under "Blistering," he will find himself referred to page 204.

Throughout the volume, though I naturally evaded all controversy, yet in a few instances it seemed necessary to advert to certain existing errors and authorized 
mistakes; to disabuse the public mind, to negative the mischiefs these were calculated to spread of themselves, and to assure the reader that I was not wholly unmindful of the dissonance of opinion betwixt the authors mentioned and myself. To the "Annals of Sporting," a monthly publication much devoted to the natural history of animals, I have frequently referred, and often quoted; because in the course of its earlier volumes many desirable facts, some good and useful hints, and valuable suggestions, appeared from time to time; some new opinions and statements were started, and met with repulse, or were more securely placed upon their proper bases *. In these respects a favourite project, first communicated to me by Mr. Badcock in 1802, and partially acted upon + , was therein realized, viz. of collecting to-

* In that useful publication ordinary passing events are recorded monthly under the head of "Horse Intelligence," with brief comments, accompanied at intervals with exhortations to veterinarians to contribute their experiences to the same stock. In one instance, a vivid appeal, in the number for September, 1824, page 191, produced several valuable communications concerning hydrophobia, that are embodied in the present work, and acknowledged at page 425. The intelligent papers of Mr. Perry, of Swaffham, and others, also owe their origin to the same stimulus to publicity and the desire to establish a name for ingenuity in their profession to the writers.

+ I took occasion to advert to that project in my preface to $\mathrm{La}$ Fosse's Pocket Manual, and to lament that " the want of a more liberal practice is felt as an insuperable bar to improvement in the art of farriery, which would be best served by communications of the discoveries made, and the mode of treatment most successfully followed by various practitioners. This it is which of late years has done, and is still doing, so much for other branches of medicine, and which, for the sake of humanity, it is devoutly to be wished could be extended to this branch also." Page vi. 
gether the scattered opinions, remarkable cases, and fugitive suggestions that should occur to various isolated practitioners throughout the kingdom, in the same manner as had long effected so much progressive good for human medicine. He had engaged me and Mr. Rickword to assist him in this undertaking, and wrote to $\mathrm{Mr}$. White and others for their contributions; but it failed at that period, like many other projects of a sinilar nature; and I observe that the last-named gentleman, in every successive edition of his "Compendium," constantly inserts his correspondents' letters on various topics at length, though it was clear to me that discussions like these rather belong to periodical publications, such as the "Annals" professes to be (where they admit of refutation), than to a "compendium." For my part, I was early induced to enter into the spirit of those periodical investigations, and the inquiries set on foot in that work, and occasionally to furnish the materials for an article, or the argument in point for a controverted doctrine, or disputed "improvement." An offer of two premiums of ten and five pounds for the best and second best of an "Essay on the Structure of the Horse," had first induced me to labour in the pages of the Annals. The award of the highest premium to my paper* encouraged me to hearken to proposals for its enlargement, and the present volume is the result + .

* Divided into magazine-like portions, and inserted as convenience offered in many successive numbers of the Annals of Sporting, for the years $1822,3,4,5$.

+ The second premium was followed by the like result: the writer of it, Mr. Percivall, ( $I$ presume) having since then published his volume on the "Principles of the Veterinary Art." 
The volume has been a long time at press, and in $O_{c}$ tober last was fully announced by advertisement. The author could not, therefore, satisfactorily account why his title was adopted by another in the month of April of the present year.

The utility of such periodical works that devote their pages to the promotion of useful arts, is thus manifest in the fact that to those premiums the public owe two volumes at least on animal medicine.

London, July, 1827. 


\section{CONTENTS.}

\section{BOOK I.}

THE origin and seats of various diseases in the horse explained, with a view to their cure or mitigation.

InTRODUCTION. The necessity and advantages of veterinary knowledge, and the means of acquiring it, as regards prevention and cure

Explanation and practical use of the skeleton . .

Chapter i. External formation or structure of the horse, and the disorders originating therein . . . .

Chapter II. Concerning the horse's inside, of its conformation, the functions of the organs of life, and the diseases to which each is liable: together with outlines of the principles upon which the cure is to be effected

Chapter III. General observations on the animal system of the horse, with reference to the origin of constitutional diseases : recapitulation and further development of veterinary practice, upon the principles before laid down .

\section{BOOK II.}

The causes and symptoms of various bodily diseases incident to the horse ; with the most approved remedies in every case.

\section{Chapter I. Of internal diseases}

Chapter Ir. Of external disorders_abscess and tumours

Chapter III. External disorders-purulent tumours, diseases of the glands 


\section{BOOK III.}

Of the leg and foot of the horse; or, shoeing-smith's guide.

Chapter I. Structure and physiology of the foot; mode of studying it advantageously . . . . . $426^{\circ}$

Chapter II. Disorders of the font and leg . . . 444

Chapter III. Shoeing . . . . . . 471

Chapter IV. Diseases of the foot . . . . 499

Chafter v. Of strains generally . . . . • 516

\section{PLATES.}

1. Skeleton of a horse . . frontispiece. 2 and 3. A natomy of the foot . page $4+1$. 4. Terms used . . . . . 554 . 


\section{FARRIER Y}

\section{ON AN IMPROVED PLAN.}

\section{BOOK I.}

THE ORIGIN AND SEATS OF VARIOUS DISEASES IN THE HORSE EXPLAINED, WITH A VIEW TO THEIR CURE OR MITIGATION.

INTRODUCTION.-The necessity and advantages of veterinary knowledge, and the means of acquiring it, as regards prevention and cure.

Although it cannot be denied, that " 'tis better, in a humane point of view, to prevent diseases than to cure them;" yet, looking at the fact as a veterinarian, without forgetting my feelings as a man, I do not hesitate to say, "this is a consummation we cannot reasonably hope to arrive at, whilst the horse is compelled to exert himself to the utmost of his power for our daily profit," whereby he acquires a constant disposition to create disorders. Nor would I be thought to 
maintain, that "preventives ought never to be employed:" the succeeding pages fully disprove such a conclusion. I merely mean to inculcate, that, under existing circumslances, they cannot be resorted to generally: and this I say, notwithstanding it will be found I have here noted very many occasions, when rest, alteratives and regimen, might be often substituted for active medicines, more economically, (in my opinion,) both of time and expense. The hour is not arrived, however, for me to insist too strenuously upon an entirely new mode of treatment of the horse in health and in disease, since that course would appear rather too theoretical for a Treatise designed to be wholly practical.

Those are the reasons which have induced me to keep in view the readiest way of enabling the sick animal to return to his work again, according to the long beaten track of my practice; whilst my main purpose is to show, by an examination of his powers and his parts (external and internal), that a moderate mode of treatment, in sickness and in health, would be not only more humane but more profitable, as preventive of many of those evils to which thousands of horses prematurely fall victims every year. More conducive, also, to a profitable result to their labours would it be for the owners of horses, instead of studying how to "physic" their property, were they to put them= selves in a condition, as near as may be, for rejecting, with some degree of certainty, not only such 
horses as are offered to them actually diseased, but such also as, by their awkward built or structure, and consequent ill-formation of the internal parts, cannot fail to possess some inherent bad quality, and thereby a proneness to its corresponding affliction to the end of their days: This ought to constitute every horseman's first step to horse knoreledge, whether he undertake it as an owner or as a farrier, the latter most especially; of him I may justly add, that he cannot be said to exercise his calling honestly as he ought, who sullenly neglects to learn those rudiments of art and practice that teach a knowledge of the animal economy, and the functions of the horse in particular. I do not hesitate to insist upon the examination of the animal's internal parts, as constituting one main item of those rudiments; and I would not avoid giving this operation the proper name of dissection, but that I fear to alarm the general reader with an apparent difficulty where none exists in reality. How, without that previous knowledge, durst he venture to pronounce what particular ailment, out of the numerous catalogue that pertain to the horse, his patient labours under? How can he ascertain the degree, or quantity and quality of the attack, so as to know when it may be increasing in malignity, or its virulence is expended? Least of all can he succeed in the cure, when so much uncertainty hangs about his means of discriminating between one disorder and another, - to say nothing of the usually attendant ignorance of the mode in 
which medicines operate* upon those internal parts that lie concealed from his view, but upon one or the other of which they are, nevertheless, destined powerfully to act. If it be allowed, that no two horses are ever affected exactly alike in those disorders that depend upon the secretions, as I shall show at the end of this chapter, how is it possible that such neglectful men could ever reduce the symptoms of any disorder, without reducing, at the same moment, the power or functions of the part upon which their strange and ever-violent mixtures expend their force, and thus entail upon the animal a disposition to acquire some other disorder.

Every man who would make himself proficient in the knowledge of diseases should open his own dead horses, and as many more as he can obtain access to, and attentively examine the state of the stomach, the liver, the lungs, the heart, kidneys, and bladder. If the animal be recently dead, this profitable inquiry will be far from disagreeable, unless the cause of death has been of the putrid kind, spoken of in Book II. Chap. 1. as Typhous, but which rarely happens. In the pursuit of this necessary first step to veterinary knowledge, he will proceed in this manner. The horse being on its back, two legs on the same side are to be ele-

* Called the "modus operandi" by the most intelligent of our late veterinary writers ; but, with all due respect, the gentleman ought to be told, that the phrase is a puzzler for nine-tenths of his readers, and he has deservedly a good number. 
vated by a cord passing round the fetlock of each, and fastered to a nail in the ceiling or elsewhere aloft. Then with a sharp knife, of the common shoemakers' kind, he will draw a straight cut all the way from the first ribs or breast bone, at the intersection of $\mathrm{O}$ with 21 in the picture, to the sheath, or thereabouts, taking care not to hurt the hide by clumsiness. If the cut be not too deep, the skin will recede a little, and expose the membrane; cutting through this the guts will protrude, - and drive forth a thin expansive membranous sac, apparently unattached, being designed for holding the guts, and preventing friction. This soon bursts, and the blind gut (or cocum), described at section 48, appears. He will slit open this pouch, and examine its contents before he quits the subject, probably; but his first business is with the stomach, which is depicted in the annexed plate, as situated at the conjunction of IKL with the figures 26-29. Herein will be found the last drench that sent him out of life, or the last food that gave hopes of a prolonged existence; and on its surface, vulgarly termed the coats of the stomach (when turned inside out), may be discovered the havoc committed by the farrier's unskilfulness : according to the strength of the poisons so administered, will the coats show the dilapidation, or at times a hole will have been perforated, that is the cause of instant death.

The young operator will keep in mind what is 
said of those parts at sections $45,46, \& c$. , if he do not turn to and read them over once more before he takes up the knife. With the same precaution as to re-reading section 5\%, \&c. he will proceed to examine the state and appearance of the liver and kidneys. The description of these will be found at sections 52 and 53 respectively; and they are delineated as situated in the picture, the liver between the parallels of $\mathrm{J}-\mathrm{N}$, 22-28, and the kidneys at $\mathrm{H}, 29,30$. Returning forwards, the operator will find his way to the heart and lungs obstructed by the midriff, (see plate at 22 to 28 , ascending slantwise from $\mathrm{L}$ to $\mathrm{H}$ ) that divides and keeps asunder these from the firstnamed parts, lest the guts and liver should obstruct the action (functions) of the heart and lungs, and vice versa. Its appearance has been described (sect. 35.) as resembling a drum-head; and like it, if pricked with the knife, the cavity of the chest is instantly laid open-an immense vacuity, that proves to what a vast extent the lungs must fill at every inspiration of fresh air, to occupy so great a space, and further spread out the ribs to the utmost extent of the intercarpal muscle that holds them together. In the plate the lungs are depicted in a quiescent state, at $J$ to $N$, and 15 to 22 ; but when filled they occupy all the vacant space above, in addition to their lateral width. Hence, the importance of this viscus (as they call each of the vital parts above-named), to which I 
have attached such high consideration in the sequel, will at once be seen and appreciated. See sections 31--36.

Concerning the Heart, its structure and functions,-so much has been said in another place, and so minute is the description of each, that I shall add no more here, than refer to the sections, where the reader may find ample instructions for examining this main-spring of animal life. See sections 37 to 40 . In the annexed picture, it is delineated as lying near the lungs [LMN, 19$21]$, to the upper part whereof its pipes are attached, as described hereafter.

By pursuing this course of inquiry, the operator will discover what is, or ought to be, the healthful state and appearances of the main functions of the animal system, - he will perceive the auxiliaries and their uses,- -he will have informed himself (it is hoped) of the treatment any horse has received previously to its death; and he may thus store up in lis mind, or better still, upon paper, what dread effects may be produced by the drenches, cordials and diuretics that stimulate but to destroy the vitals of the animal. He will see and compare the animals that die in health (accidentally), or after short illness, with those which die after protracted illness; upon the healthy ones that are doomed, a few hours previously, he may try the experiment of some favoured farrier's celebrated mixture, and subsequently send him the stomach. to prove its efficacy in " killing all disorders.". 
Happily, the cause of humanity may be served, and the interests of his owner promoted at the same time, by our ( first) ascertaining the nature and amount of the horse's powers by his make, shape, or built; and, thereupon, demanding of him no more, in the way of service, than is clearly proveable to lie within his power, or putting him to those labours only to which his capabilities are best adapted. In the neglect of this plain rule lies the root of all error as regards preserving the health of horses. Some materials for making a tolerably good estimate as to this head of information, are arranged in the first chapter: the second being well pondered, and the facts and observations it contains rightly stored up in the reader's mind, he will learn what functions belong to each part of the animal in health; or, these being deranged or obstructed, he will know in how much the horse is affected: and the third chapter being read with reference to both, I entertain the well founded hope, that this course will enable the general reader to form tolerably accurate notions of the nature, origin, and tendency of the animal's internal and constitutional diseases, upon which all the others depend, but which have hitherto received but little attention any where here, and, consequently, are but imperfectly known among us. Not only so, but the reader may, by these means, by study and close observation, enable himself to demonstrate, nearly to a certainty, when $a$ cure is hopeless; and further the cause of humanity, 
and the interests of its owner at the same time, by ordering the horse to the knackers at once, rather than, by fruitless delay, and at a heavy expense, prolonging the animal's sufferings to no zeorthy purpose *.

I have not confined my researches to disecse only: in the first chapter, the SHOEING-SMITH will find explained the principles upon which depend deformities of the hoof, and he may fashion his work accordingly; whilst the choice of a HORSE may be undertaken with some confidence, if THE PURCHASER keeps in mind the practical advice and precious information here collected together from various sources, and added to my own observations, and long, extensive, and successful experience, in all matters of this nature.

* If he be a regular practitioner, who thus settles at once the doon of the suffering animal, he has a legal claim for the attendance, as much as if he had " physicked" the horse. 


\section{Explanation and practical use of the Skeleton an- nexed.}

'THE references that are made to the annexed plate, and which will necessarily be found rather numerous in the chapter on conformation, are so made by means of letters and figures, corresponding with similar letters and figures upon the plate. The letters direct the reader's eye across the picture, the figures from top to bottom: when he is referred both by letter and figure, the place of intersection is the point to which his attention ought to be directed. Thus [G. 37.] which, by placing a flat ruler, or a piece of paper, across at " $G$." and running the finger downwards from the figure " 37 ," would be found to intersect each other at the insertion or commencement of the horse's tail; whilst [Y. 40.] would bring us to the hindermost pastern. Again, [K. L. M. N. 14, 15, 16.] or [K.-N. 14-16.] directs the reader's atterition to the shoulder-bone; at [M. 20.] is his heart, and at [H. 29.] his kidneys are placed.

The reader will please to observe, that the Frontispiece is meant to be, less what is termed " a pretty picture" than a practically useful one, calculated to facilitate his comprehension of what is said in this treatise about the living horse, his structure, and internal formation; of his capabilities and all of the diseases arising from their misapplication. 'To this end, a mere elevation of the skeleton was requisite; and, that this should be rendered more practically useful, it is divided into squares, for more ready reference. The figure itself, is that of a rather long bodied horse; the blade-bone having been lowered to show the continuity of the vertebra, or backbone, between the shoulders, and the elbow being bent forward for that purpose, so that the shoulder-bone is brought to form its sharpest angle. This position of the limb, of course, rendered the sulject of the plate lower before than he would be were those bones more straight up and down than they are. See Section 8.

He will observe, too, that the situation only of some internal parts was required for the purpose of elucidation ; thus, the heart seems unsuspended by its vessels, as its pericardium and part of the lungs are removed; and it follows, that whcever expected to find a delinea- 
tion of evcry viscus, perfect, has deceived himself, -if any such there be. Respecting the poll, or noll-bone, the reader will find some remarks in Section 16.

Further, the REFERENCEs my readers will meet with in the midst of the text are necessarily as brief as they are useful, and are made to the sections, or parts, into which the first two chapters are divided after the manner of verses.

This mode of reference will be found highly serviceable in his inquiries by the attentive reader, who is unused to study things of this na. ture, but who must soon perceive the great practical advantages to be derived from so intimate an acquaintance with the subject as this method of learning it will furnish him the means of acquiring. If, in the prosecution of his studies, he happen to forget what has been before said, tending to the same point of information, or he be at a loss whereabout he should look to refresh his menory, these references supply him with the ready means of overcoming the difficulty. $\bar{B} y$ adopting this method, I have likewise avoided the repetitions insepa. rable from a work of this nature, and have thus saved room. 


\section{CHAPTER I.}

External formation or structure of the Horse, and the disorders originating therein.

Section 1.-Scarcely any man who is in the habit of seeing many horses perform their labour, and observing their capabilities of several kinds, but acquires, thereby, some insight of the properties conferred on the animal by such or such points of conformation. He can tell, at first sight, nearly from this habitude, "what a horse ran do ;" but few men reduce their observations to writing, least of all to principles, upon which we may afterwards reason, or draw conclusions with any degree of certainty, as to what duties a horse cannot perform properly, when wanting those points of excellence, and which duties ought, therefore, never to be required of him; or, being so imposed upon him improperly, are productive of certain disorders that invariably attend such misapplication of his powers. No doubt it has happened, that a horse with a radical defect,-in the shape of his hind quarters, for example,-yet having a corresponding defect $b$ fore, the one makes up for the other, and such horses may occasionally perform well for a short time, but then they are no lasters: all the while they may thus be at the 
full stretch of their physical powers, straining to the utmost the immediate coverings of the bones, something or other is going to wreck-of muscle or tendon, of ligature or sinew. Sooner or later so much excessive fatigue of the deformity runs along the solids, and reaching the vitals, occasions constitutional disease, or leaves behind it an incurable malady of the limbs, mostly descending to the feet. Equally true is it, that we frequently find out new properties, or hidden powers in a horse, which had never hitherto been known to his owners; but, then, as I shall particularise by and by, no such latent powers were ever discovered in any horse, without his possessing certain just proportions of the bones taken all together*. What these proportions are, as well as what they are not, I come presently to lay down: the integuments (or coverings) ever adapting themselves thereto, in one case produce what is called sym. metry; but if the limb be disproportioned, the coverings adapt themselves to that particular defect, and enlarged muscle at these particular places becomes visible to the common observer.

The acquiring a ready mode of discuvering

* Eclipse, a horse whose very name is used as synonymous for speed, had none of the proportions generally deemed indispensable to great speed, and he was cast, by the Duke of Cumberland, for his apparent deformities when a colt; but his defects in one particular were amply supplied by excesses in another, and, taken altogether, composed the very best bit of bone, blood, and muscle ever produced. His lineage, lateral consanguinity, and the kind of cross by which he was got, demands the breeders' serious attention. 
when a horse of the one or the other formation is presented to our notice, forms the perfection of art in purchasing a horse.

2. But the horse's achievements, or "what he can do" under certain circumstances of shape and make, would ill employ my pen at the present moment-valuable as the investigation must always be in itself-were it not for the practical application I mean to make of it shortly, by way of illustrating the direct contrary, or defective shape and make, as being the harbinger of several radical disorders of his frame. Nor is this all: some are so evidently ill-formed in the chest and carcase, from the moment they are foaled, that no art of ours is equal to preventing the return of certain disorders which are sure to attend a horse of that particular formation all his life-time. As the one is known and inevitable, so the effects of the other may be foreseen, and, in some degree, alleviated, if so much trouble and expense be not greater than the value of the horse. This is all that can be done for such an animal; and since the resources of art are not equal to the obstacles of animated nature, so no man ought unreasonably to expect, least of all, to force his beast, to perform any species of labour or exercise, for which nature or the accident of birth hath rendered him anywise unfit; although it must be allowed, as a general axiom, that it is only by pushing the animal to the extent of his powers, that we can find out the most he is capable of performing at any given 
work. In this way it was the fast-trotting powers of the Phænomena mare (which was before then a butcher's hack) were discovered; for people of this trade generally try the utmost their nags can perform in the trot.

To be able to judge of a horse's defects as to what he cannot do, undoubtedly it seems necessary to ascertain what constitutes a fine figure, or a perfect one, that can do every thing; but when it is considered that the exposure of those defects is intended to apply wholly to the origin of disorders for which he will require medical treatment, if he does not deserve rejection in toto, I shall find less occasion for adverting to any known horse, entirely without error in his form or built. In most cases, however, good symmetry being accompanied not only by the power of achieving great feats, but a good portion of health also, or, at any rate, the absence of the diseases incident to a bad form, I may be allowed, while exposing his faults, to deviate a little, and to contemplate some few of his perfections also.

3. The most obvious physical truths are those which can be explained upon the principles of mechanics; upon such a basis, even the most abstract can be securely grafted; that intelligence which is derived from experience, from observation, experiment, and acute reasoning, is rendered more understandable when conveyed with mechanical precision; and, however strange it may appear to some, the gift of speed, if not of all 
progression, depends more upon mechanical principles than is commonly understood to be the case. See farther onward at Section 9, where the details are given. In all compound bodies, whether animate or inanimate, intended for our active use, it is above all other things requisite that they should stand well upon their bases or legs. A horse, or a joint stool, evidently defective in this particular quality, would be shunned as insecure; and the one is sometimes endued with movements as little suited to one's ideas of getting on safely as the other, both being indebted to its original bad built (or charpente, as Lafosse calls it) for the defect. Cover them both, the one with muscle and skin, the other with drapery, how you will, the faulty legs are faulty still. A good stable aphorism has it thus-" a horse that does not stand well can do nothing well;" and by natural inference, "the horse that walks well can perform other paces well."

A much better example, however, may be found in a four-legged table, of which every horseman knows there are many of different sizes and of various workmanship, some for heavy or rough usage, others more for show and to sustain light weights. But, if the fore

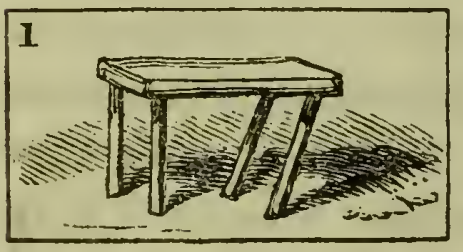
and hind legs bend towards each other upon the ground, any carpenter may see that this first element of an illformation must sooner or 
later produce a fall; he will know that more strength for supporting great weights would be found by making all four legs perpendicular. But a horse, not being like a table, immoveably fixed upon its legs, but being required not only to bear up but to proceed with his load,-which is sometimes effected with difficulty on account of its weight; then must his powers of pressing onwards be estimated by the positions in which he can place the bones of his hinder part, the legs particularly, since it is to these the propulsion of his body forward is chiefly indebted. In his efforts to accomplish this duty, the position of his hind legs will resemble those of the second table in the margin, stretched out constantly as much as these

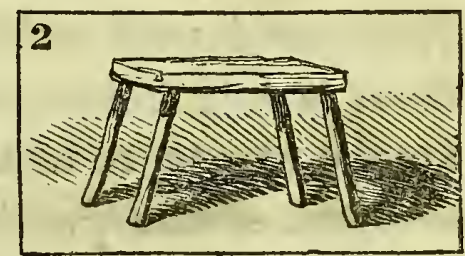
are, and each leg alternately twice as much beyond his body; while his fore legs will bend under him alternately also, like those in the first table. In both movements his legs are stretched to their utmost when the $d r a g$ is up hill, because the resistance to be overcome is then greatest, and we can thus form an opinion how much "he has the free use of his legs." When this is the case, all horses step short; but, upon even ground, the hind leg, to be perfect, should come finely forward in the roalk, and occupy the identical spot which the fore leg had just quitted. See further at Section 8. As the horse gets old, is 
tired, disordered, or over-much laden, he ceases to do this as usual, in the exact ratio that he is affected the one way or the other.

4. Mares, occasionally, and skittish horses, frequently bring their legs together, much resembling the first figure, and are insecure roadsters as well as poor draught horses. The second sketch is the walking motion of an unladen carthorse, or a coach-horse standing still; these, as well as hunters, take the same position, which indicates that they have the free use of their limbs. In the drag, the former bring their fore legs under their bodies, the principle being applicable to any quadruped performing the like task; and such a horse would consequently fall down forward but for the resistance of the load he draws. But this accident seems provided for, by the power the horse has of contracting the muscles (see Section $10)$, and drawing up quickly the lower part of his limb, in time to get it out of the way of his hind leg, both motions forming each a separate effort toward progression. I still have in view a walking pace, all other paces being no other than modifications of the walk; and, in fact, "a horse that walks rell can do any thing else well," an aphorism that is a-twin with one equally well founded in the preceding Section.

With some horses, the hind foot, instead of coming forward, as described at the bottom of the last Section, upon the spot of ground marked by the fore one, falls short of the mark.-These 
never turn out fast ones, although their fault does not always consist in the shape or disproportion of the bones, but in the contraction of the muscle or tendon (see this tendon described under the head of "Foot"); at times it is owing to the relaxation of the immediate coverings of the bones, described at Section 16. Such horses may be well enough to look at, but cannot perform properly. The extreme of this misfortune is termed stringhalt; but every approach towards it, however trivial, is good cause for rejecting the animal. In case of the hind foot coming too far forward (in the roalk still) and striking the fore one, the fault lies in want of sufficient strength (or quickness) in the fore leg; besides which, see further at Section 10. If the hind foot comes down sometimes inside at others outside the justquitted situation of the fore foot, the animal has a disagreeable rolling in his gait from side to side, the fault being as often in the fore leg as the hinder one, sometimes in both. Such horses commence a journey with much apparent confidence, but, tiring soon, they fall into their old error, and the security they have inspired is found to be deceptious:-many accidents are the consequence. This fault I lesitate whether to ascribe to the fore leg or the hind one, but it certainly originates in a disagreement between the fixing of the two upon the body, either as to the situation, or want of muscular strength at the place of joining. Such a horse is a stumbler, and 
when he trots azoay from us, we can see nearly as much of his fore legs as of his hind ones; in the straight-built, well-set limbed horse, the fore legs are then concealed from our sight by the hind ones. I own this is with me a grand criterion for judging as to a horse's capability of going over the ground. In racing, or indeed any running, the fore legs are then brought closer together, the hind legs rather wider (so in leaping), as we see in grey-hounds, hares, deer, and all other Aleet creatures.

Such as I have described is the act of progression with all horses, but in various degrees, according to their sizes (as with the coach-horse, saddlehorse, poney); four such efforts having called into action all the bones of the body, including more or less that of the head, tail, and neck, according to the pace, or other circumstances.-See Section 11. Hence it must be clear, that to perform this duty of progression, or getting forward, properly, as regards either the length of time he sustains it, or the quickness of performance, weight, or velocity, the limbs must be adapted to the kind of work the horse has to perform and to each other, whether that be in harness, on the turf, the chase, or the road. It follows, naturally, that if we bear-up a horse's head or cut off his tail, some part of his exertion must be thereby abridged.

5. We do not find this adaptation of the limbs so much in the amount of covering the bones may have on them, as in the size and proportionable- 
ness of these, and the suitable manner in which they are fastened together; as may be seen in those horses (blood) where tendon supplies the place of muscle, and most strength resides in the smallest compass; and, as may be proved by the obstruction to his paces, which is always observable in the horse burthened with very muscular shoulders. Equally true is it, that, after we have approved of the proportions of a pair of horses in respect to bone and built, certain powers of going or lastingness are frequently discovered to be possessed by one so much beyond his match, that we are compelled to admit those powers do reside in something else than in his built. Superior health, sound wind, courage, give this strength, with speed and lastingness : the bones being then well cased together, and strongly supported by their immediate covering, have full and fair play*. But wherever they be fundamentally ill-adapted to each other, in whatever degree this escapes our observation, the muscles and tendinous parts adapt themselves in some measure to that lamentable kind of form, but which no filling up, or afteraccommodation of the parts to each other, can completely eradicate, though it may be concealed from our view. The muscle that is so perverted

* Firing is supposed to restore derangement of the integuments, by causing inflammation and contraction, thereof upon the bone, so as to embrace it more tightly. This is effected by much of the muscle being taken up into the system, or sloughing off in the cure; as well as the contraction of the flexor tendon (back sinew) and its sheath. 


\section{STRUCTURE OF THE LEGS: INSIDE TREAD.}

rises up in the middle preternaturally, as if some sprain or other had caused that appearance; the contiguous parts, consequently, undergo greater fatigue than, in the event of finer symmetry, would have fallen to their share; and the extraordinary friction or working thereof, occasions, at a day more or less remote, the exhaustion of its moisture (see section 21) and the lodgement of acrimonious matter in the cellular membrane, which appears in tumour, abscess, \&c. 'This protuberant appearance of the muscle is most visible at the stifle [N. 30], and on the shoulder [M. 16$\rceil$ just above the elbow.

A more minute inquiry, however, on those points would lead me away-too far from my main purpose, at present; I therefore return to notice, in the first place, the structure of the legs of such horses as, by their untoward position, entail on them the chances of producing some one or other of those evils that are known to afflict certain horses, incurably, to the end of their days. Thus, some are known to tread on the inner quarter of the hoof, others on the outside, without the real cause being ever ascertained, and remedies are frequently applied that have not the remotest chance of achieving any good, on that very account. Some horses "cut," in consequence of treading on the outer quarter; on the contrary, by punishing the inner quarter in treading, others contract a disposition to "quittor and ringbone;" both instances of mal-formation, or bad built (as I call it), 
produce splents, diseases of the frog, of the sensible sole, and of the coronet, as the case may be: how the various modes of wrong treading are brought on remain to be examined into hereafter. Meantime, it may not be amiss to observe that the right mode and make may be discovered by noticing the proportions of those horses, that, by the acknowledged just symmetry of their bones, the agreement in size of one limb with another, and the faultless manner in which these are attached to the body, go tolerably free from any such diseases, until old age, accident, or the misapplication of their powers, brings on disease.

6. There are, then, three kinds of mal-formation, or bad shape, attendant on the limbs of horses, which I consider original faults; those others to which they give rise being but secondary ones. 1st. That wherein the leg is ill-formed in itself. 2d. When it is badly joined to the body. 3d. When the fore legs disagree with the hind ones in length or quantity. Each, being attended by its respective defect in going, as to safety, speed, or strength, and liable to incur one or other of the ills enumerated, as appearing on the legs and feet-is worthy of the reader's separate consideration; although it frequently happens that an individual horse is afflicted with all three faults at the same time, the two first being found together, subsequently producing the other also. But I have generally noticed that one of those faults sometimes accommodates itself to the other, amending 
it considerably; as, when a limb that is too long is set higher up on the body than is esteemed right construction, in the same manner as a horse lame of a leg. may be passed off for sound should the corresponding leg of his body also fall lame*. Much the same is it with the third kind of disagreement, in the opinion of many people; because it has existed in some celebrated horses, and they would have us believe that this very disagreement was itself the cause of the celebrity those individuals arrived at. This, however, was not the fact.

7. The Phanomena mare, unquestionably the first trotter of her inches in our days, never did her work in style: nobody could account for her achievements upon the vierw, and I had always my doubts whether hers was a fair trot, though I won upon her. In the trot she had an unaccountable shuffle. She was low before, but had the gift of taking her fore feet out of the way of the hinder, which fell (in the walk) about half a shoe beyond that of the fore ones, the feet reaching the ground in succession.

Laertes, a grey horse, hunted in Leicestershire, $1818,1819 \uparrow$, of no particular powers any where, and confessedly clumsy in the fore-hand, without much fire, was yet in the habit of taking the ordi-

* Certain dealers are known to have inflicted lameness on the foot with this view ! Horrid and disgusting as is the relation, 'tis no less true.

+ At that time the property of Mr. Maberly. 
nary six feet leaps with ease, and clearing a ditch of twenty-five feet with pleasure, often exceeding those admeasurements by nearly a fourth. Eclipse is known to all of us (as matter of history) for having had a low shoulder, which gave his fore quarters an awkward appearance: but this was compensated for by the fine form of his hind quarter, which, being particularly strong and muscular, threw his body forward at every leap in despite of his low fore quarter,-for running is no other than the leap reiterated. One leading characteristic, however, denoted all three horses to be of the right stamp in the main: they stood even on their leg-bones and the soles of their feet; that is to say, straight up and down, nearly, from THE ELBOW [N.16] to the ground before, and from the sTIFLE-joint [N. 30] to the ground behind, respectively; both those parts, viewed sideways in the plate, being placed nearly horizontal, as regards each other, on the line $[\mathrm{N}]$; at least, this was the relative position of the stifle and elboro, in the two first-mentioned animals, and of the third $\mathbf{I}$ do but presume that he. was so, for "the history" of his form in this respect leaves us a little in doubt.

But " the shoulder of Eclipse was a low one," say the published accounts of him; yet, as this defect, real or supposed, consisted in the inclination of the shoulder-bone [ $\mathrm{K}$ to N] above the elbow, by reason of the great freedom of the muscles which held it and the shoulder-blade in position, he would, rohen stepping out with the fore leg, rise 
higher than when he stood still; a particularity that is reversed in horses whose shoulder-blades are set on more nearly upright than those of Eclipse were. This accounts for the vaulting manner he had, as we read in the printed accounts of his exploits; and his running greyhound fashion, with his chest close to the ground, for he would thereby keep off the ground longer betwixt each leap, until the impetus received from his hind legs was nearer spent than it would have been but for thus holding up his fore feet. On referring to those parts in the annexed plate they will be found thus drawn.

\section{Reader,}

8. Viewed in front, the fore legs, upon which the safety and ease of the animal's going chiefly depends, should, to be perfect, be widest next the chest, approaching each other gradually, until the eye, having compared that part with the pastern,

Fig. 3.

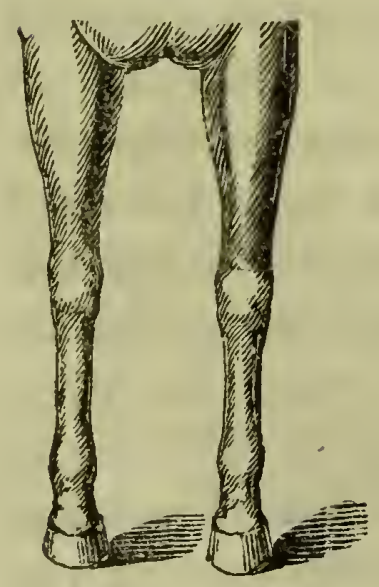

scarcelyperceives the difference. Here, the leg, taken by itself, is smaller, though the interval between the knees and the feet do not differ, on account of the width and flatness which ought to exist in the well-formed knee, yet, taken on the outside, considerably more breadth will be found above than below. Such a knee, when flat and 
finely marked at the joint, is always well covered in a healthy horse (see section 15), he then throws it out with great freedom, and takes a firm step fairly on the entire bottom of his hoof; but, should the leg be,ever so good a one in itself, yet placed too high upon the chest, where it is held, not by a socket or insertion of the bone, but by strong elastic muscle only, this throws the feet too near together upon the ground; the horse then treads on the outer quarter of his hoof, and wears away the wall; and, when tired, is most commonly given to cut. Endeavours are used in shoeing to amend this fault, by paring away the inner crust; but it is one of those defects in the built which no art can completely eradicate, and has been termed "pigeon-toed."

Nor is the matter rendered any better when, by reason of the knees turning in, the toes turn out, and the horse then treads on the inner quarter; and, however those of the one or the other description may have the reputation of great speed, it can be for a short distance only, because the action of such horses must be laboured and imperfect, particularly one of the latter kind of make. He must, consequently, fatigue himself more at every step, and tire sooner than one of the same size, and formed in every other respect similar, but having legs that come nearer in shape to those in the annexed sketch [fig. 3]. That such knock-knee-form is occasioned by weakness, is evident from the position of the knees, when the 
animal stands at rest. This he does by supporting himself at times like a dancing-master, with one foot before the other; and, no doubt, the twist with which his pace is always attended when going, occasions certain disorders of the feet, which he seeks to ease by shifting the weight now from the one, now from the other foot. He will, moreover, sooner "knock up," and ultimately "get done for" earlier in life, by reason of the origin of this species of malformation being seated high up on the limb, thereby incommoding the action of the shoulder-muscles: the elbore, at N. 14, by being pressed close to the ribs, having thrown in the knees, receives, at every step the leg takes, a kind of double motion, which, of course, doubly affects the action of those parts; and much fatigue, pain, and anguish succeed each other, until it communicates to the cavity of the chest, or other internal and vital parts. Such animals have frequently the shoulders unusually muscular, hiding, in a good measure, the original defect from the eye and touch of a common observer; but it may, nevertheless, be ascertained to exist, by the symptoms just now mentioned, as well as by the appearance of the protruding muscle before noticed at Sect. 5. To knocked knees and inside tread, let me add the circumstance, that such horses have a broken pace, kicking loose stones before them, with a certain rolling from side to side, to the great annoyance of the rider. All this arises from awkwardness, by reason of the shoulder's bad 
position, whereby the leg being thrown sideways removes the foot in an increasing ratio from the centre of gravity, and, instead of its being thrown straight forward, describes part of a circle, more or less curved, according to the amount of the original defect. The straight Fig. 4. dotted line shows the space a well-formed foot, such as belongs to the leg in our preceding sketch(3), would take, being on paper just

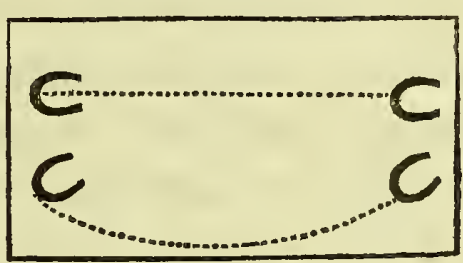
one inch; the curved line shows the course, or nearly so, the foot is thrown which belongs to an ill-formed shoulder, contracted at the elbow: as this line is an inch and an eighth ( 1 in. $\frac{1}{s}$ ) in length, the horse so formed does an eighth more work than one with straight legs would do on going over the same ground.

In addition to his other evils, a horse with such a shoulder (being muscular) is most liable to contract " fistula in the withers ;" but, if not so muscular, "strain of the shoulder" is likely to attend his twisted manner of treading, when hard worked. With such a built horse, "splents" are usually more tedious than with a straight-limbed one; and strains of the sinews, $i$. e. of the tendon, as well as those of the coffin-joint, happen oftener, and appear with worse symptoms, in proportion as the limbs are more or less cross-built*

* I reserve until a later part of the volume what I shall have to 
9. Long and sloping pasterns [Y, 13-16, and $\mathrm{Y}$, 34-39] partly denote the Arabian, are handsome to view, and make easy goers; but such horses soon tire, and, I may say, are generally weak, having the flexor tendon, or back sinew, considerably relaxed, so as to render him " a high goer." The small pastern, or bone inserted at the hoof, always rises in a direct line from the hoof, both being about 45 degrees for saddle-horses, as at $b$, (fig. 5.) and the large pastern is then several

Fig. 5.

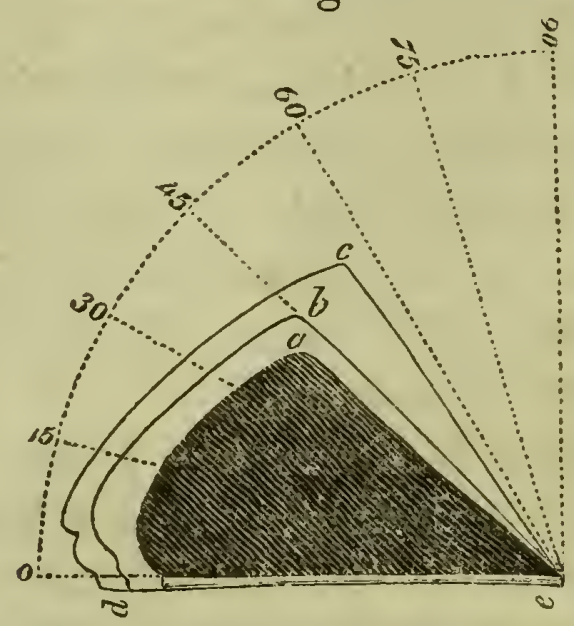

degrees nearer to upright. These hoofs stand of an oval shape, and have small well-marked frogs. But some, as draught horses, have large frogs, the hoof round, thin and brittle, and more upright by nearly ten degrees in early life, as at $(c)$ in the annexed scale, in which case they are liable, if no

say, respecting strain of the back sinere and of the coffin joint, which I have thus named in conformity with the general vulgarism, in order to make myself intelligible to the meanest capacity.-See Foot, a section of. 
change takes place, and they get older and weaker in the joints, to "knuckle over." But, getting aged, and the supply of nutriment for repairing wear and waste falling short, the heels contract, and the horse becomes pommice-footed. The wall or crust is then lower; and as the bottom of the foot grows convex, causing the animal to slip about, so the front of the hoof $(a-e)$ grows concave, the toe $(e)$ almost turning upwards, or cracking. Such horses pull no more than their own proper weight, and nothing by their muscular powers, being incapable of making a purchase with their toes. Horses kept for heavy draught have short pastern bones, the small one entering the hoof at the coronet $(c)$ in early life, but afterwards changes, as I say, to $(a-d)$; and this new inclination, it will be seen, must depress the bone, as the animal acquires the sort of hoof called pommice-footed, and causes a constant straining upon the coronet; hence, ringbones and the crippling, insecure gait, horses of this description acquire, even before they get old; and hence those numerous disorders of the sole, arising from contraction of the heels, that have but this one fault for their common origin.

Contracted heels of this or any other species of horse, being thus destructive of its capability of going, should be guarded against as much as any other individual misfortune to which he is liable: a disposition thereto constitutes sufficient ground for rejection. When this is the case, the interval 
or cleft between the heels, at $(d)$ in the annexed scale, is found to be more or less tender, according to the progress of the disease; the cleft will, in health, receive two fingers lain in deeply, the part having in it nothing unusual in the feel. Soon, however, the heat increases, the part hardens, and the cleft scarcely admits of a small finger; the horse flinches as if you touched a sore, and nothing but time and treatment can restore him, if any thing can. Most commonly, however, the disease proceeds until the clefts of the heels meet and become rotten. Pressure upon the frog, with moisture, is the certain preventive of contraction. See "Foot."

When the pastern-bones (great and small) rise one above the other too uprightly, the small one receives the whole concussion, and communicates the jarr to the very minute construction of the internal foot. See Foot, section of. The jarring of his pace is then very great, both to the horse and his rider. Such horses are very liable to go lame occasionally, but they recover by rest: the principal damage is to be found in the sensible sole. The ass and wild horse (poney) are thus formed; but being hardy, and having less blood and less weight of body to carry about, suffer less by it than the horse.

The just form or elevation of the hoof in front, upon which mainly depends its form behind, has been discussed by various writers, but remains yetawhile uncertain and unsettled. Mr. B. Clarke 
judged 33 degrees of elevation from the ground to be the best form of the hoof, and Mr. White quotes him with a portion of approbation, but most unaccountably refers to his "plate iv," on which an inscription tells us the fact is not so, but 45 degrees is the best possible elevation of the hoof; whilst those which are higher (lower he writes it, or "33"), "approach too near the perpendicular " the figure on the plate itself differing with the diagram on the page of his book (305).

My ideas, however, on this subject are not so general; for I have found the best form of the hoof differ, according to the shape of the two pasterns, as they regard the hoof and each other; deeming that the best, in its particular case, where the small one follows the same declination as the boof, and the large pastern ascends twenty degrees nearer to the upright, as before stated. The preceding figure (No. 5) shows the outline of three feet of different degrees of elevation: $b d$ describes the line of the coronet, or orifice, into which the thickest end of the small pastern-bone sinks, and rests upon the springy substance attached to the inside of the hoof, and which bone, we naturally expect, should ascend out of, and take the same direction as, the hoof, whence it springs. Any departure from this rule of nature is clearly an approach towards disease. In the paragraph above, I showed what mischief might be derived from an upright small pastern, such as would suit the outline hoof $(c)$; of course, this elevation, or a greater, would be a mis-shapen hoof

c 5 
as well as pastern. In like manner, we know that the pommice-foot is out of point and diseased, and it follows that the best possible elevation of the hoof must necessarily lie in the medium of those extremes, which we know to be diseases in themselves: this it is to determine a contest mechanically, without once adverting to the wellknown circumstance of the health and free use of its heels, which attends the horse whose hoof is, at any time of life, near 45 degrees of elevation or depression. Did we require more arguments to prove this to be the proper elevation, a conclusive one could be found in the well-known circumstance of those hoofs of horses which are very upright in early life becoming the lowest when the animals get old; whilst those hoofs which come near the standard of excellence in youth (45 degrees), retain the same form, as nearly as the injuries of shoeing admit of, to an extreme old age.

Reader,

10. So far as the foregoing observations on the fore-legs apply, they do belong, in every particular, and with equal reason, to the hind legs also ; with the exception, however, of what is said concerning the elbore of the fore-leg, and its adhesion to the chest, for which we must now substitute the stifle of the hind-leg [N.30]; and add, instead of the kind of defect described as being occasioned by the contraction of the part, it is here owing to the expansion or spreading of the stifie from the sides. This throws the houghs together, 
and forms "cat-hammed horses," as they are termed; the mode of going such animals are constrained to adopt, the circle their hind feet describe, at every step, the additional fatigue they undergo, the awkwardness of their tread, and the consequent diseases communicated to the sole, lately described (in sec. 6.) as pertaining to the fore-leg,--most undoubtedly afflict the hindleg also, with the additional fact, that this one is more liable to "grease." At rest, if an animal so built does not place one foot before the other, his houghs not unfrequently touch each other,poneys and low horses more particularly so; and it seems worthy of remark, that this species of malconformation seldom appears on the fore and hind legs of the same animal. Indeed, I cannot recollect having seen one instance, and I am thence led to conclude that this twist of the legs is a contrivance of $\mathrm{Na}$ ture to accommodate itself to the disproportionate length of legs before or behind. But, when it so happens that the strength of the parts resists this bending of the hough or of the knee, such horses walk higher behind than before, and vice versa $; i$. e. when one pair of legs seem to have outgrown the other pair, a defect

Fig. 6.

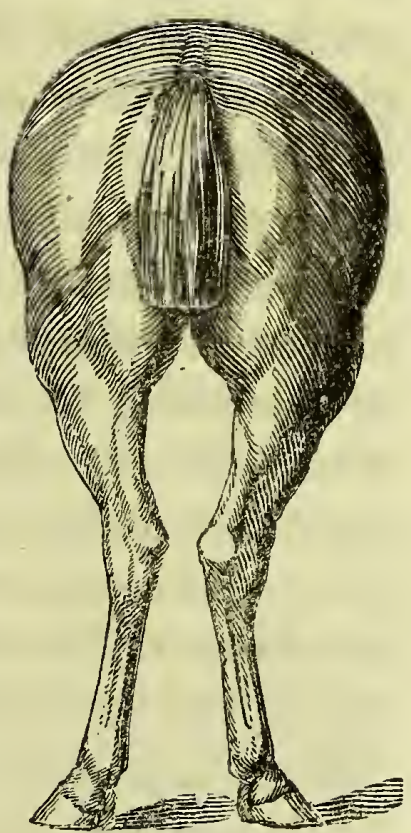


which, though often overlooked, is no less deserving of notice. The wound termed "overreach" is inflicted by the hind leg of this formation upon the fore one. "Forging" is, likewise, occasioned by the hinder toes striking the shoe or shoes of the fore-feet; and is sometimes brought on by injudicious shoeing on feet of the very best construction, and a loose rein; it is, therefore, to be corrected only by the contrary practice, keeping the hind-toes short, and the heel of the fore-foot low, and driving with the reins borne up. By these means, the fore-hoof will spread at the heel, and the animal be enabled to take it out of the way in time for the hind-foot to occupy the identical spot on the ground it had just quitted; for very few horses have the greyhlound-tread of, Eclipse before-noticed, wherein the hind-feet tread much wider than the fore-feet. Neither is such a gift desirable to any but racers, perhaps; nor is it, indeed, compatible with the duties the generality of horses have to perform.

The great additional labour horses with houghs so formed undergo, added to the pain and anguish of continuing it, occasions irritation of the whole hind quarter, that communicates itself to the region of the kidneys and intestines, and superinduce inflammatory complaints, which frequently terminate unfavourably. Constitutional diseases appear on the leg and foot behind oftener than before; and those of the Coronet, with Curb. Thorough pin, spavin, strains, windgall, scarcely 
fill up the catalogue of evils caused by, or receiving aggravation from, too much expansion of the stifle, with its attendant, the cat-hammed hough, and, consequently, a twisted tread of the hoof. No doubt exists in my mind that Eclipse would have been a cat-hammed horse had he been raced at two or three years old, as our practice now is : both he and Flying Childers were five years old before they started on the turf. Heavy longlegged children of our species, in like manner, become knock-kneed men, by being put on their legs too soon; this form of their knees deprives them of calves to thin ill-formed legs, and the thigh, too, seems wasted, when the deformity is great.

11. When the fore-legs are shortest, the horse, whilst going, nods his head up and down a good deal, as he does when these are either weak, tired, or tender of foot: when they are very feeble, without other ailment, he carries the head high constantly; but he works his head from side to side when the same subjects of complaint assail the hind legs and feet. Poneys being ever out of point in one or the other of these respects, afford unerring proofs of those remarks*. The value and advantage of the straight position of a horse's

* I have long been of opinion that the name the wild horses of our forests bear, viz. poney, is derived from the apparently great labour or pain (in Latin pone) they sustain in performing their work. Hence, I infer, Dr. Johuson was not justified in leaving out the $e$ in poney. So puny persons are weally, little, emáciate. 
houghs are never more apparent than when he rises upon his haunches to take a leap, a service which never was performed satisfactorily by a cathammed horse, because he seems to hesitate about what shall be the distance between his feet at the precise moment they are to leave the ground; a blunder which is most visible in the standing leap, when the feet are seen first to straddle to their utmost; in an instant they are brought so close together as to lose all purchase, and he goes ower from an intermediate spot, the whole transaction occupying as much time as does the counting of one, two, three, and away!

The motions of the head are always good indications of pleasure as well as pain. A horse will frequently throw up his head, almost in his rider's face (as if to rebuke his barbarity,) when he has been hit on the head, ears, neck, or poll. (See Section 16.) He looks at his flanks dolorously when affected by a dull pain in the intestines; if it be sharp pain, he turns about quicker; he thrusts his nose towards his chest, when pain assails his lungs generally; but when one lobe only is affected, he turns his head only to that side. If a horse be girthed too tight he will sometimes (justly) bite his tormentor, for this operation retards the action of the muscles between the ribs and of the ribs themselves, so that the lungs do not get room to play. (See Section.31, and Introduction, page 6.) Old horses contrive to avoid this punishment by "holding their wind" 
(keeping the lungs filled) during the girthing; a fine proof this of Nature's dealings, for which they usually either get kicked under the belly, or hit about the head; but both kinds of punishment are the harbingers of further disease, viz. the first of the blind gut, as described at Sections 48 and 49 ; and the other leads to poll evil, as described in Book 2.

A horse is frequently found to have contracted lameness in the fore-leg without showing any visible sign of its exact situation, and applications (of the oyls) to the shoulder is the usual remedy in the hands of the generality of common farriers. Some of them imagine the strain is situated lower in the leg; but they are no nearer the fact, though they are to the spot. A defect in the conformation of the limbs occasions the foot 'which leads to come upon the ground with more force than its fellow; the concussion of the hoof is greater, and is unequally placed when the leg is a-twist than in the upright form; the leading leg tires sooner, and the sensible sole becomes inflamed when the horse is constantly urged to step out with it, the affliction barely showing itself between the frog and the toe, if any where. If a horse receives the impulse to proceed from the right hand or heel, he will step out with the fore-leg of that side, accompanied by the hind-leg of the near side; but his rider, or driver, should early teach him to change the leading-leg, by sometimes touching him up on the contrary side. It is 
worthy of note, too, that the horse which executes this change with the least trouble, and oftenest, has most power and command of his limbs. [See Index-Fever in the feet.] When both legs bcfore are attacked, the horse exhibits a crippling uncertain gait, not unlike that of a drunken man, whence the term "groggy" has been applied (in Yorkshire pronounced "graw-gy"); and, if he is not timely indulged in rest and a run at grass, he is a ruined horse, and becomes soon what is termed "foundered," of which disorder there are several kinds. The mistaking one kind of founder for another generally costs the animal his life, sooner or later, and the studious inquirer had better turn to the next Chapter (at sect. 21, paragraph 3), where he will find a few words on chest founder, many of the symptoms whereof are not unlike this of the feet.

Horses full of feed, and requiring purgative physic, stand with the legs stretched, more than our second cut, at page 18,-inordinately at times. Old Gibson attributed it to vice, and a disposition to kick, when a horse holds his toe scarcely resting on the ground; this is not always the case, for his fore-leg is as frequently so held a-trip as his hind one; and I consider it the token alike of sore foot, of tiresomeness, or of incipient founder.

12. Besides the disproportion the fore and hind legs bear to each other, another series of defects in construction exists between the length of the fore limbs and that of the trunk, being sometimes 
most apparent at the belly and flank, at others on the back; its tendency always depending on the turn taken by the latter. Although this is the old English way of judging of long carcased horses, Lafosse (an old French farrier) took the measure of proportions more properly from the breastbone to the buttock, in the annexed plate being from the parallel line 11 to 38 ; then comparing this with his height, he tells us "a good horse, as we can learn from experience, should be a tenth longer from the breast to the buttock than he is high from the top of the shoulder to the ground." The latter admeasurement will be found upon the annexed plate to extend from the line [D to $\mathrm{Z}$ ] and, with the former, will compose a square rather wider than high,- the integuments being removed from the bones on all sides. My notions of just proportion, however, differ from the French standard, though they do not run into the contrary extreme; for I cannot help thinking inordinate length of body, as compared to a horse's height, a very great defect as regards his health, that form being invariably attended with meagre, washy flanks, and a painful manner of going. But the Flanders and Norman breeds have all this tendency; and they are invariably of a sluggish nature, when the belly, also, hangs low.

The major part of our horses of this built have their sides falling in, more or less, towards the hind quarter, some few of them to such a degree that the flank appears as if it were fastened to the loins. 
These are remarkably poor feeders, have a good deal of short-lived vigour, without the gift of keeping it up at any kind of thing. Nutritious food, but less in quantity, does for horses which are out in the first-mentioned point all that can be done, and that is very little: those of the second species of bad form cannot bear long journeys, nor long privation, or they contract flatulencies and spasmodic cholic.

Another species of disproportionate length, as compared to height, consists in what is called "high-mounted," the limbs having then much more length than the body; a defect that is rendered still more apparent when (as generally hap-

Fig. 7.
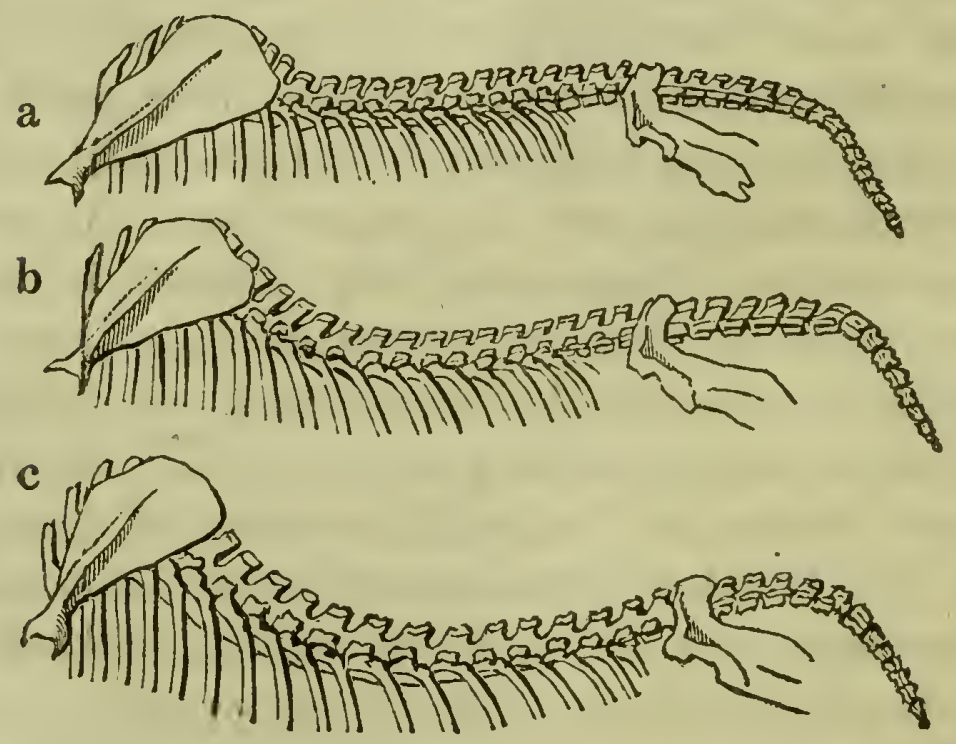

pens) the horse is also roach-backed, like the first sketch of back-bone in the margin; and it is still more striking when a little man is mounted upon 
it, with a saddle that is ever sliding forward upon the withers. Such a form always denotes weakness of limb, and want of freedom in the forehand; nor can a horse of this built take a long step, nor trot well, nor thrive in the field, by reason of the difficulty he has in reaching the grass, which induces him to bend one knee forward, whilst the other leg is drawn back under him. A ludicrous story is even told among horsedealers of a horse so formed having starved itself in the fields, while the food lay within an inch of its nose ; and though such stories are no argument, they, nevertheless, convey the general feeling of the narrators, which is seldom completely wrong.

13. But a horse may be short in the carcase, which is not exactly " high-mounted," in my view of the term; since much will depend upon the shape (or bend) of his back-bone, to bring him under the one or the other description. We have seen what sort of character a roach back bestows on a horse; the direct contrary form, or hollow back-bone, [see the lowermost sketch in the mar$\operatorname{gin}(c)$ ] is no better, though built upon long limbs, horses with this shape back being in all cases weak in the loins; and, therefore, are they more liable to contract inflammation of the kidneys, and to resist the cure longer than those of any other shape back whatever. Yet are they preferred by timid horsemen, principally on account of the easy seat a hollow back affords. Great caution in adminis- 
tering strong repeated diuretics should be impressed upon us at the sight of a very hollowbacked patient. See Sections 53-56.

When the bend in the back-bone, or "hollow back," is restricted to the fore part of the animal, the loins being well filled up, his built in other respects is less material, to be "short in the carcase" being then an advantage; and it is much greater when the bend is confined to a gentle curve, scarcely distinguishable, just behind the withers. [See middle sketch in the last cut(b)]. This is considered a straight back, belonging to a light made, compact horse; he is invariably ribbed home; and, as there then exists but a small space between the last rib and the hip-bone, as seen in the plate at 30 to 32 , so is it always accumpanied by the deep chest, good hind-quarters, and wide loins (i. e. not pinched together), and his ribs finely curved. Horses so formed are always healthy, and esteemed at first sight superexcellent, being supposed, with justice, capable of doing more work than those of any other built whatever. But the gift of leaping or of great speed do not always belong to horses of this form, however perfect in other respects, though health, vigour, strength, and lastingness do. Such horses always feed well and retain their condition. The inquiring reader would do right to turn back to what is said under Section 10, and draw his conclusions from the nice distinction.

14. Low-buttocks generally accompany roach 
back, [see sketch a.] and are always attended with another fault,- " " hind legs too straight," and incapable of stepping out. A horse so formed can execute no pace tolerably, and trotting worst of all. In the drag, such a horse steps short, and is always upon the bustle, as if his legs were tied. A large head, with short thick neck, denotes a sluggish horse, heavy in the hand, and usually "carrying low:" these are faults generally attending his cntire breed. When the neck is longer, the case is not bettered, for then the animal is of the long-bellied kind, with thin flanks and washy. All large heads are attended with thick fleshy legs, much disposed to grease: and as a small light head, but wide at the forehead, with expanding nostrils, and bold prominent eyes, denote (blood) strength of body, and vigour of constitution, so the contrary may be looked for in horses which have narrow foreheads, small or sunken eyes, and small arid nostrils. I never saw a fine well-turned head that did not belong to a good set of legs, well fixed upon the body; the correspondence goes still further, inasmuch as the quantity of rihite in the face is commonly attended with a proportion of white upon the heels, thus: a star, one white foot; a blaze, two white feet; wohite face, four white legs, \&c. Horses with large jaws are given to keep open their mouths while at work; and, when aged, grind their teeth more than is necessary in feeding. The manner of brcaking his food being, with the horse, different 
from that of other animals, viz. by rubbing his under teeth from right to left against the upper ones, - a motion to which the term "grinding his corn" has been applied;-an old horse will sometimes continue it when he has nothing to eat, thereby wearing away his teeth; a circumstance that occasions imperfect mastication and its consequences*, besides subsequently leading us into error in examining his age. Hard-mouthed horses, and those which champ the bit much, fall into this idle habit.

Flat, or narroru-chested liorses are subject to those attacks which lead to consumption (see sect. 36), and, consequently, are liable to show bad condition; or, it may be, that disorders of the chest do contract its capacity: as horses that die after long-suffering in the lungs, and parts adjacent, as I mean to show in a subsequent page of this volume, have the internal part of the breast-bone much affected, as if the moisture thereof were dried up by the heat of the contiguous disorder. In some horses, on the contrary, the cavity of the chest seems too great for its contents; they are short-winded horses of one description (there being several) that are afflicted with these kinds of mal-conformation, or disagreement in size between the parts containing and those contained.

* Indigestion, flatulency, cholic, worms, are all produced by animals swallowing their food unbroken. 


\section{Reader,}

15. My purpose in making this exposition of the ill-effects produced by mis-shapen limbs, \&c. on the horse's health and usefulness, would be incomplete, were the original causes thereof left unnoticed. The most remote, or more general one, resides in the breed, or the manner of breeding the animal, whence we are sometimes led to say, "What is bred in the bone will never go out of the flesh." As regards the kind of stock from which to raise a supply of young ones, breeders may undoubtedly suit their own fancies; but it must be seen that a brood mare which receives too much of the horse for her capacity will produce a foal all father, as it is called, being at the same time larger than she can conveniently carry; it then bids fair from the beginning to be a misshapen animal. This happens oftener than is commonly imagined; but it is easily prevented by adopting a horse for her whose strength comes tolerably near that of the mare. Disregard of this precaution is found to produce the first foal much smaller, though more lively, than the next and subsequent ones, especially if care be taken in the latter case to give her a horse more and more vigorous as she becomes more roomy. For it must be clear to any body [upon mechanical principles again] that if the futus, growing too large for the cavity in which it is generated, originates too much bone, it must determine towards some 
particular part of the young animal; and the colt will be brought forth with that deformity, and carry it through life to the knackers, after plaguing two or three of its owners with fruitless encleavours to physic off its ills.

I say nothing whatever of the cross to be adopted; that being withoutside my plan, would carry me too far away from my inain subject. But I may observe, in passing on, that no breeder in his senses would think of employing a horse to raise stock that has served half a dozen or more mares in the course of the day; and yet nothing is more common, nor more inevitable when the payment for covering is low (say a guinea or two), than that the smallness of the sum must be made up by the number of mares served, the price, keep, and attendance, upon stallions, being expensive. This error must be so palpable to any man who calls himself $a$ father, as to render any further argument upon that topic utterly unnecessary. Some twenty-five years back into the last century, I recollect reading a well-attested account of a celebrated horse's dying in consequence of twelve or fourteen successive efforts in procreation; and if such be the deplorable case with the parent, what strength, bottom, or lastingness, can be hoped for in the progeny so begotten? Nevertheless, I am of opinion that a vigorous horse which may have been freely engaged (if early in the season) may be in a better condition for raising large and lively stock, than under any other circumstances 
whatever, except recent exhaustion. Aged stallions produce hard-mouthed foals, and further proclaim the ill-adapted ages of sire and dam by extraordinary hollowness over the eyes.

Much depends on the country, the climate, or kind of land, in which the gestation or breeding may be carried on; and it may be presumed, that no one in his senses would choose such a situation as is known to be disadvantageous to the particular kind of breeding he may have in contemplation to pursue; whilst those who may already be so placed, have no right to complain when they engage in a branch of business thus ill adapted to their plan of farming, and they get disappointed. As both objections lie at the option of the parties concerned, they require no farther remark; but another point of consideration well worthy our careful attention is, the treatment the mare ought to experience at our hands while she is breeding; this being a matter of some moment, and within every one's control, should not be neglected. Though a brood mare in foal requires no pampering at any period, yet is it clear that, from the third or fourth month, she should not be worked so hard as usual, and from this period to the day of her foaling, the duty to be required of her should be less and less every week. Nor, on the other hand, is complete idleness befitting her situation: in cases where she has not been used to hard labour, a run at grass, in a paddock, with access to an outhouse or stable, as it leaves to 
her option the quantity of exercise her strength is capable of sustaining, would be found most conducive to the best purposes of nature. Her food should be of the first quality, and regular, and, though full enough, should not be too much. Occasionally, she may be off her feed, during the "time," but she does not therefore require "physicking," nor coaxing to eat. Great care should be taken that her body is emptied regularly, that no derangement take place either way; and that if opening physic is required at all, aloes is not in her case the best that can be prescribed for that purpose, since they act mostly upon the intestines lying immediately in the vicinity of the foal. An opening draught or drench should be substituted for the pill, as its operation begins sooner.

A very general cause of mis-shapen limbs is the placing upon younkers too great weights at first, whereby the houghs or the knees are thrown together, particularly when the animal is constructed with the fore and hind legs disproportioned to each other, as noticed at sections 9 and 10. Splents and sprains are the inevitable consequences of mounting colts, \&c. too early in life; and hollow back is oftener induced by this premature error than existing originally. As if all this were not enough, many breeders nearly starve their young ones until they are brought into use; whereby they beçome deficient in solidity of bone and quantity of muscle, if they do not imbibe some internal or constitutional malady, and the event 
of their limbs growing mis-shapen is no longer left to chance.

16. Notwithstanding all that has been said and done, little would avail the finest proportions of the bones towards the formation of fine-shaped limbs, least of all to symmetry of the whole horse, but for the seemingly adventitious circumstance of the covering with which they are immediately invested; and which, embracing tightly several bones, and connecting them together, constitutes a limb. Some of these coverings are confined to the joints only, holding them in position as near as the Creator designed them, unless accident (of parentage, of birth, or mis-usage), as before described, should induce them to a perpetual strain, and they enlarge at these joints in spite of the next or universal covering of the bones: this is membrane (of which more shortly), the uses whereof on the bone may be illustrated by taking a stocking of good length, and having filled it with pebbles of its own size, and tying the end tightly, a stick or club is produced of some degree of flexibility resembling a limb and its joints. If the tying be not performed well, by bracing the stocking to its utmost, the flexibility of certain parts (or joints) of the limb will be greater: it will possess less strength at the joints when bent, and be liable to give way or break unless supported by some other covering. It is easy to perceive that the horse which has those coverings in the highest perfection would move his limbs more 
correctly after the fashion they were designed for, than he which constantly strained them out of their places. He who was endowed with the firstmentioned quality in perfection would be considered a sinewy tight-built horse; the second kind I have already depicted in section 10, where the houghs are described as keeping those integuments in a perpetual state of derangement, straining or twisting them in such a manner that constitutional enlargement at the joint is the consequence.

At the ends of all bones, a yielding substance, in appearance like bone itself, prevents friction, and by its elasticity gives a spring to the animal's steps. The ease of a horse's going mainly depends upon this substance, which receives the name of cartilage, and is liable in some measure to be absorbed or taken up into the system, or, in cases of diseased joint, to become stiff and bony. Consult sect. 23, \&c. on those points of information. We may notice this absorption in very young animals, whose bones are all substituted by cartilage, until the blood furnisheth the means of forming a more substantial frame, such as I have been describing; and teaches the validity of some remarks I made in a preceding section (15) on the kind of attention we ought to pay to our brood mares while the fatus, or unborn animal, is being formed in the womb.

Not only between bones, and embracing every joint, but at the termination of the four legs in 
their horny feet, is this springy substance to be found, the whole being liable to wear out, to contract or to harden with age or disease; whereby all old animals appear shorter than those in the vigour of youth, and horses more particularly are liable to contract a stiffness of the limbs, and a rigidity of the whole frame, that at its last stage is termed "locked jaw." Besides this casing of the joints in cartilage, the ligaments connect or tie the bones together. These ligaments are seldom troubled with any ailment but that of great lassitude when the animal is tired, and occasionally to sprain. This accident takes place when the horse steps aside upon uneven ground, and the ends of the bones press laterally upon the ligaments. It follows, of course, that mis-shapen horses whose feet are always constrained to take an uneven tread must be subject to a constant strain, and must be more liable than others to incur per. manent accident,-every step forming a trivial one.

But the ligament demanding the student's most serious attention is that which suspends the neck bones, on the same principle as our old fashioned lamp-irons are suspended by a small one from above, only that the ligament lies closer, and covers the intervals of the bones on the upper side, as at $a-b$ of the annexed sketch*. So placed,

* Called by the learned "cervical ligament" and "the cervicular." In operations for the poll-evil this ligament is frequently divided by the unskilful farrier cutting it across rather than lengthroise, which is the only right practice. 


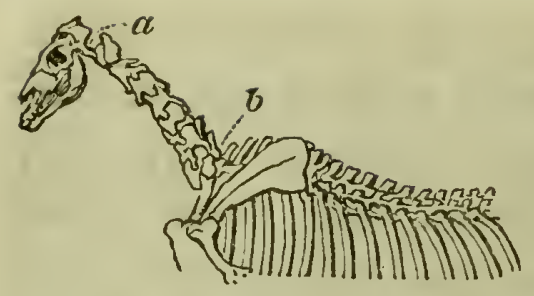

and passing from the skull to the blade-bones, to both of which it is fastened, it has the power-at the will of the animal, of bending down or drawing up the head, which would, in fact, but for this support, fall to the ground. Horses in their last moments, when that will may be supposed to have left them, always cast back their heads considerably, by reason of the contraction of this strong ligament during the paroxysms of departing life. At $a$, however, where is the seat of poll-evil, it is usually thin, the cavity there found between the bones being mostly filled with muscle (s. 27 ); but this does not happen invariably, as some horses have little or no cavity to be filled with ligamentary substance, or with muscle. Our frontispiece is the portrait of a subject of this latter kind; but the reader is referred to some subsequent observations and cases on "poll-evil" for more detail on this hitherto-neglected point of conformation.

17. At the joints formed by the bones and covered by cartilage, the whole are surrounded by a strong membrane, which wraps the bones tightly, and secretes an oil at the joint for its further defence from the effects of friction. Of this secretion, and of the membranes generally, some further notice is given in the second chapter at section 22.

This strong membrane is not, however, confined 
to any particular part, but continues its close attachment, or embracement of the bone, over the entire frame of the horse, from the crown of his head to the soles of his feet, at the latter parts protecting and farther defending them from the harder substance with which they are surrounded. Throughout its extended course it serves as an excellent holdfast for the sinewy ends of the muscles (see sect. $2^{2}$ ), which are attached to it above and below joints, whereby they act as levers to raise the lower bones of the limbs, as described hereafter.

According to the parts this membrane may cover, it has received from the learned in hard words and many, a separate name for each, as if that course would further the cause of science; and whenever they speak of it as being found upon the joints, the skull, or the bones generally, they term it perichondrium, pericranium, and periosteum, as the case may be: rohy, no one explains. It has been considered insensible, because in health it has not the sense of feeling so fine as other parts of the system, which are furnished with more nerves (s. 30); but, the very few of these fine organs with which the membrane of the bone is furnished, renders the pain occasioned by disease, whenever it may be attacked, the more acute; when flying from one nerve to another, those wellknown shooting pains are felt (by us) that are universally mistaken for pains in the bones themselves. We do not go too far in inferring that 
the horse is similarly affected. This takes place in splents and spavin, when the bone enlarging forces its way through this tightly-braced membrane, and causes inflammation, temporary lameness, and, at length, those well-known appearances I have just named. In the living horse this membrane is red, by reason of the fine blood-vessels with which it abounds; but in the dead subject, the supply of blood being withdrawn, it then turns white.

\section{CHAP'TER II.}

Concerning the Horse's Inside, of its Conformation, the Functions of the Organs of Life, and the Diseases to rohich each is liable: together with Outlines of the Principles upon which the Cure is to be effected.

18. Such, dear reader, as I have endeavoured to teach, being my view of the external frame or structure of the horse, which I have termed his built, I come, in the next place, to speak in a more particular manner of his inside; noticing, as I pass on from one part of him to another, the seats and causes of his diseases, with a view to their cure, but referring you to the second book for the separate treatment each requires. In the third chapter 
will be found my reasons for following up the principles herein laid down, by a line of practice, at variance, in some material points, with the present mode of treating the animal in health as well as in disease.

Organs.-But, before I proceed to describe those 'several parts of the horse's inside, there appears to me an absolute necessity for previously bringing the unlearned reader better acquainted with a few general topics, that we may proceed with the details smoothly and more intelligibly together; viz. the names, uses or offices and powers, of that infinity of small organs which lie spread over most parts of the body, and belong in common to several of these parts in nearly equal degrees. The large organs, having the power of carrying on the animal system, first, as regards digestion, secondly, those employed in the circulation of the blood, and, third, those of respiration, are too well known to the sight and touch to require explanation here; yet are they (the heart, kidneys, lights, liver, \&c.) composed or made up entirely of those minor organs I mean first to describe. But the precise way in which these act in and upon the large ones, the great share they hold in furthering the system of animal life, and the eminent rank their services maintain in restoring health when the system is any way disordered, has not received, in the practice of horse-medicine, that share of serious consideration the importance of the subject imperiously

D 5 
demands. To these points, then, I shall shortly call the reader's undivided attention; meantime, as some cramp words and phrases are applied by most people (writers and others) to those offices of the animal's organs, they stand in need of previous explanation.

19. Each kind of organ, whether small or'large, was designed by the great maker of all things to perform some office towards the preservation of the animal in health. When such office is performed properly, as ordained, the organ is said to "perform its function well." For example, the heart is given for the purpose of sending the blood through the arteries, all over the body; but when the pulse beats low or irregularly, that organ is said to "perform its function badly ;" when it ceases to beat, this function is lost or gone. So, certain of the organs are said to secrete something or other that is liquid; the doing this is their function; the power of doing so, that of secretion, and the article secreted or collected together, is called the secretion of this or that organ. 'Thus, the kidneys secrete urine, and it runs off (sect. 53); the glands, under the jaws, secrete spittle (saliva), which passes off with the food by the intestines: therefore are they properly considered as excretory also, seeing both the secretions are drawn together for the express purpose of being so sent away, this last by the grand canal (or gut), as the first mentioned is by the bladder, and the perspiration is through the pores of the skin. But 
some secretions are found that have no outlet visible to us weak mortals, though they find their way through the skin, sensibly enough at times; and this then becomes the sensible perspiration or sweat, but when we do not see it, this third species of evacuation is termed the insensible perspiration; and, in health, one of the two is always in action,--in disease not so: we then give sweats.

When, however, it happens such functions are obstructed, or, on the other hand, too much of either secretion is furnished to the system, then disease begins; as does, also, our duty of finding out what part of the vast machine has ceased to perform its office properly. For, without this previous information, no man can possibly know how to apply the remedy in restoring the disordered organ to the proper exercise of its function; nor can any one hope to arrive at this desirable point of veterinary knowledge, unless he has acquired the means of ascertaining where, when, and in what degree the mischief has taken place, by patiently examining the action of those organs while in health, and comparing their appearance, after death, with the particular symptoms which preceded that event.

20. Secretron.-Although, as I say, the secretions just spoken of are important in themselves, and of several sorts, as bile or gall by the liver, urine by the kidneys, \&c. yet the chief object of our present notice is the secretion of a fluid, more or less watery, which pervades the whole system. 
It differs in quality a little, and very little any where, being adapted to the nature of the parts requiring its aid :- -1 st, In softening and enabling them to move freely over each other ( $a s$, between the ends of bones);-2d, Acting as a defence against injuries from extraneous bodies (as, on the inner coat* of the intestines); and, 3d, To prevent the parts from growing together (as the liver to the midriff), \&c. Misfortunes these which invariably happen when the supply of this fluid falls short of the quantity required for a long while together; and this is the case whenever the animal is worked until the fluid, at some part or other, is exhausted; a circumstance that strongly bespeaks the propriety of allowing the worn-up poor creature more frequent supplies of water, although this be done in smaller quantities. Inflammation, or fever, which is occasioned by suddenly checking the secretion, eventually exhausts this moisture by its great heat. Both those disorders are therefore referred in the sequel to the same origin; the first being local, or pertaining to some particular organ or part, whilst fever pervades the whole system, and the solids in particular. 'The total absence of perspirable matter marks both diseases.

On the other hand, when too much of this fluid

* The surgeons of human practice will observe, that I here transgress the doctrine of the surfaces; but they will please to recollect that my object is to make myself understood by a certain class of readers, of which they compose a very small part. 
is secreted, and remains unabsorbed, disease ensues: upon the heart it forms "dropsy of the heart bag;" on the covering of the lungs, it becomes "dropsy of the chest;" in the membrane of the belly it forms "ascites," or dropsy of that part, and usually falls into the scrotum. The powers of medicine have hitherto proved of no avail in the first description of ailments; and are but partially applicable to the last mentioned: the operation of tapping too frequently disappoints our hopes, to induce us to rely upon it as any other than a temporary relief, and it is, therefore, seldom or ever applied to the horse. Thus, in whichever way we view this important secretion, its eminence must strike us as quite equal to any other. Whenever obstruction in this part of the system takes place in the horse, the consequent adhesion of the parts being invisible, he gets worse used by his inexorable master for his inability to perform his usual work, and he soon falls a victim to the lash, the spur, and the bit. At the joints, this fluid is considered tó be an oil (synovia); at the heart it is confessedly nothing but water; whilst it partakes of a mucous, unctuous, or slimy nature at some other parts of the body. This is the case with the membranes of the throat and gullet; on those of the nostrils, the heat of the horse's breath converts it into a "viscid mucus:" when the secreted watery particles come off by sweating, it assumes a white or milky appearance, after a little time appearing thicker and more 
slimy as the sweating continues, and the watery particles becoming less and less, its fluidity is also lessened. See Membranes, sect. 26.

21. In all animals, the secretion of this watery fluid is carried on by the membranes, which are thin films placed between the various organs, over the bones and among the fleshy parts. These not only secrete, but sustain the fluid in its place, for the purposes above mentioned, and being of various texture or fineness, the fluid that is so secreted and held to its purpose by each, partakes more or less of water, is more or less slimy, or consists more or less of an oily nature, according to the use it may be designed for. Each kind of membrane, and its proper secretion, has received a learned name,-the first being called serous, the second mucous, the third fibrous; but, having resolved to abandon learned words, whenever the thing can be understood as well without them, I find less occasion for introducing them here than is generally practised. For, the peculiar nature of the horse having assimilated together, by its action, the three kinds of secretion more so than is the case with other animals; and his habits contributing as much more to the hasty calling off of one kind of fluid from certain parts to the assistance of another part, which may have been exhausted of its kind; and as the treatment of the horse in all cases of a disordered secretion of these fluids is the same throughout, the action of medicine upon one always affording assistance to 
another (as I shall prove shortly), there is no such necessity for carrying the distinction farther in horse-medicine, although it may be so in the human practice.

Perspiration is always at a great height in the horse; it is one of the chief means of cure in most of his disorders, and consists in drawing the watery secretions from all parts of the body. These pass to the surface readily, coming through the membranes from the joints, the solids, the bowels, and their coverings; as may be noticed in the case of hide-bound, upon opening the animals that die in this state of exhausted nature the mesenteric canal (hereafter described) is invariably discoloured with yellowness, being, at times, almost orange colour; but I have as constantly found the lacteals of a fine coated horse shine through as white as milk. Again, on over-working the horse, so much of the joint-oil is sometimes drawn off by perspiration, that he becomes stiff in the knees, for want of that softening quality which kept the parts supple: we feel the same ourselves upon such occasions; and, in taking off the knee or the hough of a permanently "stiffjointed" horse, I have invariably found the jointoil affected; in very bad cases it no longer existed. During life, the escape of this oil, by reason of wounds (as bad broken knees), leaves the joint stiff. Further comment on its uses is unnecessary; but those facts should teach his owners a practical lesson of moderation. 
On the subject of absorption of these secretions, I noticed, many years ago, a very ingenious reason assigned for "lameness of the fore legs, of English horses particularly," in the great work of La Fosse, the elder, on what he calls "Hippopathology," or the diseases of horses. He says, "The fluids which did lubricate the parts (the shoulders) and keep them supple, being reduced in quantity, the fluid flying off by sweat, the remainder gets thicker in consequence, and the solids of his limbs become stiff and dry." It happens mostly in the fore limbs, and he calls it a cold or chill, and says, page $26 \%$, it resembles a "stroke of the shoulder,"-" Cheval froid et pris dans les epaules." A species of founder, that is clearly not to be cured by external applications, (as the oils, firing, \&c.) but by restoring to the part the function of secreting a sufficient supply of the fluid rohich had been so exhausted. In these few words are included the whole secret of my method of cure in such attacks; and, in this case, gentle sweating is that remedy which is best calculated for restoring the function.

22. When the skin does not permit evaporation, and send forth the secretion by perspiration, disease has begun, the hair looks staring near the part affected, and not a stable-boy exists, who, when he sees a horse with a rough coat, cannot tell that "something or other is the matter with him." This arises from want of moisture within; the skin itself not having the power of secreting. 
or drawing towards it, by effusion, the moisture which is necessary to keep it supple, it shrivels up, and this important evacuation, which is second only to the urinary, is then stopped, so that even the insensible perspiration ceases. Some idea respecting the amount of this insensible evacuation may be formed by placing a horse, that has been exercised, between ourselves and a well white-washed wall upon which the sun shines; when the shadow of the insensible perspiration may be seen upon the wall ascending in tolerably thick volumes, something very like steam from a boiling pot. Indeed, the insensible perspiration is, when compared to sweating, the same as warm water compared to boiling water.

Yet, although we do not know the exact workings by which this internal effusion (as it is called) of the watery particles from one part of the animal to another takes place, we do know, accurately enough for our purpose, that abundantly perspirable matter lies in and upon the intestines: as any affection of the heart, arising from the organs of sense (sect. 30), causes a sudden suffusion of blood in the skin, and induces heat and irritation there*; so do the intestines send forth their

* Fear, for instance, of the dealer's whip often occasions the skin to contract and expand, so as to cause the tail to shake with every alternate vibration of the heart; and $I$ once rode with a fellow, a right-out journey of forty-four miles, who whipped and spurred his horse to such a degree, that the hairs actually fell off from his tail, except a few at the end, an occurrence that is usually ascribed to scrophula on the horse's hide; a disorder it might have also laboured under, for aught I know to the contrary. 
watery particles, upon the slightest occasion, to the same place of exit, in order to moisten and render it more supple. Whether the very transparent membrane, called peritoneum, which sustains the bowels, or that other large part of it which covers these and all parts of the inside, is most concerned in this secretion and effusion, is not worth the trouble of inquiry here. But, in addition to what is said in the last section respecting the colour of the lacteal duct, as it passes along the mesentery in cases of hide-bound, I may be allowed to observe, that we may daily witness the sensible perspiration from young and healthy horses to contain more of water than is found in feverish, old, or generally unhealthy animals ; and that, with these the sweat is more frothy, or becomes so much sooner, his mouth gets clammy, and his tongue dry and hot underneath, with less work than they; and that horses so affected are always found insatiably craving after water. Moreover, as regards the connexion that subsists between one part of the animal and another, I have many times found purging physic, given in the usual doses, fail of the effect intended, and come off in the shape of profuse perspiration. Not only in those large and decided doses, that are intended to produce much effect, but even milder ones, as alterative-laxatives, often turn out of their course, and, as well as diuretics, not unfrequently disappoint us in the same way, the latter also coming off by the skin instead of urine; which is, besides, a very well-known natural 
operation, usually described by a vulgar saying; "The more you sweat the less you'll p__ *" It follows, of course, that the less sweating a horse has got, the more he must stale, and accounts for the profusion of the latter kind of evacuation in winter, when he scarcely ever sweats, and perspires but little, comparatively speaking. As a farther proof of this connexion between the secretions and evacuations, let any one notice a horse when he first stales in consequence of taking a diuretic, and he will find a transparent water hanging in little globules at the end of each particular hair of his coat, all over his carcass.

\section{Reader,}

23. We come now to speak of glands, nerves, membranes, absorbents (being 1st. lymphatic, 2d. lacteal), and muscles, which are the names writers and practitioners of eminence have agreed upon to speak of those numerous minor organs that are employed throughout in carrying on the functions of animal life, and the uses whereof $\mathbf{I}$ shall come shortly to explain. The reader is

* Tears, or any other evacuation of the water that moistens the animal system, are liable to the same kind of comparative remark. In man, when excessive salivary secretion attends the toothach, the glands of the mouth and jaws carry off so much water as to affect the quantity of urine voided, and we may infer that a diuretic would reduce the inflammation of the jaws. So much for the comparative practice; but not worthy of rejection on that count alone. 
already aware of the sinews, of three kinds, that more immediately cover the bones and keep them in their places (sect. 16, 17), to which if we add the bare mention of the muscular, or fleshy parts, and refer to the "circulation of the blood" (sect. 37-44) for a description of the veins and arteries, he will have before him the names of all the integuments of a horse's body beneath the skin. Detailed particulars respecting all these follow next in their order; the larger organs of the inside being reserved to the subsequent sections of this chapter. By this course of proceeding the will be better enabled to comprehend, as we study those things together, why and wherefore these were given to the animal, and what functions each has to perform in health; or these ceasing, or being obstructed, we shall be led to consider, in the next place, what species of remedy is proper to be applied for removing such obstruction, and thereby of restoring health; for, he may rest assured, that not the least atomy of matter has been conferred upon the animal form without intending that some good and demonstrable end should be answered by its creation. In addition to all which, there are many causes incessantly operating towards the simply-grand purpose of prolonging life, and of providing for the waste which is constantly going on in the animal system, that are far removed from our sight, and others almost surpassing our comprehension, but which are nevertheless known to exist by their effects; but, of all these several 
matters, more in their proper places; one instance of the insufficiency of human knowledge having been already adduced in the preceding section, as regards the unknown mode in which the watery secretions penetrate from one part of the body to another.

24. All those important points of knowledge in the first principles of our art lie within the com. pass of every man's capacity, who can read; they are certainly open to his inquiries; and he who is constantly among horses cannot fail to learn (after studying the subject in the manner I now propose) to make himself as well acquainted with the symptoms or signs of approaching diseases as the generality of veterinarians. He certainly may render himself much superior to the old, ignorant set of farriers, who were bred up in the days of stupidity that are just gone by-never to return. Let such an inquirer after knowledge bring to the task Industry, Patience, and good Common-sense, and he may soon acquire knowledge enough of the outlines of the art to be able to pronounce when a pretender is at work, or when it is that a man of judgment and real sound learning in his art has undertaken the treatment of this valuable animal in the distressful hour of sickness. On this head I am not ashamed, after the lapse of nearly half a century, to own that I once wept over the sufferings of a sick animal which died of the medicines administered by a stubborn selfwilled ferrier, who could read, and write, and talk, give a drench, and drink himself-nothing more: 
he could not think, of course could not compare one disease with another, nor mark the difference that exists betwixt two or more that are frequently and fatally mistaken for each other. And here, once for all, I cannot refrain from thus early insisting most strenuously on one point, which therefore I shall not have to repeat when I come to notice certain barharous practices perpetrated by some such men, and the not unguilty practice of other physic-giving horse-doctors; and this is, in short, whoever of them dares to undertake the administering of medicines to this incomparable animal without paying especial attention to the subject-matter that is handled in this chapter, commits an unpardonable act of inhumanity on his suffering patient, and of gross dishonesty towards its owner. The remedy for a disease is not always to be found in medicine; preventives never. Purgatives are not only the most obvious means of cure, but the best, the least dangerous, and those which promise in the readiest manner to dispose the most vital function to resume its wonted action. Alleratives are the safest and most effectual remedy for valuable horses, and those which cannot be spared from labour; they are indispensable in all cases of vitiated blood, and where found ineffectual nothing else can be of service. Bleeding is the very best or the very worst auxiliary we can employ; its efficacy and precise periods of utility may be learnt in the sequel (see sec. 37 to 44 ), where "the circulation" comes under 
consideration; also in the first pages of Book 2, where the Pulse is justly made a subject of prime consideration.

25. For the sake of making myself more clearly understood, I shall, when explaining the formation and functions of the horse's inside (i. e. as much of it as will answer my purpose), consider it under two distinct heads; namely,

lst. The fore part, or throat part, as it is called from its neighbourhood to the throat, or gullet, page 84 ; and,

2d. The hinder part of him, being his belly, properly speaking, page 116 , \&c.

Both of these parts have obtained learned names; but that is no business of ours.

The fore part of a horse is that which lies between the rider's two knees, within the chest and true ribs. To the farthest of these is attached, as well as to the middle of the back bone, a natural division of the two parts, stretched tightly across his inside; like the head of a drum; and it is also fastened to his breast bone, but admits of the gullet to pass through, as it does of the great vein and great artery which carry on the circulation of the blood of the hinder part. With these exceptions it is air-tight, and it bears resemblance to the head of a drum in another particular-it is membraneous, except round the edge next to the ribs, \&c. where it is found somewhat fleshy. From its situation in the mid- 
dle, this natural division is termed the midriff, or skirt, and appears to have been designed for keeping back the stomach and bowels of the hinder part, which as it is, when full, press it out of shape, not urlike that of a watch glass, and would, but for this barrier, interrupt the action of the heart and lungs. But by the present contrivance, as we shall see presently, this pressure from behind soon recedes, the midriff returns to its level, and the ribs, no longer contracted towards each other by the aforesaid pressure, expand, thereby enabling the lungs to perform its function of drawing in a fresh supply of air. Upon this principal agent in the function of respiration see more detail in the 35 th section of this chapter.

26. After this necessary preamble, let us proceed, as before proposed, to consider the construction of

The Membranes,

Muscles,

Glands,

Absorbents (i. e. 1st lymphatics, and $2 d$ lacteals),

Nerves*.

Of these the most universally dispersed over the frame, those which occupy, defend, or embrace every part, are the membranes. As well behind

* For ligaments, cartilages, tendons, \&c. see sect. 16, 17. 
as before the midriff, not only inside, but on the outside and every part of the animal are these skinny films placed, for the purpose, lst, of keeping those parts which they encompass in a compact state; $2 \mathrm{~d}$, to secrete a fluid more or less oily for protection (see sect. 21); and, 3d, to prevent those parts from rubbing against and injuring each other, or adhering together. The better to accomplish these purposes, they are admirably calculated for the secretion of a fluid, as I observed before (sect. 20); but, whenever the property of secreting such fluid is suspended, then disease begins, and according as the secretion may prevail, being either too little or too much, will be the kind and quantity of disease. Hereupon may be calculated the importance they hold in the animal system : but of those matters I have already spoken higher up.

Membranes. - To appearance they are nearly transparent, web-like, and of a strong texture; some are simply flm, having more or less of feeling according to their uses, and are those which, being interposed between one organ, or part, and another, prevent the interruption which would otherwise ensue; as the midriff, for instance, which I have just above adverted to (see sect. 31 and 35), which is the thickest of all, or the loose membrane that covers the lungs and divides them into two parts, so as each may act separately (see sect. 32). The second species of membranes are finer, more transparent, and paler than the first- 
mentioned, and possess the quality of containing in their cavities, resembling sponge, the matter deposited within them by the arteries for the purpose of repairing waste and adding new flesh; these we term cellular membranes, from their sponge-like texture, and they are, moreover, so infinitely thin as to pervade all over the solids, or fleshy parts, without being in every case visible to the eye. They are nevertheless proved so to exist, from the circumstance of those being greatly distended, when the subject dies of being "blown," as I have shown lower down (sect. 35.) Then, not only the forehand, but the linder quarter, even down to the hocks, become inflated with the wind, which, by reason of the animal's being strangled, the lungs had no power to discharge, and the cellular membrane admits it into its cells, or cavities. Any one may perceive this membrane and its numerous cells to advantage in buttock of beef, or leg of mutton, after being dressed; upon taking a slice between the fingers and straining it nearly asunder, the membrane appears, but more evidently at the corners where two or more muscles meet; and in summer time, particularly with over-driven beasts, the membrane between the muscles will be found charged with a dull brown sort of matter, that may be, and frequently is, scraped away with the knife. Another familiar illustration of the uses of the cellular membrane, first mentioned by old Dr. Bartlett, of Windsor, in 1764, is that of "the inside of a 
shoulder of veal, which butchers blow up with a tobacco-pipe, or quill, to delude their customers. When the animal becomes adult (or full grown), the membrane that is so capable of being blown up is filled with meat, and shows the impropriety of pushing young animals in their work before those solids have reached maturity.

Experiment.-If one draw in his wind, and keep it longer than usual, a sense of fulness is imparted to the solids. This is no other than the cellular membrane being filled with air.

When once divided, membrane of either species never again unites, but in case of a healed wound the granulations of new flesh hold the divided parts of membrane to their respective places; the obstruction thus occasioned in the deposite of blood causes pain upon change of weather, when the new flesh either expands or contracts, as it may be affected by heat, cold, or by humidity. In the human physiology, another kind of distinction is made between the kinds of membrane (as I said before), tending to show whether their respective secretion is more or less watery, slimy, or oily; but this view of the affair is not applicable to the physiology of the horse. My reason for abandoning that course was given at section 21. I may, however, here aptly observe, regarding that species (the slimy or mucous) which lines the nostrils, throat, and intestines, that its chief disorder is a cold, which shows itself in the cessation of the secretion; soon after this, the parts being inflamed 
throw forth a thin acrid discharge, which is greatest when the inflammation arrives at its height, sometimes producing a little blood, either upwards or downwards; when the inflammation wears off, these appearances are also lowered by the mucus becoming more and more thick, until it reaches its usual consistency. The cure is to be effected by lowering the inflammation; but this is most frequently effected by the natural discharge of the mucous matter just spoken of.

27. Muscles are fleshy bodies of various sizes and shapes, according to their uses; reddish, of a grainy, fibrous texture, easily separated, but more stringy at some places than at others: the last-mentioned are termed "coarse parts" or pieces, in the animals sent for our sustenance, and are those where the greatest strength lies. These fibres formed into bundles, and surrounded by the cellular membrane, are visible to the eye, if there be not attached to each fibre a continuation of the same membrane that is not visible. Several of those bundles, being further enclosed by a stronger membrane, form a muscle; each whereof is attached by its two farthest extremities to some other, or, to two different bones, upon one or the other of which it acts as a lever. A muscle accomplishes this motion of the bone by expanding its belly or middle part, and contracting it towards the centre; whereupon the bones to which the muscles' ends are so attached are drawn towards each other, and that which is farthest from the 
trunk is drawn forwards or backwards, at will. Thus, if we wish to bend our elbow, the muscle which is situated just above that joint, inside, contracts in length, and expands in breadth, till the fore-arm is brought up to touch the muscle itself. Fighting men (boxers) exhibit this muscle, as indicative of their strength; and horses of good action show the same sign at every movement, whilst with those that are over-fed, the muscles are concealed in fat, that obstructs their movements; whilst, with those which are impoverished, the muscles dwindle away, hang slack, and illsupport the wonted action of the bones. When much compulsory exertion, in hot weather, has exhausted the secretions that keep these parts supple, aridity and stiffness follow, and the action becomes impeded, difficult, and uncertain.

All muscles of the limbs are long and narrow, when quiescent; those of the body are more wide than long; in a good measure, squarish, oval, or tri. angular, according to their uses. They have been compared, with good reason, to the shape of flat fish, some being long and narrow, like the sole, others wide, like the plaice. At their ends muscles often terminate in a much stronger substance, closer in texture, inelastic, bending with facility, and insensible, answering the same purposes, but occupying much less room than muscle. These are tendinous, and the horse which is well kept, having the tendons strong and vigorous, is bold, strong, and "sinewy," moves his limbs with agility, 
and gets over his work to admiration, by picking his feet off the ground well, and replacing them (as you can see while he is going) within a hair's breadth of the spot you may mark out for them to pitch upon. On the legs, tendon supplies the place of muscle, wholly so in blood-horses, less in the cart-horse breed. Muscle is constituted of blood deposited in the membrane, innumerable small arteries, some of which are scarcely visi-

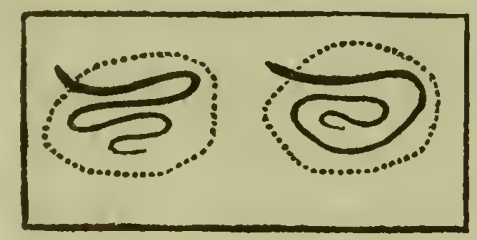
ble, terminating within each muscle, by a kind of doubling up, or curl, as shown in the margin; within each of these a correspondent vein is twined, and the whole being covered with the finest membrane constitutes a gland. Herein it is that the veins commence their share in the work of circulating the blood afresh, as we shall see in the sequel, and the lymphatics obtain the watery particles into which the morbid matter of those solids are converted: those figures receive the name of "glands."

In blood horses (natives of hot climates), as we have seen, tendon supplies the place of muscle, or flesh, upon the limbs particularly, which are always finer than those of other breeds; this accounts why our fleshy horses in sultry weather, or hot stables, feel the greatest lassitude, even to weakness, whilst those of full blood seem invigorated by the same circumstance. When, however, the atmosphere of the stable be moist as well as hot, both breeds suffer equally in one way 
or another; laxity of fibre and profuse perspiration, with weakness, follow, and this producing an obnoxious effect upon the excrematory organs, occasions in stables those stinking ammoniacal vapours that destroy the lungs, by disposing them to contract inflammation.

28. Besides the Glands just alluded to, that are situated in and about the solids and more secluded parts, and are so small and concealed as to be scarcely exposed to the sight or touch, unless when inflamed and enlarged by disease; other larger and more evident ones occupy the hinder part of the animal, of which I shall speak in their place. They are, 1st, the liver; 2d, the kidneys; and $3 \mathrm{~d}$, the testicles; the functions of each being tolerably well known. See sections 52-55. All glands, of whatever size or shape, are employed in secretion, taking up and separating from other matters that quantity of watery particles which is constantly escaping out of one part of the system into another, by means of the cellular membrane, as described at sections 21 and 22. The smaller glands, just now described, have each a small tube attached to it, which seems intended to hold the acrid, or otherwise noxious, matter which its lymphatic had refused to take up, as being at variance with its function; here it remains concealed, until the proper occasion arrives for carrying it off, and which may be found by one of the three natural evacuations; but these failing, it is clear disease of one sort or other must 
ensue. Perspiration seems to be its most natural mode of passing off, unless the demand for that kind of evacuation happens to be low, and then it is drawn to the kidneys (sect. 22). But, if the discharge by dung has been so copious as to afford too little of this acrid matter (essential probably in a certain degree), by means of the absorbents of the intestines, then, and in that case, it is taken up once more. When the animal's spirits are low, the absorption imperfect, and this offensive matter lies a long time in the tubes of these small glands, a general languishment of the beast takes place (called lentor by the old farriers); he perspires upon the least exertion, becomes unnerved, shows a rough hide, and refuses his meals. This constitutes "low fever," when the whole animal system is affected. This state of things, which is very common, points out the impropriety of now resorting to diaphoretics (sweating powders); for it has been neglected so long, that tired nature, being offended thereat, refuses to part with those particles which occasion the greatest injury. "By the urine," be it said. This way offers the same difficulty, and the answer resolves itself into my plan of opening the principal evacuations first. See what I shall offer concerning bleeding and purging in a subsequent page. So much, however, seemed necessary to be advanced here, that the reader, who reads straight an end, should be at no loss as to what lately passed between us concerning secretion and effusion at sec- 
tions 21 and 22. Of all the smaller glands, the best recognised are those termed salivary, situated near the jaws for the secretion of spittle, wherewith to moisten the food while descending into the stomach, and thus assisting digestion in its first stage. The strangles and vives are disorders of these glands: the swelling at this part is a corresponding symptom of glanders, and sometimes attends farcy. But the largest of these minor glands is situated in the solids, and lies within the buttock, concealed near its centre, into which passes an immense quantity of blood for its size; since it is found in the dead subject most disposed to putrify, especially when the animal has been driven hard, as is the case with all the cattle killed in London for food: they then call this the kernel.

29. Lymphatics are one of two species of absorbing vessels; the other species (the lacteals) being reserved for description under the head of "digestion;" at sect. 44. They are small tubes, with mouths that suck up or absorb the thin watery particles of the solids, one or more being placed on each gland of these parts. Some idea of the important nature of this part of the animal system may be formed from the circumstance that mercury applied to a glandular part of the body undergoes immediate absorption by the lymphatics, and is conveyed by this means through the jugular vein to the blood. Persons who may be unfortunately ordered to rub in mercurial ointment on 
the thighs will feel a fulness under the left ear in the course of a few minutes, according to the previous state of their bodies. How mercury acts upon the second species of absorbents-the lacteals, remains to be seen hereafter. The tendency of both is towards the heart, or rather the left collar-bone; increasing in size and diminishing in number, until the lymphatic duct meeting with the milky juices of its co-absorbent in the thorax, the mixture soon becomes blood by the action of air in the lungs, as described at sect. 39. As the lacteals, it will be seen, absorb only nutritious juices, so the lymphatics absorb none but offensive ones, as the matter of diseases, wounds, spavins, broken bones, ulcers, and the useless part of the deposite made by the arteries as said at Section 27; these being mixed, pass through the heart, there receive fresh vital powers, as hereafter is described, and thence to the liver, there to be purged of its bad qualities, which, passing incessantly into the intestines, is soon eliminated with the dung. At least, such is the natural course in health; a change takes place when these organs do not perform their functions aright, and we can perceive this misfortune in the dung, when the absorbents are at fault, particularly in the yellowes. The importance of stimulating the lymphatics in all disorders of the outer surface, as mange, surfeit, farcy, \&c. must be evident: as it is, also, in cases of tumors, as poll-evil, fistula, \&c. 
30. The Nerves, like the glands, run in pairs, mostly, to all parts of the body; they are the organs of sense, communicate immediately with the brain, and are thus principally concerned in the function of voluntary motion. That the horse entertains likes and dislikes is certain; he has a memory too, both for persons and places, as every one knows; he must, therefore, have perception, and he is kind and docile in his nature, which entitle him to a kinder return from his master than he usually receives. I have often lamented that he was not endowed with one more faculty, even in the smallest degree, that he might distinguish between those who really love him, and those empirics who make a profit of his sufferings; he would then be induced, probably, to kick some among them, as an example to all the rest; and I never hear of one of those fellows, or their employers, being unhorsed, but I think of retributive justice. So, when the horse is girthed up unmercifully, in such a manner as to obstruct his respiration, he frequently attempts to bite the operator-and, "serve him right," I say. As the nerves of a horse are the seat of no distinct disease (the relaxation of the curtain of his eye being a constitutional defect), and all further explanation would be unnecessary, I shall content myself with adding, that they consist of small cords, white and roundish, like thread; and are certainly the vehicles of pain, which vibrates from one to the other, pleasurable sensations being conveyed by the same means to 
the sensorium, or brain*. The nerves are closely connected with the circulation, and with the brain, where they originate.

Reader,

31. Respiration is the act of drawing in the air by the expansion of the lungs, the cells whereof thereby become filled to their utmost, the ribs are distended, and the midriff pressed back upon the stomach, liver, \&c. This is inspiration; the expulsion of the air, forming the re-action, being termed expiration; both together constitute what we call breathing or respiration, and the matter was before introduced (in section the eighth) when I noticed that powerful auxiliary of this function -the midriff. Now, as I have always attached much importance to the act of respiration, seeing its close connexion with the formation of blood,

* Conscience (consciousness), which agitates the nerves by the faculty of thinking, when applied to the evils that are in the world, does sometimes cause the accession of fever to those delicate organs in human nature; but brute animals being denied those powers (or of memory, except as regards the means of prolonging life) are little likely to contract "nervous fever ;" although that state of fretfulness some high-bred horses are prone to, partake of a good many symptoms of the human ailment, and may be cured by the same means. Sedatives, quiet, and a cooling regimen are those means. The loose stable recommended by John Lawrence, and now much adopted, contributes much to soothe the fretful horse. When the same fretfulness or despondency comes over a horse, one of condition, or whose condition has been recently reduced, he acquires slow fever. See what is said under this head in Book 2. 
and the almost constant state of disease in which are found the organs that contribute to this great function of animal life, I shall enter into more minute particulars respecting these, than $I$ have thought necessary for any of the preceding organs. By this course, the reader will be enabled to form more distinct notions respecting the forming and "circulation of the blood," and its concomitant, the formation of chyle, commonly called " the Digestive powers"- both of them functions most essential to health ; but, unhappily, both together become, by contravention of those powers, the fruitful source of numberless ills, we thence call constitutional or bodily disease, as fever, abscess, farcy, \&c. To this point tends all that I have hitherto said concerning the inside of the horse; and the inquirer after veterinary knowledge will find his labour in studying this portion of it amply repaid, by the just principles upon which he will subsequently conduct his practice.

32. The Lungs, or lights, are two well-known spongy bodies (called lobes), having at their conjunction a small lobe nearer to where the pipe enters that is to inflate them. At the same place is fastened the ends of a thin membrane, or rather two membranes, that enclose each one of the lobes: this membrane is termed the pleura, and seems designed to admit of one lobe performing its functions whenever the other may, at any time, be diseased. Between the two lobes, the membrane (pleura) is double, and, from its situation in the 
middle (in medio) is called mediastinum: it forms a passage for the great blood-vessels running near the spine, and is very liáble to contract cold, which shows itself in "thick wind," or rather short wind. Sect. 36. In the pleura, then, are wrapped up, as in two silk handkerchiefs, the two lobes of the lungs, the upper part of that membrane being fastened to the spine and ribs; and on its surface is generated or secreted some of that oily fluid I before spoke of (sect. 20, 21), which is designed to keep the parts moist, and prevent their adhering together. His powers of secretion, however, and those of this organ in particular, often fail in the horse, in consequence of his very great exertions, combined with the heat of his blood, exhausting more than the secretory power can supply; and we frequently find the pleura growing to the ribs, the lungs, or the midriff, by reason of its wanting a due portion of this oily fluid; from the same cause (a defect in the secretion), we sometimes find the upper orifice of the stomach partially attached to the midriff, evidently caused by inflammation of the parts. But whichsoever of those misfortunes attend the horse, he is invariably "hurt in his wind," suffers much pain at the commencement of a journey, and subsequently, if pushed hard, dies of locked jaw, through excessive suffering. Disorders of this nature were hitherto unknown to farriers of any description, being mistaken for the rworms by every one who has zoritten a book upon horse diseases; and, by the most eminent veterinary 
author of modern times, the last stages of this mal-conformation are vaguely noticed by the erroneous term of "debility" and "general debility," which may mean, any-thing amiss. Whenever the animals that are slain for our sustenance turn out to have been so affected, their flesh is rejected by the Jews, under the denomination of trifer; for the whole animal system is entirely affected by the horrid circumstance; the secretory functions in general refuse to perform their share in the production of good and sufficient animal matter, and lentor, or sloro fever, is the consequence, as mentioned higher up, in Section 28.

33. The wIND-PIPE, as its name imports, is the pipe or tube for conveying to the lungs the air which every act of inspiration draws through it. Extending from the throat to the lungs or lights, at their conjunction this tube divides into two branches, one penetrating to near the bottom of each lobe, and these again, having a dozen holes apiece in their sides, inflate an infinite number of little tubes, or pipes, which compose the lungs much in the fashion of sponge. Except eight blood-vessels, which enter the horse's lungs, the intervals are filled with cellular membrane, and these being also connected with the same kind of membrane in all other parts of the body, accounts for a phenomenon I shall take occasion to notice shortly (sect. 35), in the case of a bloren horse. At its upper end, the wind-pipe is composed of strong cartilaginous plates, connected together by liga- 
ments, and put in motion by small muscles for producing the sounds expressed by the animal. Next to the throat these cartilages, which are there strongest, form a curious kind of chamber, termed epiglottis, over which is a lid or valve, placed there to defend the passage into the airtube, from the entrance of victuals, drink, \&c. For, upon the descent of any such substances, this valve shuts down like a trap-door, and they pass over it. No sooner, however, are they gone past, than up rises the valve again, lying back towards the mouth upon the palate, and being very large in the horse, accounts for the gulps with which he takes in water, and his peculiar mode of feeding. For the same reason it is, that the horse breathes only through his nostrils, between which and the wind-pipe there is close affinity in some diseases, and accounts for his incapacity for bellowing like the ox, or vomiting like man. At this spot it is, that certain savages in human shape press the finger and thumb with brutal force, in order, as 'tis called, "to cough him." No certainty, however, lies in this imagined test of his wind; for, although a thoroughly broken-winded horse will not cough, yet one which is partially affected will do so in most instances; whilst the soundest horses do most obstinately resist the coughing; and in a few, the circular cartilages so well defend the muscle, as to defy the inhuman effort, and seem to rebuke the ignorant attempt "to prove the goodness of his wind." 
34. Farther towards its lower extremity, the wind-pipe becomes more membranous, but less sensible of injury, and the cartilaginous rings gradually lose their form: they no longer describe a circle, being composed almost wholly of strong elastic membrane, that it may bend out of the way when the gullet is distended with swallowing. Its internal surface is lined with a membrane, which incessantly secretes a quantity of the oily or $m u$ cous fluid spoken of in sections 20 and 21 , hereby defending its coats from the action of the air in passing to and from the lungs. But this secretion being exhausted, sometimes by the very great exertions of the animal, he then coughs so as to shake his entire frame, as if to incite the membrane to make fresh secretions of fluid for its defence; or, in default thereof, the cold air still rushing in at each inspiration, he contracts a permanent cold, or catarrh, which if suffered to continue, increases and runs along the membrane to the lower branches of the pipe, and ultimately communicates its baleful influence to one or both lobes of the lungs. If the attack be trivial, small green spots are found on the surface of the lungs, which afterwards form ulcers, increasing in size and number, according to the number of small tubes or cells that may be affected. These tubes lose their functions in consequence of the first attack, the animal's wind becomes worse every time he is hard pushed, and the cells burst into each other, until, perhaps, one lobe, or half of 
his lungs is rendered useless. In process of time, it turns black as one's hat, infects the other lobe, and mortification ensues, which is rather accelerated by the cordials with which the poor creature is usually punished, and it dies.

But when it so happens, that too much of the oily fluid is secreted in the wind-pipe, the animal snorts or coughs it off by a sudden natural effort; wherein, the midriff being made to press forcibly upon the lungs, by the sudden contraction of the muscles of the lower ribs, out flies the wind through the nostrils, carrying with it whatever may have adhered by the way. Whenever this is the case, the membrane that lines the nose inside becomes irritated, and fresh accession of its own secretion, thickened a little, is the consequence; inflammation of the part, ulcers, and a running of foul matter ensue-and this, if the blood be not in a good state, soon becomes that obstinate malady - the glanders. Horses of good condition never contract the glanders, though they may catch the infection; in fact, good keep will sometimes cause them to run off.

An instructive experiment may be made upon the pluck of a sheep-the relative situation and functions of these parts in all quadrupeds being the same, except that the sheep's lights, compared to those of the horse, are not so long in proportion to their thickness. Take a pair of bellows, and having introduced the nozzle tolerably well into the windpipe, tie it round with a cobbler's end; 
then, blowing hard with one hand, while the other is employed in squeezing the pipe, to prevent the escape of the air back into the bellows, you may form an accurate notion of the effect of inspiration. The lights or lungs at first give out the whole of the air which has been driven in, and may be inflated to an enormous size; but, if much force is used, the cells burst into each other, some appearing on the surface thin and transparent, and refuse to give back their wind; this forms "broken roind" of one description, and is that wherein the expirations are slower than the inspirations-the pleura being then affected in its thickest part, and the midriff also. Out of the first part of this experiment may, likewise, be derived a more accurate knowledge of what is termed "second wind," among sportsmen: when the animal (or man) has made great exertions, so as to fill all the cells of his lungs to their utmost, and then relaxes from the labour, he finds himself renovated, the cells being rendered more capable of distension and expulsion, when each inspiration and expiration also occupies more time and less labour.

Sporting men, who are fond of our bear-baitings, Pecora-fights, and monkey scratches, may daily witness a practical natural illustration of the same doctrine, in the conduct of the bear towards his antagonist. Seizing the dog between his paws, he squeezes him up till he gasps for breath, when Bruin, being muzzied, rams his nose tight into the dog's mouth, and, blowing with all his might, you 
may hear the wind whizzing: the dog swells all over, by reason of the air entering the cellular membrane, and he dies unless timely pulled off. A dog which has "had a hurt" of this sort seldom regains his proper wind; he must be "a good one" to face the bear again, "as long as he crawls." - Such is the polished language at those elegant places of town amusements.

35. The Midriff has been already mentioned (ss. 25 and 31). It is termed diaphrag'm by the learned in hard words; and we have seen how materially it is engaged in the business of respiration. But for the action of this drum-head-like nembrane, neither the lungs on one side of it, nor the stomach, bowels, and liver, on the other, would obtain their full degree of motion, which is thus kept in tune, as it were, by those organs acting alternately upon each other: the action of the heart, too, is in unison with that motion; but when through agitation (occasioned by great exercise, affright, \&c.) it does not keep time, the temporary disorder, termed palpitation, is the consequence. We may infer that, when the lungs have discharged their contents, the lower or thinnest end of that organ, falling upon the muscular border of the midriff, is by it repulsed and excited to action. Any man can feel, when he has expired all his wind, a kind of throbbing internally, lower down than the heart, until he inspires a fresh portion of air. When the lungs are in such a state of supineness, those of the horse are about three or four 
inches thick at the conjunction with the windpipe, and ten to thirteen inches from thence to each extremity, according to the size of the subject; but, when fully inflated with air, they together fill up the whole carity of the chest, obstructing in a trivial degree the vibration of the heart: then do they reach to the enormous difference of twelve or thirteen inches in thickness, and somewhat more in length. At least such were the dimensions of this organ in a horse which was opened by me in May, 1820: he was of the cart-horse breed, under sixteen hands, and healthy in other respects than having been blown by eating too much corn; whereby nature was compelled to leave the lungs quite full at the moment of his death. The same subject is alluded to in the 26th sect. where I intended to illustrate the formation and functions of the cellular membrane.

"No part of the animal has been formed in vain," as I before observed (s. 23) : quadrupeds and bipeds both press the earth which gave them birth, and which affords them the means of prolonging life; accordingly, this order of beings is furnished with a midriff, but fishes and insects, having no such occasion for this organ, are without it : neither have birds a midriff; but $\mathrm{Mr}$. John Hunter was of opinion, that the want of it is supplied by the hollowness of the bones, which not only increase their buoyancy, but the air contained in them re-acts upon the lungs in the same manner as a midriff would do. 
36. In health, as in disease, the midriff is liable to be affected by its neighbours, both before and behind it, the stomach often communicating its state of feeling to the lungs through the midriff; for it is by this medium that medicines impart their beneficial effects upon the lungs, as may be experienced upon our swallowing cold water at a time when our lungs are heated-the relative situation of those organs being much alike in man and in the horse. Immediately hereupon, a sensible difference takes place in the number of respirations; and the quality thereof is also changed from a hot to a cooler temperature : well be it, if the suddenness of the check do not occasion inflammation of the lungs: again, whoever swallows spirituous liquors feels an immediate disposition of the lungs to repel the heated air of the cells which lie contiguous to the midriff; the first breath which escapes the mouth being less heated than that which follows and finishes the expiration, and imparts a sensation wholly different from the vulgar belchings of an overcharged stomach. These come up by way of the gullet, and carry forth a nauseous effluvia; whereas air from the lungs is ever sweet, unless this organ be already in an advanced state of decay. This state of the case leads me to make one practical observation, which shall not be set down, as more curious than useful: out of seventeen subjects, which successively fell to my lot to examine as to the immediate cause of death, only two, tolerably sound at 
the lung's, presented themselves; which I take to be the fair proportion of sound horses, as respects the lungs, of all that live or die. All those cases occurred from February to May, a season when such an affection might not be considered most prevalent. Hence, (my reader may smile !) I conclude from all that has been said, that a tolerably good guess at the state of a horse's lungs may be formed, by smelling at his breath after a canter, in like manner as our Smithfield dealers smell the animals' nostrils, in order to detect the glanders.

From what has been said, it follows, that a diseased stomach may be produced by diseased lungs, and vice versa, and that the midriff suffers in either case: then does the midriff become livid, purplish, and inflamed, with dark-coloured stripes, as if thickened at such places, the muscular border thereof assuming a putrid appearance, and sending forth a villanous stench. When this is the case, or any other ailment prevents the midriff from performing its proper function of inhaling and expelling the air from the lungs, that species of "broken wind" takes place which is known by the sort of breathing wherein the expirations are quicker than the inspirations; being thus contradistinguished from that other species of broken wind, which is occasioned by rupture of the air cells. A paralysis of the midriff, or the adhesion of the stomach to its lower side, is equally obstructive of its re-action upon the lungs; and I 
have this day (May, 1820), cut away an adhesion of this sort as wide as the palm of a man's hand.

Unfortunately for the horse which is affected either in the midriff, the lungs, in the pleura, or covering thereof, his doctors heal the whole series in the same manner, not unfrequently including, in their uniformly mistaken practice, the affections of the stomach, liver, pancreas, \&c. In all, the inflammatory symptoms are predominant, and a cooling regimen presses itself upon our notice as more proper than the best of medicines, although having the same tendency; whereas, the direct contrary is the practice mostly followed, and heating medicines, under the fascinating name of cordials, made of spices, ale, wine, \&c. are administered daily. Or, at most, if a sedative or opiate, by chance, finds its way (properly enough) into the animal's stomach, this organ is thereby only rendered more susceptible of the heating mixtures which are again had recourse to immediately thereafter.

Now, Reader, let us take a rapid glance behind us !

The organs of respiration are liable to seven or eight several kinds of disease, mostly originating in the horse's having caught cold; they are denominated according to the particular place where he may be affected, and in one respect, according 
to the degree of attack. A cold (simply) or catarrh, produces that affection which denominates the patient "a roarer." Chronic cough brings on "broken wind," of which there are two sorts; and consumption usually follows the long continuance of either. When either has continued awhile, and reduced the animal's strength, he is said to be in a consumption; "worn out" is also a common phrase, as is "rotten;" "debilitated," and " done for," stand a little higher in gentility; but all mean, that there is small, chance of his recovery.

Pulmonary consumption is the only kind which may justly be attributed to constitutional defect; i. e. heated blood, with viscidity, causing overmuch action of the parts (see section 32), when the pulse becomes powerful and quickened, and the horse seems anxious and fearful. Should it subside by judicious treatment, or the natural strength of the horse, he commonly retains so much of its effects as to cause great danger whenever he may catch cold, or be worked too hard. This attack is too frequently neglected, or put off with the remark, "only a little touched in the wind," unless by the addition of a cold, the disorder comes on rapidly, when it is termed "inflammation of the lungs," and the animal goes off in four or five days, if he be not promptly relieved.. On dissection, the parts are found spotted with a livid colour, and evident gangrene: every variation, indeed, is equally appalling to humanity, and I have often wondered how the horse could 
have lived an hour under such horrid circumstances.

A cold, simply, or catarrh, commences by inflammation of the lining of the windpipe, which may be confined to some given part of it, or extend itself generally from the nostrils to the lungs, both inclusive, much resembling "a cold" in man; in either case, much matter is secreted, and thrown off by snorting: when the attack is confined to the upper part of the pipe, and lasts some time, the horse becomes a confirmed roarer. his groan bearing great resemblance to the roar of some wild animals, and he is equally incurable.

Chronic cough, is that obstinate cough which remains and plagues the horse long after vain attempts at curing his cold ought to have taught his tormentors the inutility of their endeavours, and the dishonesty of their prescriptions. Broken roind is of two sorts: the first is caused by the rupture of the air cells of the lungs by over exertion, in which the expirations being slower than the inspirations, he is, aptly enough, said to be "broken winded ;" the second kind of broken wind is known by a breathing the direct contrary, and is occasioned by the cold having settled upon the perforations of the branches, and enlarged them, so that the air escapes too readily. Thick wind, on the other hand, arises from the secretion of the pipe getting into the cells of the lungs, and affecting the orifices or perforations by thickening them, so that the air passes through with difficulty. 
Similar symptoms attend inflammation of the pleurce (section 15), particularly when it reaches to the mediastinum, or double part; as they do when the muscular border of the midriff is affected. But these, though perhaps considered two different diseases at the commencement, in the horse, very shortly become one common affection, more or less, of all the organs of respiration: inflammation predominates over the whole series; and if the per-formance of his duties does not render them fatal, an injudicious treatment will fix upon him an incurable disorder, until the knife terminates his usefulness.

Lafosse, junior, observes, that "Flat-chested horses are almost always subject to consumption, whilst (again) consumption narrows the capacity of the chest, and reproduces itself-there is no remedy for mis-construction." He further says, "Short wind is either produced by disorders of the breast, or it is a fault of construction, and both are irremediable. Such a horse is generally of less use than one that is thick roinded."

\section{Reader,}

37. The cInculation of THE BLOOD is carried on through all parts of the body, to which it affords the means of life and health; or, being ill performed, is the fruitful source of lingering, obstinate, and incurable diseases, some whereof almost baffle our skill and care; and, while they induce 
us to admit that the practice of veterinary physic never will reach perfection, inspires the hope that, by patient investigation, we may at least find out the means of alleviating their evil tendency. These considerations should excite particular attention to the subject in hand, being that to which all other functions are but subservient or conducive; respiration and digestion being more closely connected with it than any other, and requiring a corresponding degree of attention. The heart, jointly with the lungs, occupies the cavity of the chest, rather inclining towards the left side, against which its point may be felt beating, whenever the animal is agitated by exercise, or internally affected by inflammatory complaints. Its figure is too well known to render description necessary : in size it approaches that of an ox, and, like it, is enclosed in a membraneous sac, but very thin, not unlike a tight purse. Another sac, called the heart-bag, less tight, surrounds the former, but is never so large, nor encumbered with fat like that of the bullock. On opening this sac there issues forth a fluid which turns to water, if it were not so already ; in the ox it is confessedly water, and rather more in quantity than in the horse; - the reason for which difference I will show presently. So great is the stimulus of this organ, that its contractile power ofien exists long after the animal is dead, and the arteries cease to flow: a phonomenon that occurs when the horse is killed in full health; by an accident, or otherwise, while in full possession 
of its functions. In animals of much mettle or courage the heart attains to a great size, that of the famous horse Eclipse weighing 18lbs. In some horses, the vessels that nourish this muscular organ lie exposed on the surface, with others they lie wholly concealed; a fact from which $I$ have yet found no opportunity of making any sure deduction, but apprehend it may arise from the breed, and conclude it must have considerable effects on his disposition.

As the heart is the principal organ employed in converting into blood what is drawn from the finer particles of food sent into the system for that purpose, as well as in renovating that which has been exhausted of its vital principle in the circulation, it may well be supposed full of small blood-vessels. Four large ones meet at its thick end, and suspend it, by being attached to the bones of the back and ribs: two of them, bringing the dark vitiated blood from the extremities of the fore-part and of the hind-part, are veins; the other two large vessels are arteries, which, receiving the blood from the heart, just now refined by the process of nature, convey it with rapid contractions to every part of the system, there to give fresh vigour, and to impart health to the whole. These contractions constitute the pulsation, or pulse: a criterion of health as of disease which we investigate with primal anxiety, as from it may be deduced the best prognostic of the state of disease, especially of inflammatory ones, to which this noble animal 
is more than any other subject, from causes to be explained hereafter.

38. Two large chambers (as I call them) and two small ones, each of the latter appended to one of the former, mainly contribute to the process of circulation; these, by their co-action, aid the contractile power of the heart, compelling the contents of the larger chambers to issue with much force into the arteries. But, before the blood can be thus again fit for circulation, nature has provided the means of rendering it so, by the action and re-action of these four chambers (or cavities) in the heart, contributing to refine it for that purpose; one large chamber, with its small one, being placed on the right side of the heart, and the like pair on the left side thereof. The blood from the veins flowing into the small chamber on the right side, irritates its inner coats, and they each contract upon its contents with nearly as much strength and quickness as we can open and shut the hand;-but certainly not so much open, although there is a flap on the entrance of each small chamber, which they liken to " a dog's ear," and call by the Greek word auricle, that being an eur. At each of those closings or contractions, the blood is forced out of the small chamber into its large chamber on the same (right) side, through a small door-way, or valve, which opens only inwards, the door being too large for the door-way. By the way, these valves are very numerous in the animal system, principally as regards the circula- 
tion of blood in the veins; and the reader will do well to recollect, when I speak of valves in future, the illustration just given by comparing the same to a door-way, which bears a near resemblance to the valve. In the performance of this office, the heart may be said to have three several motions belonging to it: 1st, a quick one, by the contractions of the smaller chambers upon their contents : $2 \mathrm{~d}$, the contractions of each large chamber upon its contents, being just half the number of throbs made by the first mentioned: and, $3 d$, the vibration or tremor of the whole heart in consequence of all those motions.

Well, on the right side still, the large chamber being filled with venous blood through the valve, or door-way, from the small one, becomes in like manner irritated so as to contract upon its contents, and to drive it out somewhere or other. Back to the small chamber it cannot possibly go ; the valve does not open that way, as I have just now said; and therefore it issues with much more force through another valve into a short artery, which soon opens into two, like the letter $\mathrm{Y}$, the heart being supposed it the bottom of the letter. Up rushes the blood to the top of the two branches -where it meets with_What? What do you think it meets with, gentle Reader?

Here, however, let him stop a little, and consider awhile; for, upon his rightly understanding what now becomes of the blood (thick, dark, and unserviceable as it is), and how, in a trice, it becomes 
healthy, of a bright scarlet colour, and invigorating, mainly depends his being able to comprehend, by-and-by, what I shall have to offer concerning the diseases to which a vitiated or corrupt state of the blood gives rise. He will not, otherwise, make out sufficiently clear in what manner the blood of an animal can contract and retain that morbid state which shall pre-dispose it towards acquiring a constitutional disease that, however differently named according to the parts whereon it may fix, has but this one common origin for the entire series. To this page, then, I shall frequently refer him when speaking to these points more in detail, hereafter; and he had best way, also, keep the book open at this place, whenever he may be endeavouring to comprehend what the learned veterinarians of the present day are striving to say respecting " the circulation," as they quaintly term it. Another of them, speaking upon the topic I have just brought to a conclusion, says, "The heart is divided into two cavities, termed ventricles, each having an auricle, resembling a dog's ear. The blood-vessels proceed from these [those] cavities, the arteries from the ventricles, the veins from the auricles, \&c." All which is very true, but not very intelligible to the generality of readers ; and yet is the author, who thus speaks, (Mr. White, in vol. i.p. 63.) said to be the plainest spoken among the moderns; indeed, were he any thing else than a good one, I should not have deemed him worthy of this rebuke. 
39. The Blood, as I have said, rushes out of the large chamber on the right side of the heart into an artery that soon divides into two branches; whereof one enters each lobe of the lungs, and there disperses, through certain cells, the blood with which it is constantly supplied. Here lies the secret! At this point it is, that health or disease (at least a pre-disposition to one or the other) is imbibed and engendered in the blood. The lungs having received the thick discoloured blood from the right side of the heart, and being the receptacles of the air we all breathe, do, by means of that air, bestow upon the blood afresh the principles of life, and health, and vigour. The cells, or tubes, through which the blood passes in the lungs, termed pulmonary, are eight in number, being double the quantity given to man, and show, from that circumstance, the immense circulation of which they are the agents. A cruel and almost incurable malady, that attends most horses at this part of the organs of respiration, with many and variable symptoms, was alluded to higher up, at sect. 36 ; and is what we term from those vessels, pulmonary consumption. But then, it is clear, that the air which is so brought to effect those beneficial changes upon the blood in the lungs, must be fit for the purpose; - that is to say, it should be vital or atmospheric air, uncontaminated by any noxious stench (as the ammoniacal smell of the stable, or the stench and smoke of cities); no. 
poisonous vapours (as burning brimstone, the gaseous fluid, smelting of minerals*), nor infectious effluvia (as of cesspools or stagnant waters, producing fevers, glanders, \&c.) can give to the animal's blood that healthy vigour which was designed for his well-being; but, on the contrary, every departure from purity in the air he breathes must be an approach towards disease + . Yet, how constantly is this simplest law of nature transgressed! And what, in such a state of things, can be expected, but that the blood will assimilate in character with the kind of air the creature is

* Scarcely any truth is easier proved than this: Horses that are constantly kept in close stables, in large numbers together, very soon become unserviceable, by the constitution throwing off some evil or other upon the surface; as one proof whereof, those which are occasionally placed in the under-ground stables, at the Swan with Two Necks, Lad-lane, show evident signs of distress, which subside upon being brought into the air. I hear from good authority, that at New Orleans, in South America, where the atmosphere "exhibits a blue misty appearance," nothing is more common than a disease which affects the knee, hock or pastern joint, with abscess, or near those parts with cancer, and the limb actually rots off. The like kind of attacks were found formerly most common in Cornwall and in Wales, and are attributed by all to the arsenical vapours of the copper-mines being inhaled; they are, however, much less frequent at the present day, owing to the higher state of cultivation to which the land has been brought, and to the change of situation horses now enjoy. The free use of sweet oil is a good preventive of this poison in human as well as in cattle medicine.

+ This is not the place for a finished dissertation on the communication of the glanders; but I must observe, in illustration of the text, that horses which have eaten glanderous matter without recsiving the infection, no sooner smell it than they become diseased. 
compelled to inhale*? Accordingly, we find in the domesticated horse, that previous disposition to certain diseases which we endeavour to meet by correctives and repellants, but which by better treatment might have been prevented. Of these evils, abscess, or ulcer, is the most prolific, showing itself now on the head, at others on the heels, under the varied denominations of poll-evil, quittor, fistula, \&c.; but more frequently attacking, and making the greatest ravages on, the internal organs, where it is generally mistaken for the zorms, and erroneously treated with hot and burning remedies, when evidently a direct contrary practice would best assist nature in casting off the evil + . Ulcer upon the lungs, as it produces a staring coat, is too frequently mistaken for worms, and if the animal be not physicked and cordialled too much, a partial cure sometimes takes place,

* In cases of much sorrow or grief, our respiration is much increased; and the presentiment of death awaiting them, occasions all animals to take harmful substances into the lungs. Pigs, oxen, and even sheep, show signs of uneasiness, "horror, or madness, at the effluvia of blood of their own kind; and I have found in each kind of animal, upon slitting the trachea as far as the bronches, dust, dirt, or other rubbish, which they had snorted up in the last paroxysms of despair.

+ Four ounces of spirits of turpentine have been given with partial success; but such a dose must go near to destroy not only worms but the horse into the bargain, whilst it is not very clear to me that the small worms we sometimes meet with are hurtful to the animal, but are designed to act as a stimulus to the intestines; and, if the doctor mistakes for worms some more serious disorder, the horse dies of this monstrous medicine, as sure as fate. 
though in what way it is carried off is most inscrutable; but, upon opening the dead subject, I have often noticed spots which had been corroded and gangrenous, where the cure had been effected in this spontaneous manner. As for ulcers upon the liver, also arising from the viscidity of the blood, if they take place near its thin extremity, the common natural process is, that that part of the liver attaches itself to the gut, and the offensive matter will then slough off into the intestine, and come away by, stool: a partial cure is the consequence; not produced by medicine acting. upon the part, as is very clear, but by a common natural effort, aided by a more vigorous and healthy state of the blood than when the disease was engendered. To assist the circulation in regaining this state is clearly the duty of the medical attendant, and is the only manner in which he can be of any service to the animal in restoring it to health.

40. In the lungs, then, does the blood receive from the air its invigorating principle, and no sooner does this take place, than it drops into another short blood-vessel (a vein), and, by it, is conveyed again to the heart : not to the same small chamber on the right side, of course, but to a similar one on the left side. Here the contractions go on as before mentioned, only that the blood differs in quality; this being now properly fitted to promote the purposes of life, and for imparting the vital principle, occasions the heart 
to assume that twisted shape we see in some animals, while in others whose bodily exertions and arterial functions are less laboured than those of the horse (the sheep's, for example) it is more, round: and, indeed, the heart of this last mentioned animal is, from this circumstance, usually termed, in the London district, a "round heart." Out of the small chamber on the left side is the blood driven through a valve, as before, into the large chamber of the same side, which in its turn contracts, with much force, upon its contents, expelling the same into the great artery. This periodical rushing of the blood into the arteries, imparts to these vessels a motion we term pulsation, whereby the blood is propelled forward, to the remotest parts of the body. Lessening in size, and increasing in number, the branch-arteries, which receive this blood, become more sensitive as they are farther removed from the heart, and afford us, at certain places, the means of ascertaining by the touch the degree of heat at which may at any time be the state of the animal's blood; the contractions of the heart being regulated, in quickness and force, by the degree of stimulation the heat of the blood may occasion it. This is termed the irritability of the heart, and the medical test of which I speak, is called " feeling his pulse." Even in the tail may this contractile power of the arteries, and its effects, be seen to advantage: when a colt is being docked, the blood squirts forth with frequent 
gushes, answering in a tolerably accurate manner to the state of his pulse, although the artery at that remote part is very small. But the blood that is so changed in the lungs, as I have just said, is still found to contain certain particles or properties, which would render it unfit for the purposes to which it is to be applied, or those particles are required to effect certain purposes elsewhere in the system. Accordingly, the major part passes into the liver, there to be refined of its bitterness; whilst a portion is attracted to the kidneys, where it leayes its saline qualities, that pass off by staling, as the former is voided by dunging. See "Liver" farther onwards.

41. 'These purposes, however, are not always effected alike regularly, from several causes. Frequently, the blood comes to those organs in a state too vitiated for their utmost activity to cleanse; sometimes a diseased state of the blood, at other's, languor of the parts, indispose them to the performance of their functions, and the blood is suffered to circulate, filled with humours that war with the constitution, and form what is termed "constitutional disease," or predispose him to receive disorders of varied malignity, according to circumstances. I shall come to advert to this point when, shortly, the liver and kidneys claim our attention; but, the chiefest cause of disorders incident to the animal by reason of defective liver, is the great exertions he is put to, and the consequent rapidity of the circulation, whereby the 
blood is propelled through it with tremendous velocity: it then acquires inflammation, and becomes ulcerated (see sect. 39); a disposition which must be increased whenever the blood has been formed imperfectly, either as regards the lungs or the lacteals. So much is this the case, that the blood drawn from a very aged patient of mine lately, that was incapable of grinding his corn properly, showed evident proofs that particles of ill-digested food had entered into the circulation, and is an answer to those writers who aver that the lacteals reject the bile and suck up only the fine parts of the chyle; whereas, all inquiring persons must know, that they take up the lighter parts of all substances rohatever that pass through the intestines. If this were sot so, how is it that the slow poisons just spoken of enter the blood? or how would it come to pass that so much good is performed by alterative medicines, that, in like manner, insensibly introduce themselves to the blood, and produce invisibly those permanently good effects we so much admire? The opposition of a few is no obstacle to this commendation of an obscure but safe and certain class of medicines, - to say nothing of an alteralive regimen, which is more safe still, and certainly more natural, though slower and less positive in its effects than acive medicine. How much longer is the horse to be treated with nothing else but violence?

42. Brood-vessels, or tubes, I have already 
observed, pervade every part of the body, and are of two kinds, whose office is directly the reverse of each other. Arteries, it will be recollected, convey the vital fluid to all parts of the body, and the construction of these, it may easily be conceived, from what has been said, is simply that of a tube with great contractile powers : they are large near the heart, but soon branch out of a lesser size, until, entering the smaller organization of the solids, they become very minute, infinitely numerous, and more sensitive, thus affording the means of renovation, or growing to the flesh, bones, skin, hair, hoofs, \&x. The large artery communicates with minor branches, soon after leaving the heart, by two rows of openings, like perforations, in its lower sides, at two or three inches asunder. Some one has likened the arrangement of these vessels to the stem, branches, and twigs of a currant-bush, and so might the veins that run nearly parallel to the arteries, through every part of the animal, but are so constructed and arranged, as to take up and reconvey the blood (which the arteries constantly deposit) back again to the heart; and the similarity will still further hold good, if we extend it to the leaves of the bush, and compare these to the glands (see Sections 27,28), in every one of which an artery terminates, and deposits its nutritious contents, and where every small vein begins the absorption of what the artery had so left behind. This absorption, when obstructed, lax, or otherwise im- 
perfect on the surface, may be restored by stimulating the parts with spirits; when it is too high, and labouring greatly in consequence of the viscidity of the blood, local inflammation is engendered, and one or other of those diseases I shall hereafter treat under " abscess," is the consequence of this constitutional derangement. Blood that is thick, heavy, or viscid-call it which we like-causes heat, which being general, is fever; the rapidity of the circulation increases violently, and the blood becomes more fluid than when the animal was in good health. Arteries may be distinguished from veins in the dead subject, by the property they possess, of retaining their tubular shape after the blood is discharged; whereas, the veins collapse, when empty.

43. If the arteries are plain tubes, lying for the most part concealed, the veins, on the contrary, are more frequently found exposed to the sight under the skin, next to the muscle. But, more delicate and more numerous, the veins perform their part of the circulation by a totally different means than is found in the propulsion and contraction of the arteries. One of the means of effecting this purpose is by the obvious and simple movement of the body and limbs, as well as by the act of breathing, whereby the blood is pressed out of some one part or other of the veins into the adjacent part; but these vessels being fur = nished with innumerable valies, within an inch, or less, of each other, the doors whereof open 


\section{EFFECTS OF RESPIPATION AND EXERCISE}

only towards the heurt, the blood must necessarily force itself out that way, and no other. If we suppose that any given portion of the vein is hereby emptied, what follows from the circumstance, but that the next-door valve, which kept back the blood contained in the adjoining portion below, while it was pressed upon from above, being thus relieved from the pressure, will now open? Then, in rushes the blood, and the space is again filled, but only to be emptied in a similar manner. It is with a view to accelerate the circulation through the veins, and to keep the blood warm in winter, that mankind betake themselves to forced exercises, as hunting, running, or beating the arms athwart the chest, and that beasts with the same propensity gambol and frisk about, or rub them. selves: both promote the same ends, by breathing short, so as not to cool the lungs too much, or by drawing in the same warm air over again, in sheltered situations.

44. By the process just described, the blood being once admitted into the minuter veins, finds its way to the larger ones, which convey it to the heart; near to which, as the quantity becomes great in the large vein, it receives a powerful auxiliary in the filling and emptying of the lungs, and the working forward and backward of the midriff, as described before. Passing through it near the back bone, and, consequently, at its more muscular part, the great vein must at every inspiration receive from the midriff considerable 
aid in pouring forth its contents-to say nothing additional of the pump-like action of the heart itself. At this part the vein acquires the appearance of a double tube, the outside thickened and muscular, the inner one membranous and col. lapsed, as if too big for the space in which it is placed. But the curious fact-how the blood which had been sent into circulation through the arteries, gets into the veins at first, deserves consideration; as this must be effected laboriously, when the fluidity of the blood is lessened, or else accelerated with frightful rapidity, whenever it so happens that fever prevails: local inflammation, by the same rule, must cause an unusual flow of blood to the part affected; and, as most of the impurities of the system will then -be drawn towards it, at that place must they leave the occasion of the most direful effects. In proof of this doctrine, it happens frequently, that when an animal is attacked with inflammatory complaints at two places at once, the greater evil of the two increases, while the lesser one "runs off," as it is called, or gets cured of itself. So, on the contrary, when a diseased horse (glanderous, for example) is well fed and well kept, he not unfrequently overcomes his disorder without medicine, to the great wonder of the unknowing; the solution whereof is, that the constant supply of new blood has quite changed the nature of the animal, his disease has been "taken up," or absorbed, by the animal system, and ultimately carried off in the common evacua 
tions. In short, absorption and effision are the great internal secrets of animal life; although we cannot say with certainty how they are carried on, it is no less a positive law of nature, that the veins at their commencement in the glands absorb, or suck up, the blood that is deposited there by the arteries, and separated by the lymphatics; equally well known is it, that effusion takes place, of arterial blood, into much larger veins, as well as from one part of the system into another, internally. These points are deducible from a multitude of facts and well-known operations, some proofs of which the reader will find more in detail in the course of this treatise. In some parts, a positive connexion of the capillaries, or smallest blood-vessels, is found to exist; in such a manner, that the section of one or more of these, and the consequent obstruction of the means of life to all the parts below it, which some would naturally expect, is hereby remedied.

\section{Reader,}

45. The Process of Digestion, whereby the food is prepared to be converted into blood, is no less curious than " the circulation" itself, is equally conducive to the support of life, and, being obstructed, is also the harbinger of disease. If, on the two other great functions of animal life, depend his immediate existence, no less does the horse's capabilities, his present health, and the 
engendering of future obstinate, incurable, and often mortal diseases reach his vitals by way of his stomach and intestines, which comprise the organs of digestion.

Every one knows that oats and hay are the chief sustenance of the horse in a domesticated state, and these, together with one or two other similar productions, and water, are given to him for nutriment alone; it therefore follows, that whatever substances are taken into his stomach, which act not to the same end, must operate injuriously, even though containing nothing hurtful in themselves: these must obstruct, if they do no more. But, when matters obnoxious in their nature, and possessing strong powers and effects, are being administered to the horse, it seems but fair to examine whether such things are likely to agree with his common nutriment, with the blood that 'is made from it, or with his constitution, his habits, or the tasks he has to perform. Or whether, on the other hand, they do not prove destructive of the food itself, of the vessels that contain it, and of those which draw up its finer particles that are to be converted into blood.

Let him who practises by violent means consider a moment the natural structure, formation, and functions of the organs on which his medicines are destined to act, and compare their altered state, that has been brought about by reason of the treatment the animal has received at his hands. Some protection, doubtless, is afforded 
by nature (as if prescient of the race of farriers), in the secretion of the fiuid so often mentioned, which defends the several organs against ordinary injuries; but these are often found insufficient in quantity (notwithstanding the supply which may be drawn by effusion from other parts of the body), and the frequent repetition of the monstrous mixture of the doctor's skill-less art, ultimately effects its purpose in destroying the tone of the fine vessels just alluded to (the lacteals), and then the symptomatic disease of the skin, called hidebound, follows, as a natural consequence.

46. The Stomach is a bag, or pouch, with two holes in it; the one receiving the end of the gullet, the other opening into the small gut. See it; plate I-L, 26-29. It lies behind the midriff, inclining a little to the left, having the lungs contiguous on the other side that membrane, and the liver next behind or under it. This main organ of digestion is but small in the horse, as compared to that of any other animal, being so designed to assist his fleetness, but which would be impeded by his receiving large quantities of food at a time, and points out the reason why he requires to be fed and watered frequently: the larger and more distended the stomach of any animal may be, the more sluggish and vicious he is. As one proof of this position, I formerly obtained the stomach of a man which was larger than that of any other subject I ever saw or read of, and its possessor in 
life had a heavy, slow, and sordid manner, together with one or two other bad qualities which brought him prematurely to his end.

At the upper orifice of the stomach, a membrane, nearly insensible, coming from the gullet, enters it loosely, and spreading along its lower part, lines about one half of it, thus defending it from acrimonious or poisonous substances, as well as from the farrier's " monstrous mixtures" before noticed; whilst the coat of the other parts thereof consists of striated muscular fibres, very sensible, and given to contraction, and running transversely to those of the insensible coat, a circumstance which has given rise to the fanciful notion, that digestion proceeds in the horse's stomach by what is termed " trituration," or pounding; but, upon reference to the figure which illustrates another organ, (at section 56,) the reader will be able to form a more accurate notion, near enough for his purpose, how the stomach contracts its sensible part upon its contents. This sensible coat secretes a juice which, from its strong gastric nature, not only digests the food, but would also corrode the stomach itself (insensible though it be), were it not supplied with another fluid for its protection, in the saliva or spittle that descends the gullet along with the food. This saliva is also secreted, in some measure, when the animal may not be feeding: but, whenever this supply fails, the gastric juice predominates so much, as to cause a galling pain in the stomach, and occasion in the 
animal a ravenous desire for filling it, if not with food, at least with some substance that may keep it distended, and perhaps carry off the painful superabundance. Horses so circumstanced, when in harness, gnaw the pole or shaft, or bite at each other, and soon learn to become crib-biters, gnawing any thing they can come near, as well as the manger ; litter, bits of old wall, and dirt, at length, are found by them agreeable to their palate. See further at section 49 .

The insensible membrane I spoke of, by its loose folds, forms, at the entrance of the stomach, a kind of valve, which prevents regurgitation of the food, like that of ruminating animals; and a similar contrivance at its termination in the lower or right orifice occasions a short obstruction until the pulp is mixed; for, when the stomach is filled, the relative position of the two orifices alters in a good degree. From these premises it seems apparent that any substance entering an empty stomach does not act upon the sensible part of it, but being soon mixed up with the gastric juice, it proceeds into the intestines, there to communicate its efrectswhatever these may be. Whether nutritive or medicinal, poisonous or beneficial, the intestines receive all with but little alteration*. But when

* At this place, for the information of those who would practise the veterinary art by comparison, it may be useful to observe, that in the human stomach is digestion principally performed, in the horse's very little; in both, the small intestines appear to mix the food with the bile and other digestive juices; but man having no 
it so happens that the food does not pass readily out of the stomach, a fermentation commences, and the sensible part thereof being then distended, the ill effects ascend the gullet, reach the head, and cause vertigo, staggers, \&c. At times, a specific inflammation takes place, and communicates itself in four or five days to the whole of that surface, taking its course downwards or upwards, according to the orifice that may be most affected; this being all the way lown through the intestines, blocking up the influx of gall (as described sect. 48), and causing yellowness of the eyes, until its appearance at the anus; or, in the other case, it ascends up to the nostrils, making its appearance first about the head, and communicates either way to the skin and its coat.

47. Of the intestines, guts as they are usually called, it is important to keep in mind, that, notwithstanding the appearance of great tenacity

cocum, or blind gut, like the horse, to receive the heavier parts of the food as they escape from the small intestines, his lacteals begin higher up than those of the horse, which lie wholly on the large intestines. It follows that, whatever is received into the stomach of man is felt through the system immediately; with the horse this does not take place until it has reached the intestines. One other dissimilarity in the mode of digestion is worthy notice: in man, the work of digestion is rearly finished when the bile is mixed with the food-say at an average of twelve hours from its being taken, whilst the horse passes his feeds into the intestines in about two hours, before it has well assumed an homogeneous appearance, which the bile seems to effect for him. With us liquid remains in the stomach; the horse passes water immediately into the crecum. 
they assume, they are, nevertheless, extremely iritable, being composed of two coats of fine muscular fibres that cross each other, the one circularly, the other lengthwise; and having a lining which secretes a fluid for its protection, they admit in their intervals an innumerable quantity of absorbent vessels, that are constantly sucking up the finer particles of their contents. This sort of conformation renders the intestinal canal obnoxious to repeated strong drastic purges, particularly aloes of the Barbadoes kind, that heat and irritate the parts by their coarseness. Inflammation is most likely to succeed such irritation, in summer-time especially, and the animal is usually destroyed by the pretended remedies of the far. riers; or, being pressed forward in his work during the attack, goes until he drops down and dies. At the fundament may be seen the earliest indication of this species of overphysicking, in the disgusting protrusion of the inner coat whilst expelling the contents thereof; an ordinary effort of nature to get rid of what is offensive to it, which, considering the horizontal position of the horse, might appear wonderful to us bipeds but for the well-known double operation of the coats of the intestines. From the top to the bottom of the canal a spiral motion is kept up by the alternate contraction of the two coats thereof, the one in circumference, the other lengthwise, resembling that of a worm, and appearing as if a corkscrew agitated its inside. By this means the mass is 
pressed backwards, and as it increases in quantity and becomes less and less clearable, the offended nerves excite the guts to renewed efforts for its expulsion, in which the lower part of the belly, with its covering, from the coecum to the sphincter, concur with all their powers of contraction. Partial retention of the breath, and consequent pressure upon the midriff, and parts behind it, contribute to lessen the longitude of the intestine at every effort. This kind of excitement, if repeated too often, it is plainly to be seen, must keep up the irritation of the parts concerned in it, and dispose them to contract inflammatory complaints.

48. In length about thirty yards, the intestinal canal has in its course two or three different offices to perform towards digestion, whereof the smallest gut nearest the stomach is for receiving the gall, or bile that has been formed in the liver for that purpose. At the termination of that small gut, at the end of twenty yards, an immensely large one occurs, called the sac (coecum), or blind gut, where the contents are prevented from issuing too soon, by reason of the internal coat of the small gut getting into folds, as 'twere. We may as well consider this as another valve; and that it was provided by the Author of Nature to correct the animal's propensity for transgressing his laws against repletion, as well as to prevent the contents of the cœcum from returning upwards, when this latter is compressing the large intestines back-

$$
\text { G } 2
$$




\section{DISEASES OF INDIGESTION : WORMS,}

vards, in the act of dunging. But inflammation sometimes, obstructions oftener, produce at this place more tedious affections than is generally imagined. When it so happens that the stimulus of the bile is insufficient (as in diseased liver), and acrimonious particles are left behind, or the halfmasticated food inflicts injuries on the very sensible surface of this passage, then the noisome effluvia reascends to the stomach; the bile, too, enters it soon after, by reason of the intestines having lost their power of compression and elongation, when the corkscrew motion downwards is changed to an upwards motion, and all becomes disorder in that region. Loss of appetite, fever and dullness, with drooping as if in pain, and a staring coat, follow each other in succession; for the secretion of bile, which I shall come presently to describe, as affecting the skin, is thereby vitiated. These appearances it has been a fashion to corsider "symptoms of the worms," or of "debility" (another term for low fever); and the practice of administering bitter medicines, that are supposed to kill the worms, is only successful on account of their restoring the tone of the stomach, and by supplying to the intestines a congenial stimulus in the place of bile. 'This was the case with Mr. White's statement, in vol. i. p. 170, where he says, "I have sometimes succeeded in destroying worms by giving aloes, one dram and a half, every morning until purging was produced." That is to say, "the horse became well;" but whether he 
had any worms to be destroyed is another question; and then, if a dram and a half would succeed sometimes, I should apprehend a larger dose (as eight drams, his favourite quantity) would more inevitably have poisoned all the worms his horses may have had, of whichsoever kind they might be; but this mode, as will be perceived, though more destructive of worms, would not have acted as a tonic restorative on the stomach and intestines, like small repeated doses. I, however, who am a man of no fashion, generally have found those kind of attacks accompany a repetition of irregular feeding; that is to say, very little one day, very much another; now all, now none; the attack varying in degree, and changing from simple obstruction to the inflammatory, as the animal may or may not have been allowed water with his food.

49. To supply this deficiency, in some measure, does the cocum, or blis d gut, seem to have been placed at the termination of the small intestines. In this second cavity digestion is supposed to be completed, much liquid being found therein; and we know that here, in a corner, termed its " appendix," are frequently deposited hard matters, as earth, stones, and other substances, little compatible with the purposes of nutrition (as noticed at sect. 46); but whether these ever pass off by stool remains in doubt, and we are left to conclude that it is much less sensible than the other intesm 
tines. In size it may be about thrice that of the stomach of the individual; and it is placed near the surface of the belly, lying on the left, about midway between the fore and hind near leg. Here it is exposed to damagement from a variety of causes: the groom, while dressing him, often hits the horse here with the curry-comb; the dealer tries whether his new purchase is a rourer by striking him hard with his lash whip, whilst he holds up his head short; and I have frequently seen one of the most noted jobbers and breakers in London terrify his "restive customers" into obedience, by a kick of his foot skilfully placed on this part. The facts are notorious; what is worse, they long remained uncorrected. The consequence of all this hard usage is, that the cæcum * loses its functions, more or less, certain heavy particles are not expelled as they ought, but, remaining behind, attach to their sides some earthy particles of the food which would otherwise pass into the colon, and the heat of the animal's body causes them to become stones of great magnitude. Six or eight pounds in weight, and nearly as many inches in diameter, are quoted as by no means uncommon sizes, in certain parts of the country,

* The muscles of the cœcum being stronger than any other part of the intestines, are compelled by the blow to contract forcibly, as do the intercostal muscles of the lower ribs, whereby the air in the lungs is suddenly expelled, and, if he be affected, the horse groans as the air passes the upper part of the wind-pipe. 
where humanity is at so low an ebb, and the police equally unmindful of their duty, as in the district of London before alluded to.

50. The colon, or large gut, commences at the only orifice of the last-mentioned sac; then, turning underneath the small intestines, and proceeding forward to near the stomach and liver, it turns about, and, in its course backward, makes a great number of zig-zag turnings, by means of two liga-ments that run along its whole length, and coil it up. Such a shape, or rather no-shape disposition of its folds, would inevitably obstruct the progress of its contents, but for the fore-mentioned double motion of its muscular coats, with which it is furnished, as well as the smaller intestines. Being heavy, it is suspended the whole length of the horse's hinder part, by a strong half-transparent membrane (called mesentery), which being fastened to the bones of the back, and hanging down in folds, or plaits, admit of the gut's filling up the same from side to side, in the semi-globular manner we may perceive when the animal is opened. But where the mesentery embraces the intestines the tightest, as if to prevent the too ready escape of the food, there is placed along the whole length of the depression, between the folds of the gut, a white vessel having numerous branches to the right and left, full of nutritious juice, making its way towards the fore-part of the animal.

This is the lacteal duct, which, from its situation between the folds, formed by the mesentery, is 
by some termed "the mesenteric canal," and by and by (in Gibson) "the mesenteric artery." Merscolon and mersectum being the names of parts which usually merge in the general term "mesentery." for the whole, I have made no distinction. But all this does not signify so much as the manner in which this duct gets filled at first by the lacteals, how it constantly flows in health, or is obstructed in disease, and what is the mode and the effect of discharging its contents near the heart, as before alluded to in sect. 37, second paragraph, as well as just below in sect. 51. Herein may be found much matter for pleasing reflection and study, by him who aspires after obtaining a more accurate knowledge of the curative art than is generally possessed; and to attain to perfection wherein, he must study the thing itself by inspection, since nothing that $I$ can find room to set down here can give him any thing like an adequate notion of its importance; nor, indeed, was it ever my intention to employ strict anatomical description, or to enter into learned definitions, any farther than should be found necessary to illustrate what I have to teach, respecting diseases in general, and some long standing errors of respectable veterinary surgeons in particular. On no other point, throughout my present labour, do I so much desire to be rightly understood, as on this one of the absorbents, and absorption altogether*; for it is only when this

* Generally termed "the absorbent system," and, until lately, wholly unattended to in veterinary practice: Gibson, in his lengthy parti. 
function takes place with regularity that health can be preserved: when it is disordered, our business is to restore it, too much or too little being equally productive of a dispusition to diseases, though opposite ones. An indolent or an impoverished absorption requires our care no less than a too rapid or feverish performance of this function: the phlegm and cathartic medicines reduce the latter kind of symptoms; a generous mash, tonic alteratives, and good grooming, are the best restoratives of a languid system. Pulsation is the test of either state of derangement; and he who is the cleverest at discovering, by this prognostic, what is going on in the system, will always make the most humane, as well as the most successful, horse-doctor.

51. Towards its termination, the colon makes a short turn, as if to prevent the too easy escape of the dung into the rectum, or arse-gut, without an effort of nature to straiten the curve at that place; as we see it performed when the animal strains the part, while contracting the lower muscles of the belly, together with the cœcum, in order to produce a stool-the whole transaction being most intelligibly termed "a motion." Several such impediments occur in the course of the intestinal canal, and some of them are so abrupt, as no after-art is ever capable of reducing to a straight

cularities respecting the horse, not having once mentioned the lacteals (as if they existed not), and contenting himself with just loosely naming "lymphatics," at page 55 of his first volume. 
line; the reason for which kind of contrivance is, that its contents still possess some nourishment, which it is desirable should be extracted, and they are thus detained that nothing might be lost; to say nothing of the existing opinion, that the food which has thus lain some time in the animal must impart a juice differing considerably in its properties from that which was but recently received into the stomach. No operation in the system is more beautiful than this one of drawing from the food, now properly mixed and softened, what becomes the milky fluid, called cliyle, first, and blood immediately afterwards; the first mentioned being performed by innumerable transparent vessels, whose fine mouths open every where on the inner surface of the intestines. From the word lacta (milk), these vessels are termed lacteals, their function being absorption (like the lymphatics); the largest whereof lying along the mesentery (as I said before), sends out smaller branches, and these again more minute ones, to encircle and penetrate the gut; in this their mouths do incessantly suck up, or absurb, and convey to the larger vessels the material for replenishing the system with new blood. Passing along the spine, the large tube, filled with this milky fluid, at length reaches the fore part of the animal, and acquires the name of the thoracic duct; here it mixes with a portion of lymph, and is conveyed immediately by a large vein to the heart. Ascending the pulmonary artery, as described in a former 
section (37), the air entering the lungs, changes its colour to a fine healthy scarlet, and at the next pulsation it is driven into the circulation, to mingle with the mass, to impart its newly-acquired properties, and to return again and again, wasting away, until at length it becomes used up and extinct, its place being supplied with other new matter by the continued process of digestion. A change of substance this, which is said to take place with the whole body of the horse in the course of every year and a half, or two years; so that at no time has he a particle of flesh, bone, hair, hoof, or other matter which formed his body two years before, and affording a fit subject for reflection and admiration in us, as it invites those who have the care of providing for his health to take advantage of the well-known circumstance, the more securely to effect those changes by gradual means, which too frequently are attempted by violence, and fail. Nature will not be forced; rather seek her in her recesses, and humour her ways. Those who act differently, generally induce some lasting disozder to appear upon the surface, which they treat as if local; when, alas! these are seated in the very vitals of the animal, sometimes in the most delicate parts of the mesentery. Heating, or cordial medicines, as well as those other untoward mixtures, which corrode, or blunt, the mouths of the finer lacteals, thereby dispose them to receive materials improper for the making of good blood; the consequence whereof is, that 
tubercles frequently are found, which fill up the carities of the lacteal duct. The matter of these tubercles is usually hardened; and resembles the yolk of a hard boiled egg. The disease appears in a staring coat, is commonly considered to be the roorms, and treated as such, with more heating or drastic medicines, which but increase the evil. Other obstructions are thereby formed, and if a solitary worm or two are found on dissection (as frequently happens), they have been generated in the obstructed part, but have not caused any disorder.

Of the mesenteric canal, it may be useful, as well as curious, to remark, that I have always found its state of health or disease to correspond with the appearance of his coat: when this is smooth, the former is full and free from obstructions; when rough, the contrary. In hide-bound, this canal is yellow; in farcy, red, as well as the bowels; these appear blucish, when the horse dies in consequence of being worn out, though, at the same time, the flaccid lacteals still preserve their healthy white, if no other cause to the contrary prevails. But, upon such fursher particulars as are connected with the subject of digestion, as influencing or influenced by respiration and circulation, I shall take occasion to say more hereafter; adding thereto a few cursory remarks, that were not absolutely necessary for the present illustration of the animal system, but will be found more in place in the succeeding section. 


\section{Reader,}

The Liver with its sweetbread, the Kidneys, and the BLADDER, being liable to certain diseases peculiar to each, besides the property of affecting one another readily, as well as being at all times mainly instrumental in maintaining and restoring health to the other parts of the whole system, now claim our undivided attention. I shall, therefore, proceed at once to a brief description of the uses and functions of each, and accompany the same with a few general, but pertinent remarks on the present received mode of treating the disorders incident to the several parts that impede those functions, reserving particulars regarding the causes, symptoms, and method of cure, to a subsequent part of the volume.-Consult the Index.

5\%. The LIver is a very important and immensely large glandular body of a dusky red colour, almost divided, like the lungs, into two lobes, having two smaller subdivisions; and is attended by its pancreas or sweetbread, a small flat part thereof, which has the property of secreting a sweet kind of saliva. This secretion was noticed before, as entering the gut near the stomach, along with the bile from the liver: both are therefore conveniently situated underneath the stomach and behind the midriff, to the skirt of which the upper part of the liver is attached; but the exact functions of this pancreas, or its diseases, are no farther known to us, except that it partakes a good 
deal the appearance of its joint neighbour, and that it is indeed sweet to the palate.

Before he proceeds farther, the reader had better consult the plate of a skeleton as to the situation and extent of this important organ (important in a curative point of view), as relates to the midriff, stomach, and kidneys, where it will be seen included between the squares marked $\mathbf{K}-\mathbf{N}$ as intersected by the lines numbered $21-27$. The side view therein presented is necessarily the left or near side, but the other lobe or right is of greater length and more substance, it touches the right kidney, and its upper surface is contiguous to the diaphragm which presses upon it at each inspiration of the lungs. This tendency of the liver to the right side seems to have been designed by nature to counterbalance the leftward position of the heart, and of the lower part of the stomach; the pylorus orifice of which is seen at the intersection of the lines $\mathrm{K}$ and 26 . In a former page (sec. 2\%.), I took occasion to describe the minute glands with which the extremities are furnished, and to advert to the secretory glands, all which are formed by arteries that deposit their contents, and which is again taken up into the veins; but the liver, the largest of all glands, and a secretory organ, differs from the others in one great and signal respect: it is formed of an assemblage of veins only. Its structure, in other respects, is much the same as that of the smaller glands.

Into the liver is brought the blood which has 
been sent from the heart to circulate and nourish the whole system (except a portion which the kidneys attract); a service that is performed by means of a great blood-vessel they call vena porta, that passes along the right side of the spine. In size very large, and always filled in health, a sight of this vessel shows how busily employed the liver must be, in separating from so great a quantity of blood the bitter qualities it has obtained by having passed through the animals' system, and imbibed whatever might there lurk of the offensive, the diseased, or the infectious. It proves, also, that any disease with which it may be attacked, must be proportionably violent in its progress, and tedious to cure, inasmuch as both will depend upon the state every other viscus may be in, through which the blood happens to have passed. Are the kidneys, or either of them, inflamed? the blood which has recently passed through them comes to the liver to get rid of its noisomeness, in the form of bile. Is an abscess to be dispersed, and the acrid matter driven from the part, to be taken up by the lymphatics (see sect. 29) at the liver it is strained off, and here must be imparted a portion of its baleful qualities. It follows of course, that whatever medicine is directed towards the liver must go thither by means of the circulation, i. e. through the absorbents : for schirrous liver this is best accomplished by the lymphatics; for inflamed liver by means of the lacteals; in other words, 
these are the internal and the external modes of exhibition, and the preparations of mercury are here mostly kept in view.

The secretion of too much bile, and the consequent inability of the vessels to carry it off, it may easily be foreseen would be the harbinger of jaundice; and its approach may be discerned by the yellowness of the eyes, by the increased number and thinness of the animal's dungings, and the constant emptiness of its belly, which both feels and looks loose and flabby. On the contrary, too little bile must leave the intestines without the requisite stimulus to expel their contents, which, soon getting dry and hard, a constipation usually follows, that defies the remedy by purgatives: nor is the mainful operation of backraking with clysters always of effectual service. Whichever extreme affects the liver, the patient becomes weak: but in case of deficiency, though he may look more brisk for a few days, stretching his hind legs out when unemployed, he afterwards becomes feverish, hot under the tongue, sluggish and dull in the eyes. Schirrous liver - a corrosion or rustiness of its fine surface, accompanies this deficiency of bile, and when it recurs often, the disease becomes permanent; but whether caused by, or causing the same, I am unable to ascertain. $U L$ cerated liver is occasioned by a too great heat in this organ : if occurring upon its thin extremity, the disorder cures itself by a natural operation, i. e. by adhesion to the gut, and passing off by stool; but 
when seated higher up, it terminates fatally, by wholly debilitating the system, and sooner or later consigns the patient to the knackers.

The preparations of mercury, before alluded to, act variously upon the system, according to the mode of exhibition the practitioner may adopt: in the form of calomel it assists the liver to discharge its functions by lowering its tone; corrosive sublimate rubbed into the glandular parts (of the thigh, \&c.) find their ready way to ulcerous and schirrous affections of the liver's surface, by increasing the secretion of bile; the blue pill (pilul. hydrarg.) is finely adapted to solve the crudities of stomach and bowels in carnivorous animals, but has never been extensively tried on the horse. For any disease of the whole system, or "bad habit of body," as Richard Lawrence properly calls that predisposed state of it which ultimately produceth tumours, grease, fistula, farcy-mercury, in its various shapes, is the only specific.

Too great a secretion of the bile, although it pass off, produces a roughish meagre coat, first about the belly; the patient becomes languid, especially after being compelled to any great exertion, when he perspires too readily on the carcass, his manner is uneasy, and after a while, partial hide-bound commences under the chest. Should the bile be of a less acrimonious nature, those symptoms are then perceptible lower down (i. e. farther back), and when his eyes appear 
yellowish, it is then a confirmed jaundice; but in very bad cases, producing death, people vulgarly call it "broken hearted," because commonly brought about by bad usage *.

Inflammation of the liver generally accompanies those appearances; but we cannot be certain, though it is to be presumed, that inflammation is always consequent upon an over-quantity of secretion. After much procrastination, medicinal remedies are of little avail when tried on the most extensive scale, although no disorder to which the horse is liable is easier of cure, if it be taken in time: the patient requires only a treat ment directly the reverse of that which brought on his ailments, and he gets well, almost of course. Regular work, moderate feeding, and tolerable behaviour, comprise these natural remedies: they are usually found efficacious in the earlier stages of the disorder, and then only. But those natural remedies being neglected, and alteratives (the assistants of nature) never thought of, languor of the whole system prevails sooner or later, and the best of medicines fail to act by reason of that languor. The absorbents are then accused of not performing their function properly; or, if

* Since writing the above, I have ascertained upon the viero, that a horse, rankling under the effects of maltreatment, absolutely broke the cells of his heart through high-spirited chagrin. The case is described much at large in the "Annals of Sporting" for July 1822, a paper which I was induced to draw up at the instance of my friend John Bee, Esq., who was present at the death and the dissection. 
they do so, then the liver and the kidneys fail in refining the blood sufficiently, so that, at its getting to the extremities once more, those particles which ought to have been carried off are there deposited, and form the nidus of those external maladies that are mistakenly considered local diseases, and treated as such, instead of correcting the foul habit of body which is thus plainly indicated. Of the whole series of tumours or abscess, grease is the only one which people in general think of taking up into the system; the matter that proceeds from the pustules that form grease is so palpably composed of arrea, or the principle of urine, which ought to have been attracted to the kidneys, that every body who would cure the grease, very properly, as if by instinct, administers diuretics; and when this means of cure is adopted early, always with a proportionate degree of success. But of these things more in the following sections.

53. The kidneys, although the seat of only one disorder (inflammation), yet are they so intimately connected with the cure of other diseases, which are constitutional, that a right knowledge of their functions cannot but prove highly serviceable in the judicious administration of the universally approved method of cure, by the urinary passage. Diuretics, or pissing balls, are so constantly in the hands of grooms and others, that I would admonish them thus early to reflect a little on the consequences of going on from day to day in urging these fine glands to over-exertion, 
whereby they are kept in a constant state of irritation, are rendered incapable of acting their part, or literally become rotten. They are situated, one on each side of the spine, close to the last two ribs (see plate $\mathbf{G}, \mathbf{H}$, as intersected by figures 28-30), where they are attached as well by the blood-vessels which belong to them, as by stout cellular membrane which cover them underneath. With this exception the kidneys of horses seldom have the covering of fat, termed suet, which we find in other animals, owing, no doubt, to the very great action of the parts. Mr. Richard Lawrence must have been thinking on the ox or sheep's kidneys, when he wrote his 289th page. For my part, so little of this fat on the kidneys has been noticed by me, that this book was already at press before I was convinced they were ever covered; and yet I have assisted in opening and noting the state of as many horses, I believe, as any man in England who ever wrote a line on this subject: in France, I have reason to conclude, they are more industrious in this respect. The left kidney lies close to the ribs; the right one farther forward, is loose, and is connected with the right lobe of the liver; which being much longer than its left lobe, seems to extend itself backward for that purpose. Excitement, no doubt, is the mutual intent of this connexion; and that deviation from her true system, which nature allows in the effusion from one part to another, takes place, when either the one or 
the other may be diseased, obstructed, injured, or destroyed. On no other grounds can we account how it is brute animals so long survive the total destruction of some vital part, as we frequently find *. One consequence of this loose situation of the right kidney is, that inflammation generally makes its appearance upon it earlier than on the left, a circumstance which is partly derived from its proximity to the liver; it also imparts some of its own feeling to that organ, when inflamed; two facts these which ought to be well kept in mind, when we wish to excite unusual secretion in either. In shape, the left kidney approaches the angular more than the right one; from which I infer that, although the functions of the two must be so nearly the same, in affections they differ; at least, a gall or slight blow will affect the left much sooner than the right kidney.

54. The section of a kidney, which should be performed lengthwise, will show in the centre its pelvis, in which the tube (or ureter) that carries off the water to the bladder takes its rise: in this pelvis stone is sometimes formed, that often finds its way to the bladder, unless it remains in the ureter, or comes away entirely $\uparrow$. The ureters

* Latterly, Mr. Travers has given the public the results of many curious experiments on this subject.

+ I was called in to exanine a horse, whose diseases had baffed the skill of many clever farriers. He had been long declared to have " a complication;" that is to say, none knew his disease, for he occasionally voided blood with $7_{i}$ is urine, in great pain; they had there- 
communicate immediately with the bladder, and the water they convey is formed by the outermost red part of the organ drawing the blood into it, and through which it is filtered by the vascular or whitish part which lies next withinside; here numerous little tubes convey it to the centre one, or ureter, that enters the cavity of the os pelvis at H I, 33, 34, of the plate of a skeleton.

The blood, which has been so filtered of its water, is absorbed by a vein, which is plainly visible in the section of the kidney; and the whole function shows how rapidly circuitous any medicine must act, which being poured into the stomach is found, in so short a space as two or three hours, to have worked its passage through the bowels into the lacteals, thence through the heart and arteries into the kidneys, filled the bladder, and caused a staling of the noxious water, which

fore given him diuretics to such an excess, that he could not bear the hand's passing along his back over the kidneys: his sheath showed signs of oedematous swelling, and upon that region being pressed he became unruly. I, however, saw enough to ascertain, by the heat and tersion of the part, that it was inflammatory, and as his pulse was high, his tongue hot and dry, I proposed to bleed him, and to foment the part; the operation, huwever, was scarcely performed when its owner resolved to take no further trouble, and the horse was slain. On examination I found his kidneys were rotten, and as pervinus as dough : ulcers appeared upon both lobes of the liver, and the neck of the bladder was inflamed a little. The sheath preserved its size; and on the top of the penis a small shapeless stone, the cause of all this mischief, lay buried under the cuticle; and would, I should apprehend, have come away in the course of a day or two spontaneously. How it got there is most inscrutable. 
is to carry off disorders of one sort or other. Here it is worthy of remark, that the operation of internal medicines is much more certain in the horse, when directed against the absorbing vessels and the kidneys, than when intended to act chiefly on the stomach; for, as hath been observed, his stomach being one half of it insensible to stimulants, we are not certain of producing upon it any effect whatever. In all swellings of the legs, the good properties of diuretic medicines may be discerned almost immediately, by reason of the connexion which subsists between the functions of lymphatics and of the kidneys; so likewise, diaphoretic medicines no sooner excite the lacteals to a performance of their function, than the skin shows evident signs of its good effects. But both means of cure may be abused, as I shall show more particularly in the sequel: the first, being administered too often, wears out the functions of the kidneys; the second, being carried on too long, at length refuseth to act upon the skin.

55. An idea respecting the deposition of water in the membranes was thrown out in the twentieth section; and another, as to variation in the proportions of urine and perspiration in summer and winter, at the bottom of section the twentysecond, to which the reader may refer. On this topic a foolish notion having got abroad as to the small quantity of acrid matier contained in the 
urine of the horse, induced Dr. Thomson* to submit a portion of it to chemical analysis in order to decide that point. "The result was, that it contains an unusually large proportion of that principle, so that without being concentrated by evaporation, it yielded crystals of nitrate of urea, very readily on the addition of nitric acid." This fact being thus satisfactorily ascertained, accounts for the strong ammoniacal vapour of stables that affects the eyes of the attendants, and being inhaled (as said in sect. 39.), is clearly the harbinger of several diseases in the horses confined in them-glanders among the rest.

* Of Edinburgh, in his Annals of Philosophy, for August, 1820. By the way, on this subject it is worthy of remark, that for seven or eight years past, the French and Italian doctors have made a great fuss about this l'uree (urea), or proportion of the principle of piss, calling it "a discovery ;" whereas our own people, in every branch of medicine, have been acting upon the same doctrine for better than forty years, to my certain knowledge. Some have regulated their practice (human) by the appearance of the water, with various success; and I have a great notion, that this test of the state of the horse's health may be added to those other symptoms by which we endeavour to ascertain the ailments of an animal which nature has forbidden to complain. Whatever practitioner should undertake to judge of the horse's diseases by its urine, must prepare himself to undergo a good deal of ridicule, and may expect some calumny; he would not, however, be far from the right path towards making a proper estimate of the quantity or violence of its ailment, though he might not so readily ascertain the precise nature of the disorder. The terms " nephrin," and " uric acid," the oldest and the newest for the principle of this evacuation, show the assiduity of which it has been deemed worthy, in that practice where it is confessedly of less im. portance than it is in ours. 
56. The Bradder, or receptacle for the redundant water of the whole system, as it is separated from the blood by the kidneys, is situated within the hollow of the os pelvis at the intersection of HI with 33,34 on the plate of a skeleton, with its outlet or neck turned towards the place of exit, varying a little according, to the sex. It consists of three coats or layers, the outer two being muscular, and having their fibres crossing each other-(as may be seen upon splitting asunder a stale bladder), the better to enable it to contract upon and expel its contents. The

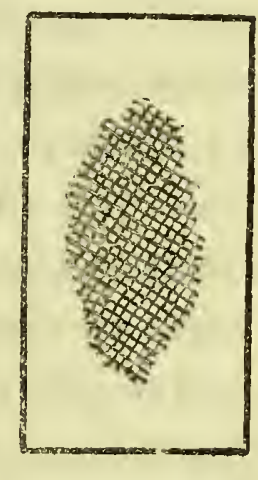
inner coat is membraneous, sensible on distension, and secreting an unctuous or mucous fluid to protect itself against the effects of the urine. When, however, the bladder becomes full, the secretion is insufficient for its protection, and irritation commences in order to induce the muscular coats to concur in the expulsion of the urine. This desire must be very great in the horse, for the reason assigned at the close of the preceding section, and shows the necessity of permitting him to stale upon his first intimating an inclination thereto. The shape of some horses' bladders differs a good deal from that of others, -particularly about the neck, those of the female being considerably wider, and shorter, than those of the male; a circumstance to be remembered when I come to treat of the disorders in- 
cident thereto, since in inflammation of its neck, for example, in one sex we are obliged to have recourse to instruments, in the other, the urine may be discharged by the fingers. But it so happens that horses are more liable to the disorder just named than mares. My Reader will also please to note, that the thin membrane which defends the whole intestine against the friction of the surface, (termed peritonceum), reaches backward to only half way over the bladder; so that it offers no obstruction to our operations upon its neck in cases of disease.

57. To recur once more to the subject of a preceding section (the 55th)-the principle (of urea) that resides in any given quantity of urine evacuated by the horse, it may be here observed, that when the animal, on a journey, has been pushed onward, and thus prevented from staling for a considerable time, he at length produces it of a deeper colour and less in quantity than usual; a change which has been effected by the great heat of his body having taken it up again, by the absorption and effusion which nature has provided, of aqueous particles from one part of the system to another. The principle, or urea, however, remains in the bladder, and produces one of two evils; either the inner or sensible coat becomes inflamed, and loses, after an attack of diabetes, some part of its function of secreting the mucous fluid for its defence, if it does not terminate fatally; or, being less severe, but often 
repeated, a deposition of earthy particles takes place, which the great heat of his body converts into stone or gravel.

Palsy of the bladder is induced from frequent repetitions of thus neglecting the calls of nature, as well as from injuries of the spine; in both which cases the nerves having lost their sensibility, the coats do not contract sufficiently, and some water is always left behind. In all diseases of the bladder, a disposition to fill speedily manifests itself; and in palsy, this is the leading symptom. When this evil takes place, the horse, while staling, seems unwilling, or is incapable of discharging the last drops of each voidance; and, if the usual practice of giving diuretics be adopted, the animal is ruined, if he does not burst the fundus of the bladder and die immediately: rather, the contrary method of discharging, instead of filling the bladder should be sought, and the readiest way to effect this is to introduce the hand into the fundament, which having emptied, the bladder may be felt much distended. In this case, we are told, "too much pressure might terminate fatally;" but by smoothing the bladder gently with the tops of the fingers, from its neck forwards, is usually successful. In fact, I never should have thought of its failing, but for what is said in one of the books on diseases of horses (White, vol. I. p. 12l), where we find a good number of pages bestowed upon "suppression and retention of urine," which are not 
diseases in themselves, but the effects of disease; the first arising in defective secretion of the kidneys, the second in the bladder, or its neck. At all times, a good deal of sympathy exists between this organ and the kidneys, and the kidneys with the liver; inflammation of either being soon communicated to all three, in a degree proportioned to the animal's general state of bodily health previously to the attack.

\section{CHAPTER III.}

General Observations on the Animal System of the Horse, roith Reference to the Origin of Constitutional Diseases; Recapitulation and further Dezeloyement of Veterinary Practice, upon the Principles before laid down.

Stunious READER,-Seeing that a recapitulation of the preceding chapters, and a few general observations arising therefrom, would be necessary, before we examine into the particular discases to which they have reference, I shall here add the notice of such minor parts of the horse, as may seem to have been overlooked; and then draw such conclusions from the whole, as to the principles upon which veterinary medicine may be most successfully conducted, as appear to me 
best adapted to your acquiring those just notions of the theory as lead to favourable results in practice.

The animal system * (which has been so often mentioned) whereby life is continued and strength renewed, diseases are contracted, and the disposition to throw them off is constantly manifested, and by which the ordinary wear-and-waste of the various component parts of the body is un. ceasingly supplied with new and healthy matter, has been shown, in the foregoing brief account of the separate parts that contribute, by their united actions, to make up this system. A system that, although apparently complex and infirm, is, in reality, simple, magnificent, and robust. It is we (mankind) who derange the due action of those parts, by our vanity, our wants, and self-will; or, by our ignorance, put the whole system out of repair, when we endeavour to control Nature instead of humbly following her track, and working after her fashion; and every mechanic knows, that a system, or a machine, being once put out of order in its minutest part, incurs the danger of complete disorganization in those that are more material to the performance of its functions as a whole: an observation that applies as well to a watch or a steam-engine, as to a worm, to man,

* A system is a course of action, according to some known rule or law of nature; and the term has been applied to some of man's con. trivances also, not very happily. 
or the horse; but which, of course, I intend should be applied to the last-mentioned animal particularly.

Our Creator, however, as if prescient of the barbarities his inage would fall into, in the exercise and abuse of the power he gave us over the living things of the earth, hath, in his goodness, conferred on brutes the means of supplying from one part of the system the losses which accident may occasion in another part:-a subject well worthy our patient scrutiny, as furnishing the means of effecting cures in desperate cases, and not to be disregarded in first attacks of malignant diseases.

But, ' the animal system,' as a term, or in fact, may be taken to imply as well that of all animals as particular kinds of animals-descending sometimes (not improperly) to individuals of those kinds. Some persons, however, descend still lower, and the term 'system' has been sadly misapplied, and bandied about from one thing to another, until it is brought to describe particular parts or portions only of the individual's system. The dog kind, the horse kind, and mankind, are good and proper distinctions, for the system of animal life differs in all three: they are not in every case moved in a similar manner by the same class of medicines; whereby we first perceive that their systems differ, and we examine the dead subject of either kind (as in the preceding chapter), to find out how this takes 
place, and in what degree, and we regulate our practice conformably to the discoveries so made. The several individuals, too, of the same kind, have particularities in their respective systems, arising from habit, from country or climate, or from crosses $*$, that demand our serious analytical reasoning, in the application of similar remedies, and adapting their proportions to the removal of similar symptoms. So, a sensible difference is known to exist between the constitution of a carthorse and a blood-horse, between a galloway and a hunter; - each requiring accurate discrimination in ascertaining the state of disease, $\uparrow$ and this consideration ought to inspire us with carefulness in applying the remedies, since that which restores the one might be injurious to the other. Among those four breeds, we frequently find individuals variously affected from the same causes according to their built, shape, or make (see pages 2,12 , and 36 ), according to the constitution and co-adaptation of the dam and sire: as age may come on, accidents have taken place, or chiefly as the individual may have been mistreated by his unworthy master, the sordid farrier, or unfeeling ostler. To all which important

* The system of the same individual, also, may undergo changes by time; so that a medicine may operate differently now from what it formerly did.

+ That surest barometer of health, the pulse, would indicate an approach towards fever in one individual, which might be the certain standard of health in another. See "The Pulse," at page 167. 
distinctions in the state of his patient's particularities, I beg to call the studious reader's most serious attention, while examining his case, in order to apply the remedy most appropriate to the degree of attack.

In the two preceding chapters of this treatise, more of the animal might undoubtedly have been described, or the same subjects considerably enlarged upon, and more parade of learning might have been displayed, but the reader would not have benefited one jot by that course of proceeding: he might, probably, have bewildered himself (as many do) in the mazes which would then surround him; whilst the description of those parts of the animal, which contribute but inferiorly to the system I had in view to illustrate and explain, might have led him to look upon these in a light, too important for the functions they perform-as regards my purpose.

The eyes, the tongue, the ears, the skin and hair, the tail, the genitals, and the hoof, or foot, though each deserving our most sedate attention, for many good reasons, yet, as they do not originate disease, I then purposely avoided taking particular notice of them*. Nevertheless, I do not mean to cleny, that they all, according to each its functions, accurately indicate the existence of disease, as they do of health, and the

* The diseases of the foot, I consider as those of accident or infliction, and with a brief anatomical description, will form a separate chapter. 
degree of both is marked on them with wonderful precision. Hence it was easy to conclude, evern though we did not know the fact to a demonstration, that they are subject to some deplorable maladies that are peculiar to each, arising out of constitutional defectiveness, to say nothing of accidents, nor of the fancied improvements man presumes to make upon the works of his Maker.

Under this last reproach lie all those farriers and others, who give pain unnecessarily to the animal in the indispensable operations. Among these, I class that of docking, notwithstanding the gibes of our continental neighbours (the French) conveyed to us in something like the following couplets, about the period of king James's abdication:

\section{Proud Englishmen avaunt, barbarians as ye be,}

Who cut your monarchs' heads off, - of horses take the queue!

We Frenchmen, better bred, who reverence the law,

Never meddle with our kings' heads, and let our horse-tails grow.

Although of no moment in themselves, these verses show the then French customs, and mark the period when docking and nicking came up among us in England, to be in the early part of the seventeenth century. But I put it to the reason of any, the most strenuous advocate for this custom, whether he ever contemplated the probability of a horse being subjected to this operation three or four several times; yet it is no less true, that, at a market dinner-table, in the town 
of Watford, this May 1820, I heard of a horse which had been so served five several times, from no other authority than that of the last owner of the unfortunate creature. I took occasion to show, in a preceding page, that in all great exertions of the animal powers, the tail and head had a share.

Firing is another of those barbarous practices that are much oftener resorted to than is necessary or proper. In fact, we may observe that this and similar painful operations are adopted in an exact ratio that the operator's education may have been neglected. Who, besides, would pull a mane or tail in such a climate as this? Who else than they would clip the heels of working horses towards the approach of winter!

Of the foot, I have already, in the first chapter, noticed some general faults, arising from constitutional defects in the form of the whole limb; and I shall thence be led to enter into further consideration thereof, with more particulars, under the article "Shoeing," as well as when I come to treat of the several disorders incident to this important part of the frame. Meantime, I am induced thus early to reprobate one other species of that busy intermeddling in the affairs of nature $I$ took occasion to advert to higher up. This consists in the baneful practice of cutting away, unmercifully, the horny part of the sole, that lines and defends the sensible sole, whereby injuries upon the road become more frequent, and 
lameness from unknown causes is incurred; but if not so, canker, rottenness, corns, are sure to follow, or the hoof contracts, and fever of the feet and founder succeed each other.

The skin and coat received some attention under the article secretions and elsewhere, as the reader must recollect, or refer to; but he must never forget, that the first mentioned may be safely and powerfully stimulated as the outlet for many constitutional affections of the system, the proper time for their use being indicated (as I said before) by the appearance of the coat.

The tongue always partakes of the general state of the system: in the horse, it does not afford to the sight so sure a prognostic of the state of the stomach as in the human subject; but, to the feel, it communicates to us the state of the blood with so much accuracy as demands our assiduous attention, to the acquiring, by practice, the most intimate acquaintance with its monitions. This member of the body, in conjunction with the coat, I lave always considered the health-gage of my patients. See observations on the "Pulse" at page 167.

The eye is a most material organ of sense, and is much studied by those who would render themselves good judges of the general soundness or unsoundness of the horse's constitution. It beams bright and steadily in health, projects most fiery when the animal is most vigorous; in lassitude it sinks, it blears with a cold, and, under 
extreme circumstances is extinguished. After a heat, horses full of blood, with ful stomachs, certainly alter in tlieir vision, shy and become troublesome; and, so sure is the eye the barometer of vigour, that horses got by old sircs have the eye more sunken than others, with a hollowness over it.

The ears, by their movements, show the apprehensions of the horse, if not his disposition. When he fears the lash, he turns their cavities backwards. Is he disposed to be resentful, they are laid flat on his poll. Following his companions, or the hounds, or going homewards, the cavity of the ear turns sharply forward: asleep, as well as under other circumstances of casy watchfulness, one ear turns forward, the other backward; but, when roused suddenly, they alternately change position. Who, then, would destroy these useful appendages of the horse's organ of hearing? Who would singe of the hairs, which, passing from side to side of the cavity, catch the sounds, and convey to his rider the first notice of langer, from wild beasts, as well as pleasure from the cry of the hounds? The Arab knows, by his horse's ears, of the approach of enemies; but the Englishman relies too securely upon his own comparatively imperfect hearing, and cuts off those better intelligencers of distant occurrences; or, he more assiduously abridges their utility, by clipping away the inside lining; or, worse still, by apply- 
ing flame to the part, he renders the horse skittish ever after. Those are the only disorders of the ears of horses; if, for want of this hairy defence, premature dulness of hearing, occasioned by rain, dust, and other substances entering these organs, be not another.

That the genitals draw off from the system and store up a noble secretion, for the purpose of continuing the kind, is certain; but I shall pursue the matter no further than to notice the change to which the coats of geldings are subject as to colour, compared to those of perfect horses; and all the inference I mean to draw from that fact is, the still further corroboration of my previously maintained opinion, as to the seat of perspirable matter residing in the lacteal part of the system.

As it is the blood which by its deposite forms all those parts, so by means of the blood must we endeavour to correct any derangement of the system of animal life, whether of quadrupede or bipede; for the working of the system in the making of new blood and cleansing the old is the same in all, though differing in degree, whilst mainly agreeing in the process. Would any one demand how it comes to pass, that quadrupeds draw so much substantial nourishment from herbam ceous vegetables, whilst man can only extract a watery juice, devoid of all nutritious qualities? let him be answered, that all depends on the digestive powers, these being greater in the brute than in man. It even appears plainly to me, that 
the animal food taken by man is the same as the herbaceous taken by quadrupeds, only that it has meantime undergone the process of digestion, sanguification, and deposition in the solids, \&c. and hence arises the difference in the practice of the curative art as applied to the one animal and the other. Every disease is in fact a compound, varying in different constitutions, and the composition of the remedy should be adapted to every variation thereof, even of the same attack. 


\section{BOOK II.}

THE CAUSES AND SYMPTOMS OF VARIOUS BODILY DISEASES INCIDENT TO THE HORSE; WITH THE MOST APPROVED REMEDIES IN EVERY CASE.

\section{CHAP'TER I. \\ Of Internal Diseases.}

INFLAMMATORY DISORDERS, GENERALLY.-FEm VER.-From all the information the reader may have collected together in his mind, respecting the "circulation of the blood," as described with instructive minuteness at pages 99 to 108 , he will naturally conclude that the horse is ever most liable to contract one or the other of those disorders we term inflammatory. The great heat of his blood, combined with his bulk, and the amazing exertions he is compelled to make, all together constantly pre-dispose him to incur fever of the whole system or inflammation of particular parts, according to concurring circumstances. Nor is the matter changed one whit, when we reflect that fever sometimes terminates in local inflammation, which we term "critical," as being the crisis and 
cure of the disorder; and that the inflammation of one part or organ (the liver in particular) frequently devolves into fever of the whole animal system, by means of the rapid circulation of the blood through the ciseased organ.

Let us proceed to discuss the subject generally at first, and to pursue each in detail afterwards; simply premising, that all the disorders incurred by the horse are referable, more or less, to this overheated or inflammatory state of his blood, and its consequent unfitness for the purposes of promoting animal life, health, and vigour. For, the more heat, the more viscidity or thickness there will be in the blood, and less will it be found capable of circulating the longer such unnatural heat continues, up to a certain point of the disease: when the animal is so far affected as to lose its appetite, and consequently no fresh blood can be formed by the digestive powers, the blood then becomes thinner every day, because its more solid particles are constantly being deposited in the cellular membrane to supply the waste that is unceasingly going on there. The reader would do well to read over again what is said concerning this process of the animal system at page 131, with the references there made, to page 101 , to page 60 , and, in fact, to the whole tenor of the second chapter. But this supply soon fails, as necessarily it must, when it is not replenished at the source, and wasting of the solids succeeds of course, unless nature is assisted by 
Dur art judiciously:-the right application of this art is what we are now in search of.

One of the immediate consequences of the horse being hard worked, or high fed and physicked with stimulants, is the constant heating or feverish state of the blood. Increased action of the heart and arteries accompany and keep up this state of irritation, which may be further accelerated by the animal's being allowed to take cold whilst in that state, whereby the perspiration is checked of a sudden, and the blood which may then fill the smaller vessels is detained there to the further annoyance of the larger ones: he then contracts inflammation of all the solids and organs of life, or, more properly, FEVER. But when only a certain part of the system, or a single organ is thus checked, we consider the affair under the name of Inflammation of that part, as of the lungs, the kidneys, \&c.; always keeping in mind, that, by continuance, these extend their baleful affections to other organs, with which a certain sympathy is known to exist. In like manner, when external muscular parts swell and secrete matter, this is in like manner an inflammation of that particular part, or tumour, or abscess, with a great variety of names, according to the place where it may be seated: poll-evil and fistula are among those external complaints to which I allude.

The latter, or local kind of inflammation, is the effect of the former or continued internal fever, and whenever such a tumour or abscess makes 
its appearance near the surface, the general inflammation or fever subsides; when it discharges offensive matter, the fever is cured. If such a tumour appear without previous general fever of the system, we repress it, so that it may disperse and pass off by stool. It may usually, however, be considered as an effort of nature to relieve itself of offensive viscid matter that lurks in the system; and in this case only, when well ascertained, would that reduction of the system which I shall shortly insist upon as proper in all inflammatory attacks, be least advisable, as nature would then require aid to assist her in her efforts, rather than subtraction from her powers, by the bleeding, purging, \&c. so recommended.

But whenever a cold is caught, whereby the trunk is affected, one of two evils is experienced that is quite contrary in its effects: 1st, Either the bowels lose the power of retaining their contents, and of contributing their aid to the purposes of digestion, chylification, and sanguification, i. e. the making of fresh blood, and diarrhœa ensues; or, $2 d$, The extreme heat of the body causes the dung to harden; the stomach then throws up its fumes to the head, and if the obstruction be not speedily removed, the most distressing consequences usually happen. Either extreme may come on gradually and imperceptibly; but as the latter (termed constipation) is of most frequent recurrence, is a disorder of over repletion, producing vertigo, staggers, apoplexy, 
megrims, or fits, I have considered it under a separate head, as "costiveness;" seeing that it sometimes supervenes without previous fever, though always accompanied by it. One or other species of affection of the bowels is also produced by catarrhal inflammation, or fever of the organs of respiration, when this is violent or of long continuance.

Respiration of confined or noxious air in close stables, as described at page 105, also produces quicker circulation of the blood, with perspiration and temporary fever, which may be confirmed by sudden exposure to the open air, and the consequent detention of blood in the small vessels which we term capillary. Sudden immersion in cold water whilst sweating and respiring with difficulty after a run, wading through a river, or standing in a current of cold air, are all prolific sources of inflammatory disorders. Indeed fever and inflammation are so closely allied to each. other, that we run little risk of creating confusion of terms by considering them as derived from the same origin, and none whatever in treating of both in the same chapter. For most stablemen and farriers, as well as many veterinary writers, do speak of the one and the other promiscuously, as if they were the same, when describing the symptoms of either; nor do I see any good cause for my deviating from this practice upon the present occasion, after the slight distinction just drawn. 
One other general observation may be aptly made in this place, which may stand instead of much discussion hereafter. As fever is a necessary consequence of any inflammation whatever, so without fever there would be no inflammation. Every run you give a horse heats or inflames his blood, quickens his pulse, and he sustains temporary fever. Whilst in this state, if any viscus, or organ, that constitutes a vital part of his system, receive such a check or damper as I have described, obstruction of the finer bloodvessels ensues-as, of the lungs, by their drinking cold water, or mere affusion of it on the chest, and inflammation is its name: if the whole body of an animal or its entire surface be so affected, the evil consequences are similar, and fever is the name by which we designate it. Horses out of condition, or already in a low state, though feverish, with quickened pulse, do not require further reduction; since this is evidently "low fever," which I have treated of under a separate head; as I have also "Typhus fever," or the affection of the whole system which arises from a vitiated or corrupt state of the blood. But, in all cases, the best guides to the practitioner for his prescriptions, and indeed all his operations, are the causes, the symptoms, general health and peculiarity of con. stitution of the animal; when it so happers that such particulars can be extracted from those about him, as will be the case in all studs of a superior cast. If the feverish affection arises 
from inactive kidneys, the diuretics recommended lower down will be all the treatment that is requisite in such a case; if a dull heavy pulse and the state of his dungings show that the bowels only are at fault, purgatives alone will restore health. So of any other visceral obstruction, when these give pain, fever ensues, and is best removed by the exhibition of mercury; if the internal irritation continues, rowelling is the remedy most appropriate to such cases, and the state of the pulse will tell the doctor when and why he should bleed. This will bring us to an early consideration of "the pulse," its indications and general oules. In all cases of inflammation, whether of the whole system, or fever, or of particular organs, let bleeding be resorted to immediately, in quantity proportioned to the amount of heat, which is ascertained by the temper of the pulse. "Open the prima via," also, is a good maxim of a late respected lecturer on those subjects, mean ing thereby-purge the bowels or chief canal, and keep them open. Copious clysters of warm watergruel assist the latter materially, particularly if a solution of salts be added, according to the nature of the case; but rather than delay the clyster through want of the ingredient being at hand, use simple warm reater only. Very often, in slight attacks, the animal requires no other treatment, if resorted to in time; but delay is dangerous, for with every hour the symptoms increase in a threefold ratio, and the animal becones weaker and 
weaker every moment; and therefore less able to bear up against the attack. In all cases, be quick, for ruin is going on with rapid strides, whenever the animal shows signs of great internal pain. Frest cir, diluting liquids, and clysters, in all cases of inflammation whatsoever, are found of as much service in the restoration of health, as the best active medicines that can be administered; the first mentioned most positively so, unless the animal perspire greatly at the time, or it suffers under a fit of shivering. Danger is to be apprehended in the latter case, and the fresh air need not then be admitted; but if shivering is succeeded by sweating, or even a small degree of moist heat, it may be considered as the crisis of the disorder, when something has taken place that is favourable to the cure-of which more particulars in the proper place. Continued shivering, by the way, denotes the termination of all inflammatory diseases_- in death; cordials then may do good, but more frequently accelerate the catastrophe, whilst the diluting liquid-watergruel, will afford relief in some measure, but can do no harm. But fresh air, that issues not in streams, is of all other restoratives that upon which I place the most reliance; even removal to a fresh stall, or up and down the stable, effects great changes in the animal's spirits, that cannot fail to strike the eye of an attentive observer, and bespeaks, more than words can convey, the vital necessity of a cool atmosphere. 
The Pulse-Being the chiefest criterion for judging of the state of the circulation of the blood, and as I have sat down with the notion that my Book will be read straight-an-end at first, let the reader attend a moment while I say a word or two on this preliminary topic Without an accurate knowledge of this touchstone of the main spring of life, no one can form a judgment fit to be acted upon as to when it is necessary to bleed or of the quantity to be taken: thus, in cases of fever, the groom begins very properly by bleeding; but he almost invariably takes too little, or in case of increased action of the pulse, through over exertion of the animal's powers, he bleeds when such a course is detrimental, and almost always administers cordiats, thus reducing with one hand, and increasing the action with the other.-See pages 99 , et seq.

When in health, the pulsations or strokes are from thirty-six to forty in a minute; those of large heavy horses being. slower than of the smaller; and of old ones, they are also slower than of young animals. When either may be just off a quick pace, the strokes increase in number; as they do if he be alarmed, or terrified, or hear the hounds' familiar cry. Fever, of the simple or common kind, usually increases the pulsations to double the healthy number; hence the propriety of grooms ascertaining the state of this index of health, while the animal is still free from disease, goes to prove over again the 
propriety of my plan of teaching the curative art in animals by closely examining the indications of kealth, and setting down in one's mind every deviation therefrom as the approach of illness, that ought to be met and combated at the threshold.

In this view of its utility, why might not the attendant groom, or horse-keeper in more humble establishments, keep a register of the state of every horse's pulse, when it comes first under his care, and renew the same examination at intervals of a week or ten days? This practice alone would render him expert in all cases of imminent danger; to say nothing of those other indications, the dungings and the reater voided. On this latter point the reader will turn back to what is said of "Urine" in page 143.

As the fever increases in violence, likewise, when the animal is in great pain from inflammation of the intestines, \& $c$. the pulse beats still higher, and reaches to 100 in a minute, or mare. The danger is then great, and less than three or four quarts, drawn from a large orifice, would do harm rather than good, by increasing the action of the blood, and the hardness of the artery would also be increased. To ascertain either state, the attendant should apply the points of his fingers gently to the artery which lies nearest the surface. Some prefer consulting the temporal artery, which is situated about an inch and a half backward from the corner of the eye. Others 
again, and they are the greater number, think it best to feel it underneath the edge of the jawbone, where the facial artery passes on under the skin only to the side of the face. In either case, too great pressure would stop the pulsation altogether; though by so trying the artery against the jaw bone, will prove whether it be in such a rigid state of excitement as attends high fever; or elastic and springy, slipping readily from under the finger, as it does when health prevails and the strokes follow each other regularly.

'The presence of high fever is further indicated by a kind of twang, or vibration, given by the pulse against the finger points, resembling much such as would be felt were we to take hold of a distended whipcord or wire between the fingers, and cause it to vibrate like a fiddle-string, sharply; whereas, in health, a swell is felt in the vibration, as if the string were made of soft materials and less straitened;-facts these which owners would do well to ascertain by practising upon the pulse of their own horses. Languid or slow pulse, and scarcely perceptible in some of the beats or strokes, indicate lowness of spirits, debility, or being used up: if this languor is felt at intervals only, a few strokes being very quick, and then again a few very slow; this indicates low fever, in which bleeding would do harm. Quickness, however, is the chief indication of the whole class of inflammatory fever; and this being my principal object at present, I shall postpone fur- 
ther consideration of the pulse until I come to treat of " blood-letting."

\section{FEVER.}

There are two kinds of well-marked fever, simply so called-first, that which arises from the pain an animal may be put to by the derangement of some main organ of life, by misusage, hard riding, wounds, \&c.; and secondly, that which consists in a general inflammation of the blood arising from a cold, a chill, or sudden check, as before described. The ancient vulgar name given to this alarming disease conveys to the common observer a better idea of its force and danger, than those which are settled by consent of the faculty of horse medicine; and the phrase "inflammation of the blood" may be taken as more plainly indicative of the cause of fever than aught the moderns have substituted in its place. Had our plain-speaking ancestors termed it " inflammation of the blood-vessels," they would have been still more accurate, probably; but no mistake is more common throughout life, than to speak of the thing contained for the thing containing it, and vice versâ. When the symptoms come on quick or acutely, the most prompt measures must be taken: a mild attack may be easily reduced if taken in time, but, if neglected, it assumes the most alarming symptoms. Evacuations and di- 
luting drinks are the proper means of reducing the patient; but before purgatives are administered, see what is said a few pages onward respecting "Costiveness ;" for it not unfrequently happens, that this is all that ails the animal, except his being worked too hard while costiveness is upon him.

In either case of accelerated pulse from those causes, bleeding should presently be had recourse to, and let the quantity taken be regulated by the force and quickness of the circulation of the blood; for this is what constitutes the fever. If the pulsation advance to above 60 , two quarts should be drawn; if above 70 in a minute, three quarts of blood would not be too much to take away at once. If the number of beats be much more, ascending rapidly, with the rigid feel of the artery above described, four quarts at least must be drawn, and that from a large orifice. Should this rigidity, or hardness of the artery continue, notwithstanding the bleeding, a quantity that shall cause faintness or tottering might be taken, or rather a repetition take place of the same operation in lesser quantities, until that hardness of the artery is no longer felt. Some skill, derived from practice, is required in watching for this lastmentioned symptom; but whatever is to be done, let there be no delay in the first operation: twelve hours should intervene between the two bleedings.

Immediately hereupon, let a mild purgative be 
administered, adapting this, as well as the amount of bleeding, to the size of the horse, if he belong to either extreme of exceeding large or very small. For one of the moderate coach-horse kind give the following

\section{Purgative Ball.}

Aloes, 7 drachms.

Castile soap, 4 drachms.

Aromatic powders, 1 drachm.

Oil of caraways, 6 drops.

With mucilage sufficient to form the ball for one dose.

In all cases of fever arising from accidents, hard runs, \&c. which may be considered as temporary excitements only, the above treatment in its mildest form will be found sufficient completely to reduce the symptoms; but in the fever, simply so called (arising from inflammation of the solid as before described), repetition of the purgative becomes necessary, with mashes, a quiet stable, and an attentive groom. When the fever arises from repletion, indigestion, or any derangement of the stomach or guts, its immediate cause will be found in hardened focces; but back-raking should be avoided if the fever has begun; and in addition to the forementioned remedies, give a

\section{Purgative Clyster.}

Water gruel, 6 to 7 quarts.

Table salt, an ounce to each quart. 
Let it be applied assiduously, and some assistance be given to bring away the first hard fceces that appear : the remainder of the hardened dung will come away, naturally; in good time. See further under the head "Costiveness."

Castor oil, in the quantity of a pint or more, will open the canal partially only, passing by the main evil in the coecum and great gut*, and producing but a small quantity of the offensive cause of disease. But help must be afforded in this respect; and if the bowels yield not to the purgative ball, other means must be resorted to, though I should never think of having recourse to oil in the first instances. Although the constipation or obstruction be obstinate, yet very strong diuretic purgatives are ineligible, as they might kill the animal, or at least injure the intestines materially, by reason of that very circumstance.

Distinctions have been drawn by some writers between "symptomatic and simple fever;" that is to say, whether the excitement, called fever, originate in a check of the circulation received externally or internally; but, as the treatment in both cases is so nearly the same, I shall make no such distinction. The internal attacks alluded

* The practical reader, whilst waiting the progress of the disease, will not waste his time by turning back to the first book, at p. 110, and see what is said of the conformation of those large guts, and the difficulty of escape that must attend their offensive contents at the turns or sinuses (which $I$ have there considered as so many valves), when inflammation or fever has once begun. 
to, when confined to a single organ, and not extending to the whole frame, are more properly termed inflammation of that viscus or organ, and therefore will be treated of. hereafter, under the following heads, viz.

Inflammation of the Lungs,

Inflammation of the Stomach and Intestines, Diseases of the Liver-Inflammation, \&c.

Kidneys and Bladder.

All these produce fever throughout the whole system, when either exists but in a slight degree; for those parts are all of them vital, and communicate their feeling to the solids by means of the circulation. It is not, however, until these attacks are well marked, that they deserve separate consideration; for some horses suffer under the one or the other during life, with more or less malignity according to exciting circumstances, the lungs being the most general sufferer, the bowels the seldomest attacked of either, but usually prove the most fatal of this whole class.

The symptoms, in all cases, are heat and acceleration of the pulse, as before described, and which in fact brought me to the consideration of this portion of my subject before the others. A hot mouth soon comes on; shivering takes place early, and the animal evinces signs of internal pain by looking at his flanks or chest. The fever is then likely to fix on the lungs, if not speedily reduced. Loss of appetite follows; but too gradually to be waited for, as a criterion for judging 
and acting promptly. He will evince languor and dulness, with half-closed eyes, and a small discharge from them, as if tears escaped, sometimes; this last will happen in cases of mere debility or starvation also, when it is not too much to suppose the animal may be deploring his hard fate. Consulting the pulse, however, will settle any doubt as to which ailment the animal labours under; for this main characteristic of health will, in the latter case, partake of his debility, and strike now hard and then soft, a few beats each: in this case a feed of corn, or water gruel, would probably restore a more healthful even pulse, whereas bleeding would go to destroy the patient. It has been termed low fever, though not very properly, and lentor, or more justly lenteur (slowness, dulness, heaviness) by the French veterinarians; yet, having no better name for it than "low fever," under that head, I shall shortly bestow a few lines on this species of systematic debility.

The dung and urine are always good indications of the state of the body: if the former fail, fever is the cause; it subtracts also from the quantity of urine, and if he stale small quantities at short intervals, some internal inflammation has taken place. See Inflammation of the kidneys. In fever, the mouth and tongue become drier than ordinary; and if any saliva be secreted, it is tough and ropy. If the animal be in condition, upon lifting the eyelid an uncommon redness appears: if he be out of condition, or in a low state, this 
does not always happen; so this indication may be reckoned among the uncertain symptoms.

If the remedy and the symptoms of fever are thus pressed forward together upon the reader's notice, as exemplifying the assiduity he should display in repelling the attack, let him know that his work is but half completed when he finds the heat and acceleration of the pulse reduced by his endeavours to the ordinary standard. The tone of the patient's stomach and the whole digestive process require restoration, and this with a careful hand, that the bowels may not again get overloaded; because why, a second attack of this sort would be more difficult to surmount than at first; for the bowels have partly lost their function of expelling their contents, through the violence of the disease, if not by the harsh action of the remedies employed. Hardy working horses, of course, recover their appetite as soon as the fever abates; and no further care is required for such than an occasional laxative or purgative, according to the amount of obstruction. The ball prescribed at page 172 may be given at intervals with the fever powders; and subsequently, the fever drink prescribed below for all other descriptions of horse recovering from fever.

$$
\text { Fever Poreder, No. } 1 .
$$

Powdered nitre, 1 ounce.

Emetic tartar, 2 drachms.

Mix for one dose. 
No. 2.

Powdered nitre, 6 drachms.

Camphor, 2 drachms.

Calx of antimony, $1 \frac{x}{2}$ drachms.

If either be deemed more desirable in the form of a ball, this may be effected by mixing the porvder with mucilage and meal; but in the form of powder mixed with his corn is most eligible, as the medicine then acts earlier, whereas the ball presently descends into the great gut.

\section{Fever Drink.}

Cream of tartar, 1 ounce.

Turmeric, 1 ounce.

Diapente, 1 ounce.

Mix in powder, and add to a pint of warm gruel, to be given once or twice a day. This is a good cool stomachic, and restores the appetite, at the same time that the disposition to the return of fever is kept down: if found of marked service, the doses may be repeated to three or four times a day, for a week.

\section{LOW FEVER,}

Together with TYPhus, or putrid fever, and RHEUMatic fever, are diseases incident to the horse, though attempts were long made to deny the application of those terms to any of his numerous afflictions, by those who dread, inordi- 
nately, the falling into analogies with the human practice; a fear that may be carried too far, notwithstanding all our care should be employed in separating this from the veterinary practice.

Cause.-Of low fever, under the idea of debility, a few words fell on the preceding pages: and truly, if "high fever" may be produced in a subject that is full of blood, or condition, by overexercise, and the other causes thereof set down above (pages 170-175; see also book i. at page $114, \& c$.$) , these same causés, operating upon a$ horse out of condition, or which has not sufficient blood in his frame to receive inflammation, necessarily occasion that languor which attends debility of the entire system. The reader will, perhaps, oblige me by turning to book i. at page 110, and reading over again what is there said as to some causes of low fever. But the respective terms we give to the various kinds of attack would signify much less than they deserve, were it not for the danger we should otherwise fall into of treating one disorder for another, when the symptoms (some of them) so much resemble each other. This danger is more likely to come upon us in cattle medicine than in the other, since we are under the necessity of finding out what is the matter with our patients, whilst the human doctor receives the information at once, in words.

As inflammatory fever is more prevalent in the spring and summer, owing to the high condition of most horses when first attacked, so does low 
fever, or irritation of the animal system of a horse in low condition, mostly prevail in autumn and winter. We owe this latter in great measure to the debility or weakness brought on by the moulting of his summer coat, when the autumnal equinox sets in. Being then much exhausted by the heat of the season just gone by, he sweats profusely on the least exercise; then his coat becomes dry and husky when at rest, and his skin sticks tight to his ribs, slightly resembling hidebound. The animal having lost much of his natural covering, and no care being taken to palliate this loss, he is more liable to catch cold if exposed and still pushed in his work. If not relieved from its severity, post-horses in particular become unserviceable in great numbers, to an alarming degree, resembling much the distemper of the spring season. Too often it happens, such knocked-up horses are considered as done for, and the owner sells off; whereas experience tells us, that a nourishing regimen would restore them to their wonted vigour; for the serous or watery part of the blood (chap. 2, sect. 20,21.) having been drained off by the violent perspiration they were exposed to by their summer work, the muscular fibres become too rigid, and the blood too thick for circulating in the finer vessels; it therefore remains rioting in the larger ones, distending their capacity and increasing the irritation. Working horses are then usually deprived of their corn, because they cannot work; this only adds to the irritation of the 
vascular system and solids, which constitutes the low fever we are now considering.

Symptoms.-Parallels, or distinctive characteristics, of such diseases as somewhat resemble each other, are therefore very proper, inasmuch as they prevent those dangerous mistakes in practice that happen oftener (even in the human practice!) than suits me even to hint at in this place. They are most particularly serviceable to veterinarians: for this reason it is I recommend the reader to compare what is said of the symptoms of high fever, just above, with the present page, as regards the symptoms of low fever. They are placed near together for that purpose, as I then said (at page $169, \& c$.) The pulse, in this case, never mounts high during an entire minute, but beats quick a few strokes, and then slow, and so low as scarcely to be perceptible; this denotes, that though fever be present, there is not strength sufficient to bring it to a crisis. The artery feels rigid, at intervals only, and again becomes supple, if not elastic, to the touch; his flanks are agitated more than usual, and his hind quarters and ears become cool if not cold. As in high fever, his eyes are dull and heavy, and water will occasionally fall from them. Though in the former species of fever he evince considerable pain, in this no such symptom appears, but despondency assumes its place.

Remedy.-Unless his body be already too open, give the laxative draught, as under; and as he 
will still feed, diuretic powders may be mixed with each feed of corn, consisting of nitre and rosin, of each 3 to 4 ounces. Should the urine appear turbid, or come off with difficulty, in small quantities, the diuretic ball is indispensable; and these, with good gruel and care, accompanied by tonics, will restore to the animal a comparative portion of health. Time and moderate usage will accomplish the remainder.

\section{Laxative Draught.}

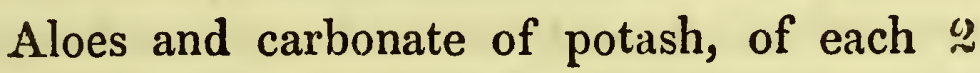
drachms,

Mint water, 4 ounces.

This will correct the urine also, and its laxative quality may be increased by adding to the quantity of aloes.

\section{A Diuretic Ball.}

'Turpentine and soap, of each 4 drachms, with mucilage to form the ball.

A good restorative for lowness, occasioned by the moulting fever of autumn, is recommended by J. Clark of Edinburgh : he says, "the end of autumn proves very severe to those horses whose flesh and strength are exhausted by hard labour. In this low and spiritless state the moulting season comes on, and carries off numbers that good nursing and feeding, with rich boiled food, at this season might have preserved. Carrots and po- 
tatoes recover some horses surprisingly; it renews their flesh and the fluids generally, and promotes the secretions: it operates upon them nearly in the same manner as spring grass, and its effects are presently visible on their coats." Many stable men give oatmeal mixed up into bergue, or crowdie, for horses that evince signs of languor and lowness of spirits, after fatiguing work in winter: if made into stiff gruel, i. e. boiled, the restorative effect is found still more desirable, and a smaller quantity of corn then sufficeth. A gradual return to hard food does all for the horse's working condition which can be desired.

Fever is brought on, in some degree, whenerer it comes to pass that either of the vital organs may be deranged in its functions. Not unfrequently it happens that a diuretic is all the patient requires, which may be judged of by the state of his pulse after the medicine has operated. When this is the case, the feverish symptoms owe their origin to suppression of urine, and the reabsorption of the contents of the bladder into the system. See Bladder and "Suppression of urine;" and, after treating the attack simply as such, a cordial ball should then take place of all further treatment, as the immediate falling down of his pulse to a healthy standard will show. Too free use of "pissing balls," however, in the hands of korse-keepers, spoils the action of the bladder. See chap. 2, page 145. The French give a bottle of their routine wine made warm, and most of our 
farriers administer a quart of ale with the same view. Those are mostly waggon-horses, full of flesh, that so absorb the aqueous particles of the urine, and ultimately the principle thereof (termed urea), and light up the fever anew. Another cause of feverish attacks, generally of the slighter kind, but liable to prove fatal, if neglected, is the retention of his dung, or constipation, which means costiveness.

\section{COSTIVENESS}

May be considered an original disease, and as one producing as well as being produced by fever. That is to say, hardness of the frees always attends a fever, and is frequently the chief cause of it: like the preceding ailment, we have only to remove the cause, and the effect ceases. See also "Diseases of the Liver."

Causes.-Want of the necessary or usual evacuation by stool, that is sometimes occasioned by the bowels having lost the power of expelling their contents, as described in the second chapter, page 122. Simply speaking, the individual having been long time dosed with purgatives, any neglect hereof causes the dung to harden and obstruct the contractile function of the intestines: heat ensues, and re-absorption takes place, as in case of retention of urine, until the dung loses all moisture and becomes as hard as baked clay, the lumps that lie in the rectum appearing like so many gingerbread 
nuts. "Hard up," and "hard baked," though gross, are goodly descriptive of this species of disorder, in the mouths of the vulgar dog-fanciers in particular.

The same kind of big fleshy horses as are liable to suppression of urine, are also principal sufferers by constipation or costiveness. Hard food and hard work in warm weather is very productive of this malady, which is often mistaken for inflammation of the bowels; the means of prevention, therefore, are obviously the direct contrary mode of feeding, and also keeping a good watch on the dunging of each horse in the team.

Symptoms.-When constipation attends general fever, it is then but a corresponding symptom of that disorder, and the reader is referred back a few pages to what is there said on this head. But, when the pulse is not so high as to warrant us in pronouncing it fever, and the dung is ascertained to be hard, there is no difficulty in treating it as simple costiveness. It may be distinguished from colic and from inflammation of the intestines, by the quiet state of the animal when he is down, which is not the case with either of those disorders, in which pain of the bowels is most evident; whereas, these do not appear to suffer from the costiveness, though the head is much affected by reason of the evil fumes of the stomach ascending there, and ultimately producing delirium and frenzy. Indeed, his actions are those of madness, which the generality of 
persons attribute to the sick animal. Its eyes offer the earliest symptoms by their dulness, contraction, and expansion, succeeded by sleepiness; he refuses his food, he will not work, the mouth becomes hot and dry, the ears cold, and the breathing difficult or nearly imperceptible on account of the pressure of the stomach and bowels upon the midriff.-See page 94. The pulsation usually increases, if he be in a tolerable good condition; but this increase is ever inconsiderable until fever comes on, and marks the period when blood-letting would be necessary. A dull heavy pulse is more common, until the paroxysms of madness may render this symptom a little sharper and quicker for a short period. At length he tumbles down, regardless of the situation, and the action of the head shows how greatly this part is affected, until stupor and death ensue, if the sufferer be not relieved.

Remedy.-Purgatives are not always the most eligible medicines even in the earliest stages of the disorder; for, if the constipation has lasted a considerable time, great injury would be done to the intestines by forcing a passage, whereby a commotion might be raised in the stomach, but would act inefficiently where the evil chiefly lies, viz. in the great guts and rectum. As soon as it is ascertained that the animal has not dunged for some days-when he seems uneasy, a fulness is perceptible towards the flank, the fundament, 
\&c., and an unusual dryness and tightness is discovered at this latter part, the operation of backraking should be resorted to. Castor oil, one pint, would indeed find a passage in the first stages of the attack, but good part of the evil usually remains behind; in the more advanced stages, especially when the patient drops, nothing else will relieve him but back-raking. Let the operator strip his arm bare, and having well anointed it with soft soap, lard, or butter (the first being the most eligible), he will bring his fingers to a point, and gently introduce the hand and wrist, when he will feel and draw forth a portion of the indurated fæces he will there meet with, in lumps hard and dry. This he may repeat three or four (or more) times, and leave the animal to himself a little, whilst a drench is preparing. Trivial as the relief may seem which has been thus afforded to the patient, he will immediately evince proofs of its benefits, by a more sane conduct, by licking forth his tongue, opening the half shut eyes, by looking about him, and sometimes by getting upon his legs. In this latter case, plain water gruel, as warm as a person might take it without inconvenience, may be administered in the quantity of two or three quarts, if he will take so much; but if the animal be exhausted, and does not get up without difficulty, or without help, one half the drench may be ale or porter. Although he will seem recovered, 
and may produce a stool, his bowels must next be emptied. In order to this, give a

Laxative Draught or Dreach.

Castor oil, half a pint.

Aloes, 2 drachms.

Prepared kali, 2 drachms.

Water gruel, 1 pint.

Repeat this next day, leaving out the oil, and doubling the quantity of aloes; or, after an interval, give the usual purgative ball, containing seven or eight drachms of aloes, as prescribed at page 172.

INFLAMMATORY DISEASES of every sort leave behind them a good share of weakness, which full feeding will not always amend. We must therefore restore the tone of the digestive powers by the aid of medicine, that may be repeated according to circumstances, and the returning strength of the convalescent animal.

\section{Tonic Ball. No. 1.}

Jesuit's bark, 7 drachms.

Prepared kali, 2 drachms.

Mucilage sufficient to form the ball for one dose.

In ordinary cases, one of these per day for a week will be found to have done as much for the animal as could be desired. But should the coat still appear rough and staring, give the following 


\section{Tonic Ball. No. 2.}

Salt of steel,

Columbo root, and

Bark, of each 3 drachms.

With mucilage to form the ball.

Great precaution is necessary to prevent a relapse, which would render the patient's case more dangerous than at first; the animal being less capable of bearing up against a fresh attack, by reason of the reductions he has been subjected to. Soft or sodden corn, fine hay, clover, a few vetches, carrots, grass cut fresh from a sloping ground, may succeed each other in small quantities, until he may be returned to old corn and hay as usual. If the heat return at intervals, as usually happens towards nightfall, give him

\section{A Cooling Decoction.}

Linseed, 2 quarts.

Coarse sugar, 2 ounces.

Water boiling hot, 6 quarts poured upon the seed. Let it simmer three or four hours, and pour off the liquid for use when nearly cold. The linseed will bear another water, less in quantity; but some horses will take the seeds also, which may be permitted. Give the whole in the course of the day, at two or three intervals, and repeat the same decoction once or twice more. 


\section{TYPHUS, OR PUTRID FEVER,}

Is caused by long-continued debility, or slow fever, as much as by the injudicious use of medicines administered for the cure thereof. Of these, the most common error consists of cordial medicines, diapente, wines, \&c.; which, as they give a shortlived vigour to the animal, are supposed to have done some good, and are therefore persisted in, until the digestive and secreting parts of the system are spoiled.-See chap. 2, page 59, \&c. Typhus is also communicable towards its termination-to man as well as beast.

Symptoms, the same as those in slow fever, mark typhus fever, only the pulse is accelerated upon taking the medicines just alluded to; its irregularity is also greater, until, by continuance of the disease, it ceases to denote any particular state of the body long together. Hence, the supply of new blood carries with it similar effects; the vitals lose their tone, and the muscular part of the system wastes and becomes rotten on the bones; and if the same stimulating treatment has been kept up until the animal dies, its flesh will be found on dissection to have acquired an uncommonly bright purple colour, not only on the surface, but wherever incision is made. Putrescence, in a high degree, has already taken place ere that catastrophe seals the sufferer's fate!

I mention these minor circumstances to prove (so far as I can do so) the real existence of this 
main type of putrid fever. Another symptom of typhus goes to the same proof, namely, delirium, which follows a continuance of the stupidity discoverable in slow fever. A well-marked case is reported in the Annals of Sporting, for Nov. 1824, to which work I have since been some months attached; and, although I was precluded by absence from examining the subject, I have reason to rely on the report afterwards made to me by Mr. Ford, that its flesh was putrid in an extremely offensive degree, and wholly unfit even to be cast to the dogs.

From the very unaffected and detailed account of the narrator, it appears plain that unskilful persons might be led to apprehend such paroxysms denoted hydrophobia; but a short inquiry into the habits of the horse previous to its last delirium, would go a good way to relieve the anxiety usually instilled into a neighbourhood by such events. None can say, however, until the experiment be tried, whether animals fed on such meat might not acquire rabies thereby.

No remedy can be proposed for such a dreadful malady, better than the knacker's knife or axe.

The mad staggers, as the term is, which has never been satisfactorily accounted for, can be no other than this delirium of the typhus fever, brought on by pushing the animal in his work although labouring under slow fever. None but common or ordinary cart-horses are lost in the staggers; whilst none but a very ordinary owner 
would so force his cattle to the last extremity during illness. As the above is all I shall find it necessary to say of staggers, I must here remark on the singular impropriety of Mr. Richard Lawrence's considering this as an attack of apoplexy! Since one pang alone denotes the death so to be named.

Rheumatic fever is one of those disorders in the horse upon the existence of which doctors disagree; but doubtless the vicissitudes of heat and cold to which the horse is subjected, whereby the whole system is checked so as to occasion general fever, is equally likely to check the circulation in one or two limbs only. And the pain the animal would thus labour under in the performance of its duties would constitute one of the causes assigned higher up for simple fever. Little good, however, would ensue by my considering it separately; so I shall content myself with referring the reader to the head of simple rheumatism.

\section{Epidemic Fevers-Distemper.}

Cause.-When these appear, from time to time, they may fairly be ascribed to the season; for the kind of attack is not of a nature to become communicative, unless by continuance putridity follows: then, indeed, infection may begin, as it would also happen in any of the preceding species of fever. A rainy spring after a mild winter produces an epidemic catarrh, as well as sudden 
chill, among horses that are out at soil whilst shedding their coats, and the most delicate receive this influence earliest. We may as well consider, that whatever may give one horse a cold, or: affect his lungs, singly applied to him, would, if applied to many, in like manner affect the whole : this constitutes epidemy, or the distemper. Cloudy weather and cold easterly night winds, when the weather is warm or murky by day, is more likely to check the action of the lungs or of the whole system, than when a colder season has prepared the animals to withstand the influence thereof. An epidemic prevails sometimes in autumn; but, happen when it may, horses at grass acquire it less often than those which are kept in, upon hard food.

Symptoms.-As just intimated, a cold, that harbinger of so many other evils, is what marks the epidemic in every case ; in addition to this, the animal will labour under the other symptoms of fever before described, according to its actual state of body at the time of attack. Thus, if the horse be in full flesh and vigour, his veins quickly fill with the stream of life, inflammation of the blood will ensue, or rather, to speak more accurately, of the vessels which contain it; hence, simple fever, or fever of the whole system follows, as before described, pp. 169-170; but, be he poor, with little blood to receive inflammation, low fever is that particular affection which accompanies the original cold or catarrh.

Hence, I feel no hesitation in classing the epi- 
demic-at least all those which have happened in my time, with one or the other of those diseases, and recommend treating it accordingly. At its earliest stage, of course, as it assumes the shape. of a catarrh or cold, (which in the more malignant cases becomes "Inflammation of the lungs,") I should treat it as such; but if not called in until this attack had extended to the animal's whole system, and catarrh had subsided into general inflammation, no reason exists why we should consider it a different disorder, merely because the patients may be more numerous than ordinary! The reader had therefore best proceed on to the next head of information, for the details as to the sufferings and cure of a single animal, which I apprehend will instruct him how to treat the many; for, neither the name or the character of the disorder can be changed by this circumstance, however alarming its extent.

\section{INFLAMMATION OF THE LUNGS.}

Causes.-Like all others of its class of disorders, infiammation of the lungs is occasioned by a sudden check being given to the circulation, by cold when the animal is heated, either by exercise, food, or close stabling, as before described. How it happens that this organ of animal life is much more frequently deranged than any other, the reader who has well studied the second chapter, 
pp. 84-91, will be at no loss to account for; adhesion of the pleura, or of the lungs, to the ribs, \&c. as described at section 32 , being very common: the labour of action, not to call it pain, is greatly increased thereby, and a certain degree of fever is thus engendered and kept up. The animal is in this manner always predisposed to acquire cold or catarrh; and ultimately inflammation of the lungs comes on, if the cold be neglected. Excessive exposure to the rougher elements, added to the changes in our humid atmospheric temperature, accounts for the prevalence of affections of the lungs. Out of the same causes arise several minor evils, to be considered hereafter; as,

Simple cold, or catarrh.

Broken wind, of three kinds.

Roaring.

Chronic cough.

The symptoms of inflamed lungs rapidly follow each other: shivering, difficulty of breathing, loss of appetite and sluggishness, with drooping of the head, become visible in quick succession. In a few hours, if the animal be in good keep, longer, if out of condition-those symptoms increase, with unusually quick action of the flanks, accompanied by hot mouth and hectic cough. Its ears and legs become cold, and he cares not to lie down, or being down, he rises languidly, as if mourning his fate. Sometimes the progress of 
this monstrous disease is accelerated by its previous habits, if the animal's constitution be predisposed towards inflammation; but most frequently, nature steps in and affords relief, when"Who would have thought it!" In this respect, brutes have the advantage of mankind.

The cure is sometimes mainly effected by the effusion of water in the chest, which frequently takes place upon bleeding the patient; the practitioner has little more to do than place himself in the situation of the handmaid of nature, and all will go on well towards perfect restoration. How this effusion is performed, none can know. Suffice it for our purpose, that such is the case, as I have shown in the second chapter, where I undertook to investigate the animal functions separately, and imagine I cannot be misunderstood. See sections 19, 20, 21, in particular, at pages 58 to 64 . We may ascertain when this effusion has taken place, by an evident remission of the desponding symptoms just set down: the flanks cease to heave so much as hitherto, the animal looks up more cheerfully, he tries to eat a bit, the cough almost ceases, and the warmth of the ears returns, all in a partial degree; but the roughness of his coat, which always accompanies inflammation, does not so soon return to its original suppleness, but assumes the first symptoms of hide-bound. When those favourable symptoms appear, much assiduity in the minor helps 
to recovery should be kept up, though further bleeding will be evidently unnecessary.

I have presumed that the patient has been already blooded in this as in all other inflammatory attacks, and that to an amount commensurate to the virulence of the attack, even to the amount of five or six quarts, if the animal is of full habit. Of this proportionate degree, or quantity, let the reader more precisely inform himself by turning back to what is said on this head and the pulse, under general inflammation, or fever, at pages 164 and 167 . The operator will of course follow up the bleeding with the purgative ball prescribed at page 172 , in the case of general inflammatory disorders. Were I to repeat over again such general instructions, however diversified in language, I should add no new information, but might make a book as bulky as Lawrence's and as thick as White's. In every case of bleeding a laxative should follow, as before directed, and clysters of water-gruel be administered in aid of both, at intervals of three or four hours. Neglect not tolerably warm clothing; and by good hand rubbing, beginning [gently, for' 'tis sore] at the neck and chest, and so proceeding towards the hind quarters, endeavour to obtain external heat, if not perspiration. When these appear, it is a sign that effusion has taken place, in a greater or less degree, according to the quantity of perspiration. This may be 
PATIENTS: HEAT, HOW REDUCED.

assisted in some degree, after the laxative and clyster have well subsided, by administering a

\section{Srweating Ball.}

Take tartar emetic and asafœetida, of each one drachm.

Liquorice powder and syrup, enough to form the ball for one dose.

Repeat the same in twelve hours, unless much perspiration has supervened in the meantime, when there will be no necessity for repetition. Thin water-gruel will assist the expected perspiration; or, if the animal be a fleshy one, a bran mash may supply its place: either must be given blood-warm.

The heat of the lungs, which is the immediate cause of the disorder, is visibly reduced by every inspiration of fresh air the animal takes. Naturally, then, this air should be fit for its purpose, or pure; at least, not the confined air of an overfilled stable, replete with noxious effluvia and gaseous air ; nor, on the other hand, a current of air that issues by doors and windows to the right and to the left, particularly in cold weather, or even in warmer weather whilst the animal is yet sweating with the diaphoretics just now recommended. As in most other affairs of life, the best will be found the medium course; for the noxious stable air having irritated and so predisposed the lungs to receive the blighting influence of the cold air, it follows that either extreme of stimulating, 
or bracing overmuch, must do harm one way or the other. A full and free inquiry into the best means of employing this main auxiliary in the restoration of health in inflammatory disorders, would be well worth the labour of any veterinarian competent to the task; but as regards myself at present, such a course would ill suit my views in writing this too brief treatise. I shall, therefore, content myself with observing here, that since it is to this want of ventilation in stables, and crowding many horses together, that we owe all pulmonary complaints and most fevers, the subject is worthy consideration as a preventive as well as a remedy.

Formerly, the general practice was to clothe the animal almost to suffocation, and to close up every aperture by which air might enter the stable; the consequence of which mistaken notion was a severe attack of the lungs, that usually proved fatal wherever these addenda to stable management could be employed in supposed perfection. Not so the poor man's or the dealer's horses under inflammation of the lungs, or the more dreaded "epidemic distemper;" his stables being more or less pervious, and his horse clothing without the nap, it was no uncommon thing to find these had recovered, whilst the more pampered and more valuable animals fell victims to every species of inflammatory diseases. These results, were known to many, in various circles, about the time of the establishment of the Veterinary College; and the mutual communications 
that thence resulted, proved the impolicy of the old plan of adding heat to heat, and increasing the disposition to acquire disease, of the lungs in particular. A revolution which had recently taken place in the human practice regarding the treatment of inflammatory and febrile disorders, also contributed to open the eyes of our veterinary practitioners in this respect, and they adopted the direct contrary practice in its greatest extremity. Mr. Colman advised turning the horse into a loose box, leaving open the apertures, without clothing or paying any regard to the seasons. Nought, however, could be more absurd than to suppose that a disease which is produced by cold should have the continuance of cold prescribed for its cure!

My practice has been to afford the animal as much fresh air to breathe as could possibly be allowed consistently with keeping out a draught or current; taking care also that none whatever should be directed towards his body, nor any enter the stable from the windward in stormy or cold seasons. With these precautions, in a loose box and well covered up about the chest, but not tightly, he would ever be found turning round to that side where the most air was to be obtained, as if by instinct, knowing whence the readiest natural relief from his sufferings was to be found. In one case, of an aperture being made into an adjoining shed, the patient was frequently discovered inhaling the little air which was to be 
drawn thence, though the orifice was no other than a displaced knot of the wood partition.

In general, the disease bends before the remedies prescribed; the hand-rubbing must be continued, particularly of the legs, which in the worst period of the disease are uncommonly fine, but should it last him some time they swell, and in either case prove they are the barometer of the disorder, as well as the necessity of rubbing them. On the other hand, should the pulsation increase after bleeding, and no favourable symptoms appear (as indeed they cannot then be expected), this necessary operation must be repeated to the same amount as at first, or up to a state of tottering, as recommended before, at page 171 : this necessity will occur but seldom, and that always with patients in previously high condition. Therefore, no danger can be apprehended from this copious discharge; for, at the end of twelve hours, or less, which is the period at which I should again resort to the flaim, the blood would have returned to its former courses in every respect: the continuance of fever, up to the same original height of the pulse, shows that the particular animal then under treatment, possessed an uncommon quantity of blood, and therefore that an unusual quantity should be taken away in order to alleviate the heat that is destroying it, and will destroy it, if the heat be not subdued at this second bleeding; for, should this fail, I expect little good from further attempts, though it is desir- 
able to try what I always consider as the forlorn hope.

Should those remedies fail, suppuration takes place usually in six-and-thirty hours, and the animal is lost. Occasionally, however, it happens with low-priced animals, that the inflammation fixes itself and terminates with the destruction of one lobe only of the lungs, generally that on the right side, the other performing all the functions; but how perfectly, or for how long time, I had no means of ascertaining. At this point of his inquiries, the studious reader had better consult over again what $I$ thought it necessary to say upon the dissection of the lungs, in chap. 2, pages 84 to 92 ; but he will please to remember, I am not at present prepared to maintain, that the real cause of a destroyed lobe, which $I$ have just suggested, is more correct than that adventured by me at page 89 .

Bleeding, though highly beneficial at first, when the animal system is in full vigour, is extremely dangerous after the inflammation has continued some time. When (the fever continuing) weakness is indicated by swelling of the legs, or nature seeks to relieve itself by a running at the nose, then bleeding will be harmful; this latter was considered a most favourable indication of crisis in the epidemic fevers of my youth; but I sincerely hope that the groundless fears the rumour of such a plague engenders, never more will 
visit us with affright: the idea of infection, in such cases, is too ridiculous to admit of refutation.

Weakness follows, of course, every attack of so vital an organ as the lungs, and is a necessary consequence of the great evacuations of each sort his extreme danger has rendered indispensable. But cordial balls, or, indeed, stimulants of any sort, are very improper, and might occasion a partial relapse, if given before the animal is quite recovered. Good grooming, diet, and exercise, constitute the means of restoring his strength. Let him be well rubbed down, daily, and his nostrils sponged out clean and often, when the discharge takes place, which most commonly attends the cure; the same offensive matter must be cleaned away from the stall and manger, and he may be led forth daily whilst this business is going on. Hand rubbing the legs should continue, so as to promote warmth; and they may be subsequently wrapped up, especially if the weather be chilly, with hay-bands, \&c. Exercise may be gradually increased as the patient gains strength with appetite. At first, good stout oatmeal gruel, sweetened with coarse sugar or treacle, alternating this with wheat meal, in order to coax his appetite; then oats which have been steeped in boiling water may be given, and next put him to hay of fine odour, in small quantities at a time. If grass or green vetches can be procured, a little, and not too much, may be cut for the now con- 
valescent horse, in order to keep open his body; on the contrary, should he appear low spirited, a little malt occasionally will give him more vigour before leading him out to the field every day, or leaving him there in clothing, whilst the sun may be out, if it shine at all.

Blistering and rowelling are recommended by most veterinarians, as tending to divert inflammatory heat from the more vital part to the surface. The theory is good: in the practice of human medicine I believe blistering is universally adopted; and this is one reason why $I$ ever looked upon this means of cure with suspicion, even before I ascertained that the general heat or fever is always increased by the employment of either blister or rowel. Both are of the same nature; and the practitioner may learn how either operates on the system by ascertaining the state of the pulse previously to the application, and comparing it with the increased action of that barometer whilst the remedy is taking effect. Subsequently, however, it must be confessed, the agitation of the pulse will subside; and although I seldom find occasion for employing either blister or rowel, yet I am free to allow, that the manner in which inflammation of these organs sometimes terminates (namely in abscess or soft tumour under the skin), seems to invite an early adoption of artificial means to bring about the same ends. The hand-rubbing just recommended effects this to a certain extent; and if it has been neglected, or 
lazily performed, then will blistering become necessary to prevent suppuration within.

As this tumour usually makes its appearance and marks the crises of acute attacks, the practitioner may form an estimate of the probable beneficial effects of blistering in any case, by comparing and noting the earliest symptoms of any two cases, in one of which the crisis has been subsequently attended with such a superficial tumour and in the other not so. He will then employ blistering with more reliance on its efficacy than I have found necessary after the hand-rubbing.

When this remedy is adopted for inflammation of the lungs, employ blistering ointment composed of cantharides and sweet oil, or hog's lard, or all three-or the following

\section{Blistering Ointment.}

Cantharides, powdered, 5 drachms.

Hog's lard, 4 ounces.

Oil of turpentine, 1 ounce.

Mix, for one extensive application over each side of the chest; which is a neater and more expeditious method of attaining the desired end than rowelling. When the latter method is adopted, let the tow used for the rowel be dipped in a mixture of sweet oil and oil of turpentine; and the skin of the breast or belly,-if more than one such seton is employed,-be separated only just sufficient to admit the rowel, in order to increase the irritation; but if the surrounding parts swell to 
an inordinate size, change the tow for some which has been sodden in digestive ointment.

Pleurisy, or inflammation of the pleura, a membrane dividing the two lobes of the lungs (see chap. ii. p. 85) -has been described by Lawrence as a separate disease; but, as the treatment is the same as the preceding, I can see no propriety in making the distinction he does, especially as we cannot know the difference until after death discloses all imperfections.

\section{A COLD OR CATARRH.}

Causes.-If I sought much nicety of arrangement, the disorder termed "a cold," would have preceded the similar but more malignant attack I have described under "Inflammation of the Lungs." Both are occasioned by cold applied to the animal's organ of respiration at a time that he is most susceptible of its influence, differing only in the part which may suffer. Thus, when the canal through which the air passes receives the check (before described), which is the immediate cause of inflammation, every one agrees in its being merely "a cold," though in most cases no attack is more replete with danger, if neglected.

But the origin and progress of such a check upon the functions of the membrane that lines this canal, having been already fully described in the second chapter, pages 88,89 , the studious 
reader must turn back to that part, if he would trace causes to their effects, and does not presently recollect all that is there said on this topic.

One prolific source of the disorder termed $a$ cold, is found in the shedding of the coat in spring and in autumn, a process of nature always attended with a certain degree of debility or general weakness. Hence it is that the animal sweats profusely upon the least exertion; and being in this state suffered to stand (harnessed perhaps) in the open air to cool, the sweating is too suddenly stopped, and he gets $a$ cold at least. That the lungs should suffer the soonest of any other organ is not at all astonishing: the very great exertions made by the lungs in the business of progression, is much increased by adhesions and other obstructions to the action of its several parts; and this, added to their exposure externally, and the constant inhalation of fresh, cold, damp air-altogether, the prevalence of pulmonary affections in every varied stage ought no longer to be matter of surprise to any person, however casually he may look at the matter.

The horse is subject to cold or catarrh at every season of the year, and some animals retain chronic cough all the year round, other some during their natural lives. But the cold which is contracted in the spring differs materially from that of the autumn. The former attacks the animal when he is full of hard meat and gross feeding"full of humours," according to a homely but 
intelligent phrase, and a malignant sore throat or an inflammation of the lungs is the ultimate consequence, however slight the cold may have been at first. Sometimes access of all those symptoms of diseased lungs, which I have already or may hereafter take occasion to describe, will be found in the same animal, and he usually bends before the complication of evils and dies, unless speedily relieved by bleeding, \&c. From its prevalence at some seasons, we then agree to call it "epidemic," and to recommend a treatment corresponding with the prevailing symptoms, if these be mild, as a simple cold; which form the epidemic fever or distemper always assumes in its earliest stages. On the other hand, the cold or catarrh which the moulting animal acquires in autumn, finds his system reduced by the heat and labour of summer; his blood, in quality or quantity, is scarcely capable of being excited to inflammation, and the first attacks are more easily subdued. Neglect, however, increases the evil at all times, especially with the more valuable well-conditioned animals, some of which are so tenderly managed, that they scarcely can stand the opening of a door or shutter after dark, without catching cold. Neither autumn nor winter is the season for remedying this defect in stable management, -if ever it can be got over at all.

Symptoms.-According to the precise part attacked, these vary not only as to appearances, but as to virulence or malignity, always increasing 
as the complaint descends lower and lower down towards the seat of vitality; the danger being also greatly augmented when the animal is pre-disposed to acquire catarrh in its worst.forms by some previons misfortune-as adhesion, \&c. A simple culd consists in slight inflammation of the membrane which lines the nose, windpipe, \&c. the functions of which membrane in health are described in the 34th section, chap. ii. together with the manner in which the disease is engendered and conducted downwards. As we find in all other inflammatory disorders, variations in the symptoms occur, according to the previous constitution or evils of the individual, and its actual condition-much more than is attributable to an adverse season, or the immediate cause of disease. For example, if two equal animals be exposed to a chilly night air, that horse which had performed a journey previously to turning out, would catch a cold for certain,- the other most probably would escape; but, if both had performed the same journey, let us suppose, and one of them laboured under the constitutional defect of "adhesion of the pleura," (see page 85 ,) he would acquire the more malignant cold, known as "inflammation of the lungs," -his less unhappy mate a simple cold. What horrid symptoms denote the former, I have attempted to describe; the simple cold, at its first appearance, is too well known to require minute description.

If the cold extend no farther than a check upon 
the mucous secretion of the membrane that lines the nose, a purulent discharge is first observed in the morning, its eyes become dull and a little bleared; and if the discharge does not run off the cold, in twenty-four hours a short cough denotes that the inflammation is creeping onwards, and has reached the epiglottis - or chamber of the lungs, described at section 33. The attack upon this point of conjunction between the throat and mouth, will be greatly accelerated by the injury most horses sustain which have been subjected to the brutal operation of being "coughed" by the dealers; - an injury that thus produces latent effects, though the pain were originally little, and that little long ago departed.

We hear this kind of first attack termed "a cold in the head," the second symptom is "a cough," and feel no disposition to quarrel with either term.

In proportion that the attack may be more severe, the symptoms increase, as does the danger. Passing the hand down over the windpipe, at the epiglottis, the animal will shrink if it be sore within, and he will soon evince difficulty of swallowing, and refuse his food: inflammation has begun. When these are not preceded by a discharge from the nose, this symptom does not appear until the inflammation is lowered by bleeding and other remedies: the discharge is then an indication that the infammation, or heat, has subsided, and no longer demands the adjacent secretions. See page 62 , for a more minute description how this demand takes place. 
With those symptoms of sore throat others become apparent, and the whole assume a malign tendency proportioned to the severity of the attack and previous state of the suffering animal. As happens in all other inflammatory complaints, the pulse tells of the existence of fever, in its degree; accompanied by languid eyes, breathing quick and laboriously, and general heat of the skin without perspiration. In some cases the sore throat is substituted, in some measure, by enlargement of the glands underneath the jowl, which are also attended by soreness more or less; and as this species of attack is occasioned by the humidity of a cold spring or wet autumn acting upon moulting horses, great numbers feel its influence at once, and gives reason for veterinary writers to consider this general distemper as "the influenza," and an "epidemic." Enough has already been said under the latter head of information, therefore let us proceed to treat of the thing as it regards the individual patient.

Remedy.-When the glands swell, as just mentioned, and there is no reason to doubt, according to the corresponding symptoms, that it is the effect of a cold-which may further be ascertained by their heat and tension, let some discutient application be used-as camphorated spirits of wine: but if the inflammation be to a great degree, bran poultice may be applied to advantage. If those enlarged glands already contain matter, the tendency to irritation will thus be reduced; if merely sordid tumours, either application will effect re- 
lief, by reducing the size and tenderness of the part, so as the animal may take his medicines with less difficulty. Steaming the head for an hour, or applying hot flannels that have been steeped in boiling water, will be found serviceable, taking care to dry-rub the coat immediately after, which also assists to reduce the swelling. If this symptom does not give way before those applications, and the throat is ascertained to be sore, blistering may be resorted to, taking care to extend it over the whole of the parts affected. See page 203.

As in all other inflammatory diseases, bleeding to an amount proportioned to the violence of the attack, with purgatives and clysters, should accompany the foregoing external applications; and these, with plenty of bran mashes, sodden corn, and the fever powders prescribed at page 176 , will reduce the symptoms. Similarly to those also will be the precariousness of his complete recovery, and so should be the care that the relapse, to which he is for a time daily liable, should not reach to a great height. I need not repeat the general precautions which are set down at page 187.

Unwilling to leave the reader in a dilemma as to the mode of applying the bran poultice just recommended, and upon the efficacy whereof I mainly rely, I have taken the pains to sketch a bandage proper for that purpose, with its fastenings, the ingenious contrivance of some Frenchman, whose name I believe to have been BourGELAT。 


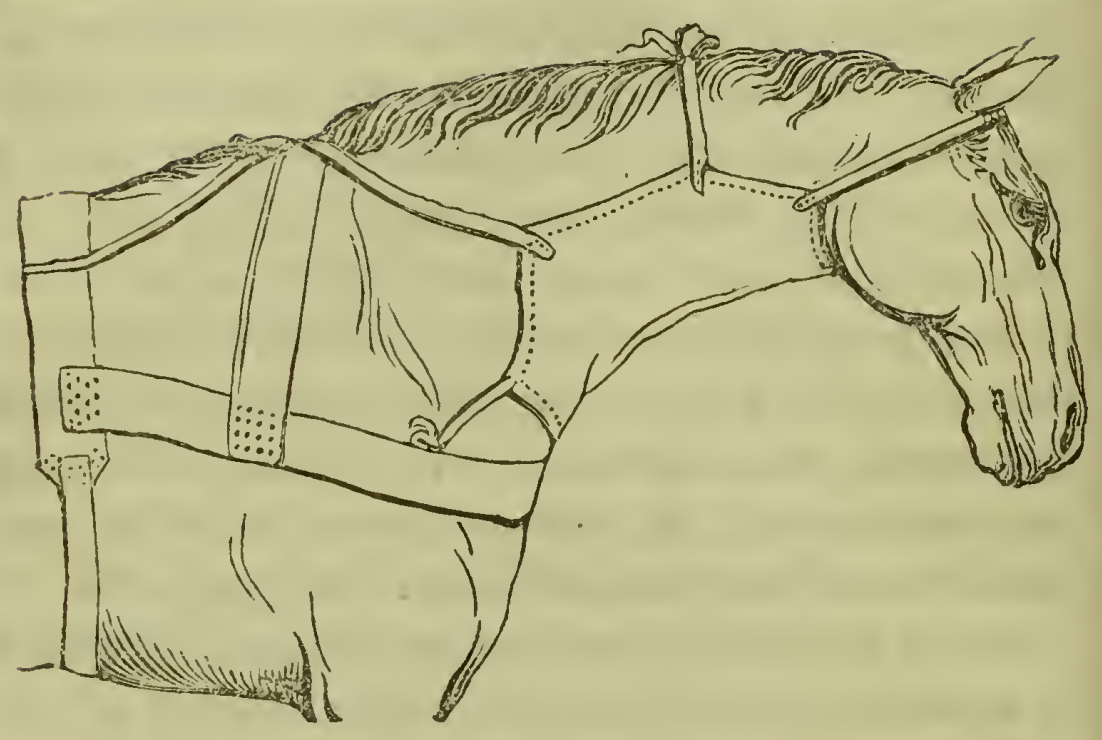

It will be seen, that unless the remedy proposed is practically applicable, the preparation thereof would be wholly unprofitable; therefore, when the poultice, the steaming, or the blistering, be found necessary, we should endeavour to secure it in the best possible manner; and as most persons are but poor horse milliners, I have undertaken in this instance, as well as in cases of Strangles, Pollevil, and Vives, to exhibit the best means of retaining the remedies in their proper places.

The cloth to be employed should be of stout but supple linen, as Russia duck, or hempen sailcloth; or in failure hereof, a fresh sheep-skin, or a piece of Shamoy leather might be substituted. Some recommend steeping the cloth in a solution of gummy substances, to render it water-. tight; but such contrivances only add to its 
unconquerable stiffness, and I should prefer oiled silk, such as is used for umbrellas, if readily procurable, and not too dear for the pockets of those more immediately concerned.

When spread abroad, the cloth will be of an irregular octagon shape, at each corner whereof is to be strongly sewed on a piece of broad tape for the purpose of fastening to the girth, or round the neck, and to a breasting of broad reeb, which is supported by another piece, that passes over the withers, and which two should be previously fastened together by stitching the cross-piece ends upon the breasting. The two extremes of the bandage will be the fillet across the forehead and the fastening at the girth; therefore measure should be previously taken of the whole length proper for the individual patient, lest the tie, which would otherwise be necessary at the ears, might discommode the animal, and occasion-skittishness; or on the other hand, the application would not be kept in its place properly. A single glance, however, at the cut will instruct a tolerably expert workman, or work-woman, how to manufacture such a bandage as would answer every purpose.

\section{THE COUGH}

Which accompanies this disorder will frequently remain after the other symptoms have abated; in some cases a cough is the only symptom of catarrhal inflammation that the animal suffers 
under, and in both we should apply ourselves to reduce the inflammation of the wind-pipe, \&c. which occasions the cough; for if not cured at once, it baffles all our efforts for a long while, and ultimately becomes what is denominated (from the length of time it has lasted) a cHronic cougr. But no absolute necessity exists for considering these as separate or distinct diseases, the one being but a prolongation or fastening of the other on the system, as described at page 226 below : therefore should our attention to the first attack be unremitted, and the remedies applied in turn to each variation of the symptoms. If these are accompanied by the swellings and soreness of the throat and glands, just spoken of, the cough will generally cease, when these symptoms are removed; but if not, the cough must be considered as a simple disease, and be treated accordingly. By the way, seeing that after all our care and anxious examination, we can but imperfectly distinguish between some cases of ill-cured catarrh, or the chronic cough, and the incipient cough, or a fresh cold, the practitioner would do well, in cases of doubt, when he finds one of those remedies fail to afford the expected relief, to try another, and another, for example.

When the cough continues, and there is reason to apprehend, from the frequent and violent efforts of the animal to expel the mucous secretion, that this is thick or viscid, and does not come away, though the animal evidently sneezes for that pur- 
pose,-the lungs must be relieved by softening the agglutination, otherwise termed "cutting the phlegm." Venesection always effects this end; but, when blood-letting is not rendered otherwise necessary, the drenches Nos. 1 and 2 will afford relief. As the cough always becomes more and more troublesome as the discharge lessens of itself, or ceases altogether, we may conclude some lurking virus that has fixed upon the lungs is the immediate cause of the cough. In order to enable the lungs to run off this cause by a more copious discharge, give the

\section{Expectorant Ball.-No. 1.}

Sulphur, $\frac{1}{2}$ an ounce.

Asafœetida, 1 ounce.

Liquorice powder, 1 ounce.

Venice turpentine, 1 ounce.

Mix for four doses, and give one on each of four succeeding nights. See his exercise be moderate, and allow him the cooling regimen before referred to (page 181), as proper for convalescent horses after inflammatory attacks.

\section{Expectorant Ball.-No. 2.}

Powdered squills, 2 drachms.

Gum ammoniacum, 4 drachms.

Powdered ipecacuanha, 4 drachms.

Opium, 4 drachms.

Ginger and allspice, of each 1 ounce.

Balsam of sulphur, 4 ounces.

Mix, for six balls, with Castile soap, 2 ounces, 
beaten up with mucilage, treacle, or syrup : to be given once or twice a day.

If this regimen cannot be followed by reason of want of attendants, his bowels at least should be kept in a proper open state by mild laxatives; or, if costiveness prevailed when the cough first came on, simply opening the bowels will then procure ease, if it do not effect a cure. This may be attained by giving, for three or four days,

\section{The laxative Ball.}

Aloes, $1 \frac{1}{2}$ drachms.

Ipecacuanha, $1 \frac{1}{2} \mathrm{drachms.}$

Mix with liquorice powder and mucilage for one dose.

These medicines, and every modification of them, which the experienced chemist can suggest, it is desirable should be tried in succession, as the seat of the disorder is so very various and uncertain, that the partial good which one may effect, will frequently be aided by another. To this end the following ball and drenches have been prescribed and used with success-

\section{Diuretic Ball.}

Yellow resin, 2 ounces.

Turpentine, 4 ounces.

Soap, 3 ounces.

Salad oil, 1 ounce.

Oil of aniseed, $\frac{1}{2}$ an ounce.

Powdered ginger, 2 ounces.

Rub the two last together in a mortar, with a 
little linseed powder. Melt the first three articles over a slow fire, and then mix in the powders. Divide the mass into eight balls, and give one a day until the water is affected.

Drench.-No. 1.

Vinegar, 8 ounces.

Squills, 2 ounces.

Treacle, 6 ounces.

Bruise the squills and pour on the vinegar boiling hot; simmer these near the fire two or three hours, then strain off and add the treacle. Divide into three or four parts, and give a portion two or three times in the course of the day.

\section{Drench.-No. 2.}

Bruised garlic, 4 ounces.

Vinegar, 12 ounces.

Pour on the vinegar boiling hot; let it simmer four or five hours, strain off and add six ounces of honey. Divide into three parts or four, and give in the course of the day at intervals.

But no ultimate cure can be effected unless the diet and regimen is properly followed up; nor, if the animal be pushed in his work whilst the disorder is virulent; and, after all our care, if the cough does not abate, but becomes worse by reason of a nero cold, it fixes upon the lungs, and the animal drags out a miserable existence. This has been usually treated of as consumption, by reason of its resemblance to the same disorder in 
human medicine, from the wasting away, or consumption of the animal system, which accompanies a diseased state of the pulmonary arteries. Of the importance of this part of the system to animal life, to existence and health, the attentive reader cannot fail to be sufficiently aware who has well perused that part of the second chapter of this little manual, in which the functions of the organs of respiration are described with requisite carepages 84 to 98 . The hopelessness of bringing about a cure, after the ruin has proceeded so far as we have just contemplated, must likewise be most apparent to him; I will not, therefore, pursue farther in detail the last wastings of this vitally essential organ of the animal system, but proceed shortly to notice some other effects of an ill-cured cold or protracted cough.

\section{BROKEN WIND}

Is already so minutely described, as to its causes and symptoms, in the second chapter, that I apprehend repetition in this place would prove worse than useless. The reader will therefore turn to page 94 , and the recapitulation of my treatise on the organs of respiration which immediately follows, at page 96. Generally speaking, broken wind is brought on by inflammation of the organs of respiration, and acquires a different name, though requiring but little variety of treatment, according 
to the part which may be the more immediate seat of disease; for it must be clear, that although this may lie in the uppermost part or larynx, in the lowermost part or midriff, or more centrallythe communicable nature of inflammation is such, that the whole must partake in some degree of each and every partial derangement. And this degree will be proportioned to the excitability of the individual's organs of respiration that may be the subject of attack: if the animal contract cold or cough in the vigour of age and health, he will experience its effects in the most frightful shapes; it proceeds to encroach on and obstruct the right functions of the lungs with rapid strides, and if the symptoms do not abate, he dies. But, being partially removed, it becomes a chronic disorder* to the end of his days; and, agreeably to the part which may experience the attack, has it been the practice to denominate chronic cough either roaring-broken wind-thick in the wind-or asthma. Hereupon, however, the doctors disagree.

How this difference arises may be worth a moment's investigation here, although so large a portion of the second chapter has been already devoted to the subject, and the reader must absolutely turn back to it. At page 95, the thickening

* Chronic disorders are those which, having lasted a long time, become almost second nature, and plague the organs of respiration more than any other viscus : thus, a tickling cough may stick by an animal for years, but it becomes worse upon any great exertion, or on catching fresh cold. 
of the midriff, in consequence of inflammation attacking the adjacent riscera, was minutely described: this thickening of the membrane also extends to every other part of the lungs, windpipe, \&c. whenever cold or inflammation prevails; and in the event of its continuance, the thickening of the membrane remains long after the virulence of the disorder may be subdued. If this state of the organs of respiration extend over them generally, the patient may very justly be said to be "broken winded;" when this extends to the thickening of the pleura only, he would then be thick rwinded, or short in the rwind, as he would also in case of adhesions of the midriff, as described at page 95, already referred to. Neither affection, however, can fairly be set down for brokien wind; though both those membranes being affected might properly enough be considered "a broken manner of drawing in and expelling the wind," for the inspirations and expirations are in this case extremely irregular, broken, or variable; whereas, when the air-cells are really broken, or burst into each other through great exertion, then the air escapes with difficulty, and the expirations are now slower than the inspirations (as before said), and both together constitute irregular respiration, or true broken roind.

But of controversies there is no end. J. White and $R$. Lawrence were for some years at issue on these points; White having taken up Larerence rather sharply, and somewhat unjustly, if he meant 
to impute error to the latter, as regards the symptom of respiration just spoken of, for each writer was right in his separate position: as they disagree as to what constitutes broken wind, so they could not of course agree as to the symptoms. See pages 159, 160, of White's first volume. This author also disorders his own positions at the same place, in two other instances, which I shorld not have noticed, but for his tart rebuke of R. Lawrence for attributing the term broken wind ot $r$ the thickening of the membranes. In this view of the case, it will be seen, I certainly cannot agree with this very clear-headed veterinarian; but I do not, therefore, harshly refute a gentleman and scholar for not agreeing with me upon a simple term of science: it was this unamiable attachment to trifles that so long impeded the progress of chemical knoroledge, until the plainspeaking Davy, Nicholson, Park, and Paris, came into vogue, and drove Lavoisier from his prostrate coterie,-Dickson was put to silence, and Fourcroy's reveries were laid in the dust of oblivion.

White says, "The lungs of broken-winded horses that I have examined have generally been unusually large, with numerous air-bladders on the surface." P. 160. Yet, in the next page, he opens a broken-winded subject, and says, "The lungs were lighter (meaning less) than usual, and without the air-bladders, contrary to the state Mr. Lawrence describes." What Larerence had said was this: "The most common appearance of 
the lungs in broken-reinded horses is a general thickening of their substance, by which their elasticity is in a great measure destroyed, and their weight (i.e. size) specifically increased. On this account air is received into the lungs with difficulty, but its expulsion is not so difficult. Thus, in broken-winded horses, inspiration is very slow, expiration sudden and rapid, as may be seen by the flanks returning with a jerk." (P.128, octavo edition.) And he is correct as to tlese two motions accompanying the thickened menbrane or substance of the lungs; only I should have termed the disorder thick roind, and not broken wind, when all would have coincided with White's statement, barring his own self-contradiction as to the size of the lungs, which Lawrence had mistaken for reight, and which had met with the counter assertion of being "specifically lighter." On this point of their dispute, however, neither the one nor the other could possibly know aught with requisite certainty; and I, for my part, am inclined to believe, that the lungs of highbred horses are specifically lighter than those of the cart breed, saving that the whole organs of lespiration are much less muscular in the first kind than in those of the latter, the skirt or border of the midriff in particular. On the other hand, the hearts of blood horses invariably run of a larger size than those of the common English horse. Vide page 101. One cause of broken wind, or rather that mainly predisposes the animal 
to contract this disorder, is voracious feeding, which distends the stomach inordinately, and for a while gives to the animal a short-lived vigour and healthy appearance. This induces its proprietor to put him upon his mettle, and try the extent of his powers at progression; and as he will best perform those feats upon a plentiful feed, the action of the midriff and lungs thereby becomes laboured, and the proper expansion of the lungs is impeded. Heat and tension are the immediate consequence, and broken wind of one or the other species is the remote consequence. Horses that eat their litter, and what other hard substances they can come near, are similarly predisposed to broken wind; namely, by the great distension of the stomach, and inability of inspiring a sufficient quantity of air to fill the lungs, whence the inert cells, or the portion not distended, fill up, contract, and become useless, or, upon sudden action and over distension, they burst at once.

Cure there is none for broken wind, and therefore all that can be done by way of alleviating its symptoms must be effected by management, or, as it is more generally termed, by

Regimen. Of course, the groom would avoid exposing the animal to fresh cold, and not push him too hard on a full stomach; nor indeed, give away a chance of increasing the malady by the same means as I have just said originally brought it on. He will, on the contrary, follow an opposite course of treatment, and as much as possible 
regulate his feeding and exercise upon moderate principles, for the stomach and bowels are always affected by broken wind. Hence it is, that flatulency accompanies broken wind of every kind, so that the animal, in his endeavours to cough, usually breaks wind after an effort or two. Much medicine is not requisite, and, in slight cases, far from desirable; tonics, bracing air, and regular hard meat feeding, broken or sodden, and given in small quantities, will do more for the horse than physic of any sort. For the first, Peruvian bark, or cascarilla in small doses, may be given occasionally, adapting the quantity to the bulk of the animal.

\section{Tonic Ball.}

Cascarilla,

Gentian root,

$\{1$ to 2 drachms of each,

Oil of Carraways, 10 drops; with

Mucilage enough to form the ball. If irritation of the bowels is indicated by a certain protrusion of the anus, add of opium 10 to 12 grains.

When the cough is particularly troublesome, or the animal seems to labour much in respiration, give the following

\section{Ball.}

Dried squills, powdered, $1 \mathrm{drachm}$,

Gum ammoniacum, 3 drachms,

Opium, 10 drachms;

With mucilage sufficient to form the ball.

If there is reason to apprehend the horse swällows his corn without grinding it, as commonly happens, bruised or sodden oats should be given, and 
the bowels discharged by purgatives, when alteratives may not be deemed equal to the urgency of the case. Those prescribed at pages 229, 230, are applicable in this case also; inasmuch as the two disorders bear very near resemblance to each other in this respect. Give green food, succulent roots, and bran-mashes, as there recommended. Let the water be soft, not too cold, and given in small quantities at a time, and frequently.

As broken wind produces disordered bowels, and is reproduced by it, the connexion or sympathy between the two, thus plainly demonstrated, should be employed in the alleviation of the former in all its stages, when it has been of long standing. The means of attaining this object has been shown; and when the value of the animal under treatment is equal to the care and expense, it frequently recovers so much of his former powers of free respiration, that his cure will seem for a short time fully effected. These appearances, however, are completely illusive; upon the least extra work he relapses into his former difficulties of continuing it, and the cough, the roaring, wheezing or labouring of the flanks and chest, return as bad as ever. If the work be very hard, as always happens when the horse has been sold deceptiously, and the new master would try his utmost powers, the relapse is then worse than before; he hereupon becomes a confirmed roarer, by the wind and lymph being driven inside the membrane that lines the wind-pipe, and causes 
titillation of the very fine blood-vessels that traverse it. Hence the number of lawsuits that are instituted to recover the valuable consideration paid for broken-winded horses that are returned upon the hands of the sellers as roarers, that never were known to either groom or stable-boy for roarers, before the day of action or trial. Hence, too, let us charitably suppose, the contradictory evidence often given, and the flat, downright crossswearing that usually takes place on such occasions. For the horse having been partially made $u p$ for the purpose of sale, i. e. nursed, patched up, and to all appearance "right in all his parts," the fact of his going in pain comes out by way of his skin at first, and the new purchaser being generally desirous of trying all he can do, the ruin is effected, by pushing him too much, of driving the wind inside the membrane, as before described.

Hercditary Roarers. Early in the present century, a question arose among breeders, whether the gift or the curse of roaring descended from parents to their progeny. The decision was looked for with unusual anxiety among the breeders of farm-horses in Norfolk and Suffolk, where a famous well-built horse in every other respect was much sought after, even subsequently to his being denounced a roarer prepense. Would his stock take after him? was a problem very desirable to be set at rest, when Mr. Wilson, of Bildestone, late Sir T. C. Bunbury's, propounded the 
question to Mr. Cline, an eminent surgeon and anatomist in London. In reply, Mr. Cline said, "The disorder in a horse which constituted a roarer, was caused by a membranous projection in a part of the wind-pipe, and was a consequence of that part having been inflamed from a cold *, and injudiciously treated. A roarer was not therefore a diseased horse, for his lungs and every other part might be perfectly sound; but when a horse was in strong action, his breathing became proportionably quickened, and the air, in passing rapidly through the wind-pipe, was in some degree interrupted in its course, and thus the roaring noise was produced. The existence of this in a stallion could not be of any consequence. It could not be propagated any more than a broken bone, or any other accident.$+ "$

Unfortunately, however, for this opinion, and not exactly in accordance with my own, several of that horse's get became roarers, but we are left to guess whether hereditarily or acquired. An account of the horse in question appeared in the Annals of Sporting for 1823; bat the colouring given by an evident partisan of the stallion-master induces one to lament the absence of that candour, from which alone useful truths

* Not always so, Mr. Cline.

+ Our human anatomist is very learly right as to an accident. not baing descendable; but seeing that roaring did descend to the first generation, we must infer that this was " an accident of birth," and not a contracted one, which might possibly go no farther. 
are to be drawn; for, we are deterred from indulging in pathological investigation where the grounds of inquiry are so impalpably sandy as were those adduced upon the occasion.

\section{CHRONIC COUGH}

Is already defined to be the remains of an illcured cold, which may or may not have been a cough originally. It bears close analogy to simple broken roind that is seated in the wind-pipe or its branches, of which it may be considered a continuation, or the natural consequence of neglect, with more inveteracy. How this effect would so accrue was described at page 216 ; and the analogy is still further corroborated by the fact, that the treatment for cough of long continuance is precisely that which is found serviceable for broken wind, the situation of the two disorders making the only difference in either respect. Again, the symptoms of both may, by long and careful treatment, be so reduced as to seem cured, for a longer or shorter period, and both will return in the shape of roaring, upon the animal being put to sudden hard work, as mentioned in the last pages. The corresponding symptoms of both are also so nearly alike, that I merely comply with custom while I recapitulate these for the use of readers who might not choose to consider that horse brokenwinded, which to all appearance is only affected 
with "an old cold in the wind-pipe." But, let the first term appear to an owner ever so formidable in sound, the latter is no less dangerous in effect, and both are alike liable to terminate in roaring.

The symptoms which indicate chronic cough are nevertheless so slight, that it is too often considered as but a small remains of the more alarming catarrh, which its owner vainly imagines will go off in time, as the other disagreeable symptoms have done. In this hope he is invariably disappointed, if the means of reducing it be deferred. After the more violent symptoms of catarrh have subsided, and the cure may reasonably be considered as complete, the horse returns to his usual feeding, and, as in the former case, eats voraciously; he is denied water oftener than twice a day, perhaps not so much; but, when at length he does drink, he gulps it up as if famished. This is commonly the cause, and the first indication of the cough which follows immediately after, but is often mistakenly attributed to his improving too fast after his long illness, and it is considered only fair that "he should be allowed to recover himself completely." Precaution is thus lulled in fancied security, and unless prompt relief be afforded before the damp season of autumn returns, the symptom increases to obstinate confirmation; until time renders cure hopeless, alleviation or abatement of the coughing being all that lies within the power of medicine or stable manage- 
ment to effect for it - the aid of the former being then of little avail. Very few small proprietors of horses use timely precautions in this respect, and the disorder goes on: large owners having more experience, adopt early measures, and if pursued with proper vigour, these usually prevail in lowering the symptoms.

An occasional cough is also brought on by high feeding, which, as it arises from the rapid production of fresh blood, is termed PLETHORIC covgir, by way of distinction. Of this symptom it would be needless to tell the better informed, perhaps, at an interval of six days, that we have but to take away the cause, and the effect ceases of course. This, however, does not always follow; for the cough sometimes remains after the giross feeding has been reduced in quantity and quality. In this case, it must be considered as chronic cough, and treated as such, by emptying the bowels, \&c. as above directed.

Remedy. As in the case of broken wind of every other kind, the horse eats every substance he can come near, chronic cough being sometimes produced by over feeding, as well as always producing that symptom. Therefore, when a horse has cough, occasionally, for two or three days, his appetite being good, we had best conclude he is too full, and must be emptied by an alterative or purgative, according to the emergency of the case : if he be of gross habit, or has failed in the proper evacuations; if his heels swell of a morn- 
ing, or his coat stare like hide-bound, the cough will vanish before the following

\section{Purgative Ball.}

Barbadoes aloes, 8 drachms,

Castile soap, 2 drachms,

Ginger, 1 drachm ;

With mucilage sufficient to form the ball.

Failing to stale properly, the patient's heels will swell, in addition to the cough, and both may be got rid of by a diuretic ball or two at farthest. If the evacuation by the skin be at fault, through cold or otherwise, accompanied by cough, the perspiration will be restored, and cough depart, by the exhibition of Emetic Tartar, one or two grains, every day twice in powder, until its effects are perceptible on the skin, and the cough then diminishes. This, however, is a very slow remedy, though sure, and is sometimes given in much larger quantities. The preparation is very simple when given in the form of a ball, being made up of liquorice powder and mucilage only, of a sufficient consistence to retain that form. If much heat of body is perceptible, though the pulse may not inclicate inflammatory disorder, add to the foregoing ball, nitre, 4 or 5 drachms.

But, whatever course is pursued, if symptoms of a bad habit of body are discoverable, it will be advisable to administer the foregoing purgative ball once or twice previous to adopting any other means of cure. If those symptoms of a bad habit of body do not appear, then the purgative should 
be of a milder nature, and given at the same interval.

\section{Mild Purgative.}

Aloes, 4 or 5 drachms,

Castile soap, 3 drachms,

Calomel, 1 drachm,

Ginger, 2 drachms,

Oil of carraways, 10 drops;

Mucilage enough to form the ball for one dose.

Some horses are more delicate than others, and being then irritable about the throat and chest, are liable to contract a periodical cough, which becomes chronic without due care. Such animals should be exposed as little as possible to any violent weather, or sudden change of the temperature: these are the kind of animals that benefit greatly, or suffer the most, by a summer run at grass, according to the heat, the dampness, or dryness of the season, and the precautions used previously to, and at the turning out. Neither should such tender animals, under circumstances of chronic cough, which generally affects their coats also, about the chest in particular, be treated with a purgative, even of the mildest form, but with alteratives instead.

\section{Alterative Balls.}
Aloes,
Hard soap,
\} 12 drachms each,
Emetic tartar, $\frac{1}{2}$ drachm,
Ginger, $\frac{1}{2}$ oz.
Oil of caraways, 1 drachm; 
With mucilage enough to form the balls into six doses. Give one every morning until a loose stool is produced, which may happen on the third or fourth morning, or longer, as the animal may be more or less relaxed.

Even with this moderate employment of laxative medicine, the kind of animal for which it is most desirable will be very unfit to turn out to grass of a sudden; as, on account of its delicacy, it will in that case be more likely to acquire a small hectic cough, which no one attends to, because of its triviality, until time renders it chronic, with all its attendant consequences. Roaring, broken wind, are among these evils, and have already received as much attention here as they separately require.

Frequently it happens that a horse has a constitutional cough, or one which comes on only upon high feeding; or a disposition to plethora will produce the same kind of cough, and in either case, it seems but an effort of nature to relieve itself. In this case, the rapid repletion of blood drives it into the smaller vessels that line the pipe, \&c. and there causes the titillation which after two or three efforts ends in cough, and so on repeatedly. None but those which are in some slight degree or other already afflicted with chronic cough are ever so attacked, I apprehend; indeed I have frequently remarked how excellent a test of "bad in the wind" was good feed, or a large feed, with work upon it. In this case, the administering of nitre and resin will thin the blood, and give immediate relief. 


\section{Drench.}

Yellow resin, $\}$ of each half an ounce.

Oil of aniseed, 20 drops.

The oil should be first well mixed with the resin, and the whole given in a quart of water gruel. Recurrence of the same affection may be prevented in some measure by giving the same in another form, which is in general reckoned more convenient-namely, as a cough powder, substituting aniseeds, I ounce, for the oil, and pounding the whole together: mix with the corn.

\section{INFLAMMATION OF THE STOMACH AND INTESTINES.}

Whenever one of those organs is affected; with inflammation particularly, the other soon feels the effects of the attack. This arises from the proximity of the two, or the continuity of the digestive faculty, which is mostly carried on in the intestines, as the reader of tolerable recollection well knows was so described in Book I. page 121, \&c. Corrosive poisons, indeed, carry on their work of destruction upon the internal or villous coat of the stomach until the ruin is complete; but, although horrid inflammation accompanies its ravages, I would not class such a species of accident under any other head than "Poison:" to call it by its symplom would be delusive. Neither is the inflammation caused by worms, proper to be taken 
into consideration here, though in this case both organs are affected at the same time; but the bott question involves other considerations, besides the best means of destroying them, of preventing the access of this irritating insect, or of alleviating the effects of its bite and adhesion to the villous coat, alike of stomach and intestine.

With those exceptions, there is no greater difference in the causes, symptoms, or means of cure of inflammation in the stomach and intestines, than exists between those of the great and the small gut. Inflammatory pain in the smaller parts of the alimentary canal will ever be more acute than those which attack the larger ones; thus, when the stomach is the seat of disorder, the pains will be duller, the paroxysms less distinctly marked, and the pulse but little altered; but, when by continuance it reaches the small gut at the lower orifice of the stomach, then will the pain and anxiety of the animal increase greatly, and the symptoms thereof, visible in his manner (to be described shortly), will become more distinct, rapid, and vehement. The pulse increases in number, in sharpness of vibration, and irregularity. Such is the difference also that is discernible between attacks upon the colon or great gut, and on the smaller guts. But all this refers to the first attack; for after a while, if the means adopted are insufficient to check its career, the ruin goes on to affect the whole abdomen, and the animal dies in excruciating torments. 
Causes.-Much the same as those which occasion fever in all ordinary cases; that is to say, a sudden check given by cold to the action of the parts, while these may be in a state of excitement, or through over action, hard work, excessive heat of the weather, the operation of cordials, \&c. By this latter means stallions and brood mares are sometimes destroyed prematurely, even without catching any cold, or this part of the system receiving any check whatever: in these eases, excitement has been carried to the utmost pitch by high feeding, and stimulating the male, until nature gives way, or rather, I might say, catches fire almost, and if not speedily arrested, the heat soon destroys the functions of all the abdominal organs of life.

To stage-horses, inflammatory complaints usually prove fatal, from the same immediate cause; the animal being fed high, and pressed forward to the accomplishment of his daily task, regardless of the first indication of this disease; and in summer time, we witness numbers of such dropping down in harness, sometimes whilst going along, seldom giving warning of approaching dissolution. But, whatever be the previous state of the animal's bodily health, he can rarely stand the mistreatment he receives from his driverwhether post-boy or coachman; viz. that of being driven through ponds and large rivulets, while he is yet perspiring greatly through fatigue and the heat of the weather. Almost every posting town 
offers some such ready watering place, and few drivers can resist the pleasure of thus abridging the labour which the heels of his horses and the wheels of his coach require at his hands. Long rests in currents of air, or unsaddling horses under similar circumstances, are alike productive of inflammation of those or some other part of the animal's inside, if it do not bring on fever of the whole system-as before observed, p. 159. The kidneys or the liver are sometimes alone affected by this species of culpable neglect; but in either case the effects are not immediately perceptible, and the disorder creeps upward unheeded, or seizes the animal violently, so that it dies at the next going out.

Neglect of the necessary evacuations, or the discontinuance of those which have been customary, even though injudicious, will occasion an accumulation of dung in the guts when they are least capable of bearing it ; upon this, pressing the horse in his work will bring on inflammation, as it will sometimes after a heavy feed and water, which some injudiciously give on account of a hard day's work lying before him. The same happens to horses that are inordinately fut, when hard worked; the dung that is then eliminated bears with it a portion of the slime or mucus that lines the intestines, and this appearance has obtained for this species of inflammation the term molten grease. I postpone, for a few pages, the consideration hereof, in compliance with custom rather than in obe. dience to propriety. 
Adhesion of the gut sometimes takes place, so as to cause partial obstruction to the passage of aliment; at others, tubercles are formed on the mesentery that holds the bowels in position; and in either case the secret is disclosed by a staring coat, which some mistake for the roorms. Both those affections are the effect rather than the first cause of inflammation of the part, and may be distinguished from "the worms" by the state of the pulse, by the heat, tension, and soreness evinced by the patient on passing the hand over the belly. See page 127, Book I. The reader will also perceive, upon turning back to page $60-62$, in what manner this adhesion is effected, by the exhaustion of the moisture that is designed by nature to lubricate the parts.

Colic of long continuance, if the animal is worked while this is on him, is another prolific source of inflammation of the intestines; as is the drinking cold water copiously, while in a state of perspiration, or after a trying journey, which is always attended with spasmodic colic of the stomach and bowels at first, and of inflammation sooner or later, according to the temperature of the individual. The necessity of getting rid of the lesser attack before it acquires a permanent and dangerous aspect must be obvious; and as the treatment proper for either is at total variance with the other, the one requiring warmth and stimulation, the other a cooling and reducing treatment, our first duty is to ascertain precisely the exact nature of the attack; for a mistake on this 
point would, and does frequently, prove fatal-ay, in human as well as in horse medicine. Therefore it is, that I have judged it expedient to set down here a table of the symptoms that will enable the practitioner to distinguish between the two kinds of attack.

For this mode of setting before the eye in parallel columns the discriminating symptoms of two such apparently similar disorders, I am indebted to $\mathrm{Mr}$. Ryding, who inserted it in his "Veterinary Pathology," 1801, pages 86, 87; and it was copied by White into his "Compendium," 1803, with a few alterations, by no means for the better. I have adhered chiefly to Ryding, with but one slight deviation.

\section{STMPTOMS.}

A table for distinguishing between the Colic or Gripes, and Inflammation of the Bowels, by the symptoms that mark the character of each.

Spasmodic or Flatulent Colic.

1. Pulse natural, though sometimes a little lower.

2. The horse lies down, and rolls upon his back.

3. The legs and ears generally warm.

4. Attacks suddenly, is never preceded, and seldom accompanied by any symptoms of fever.

5. There are frequently short intermissions.

\section{Inflammation of the Bowels.}

1. Pulse very quick and small.

2. He lies down and suddenly rises up again, seldom rolling upon his back. cold.

3. Legs and ears generally

4. In general, attacks gradually, is commonly preceded, and always accompanied by symptoms of fever.

5. No intermissions can be observed. 
Whilst marking these distinctions, which ought to be kept in mind while prescribing for disorders so nearly alike at first view, but differing so widely in effect, the reader is earnestly requested to turn to the Index, and there find the page at which I have thought proper to treat pretty much at large of "Inflammation of the Kidneys," "Diseases of the Urinary Organs," \&c. He will there perceive how fatally these affections have been mistaken for "Colic ;" he will learn that this unhappy error is likely to happen more frequently than would at the first glance be imagined; and he will observe that the symptoms correspond in many respects with those in the second column above-therefore require an equally correspondent course of treatment, but that the deposite of stone in the kidney is an incurable disorder, that admits of no remedy. Furthermore, the reader will observe, that the whole of the article alluded to, on "Calculus, or Stone," requires his strict attention; and also bear in mind what is there said as to calculous substances which are deposited in the cœcum or blind gut, producing symptoms so much like spasmodic colic, that much care is necessary in applying the appropriate remedy in each case, lest he precipitate the patient's catastrophe.

Of those symptoms the state of the pulse is the surest indication of the approach of an inflammatory attack of the bowels, or any other viscus; and the particular part which is then suffering must be gathered from other circumstances. If he 
has long suffered colic without relief, doubtless inflammation has taken place, and gangrene is likely to follow: this is the harbinger of death. Adhesion of the gut sometimes baffles the best treatment for colic, and soon devolves into inflammation. In either case, the remedies proper for colic must be abandoned, and others more adapted to the change of circumstances be employed instead.

Whenever the cause of infiammation of the bowels may fairly be ascribed to the quantity or quality of their contents-without adding thereto by any extraordinary exertion, its approach will be very slow, and denoted by sluggishness and the refusal of food at first. As they are mostly working cattle that are thus attacked, the evacuations are not sufficiently minded, or the attendant neglects to make mention how these have discontinued in a great degree, or changed their appearancethe dung being then hard and the urine high coloured; hereupon the pulse increases, and the outrageous symptoms described in the second column of the table of symptoms go on to a frightful degree, endangering the lives of bystanders. Even in this stage, the progress of the disease may be arrested by prompt and vigorous measures, adapted. to the kind of animal that may be the subject of attack, and the circumstances under which the present alarming symptoms may have been brought on. If a heavy lumbering waggon-horse, that owes his disease to alimentary indulgence, we shall 
find no higher operation necessary than emptying the overcharged canal by force of arms, i. e. backraking; but the high-couraged stage-coach horse, which falls under the exercise of the lash, and the influence of a vertical sun, has seldom aught within him of that kind to part with, and requires the introduction of some substance or liquid that shall cherish the afficted stomach and bowels, and alleviate the burning heat that, ascending to the head, causes his delirium. Presence of mind, however, or the adroitness which much practice teaches, is frequently wanting for the first mentioned remedy; and the means of applying the second is so seldom at hand, that the animals are too often left to their fate and are lost. But I anticipate the remedies. See also pages 167,186 .

Remedy.-From the rapid progress made by this disorder, when left to itself, and its usually disastrous termination, the duty of attending to the pulse of his animals as before insisted upon (at page 168), will strike every intelligent horseproprietor, as the very best means of guarding against the fatal consequences of inflammatory attacks. He will by this means be apprised of the earliest approach of the disease, and thus enable himself to meet it in its mildest form : he will compare this certain indication of heat-whether fever of the whole system, or inflammation of a particular part, with the state of the patient's urine, which will then be high coloured, and the dunging defective. The rectum will be dry, hard, 
and hot; the belly on passing the hand over it cowards the sheath will have the same feel; the animal will shrink from the touch, his eyes appear languid, or partly shut; as the disorder proceeds they assume unusual redness, or what has been termed bloodshot.

$\mathrm{Up}$ to this stage of the disorder, the first remedy will be clystering and bleeding the animal freely, if he be not very aged or of spare habit, immediately after giving the following:

\section{Laxative drench.}

Powdered aloes, 2 drachms,

Subcarbonate of potass, 2 drachms,

Water gruel, 1 pint,

Castor oil, half a pint. Mix.

If delay is to be apprehended in procuring the above drench, give castor oil one pint, or in default hereof, salad oil two pints, whilst the drench is preparing.

In ordinary cases, a voluntary stool will be produced at or soon after bleeding, occasioned by relaxation of the tenesmus that constitutes the disease. If the dung comes forth in small quantity and small hard knobs, like gingerbread nuts, the arse-gut must be cleared by the hand, according to the directions given at a preceding page, 186 . And, when the constipation has endured for a long: time, the hardened dung will not come away at all without this manual operation of back-raking, which must be performed the more assiduously 
as the difficulty may be greater and the dung harder. Let a warm clyster be thrown up that is copious enongh to fill the emptied gut, at the least.

\section{Clyster.}

Water gruel, from 4 to 6 quarts, Epsom salts, 4 or 5 ounces.

Inject warm, with a large syringe, or ox-bladder and long pipe: perform this operation effectually.

A second and third should follow, a little warmer than the first, and after an evacuation has taken place, the next clyster may be made without salt, and a small degree thicker than at first. Its effect will be to remain and rourish the parts nearly in the same manner as a poultice does an external inflamed wound.

Too often, however, those early indications are entirely neglected; the animal is harnessed in to his day's work, and the consequences are both dreadful and dangerous to behold. If he be a stage-coach horse, or destined to take his turn at a posting-house, his sluggishness and refusal of food is usually attributed to "a little overwork;" and the much abused cordial is commonly administered; which brightens him up for the renewal of his daily task, and accelerates his fate, unless rescued as by a miracle that is very seldom wrought. In these cases, the first symptom perceptible to the driver is the horse's leaning against its next horse; but, upon being touched up, it 
makes fresh exertions according to its quantity of courage, until it falls down with closed eyes in excruciating torments, lashes out behind, and beats about on the ground, seldom having the strength to get upon its legs again. Bundles of straw should be placed for the afflicted animal to roll upon, and his head pressed down with the hand whilst the severest paroxyms expend their force. When at length he gets up-which may be considered a favourable sign, that proves his strength is not wholly subdued-he may be supported into a stable. Meantime, however, an examination of the rectum must take place, and the manual operation of emptying it be employed-if need be; that is to say, if hardened dung should be accumulated there. At any rate, water gruel in large quantities must be prepared, as well for administering by way of clyster as of drench; in both, giving it now without the addition of salt, and in the latter manner nearly cold. By these means, the alarming symptoms will diminish greatly; but if there is still reason to apprehend that obstruction may prevail in the larger intestines, this must be got rid of by means of the oily laxative piescribed at page 243 , and the repetition of clysters in quantities, and administered with a vigour sufficient to reach the evil.

Bleeding, of course, would be adopted to the amount of four, five, or six quarts, according to the exigency of the case and the size of the animal. If the blood become buffed, as it is called 
by some, or sizy on the surface, a second bloodletting is necessary to complete the cure. Low, but nourishing diet, should follow; as bran-mashes, stiff gruel, and afterwards sodden corn; the return to hay provender being made gradually, and then of good quality.

In very bad cases, the return to full health and vigour will be slow, and a relapse is to be dreaded, as a fresh attack would prove much more obstinate than the first. The dung, by its quantity, consistence, regularity, and general appearance, will afford the best means of judging when the bowels are completely cleared of their offensive contents; for it not unfrequently happens that several tolerable stools may be procured by the help of medicine, and yet some lumps, replete with danger, remain behind. The pulse, that great criterion of health or disease, by dint of low living, may have regained its natural state, and so remain steadily for a tolerably long period: but watching the dung for a day or two will corroborate that main indication of health, or by its irregularity dispel an ill-founded reliance on the completeness of the cure. Yet will the administering of purgatives, or even alteratives, of aloes in particular, be found full of danger, as tending to irritate the bowels anew. The same may be said of all stimulants whatever, whether applied externally or given in the form of cordials, notwithstanding the animal may evince signs of returning pain, and these be ascertained by the corresponding symptoms of 
low pulse, warm legs and ears, to arise from spasmodic or flatulent colic only. For these returning pains are usually occasioned by the soft kind of regimen just recommended, to which the patient may have been subjected during this illness for the first time since it was a foal. I have known a small feed of corn or two effect relief from lowness, in the case of horses which had been long time previously used to hard food: if these be devoured voraciously, this will tend to prove 1 st, that the change is desirable, and $2 \mathrm{dly}$, that the next feed should consist of broken corn-or a new disease will be engendered. Adopt the tonic system, recommended generally, at page 187.

\section{MOLTEN GREASE}

Is but a variety of inflammation of the intestines when the subject of attack happens to be very fat, and little accustomed to exercise; when marked by costiveness, it may be treated as such; or, if attended by a looseness, may rather be considered as a spasmodic effort of nature to relieve itself of an unnatural load. The vulgar name given to this affection of the intestines is farther supported by the popular notion that the fat, or grease, which the individual possessed in a superlative degree, had-melted (or was molten) and passed into the guts, whence it was expelled with the foeces. This, however, is physiologically impossible, notwithstanding the support such a notion 
has received from some revered authors; the appearance of slimy unctuous matter along with the dung, more particularly when this is much hardened, being no other than the mucous secretion described at pages 59,60 , as designed by nature to defend the surface of the intestines from the injurious action of hard substances that might be taken into the stomacl. Indeed, this intention of nature in providing such a defence is demonstrable in the fact, that the harder the knobs of dung may be that the animal presseth forth, the greater is the quantity of this greasy, unctuous, or mucous secretion that is eliminated along with it, and which gives name to the disorder. Probably, the secretion of this grease may then proceed with more celerity ; its access may be greater, the more it is thus required by nature to defend the alimentary passage. This supposition is drawn from the fact just stated; but, whether the wellfounded conjecture be too hastily hazarded, is for the more minute inquirer to conclude upon, or investigate farther, as may seem good to him.

At any rate, the doctrine of effusion, or the passing of those secretions, whether mucous or æquous, from one part of the system to another, as nature or accident may require the supply, is tolerably evident from another circumstance that is often recurring in cases of molten grease. [The subject is more fully treated of at the page just. referred to.] The perspiration of the two secretions in succession, here referred to, is pretty well 
recognised, and is easily proveable, in the manner there set down; the unctuous, mucous, or greasy secretion (call it which we like) of the external surfaces following that of the more liquid, æquous, or watery kind, after any great exertion. Horses that contract molten grease are ever those which. have been highly fed, without exercise sufficient to excite visible perspiration thereby; and the feverish heat of the body occasioned by high living and indolence, in time exhausts the whole supply of the requous secretion. So much is this the case, that the animal's discharge of urine becomes less and less as its seclusion is continued, until the decided access of fever takes place, and we notice its colour is higher and higher as its quantity decreases. [Look again at section 55, page 143.] As before explained, the secretion of mucous matter takes place within the guts, \&c., or that surface which is next to the food; on the other side, and every other part of the animal system, the watery secretion destined to lubricate the parts, to keep them supple and to prevent adhesion, takes place. On that side (which is popularly considered the outer surface!) good quantities of fat accrue, all along the whole length of the intestines, which is usually scraped from slain beasts, and preserved as tallow. From this source is derived that access of grease, which, as I have said, is greatest as the inflammatory symptoms may be higher. When this has long been the case, and stools are at length procured, a long 
thin wormlike portion of this fat comes away with the dung; which would be of itself a sufficiently alarming appearance, though wanting animation, but for the well known, but inexplicable, doctrine of effusion, or communication through the gut: this appearance, then, of a long tenacious fatty portion of thin membrane, which usually accompanies molten grease, should be considered as little more than denoting the crisis of the disorder.

Let the system be reduced according as the state of the pulse may dictate-for which consult again page $16 \%$, as to bleeding, and page 183 , as to treating him for " costiveness" simply. If heat and irritation be perceivable to the touch and sight about the anus, without high pulse, the first symptom may be reduced by administering

\section{The sedative Clyster.}

Camphor, 4 drachms,

Spirits of wine, 3 or 4 drops,

to promote solution, and add

Sweet oil, 2 ounces.

Mix well, and then add thin warm water gruel, 2 or 3 quarts.

As before intimated, molten grease is rather an effect than a cause of disease, and partakes of colic in one of its forms and of inflammation in the other; the symptoms that enable us to distinguish when the one or the other prevails being precisely those set down at page 239. Allowing somewhat for the feverish symptoms that always 
prevail with such fat and bloated animals as are subject to this disorder, the practitioner cannot commit himself to the guidance of a better test than that just referred to, nor more safely adopt a treatment that is more likely to reinstate his patient in health, for very little danger attends molten grease, in either form. For the treatment which is proper in case of spasmodic colic affecting fat animals, the reader is referred to the next head of information.

\section{THE COLIC, GRIPES, or FRET.}

This disorder has been frequently referred to, under the preceding head of Inflammation of the Intestines, to which it bears great affinity in some of its points-as already stated; the cause of both being nearly the same in most cases, and long continued colic always ending in inflammation, if not effectually checked in time. Much of the difference that exists between the two kinds of attack depends on the previous state of the animal attacked: if it be a high fed and hardworked animal whose digestive organs receive a sudden check, he contracts inflammation in the first instance; but one that is lower kept, and therefore not so irritable in any part of its system, is soon troubled with spasmodic affection of the intestines, which receives the name of gripes, or 
fret in different counties, as it does that of flatulent colic in most of the books that treat of animal medicine. Colic, however, is the general name given by most stable people to every pain of the inside (of man and horse) that occasions writhing, or other demonstrations of that pain, which few can discriminate in their own persons, much less in their horses. To this undiscriminating manner of naming disorders that require such very different treatment at our hands, is to be attributed the loss of many lives annually. Into this anomalous manner of treating those disorders it is painful to notice one of the most scientific veterinary writers of our time has fallen. We do not find in Mr. Richard Lawrence's "Complete Farrier" any reference whatever to inflammation of the intestines; though under the head of "Colic or Gripes," he proceeds to describe the symptoms of inflammation in such a manner as might mislead ignorant or half-taught persons to treat both alike, and thus destroy their horses.

A violent cold, or a slight one, will also determine the disorder one way or the other, when the individual's system may be of no decisive character at the time of contracting it. That a low state of the animal system is favourable to engendering spasms of the intestines, is inferred from the circumstance, that subsequently to a horse afflicted with inflammation undergoing the copious evacuations recommended in the preceding pages for the cure of that dis- 
order, he is frequently visited with spasmodic affections that require sedatives and tonics to restore the patient to complete health.

Causes. Next to drinking cold water, and catching cold by exposure to air or water whilst heated, the eating of bad, ill-got, or rank hay, is a prolific source of spasmodic colic. If it lie in the intestines chilly and comfortless, and thus predispose the animal to acquire cold, the cause of epidemical colic is plainly attributable to such bad hay, for it then prevails usually over certain districts, and mostly among country cattle. Pushing a horse in his work when large lumps of undigested matters distend parts of the gut, will bring on spasms, torpor, and inflammation in succession. Horses that gormandise much, being worked hard, and the stomach becoming empty, occasions the fret, and inordinate action of the guts expulsetlr the mucous secretion that is designed for their defence. This constitutes molten grease, of which I have treated largely just above, and am decidedly of opinion that the expulsion of offensive matters in all cases where the animal evinceth but small sensations of pain, is but an effort of nature to relieve itself, and ought rather to be assisted than abated by hot or "cordial medicines."

Strong astringent purgatives, oft repeated, or neglect during the operation, are frequently succeeded by flatulent colic, that soon becomes inflammatory if the internal commotion be not 
judiciously arrested by sedatives. Cordial balls and drenches, as they impart a short-lived vigour, so when their stimulating effects die away, they leave behind a debility that is more excessive as those factitious effects have been most intense; in this respect, the cause and its consequences assimilate closely with those which succeed the disease of inflammation, and the debility which follows the cure thereof, with spasmodic colic. Diapente, and other provocatives, that are given to stallions in the season, leave behind them the same species of debilitating effects after covering, and would devolve into colic first, and inflammation afterwards, but that those horses' evacuations are well looked after, and the system of stimulants is kept up by repetition. This treatment, however, cannot always succeed, so we frequently find that stallions die suddenly of inflammation in the intestines, in the spasmodic cords, or other parts of generation. Cases of death, in actus coitu, from the same causes, are upon record. I mentioned this before, at page 48 .

All horses that have been pampered in the above manner, or by being kept in close stables, or having their water chilled, when they come to be subjected to common usage, are most likely to suffer by colic in its worst forms. Horses that are made up for sale by dealers and cunning breeders, in order to give their coats a sleek appearance, upon passing into the hands of new owners, commonly undergo attacks, more or less acute, of 
spasmodic colic, if they do not at once fall ill of inflanmation of bowels, kidneys, or bladder. With animals so circumstanced, mere flatulency or looseness may be considered a favourable termination of the making up system before alluded to.

Symptoms. These, as contradistinguished from those which denote inflammation of the intestines, will be found in the table of comparative symptoms at page 239. In addition thereto, other symptoms, that mark the degree of spasmodic attack, require equal discrimination, seeing that treatment which may be highly proper in the more virulent attacks, would be injurious if employed upon every slight occasion. Neither is it every horse which shows signs of pain in the inside that hath the colic, even though the symptomsset down in the second column of the "table," at page 239 , do not appear; for, he may be afflicted with pain in the liidneys, or inflammation of the bladder, which the attendant should ascertain before giving the stimulants that may be very proper in most stages of colic, but would accelerate the diseases incident to those " urinary organs." The careful reader should therefore turn to the subjects "Kidneys," and "Bladder," before he proceeds to treat the animal simply for colic pains.

In its mildest state, flatulent colic first appears in the form of violent purging, which is in fact no positive disease, as before observed, but an effort of nature to rid itself of a collection of offensive matter, either indigestible, cold, or irritating. of 
what precise kind this may be at any time is ascertainable upon the view, and requires only to be assisted in coming off, provided but little pain is evinced by the animal. If he be a crib-biter, pieces of extraneous matter are usually found among the dung, as bits of wall, of wood, litter, \&c.; if an aged horse, or one that has been kept on bad hay, his food comes off undigested; if a very fat horse, the mucous secretion comes away as described under " molten grease," just aboveand all these require at most some of the milder purgatives that are least likely to irritate the bowels.

Whenever the ears become cold, after gripes have continued some hours, it is a certain indication that inflammation has taken place of some one or more organs, mostly of the intestines. This is sometimes discovered, when too late, to attend a rupture of the distended bowels through the pæritoneum (vide Book I. page 12\%), when the protruded gut mortifies (as is found after death) in consequence of strangulation. After this, the pain seems to subside, and the animal dies quietly. The ruin that has taken place is only told on dissection. Yet do most ignorant persons pronounce horses still alive to have a "twist in the guts," and stranger still, they prescribe a remedy for it, although it is incurable. The ears act also as a good barometer, when inflammation of the kidneys may be apprehended, or inflammation of the bladder is more than suspected, on account of the 
difficulty evinced by the patient in passing its urine. If the water come off high coloured, it is a sure sign of inflammation, which is further corroborated by cold ears; if of its natural colour, the ears will be warm, and the difficulty in staling is occasioned by the hard distended gut pressing upon the ureters and neck of the bladder: procuring a good stool or two, or a clyster, then restores the functions of the bladder.

The earliest symptoms observable in his man$n e r$, is when the horse looks round at his flanks occasionally, whisking his tail at intervals; he looks at the attendant, if there be any breed in him, seeming to implore help. He stamps with his hind feet alternately on the ground, sometimes striking at his belly. As the pain increases, these symptoms are oftener repeated, and with more vehemence; he gathers his legs under him, as if preparing to lie down; which he at length effects, rolling about in the stall and getting up again repeatedly. It may here be remarked, that this rolling on the back is well calculated for affording temporary ease to the bowels; but should inflammation have already attacked these, or at the kidneys, this rolling on his back would but increase the pain of the animal, and his jumping up instantly upon his legs, as if the spur or rohip had been applied, goes to prove the existence of inflammation at one or the other viscus.

Cure. Too much care cannot be exercised in ascertaining the precise nature and amount of the 
disease; for, in error in this respect resides extreme danger of life, which is too often sacrificed to precipitancy, to ignorance, and presumption. As soon as a horse is pronounced "ill of the colic," the attendants, without investigation, proceed to give "something to do him good ;" which is ever of the stimulating class of domestic remedies. Warm ale, with ginger, peppermint water, gin and water, and Daffey's Elixir, are the common popular remedies usually applied in this case; and, provided the disorder be really fatulent colic, relief from the pain must follow the exhibition of either one or the other. Frequently, however, it happens, that the doing good is carried too far, and inflammation is thus superinduced, if it do not already prevail. By such persons every internal pain is pronounced "the colic ;" and they all conclude that what has removed it once will remove it again, without being certain that it is the same disorder-as they do, that whatever is good in small quantities must needs be more so in larger ones. But I have already observed, that the removal of umbilical affections, whether flatulent or inflammatory, by rough, harsh, or protracted means, scarcely ever fails to produce the other concomitant disease, and the inflammatory symptoms no sooner subside, than the jaded vessels contract spasmodic affections, as do also the continuance of flatulency, and some of the means of curing it, superinduce inflammatory symptoms.

In whatever shape the horse is attacked with 
those disorders, the first and most obvious duty is the employment of clysters, to be repeated at short intervals, with this single variation; viz. in cases of relaxation, where the animal is already purged, the clyster is to consist of simple watergruel only; but when the patient's bowels are overloaded with hardened dung, the addition of salts, as prescribed at page 244, will be found most effectual. In the absence of Epsom salts (for no time must be lost), a handful of common culinary salt may be employed, in the quantity of four or five ounces. Back-raking, too, should be assiduously applied, when the body is in this state, as recommended in the case of inflammation at $p$. 243 , with the laxative drench prescribed at the same page, or the simple salad or castor oil in default thereof.

In orcinary cases, when the attack is not of the most violent kind of either description of colic, that is to say, when neither purging nor constipation prevail extremely, let the following be given.

$$
\text { Colic Drench.--No. } 1 .
$$

Epsom salts, 4 or 5 ounces,

Castile soap, sliced, 2 ounces.

Dissolve these in a pint of warm ale, and add

Oil of juniper, 2 drachms,

Venice turpentine, 2 ounces.

Mix well together, and give it warm; repeating the same in four or five hours, and if the symp- 
toms do not visibly abate, repeat once more. 'Tincture of opium is sometimes substituted for the turpentine to the amount of 4 drachms; but the drench is thereby rendered exceedingly nauseous, and should be given deliberately. Opium is, moreover, least proper when a tendency to costiveness is discovered to exist.

\section{Colic Drench.-No. 2.}

Tincture of opium, 2 drachms,

Oil of juniper, 2 drachms,

Spirit of nitrous ether, 1 ounce,

'Tincture of benzoin, 4 drachms,

Aromatic spirit of ammonia, 3 drachms.

Mix together, and preserve the same in a bottle, and give in a pint of warm peppermint water. Repeat in three or four hours.

Whon the case is not very alarming, a neater manner of giving opium, in the form of a ball, is recommended :-

\section{Sedative Ball.}

Asafœetida, 4 drachms,

Opium, 4 drachms.

Make into four balls with liquorice powder and syrup, and give one every two hours. The balls may be given along with the oily laxative at page 243 ; immediately preceding it, or before the laxative has operated. These balls are very serviceable to travellers on their journeys, and may be 
given to horses that are liable to contract spasmodic colic, which is the case with heavy, fleshy draught cattle, with post horses and the like.

Colic is never fatal, unless it terminate in inflammation; whilst it should be kept in mind, that colic always ends in inflammation if not removed in time. A day, or at most two, may pass away without danger and without relief, in ordinary attacks of spasmodic colic; and where a looseness takes place, a short time longer of neglectful carelessness might not terminate the life of the animal; but, when inflammation commences, a shaking or undulation of the tail is observable, with evident shivering of the whole frame. The danger is then great; especially when each fit of shivering is not succeeded by perspiration: MARK THAT.

If the costiveness is not well removed when those symptoms, with cold ears and legs, come on, let the belly be fomented with warm water by means of woollen cloths steeped therein. A horse rug may be used to advantage in this way by two men, one standing on each side the horse and fomenting the belly by bringing it nearly together across the back and supplying it with warm water. After half an hour's application, or more, let the coat be well rubbed with dry cloths, and the animal wrapped in body clothing. The clystering, and other remedies recommended in cases of inflammation, should then be employed with assiduity. Lastly, employ the tonic system recommended, generally, in all inflammatory cases, at page $18 \%$. 


\section{DISEASES OF THE IIVER.}

1. INFLAMMATION.

2. THE YELLOWS, OR JAUNDICE.

When we consider the vast active functions the liver has to perform, in cleansing the blood which takes its passage through it, and the secretion of bile, that becomes more obnoxious as this organ is more diseased, we ought to feel surprise that so large an animal as the horse has so few ailments springing out of that source, rather than lament the frequent existence of this one. For, the two names set down at the head of this article, agreeable to the general practice, have only one origin, viz. inflammation; but differing as to the amount of heat, and situation of the evil, which is scarcely distinguishable until after death. The symptoms of both are the same, and the first attack ever becomes the most lasting, if the remedies be delayed, or wholly neglected.

Having been led to enter somewhat at large into the causes and remedies for certain affections of the liver, while describing its structure and functions in the first book, p. 133, I shall find less occasion to add much more at this place. The reader will of course turn to that page.

Cause of inflamed liver.-Inflammation of the proximate organs, as of the diaphragm, to which the upper portion of the liver is strongly attached, 
as well as of the kidneys, to which the off-side thin portion of the liver is adjacent, communicate their baleful heat to this fine organ, and an increased formation of bile is the immediate consequence. The blood, in passing through the liver, acquires a portion of this extra heat, which reproduceth more at its next passage through it, more at the next, and so on, until the inflammation of the whole liver is completely effected. Increase of the bile or gall proceeds in the same ratio, until the gall duct, that communicates with the small gut, is closed by the uncommon heat of the inflammation, or by the thickening of the gall, or by both operations united, no matter whether. At any rate, the bile which ought to be conveyed away by stool, is returned into the system, and occasions yellowiskin-whence the vulgar name. When this occurs, $I$ apprehend the inflammation lessens, but the communication with the bowels does not always return to a healthy state, though I believe it to be partially the case. Indeed constipation in the first instance often obstructs the passage of bile into the bowels, and thus increases the evil. Overfeeding has the same effect, and both produce slight temporary yellowness, which goes off upon the removal of the cause, generally followed by diarrhac. The feverish symptoms also which accompany the commencement, also pass off, leaving a low, irregular pulse, until the bowels resume their wonted course, either naturally, or by the aid of medicine. 
Symptoms of inflammation beforeyellowness comes on.-As this last and surest indication of diseased liver only appears when the evil is a confirmed one, and is extremely difficult of cure, particularly in old animals, we should assiduously set about ascertaining its commencement, so that the remedy may be promptly employed, and a further procrastinated mischief be timely prevented. And the more so, seeing that what constitutes a remedy in its earliest stages is no longer so after a while has been spent in delay.

Whenever inflammation, or extraordinary action of the kidneys, or of the diaphrigm, has lasted some time, in ever so small a degree, in that degree will heat or inflammation attend the liver. It enlarges upon the accession of this heat, visibly so when this has continued a while, but may be previously ascertained by the feel. As will be seen *, the liver extends much farther back than

* In the plate of skeleton, at the parallel lines $\mathrm{H}, 30$, is placed the kidney of the near side; whilst the off-side kidney in the same subject would be intersected by the line 29. With this latter, the right lobe of the liver lies in contact, and when an enlargement of it takes place, it may here be seen and felt; when the access of inflammation and tension render it painful only, the doctor should press the points of his fingers (of the left hand) gently behind the last or false rib several times, whereby he will ascertain whether any and what degree of pain the patient endures. If seated high up on the liver, he will not, of course, flinch at the first slight touch.

* * To prevent error, I would here mention, that in the picture of a skeleton now referred to, it is the left lobe of the liver that is there represented, and this was reduced in size, in order to show a clear profile of the stomach. 
the last rib, and a little beyond the false one. Here a considerable protuberance appears when the liver is enlarged, and disease may be ascertained that is attended by the presence of pain only. Old horses, which have been roell bred, retain chronic affections of the liver to a very great age; and this is frequently the main disease under which they suffer for many of the last years of their lives: great numbers of such animals die without liver, for want of sufficient action, or being of so small a size, that nought but its situation could assure us it ever had any functions to perform. Horses so visited with a trifling undetected affection of the liver lose their courage, and gradually sink into lethargy the longer it lasts : we often hear such animals accused of being " used up, done for, or "tis all up with him," and yet driven about to the last moment of a painful existence.

When the attack is rapid, and acute inflammation, arising from the causes just set down (page 263), the pulse is the sure indication of the ruin that is going on, by its irregularity, quickness, and uncertain vibration. See page 16\%. One lobe only suffers in this case, and then the animal turns its head round sharply to that side, from time to time. Constipation always accompanies acute inflammation of the liver.

Remedy.-Acute inflammation, which comes on with dangerous strides, when the subject of attack is of vigorous habits, must be met by a bleeding 
proportioned to the state of its pulse, and that without delay. For, it speedily communicates to the intestines, and death ensues; or, being suffered to expend its virulence (provided the animal possesses strength sufficient) by stool, the bleeding will then be unnecessary; or being persisted in, will confirm the slighter affection just spoken of probably to the end of his days. A purgative ball should accompany the bleeding, as in all other cases is prescribed generally at page 172 ; but, if the animal produce a stool voluntarily, the disorder has taken a turn, and neither the operation nor the physic is required.

After bleeding, let the sides be rubbed with the blistering ointment (vide page 204), and apply a rowel to the chest. These latter, however, are doubtfully eligible, though always employed by the regular collegians. The patient will require the same treatment, as to diet and regimen, as for inflammation of the organs of respiration and general fever, before treated of at page 165 , in the course of which his pulse and freces should be watched, and a relapse provided against. C'alomel is that medicament which more immediately acts upon the liver, and unless the horse scours, should be administered in the form of

Alterative Balls.-No. 1.

Aloes, 9 drachms,

Calomel, 1 drachm,

Hard soap, half an ounce. 
Mix with mucilage sufficient, and divide into three balls ; to be given on three successive nights, unless a thin stool comes off with the second ball. But in case of scouring, give

No. \%.

Oil of turpentine, )

$\left.\begin{array}{l}\text { Hard soap, } \\ \text { Ginger, powdered, }\end{array}\right\}$ of each 1 ounce.

Mix with flour and mucilage to form three balls; and give one on each of three successive nights.

\section{THE JAUNDICE, or YELLOWS.}

Cause.-Infiammation of the liver, or any other obstruction of this organ, which, preventing the escape of the bile into the duodcenum, or smallest gut, through the gall duct, by reason of this duct being inflamed, or choked up with the thickened bile; whereby it is sent again into circulation, and thus pervades the whole system. When the inflammation is very great, the disorder quickly carries off the patient; the inference therefore is, that poor animals alone acquire the yellowness which gives name to this disorder; though it must be allowed that the same effect may be produced by over-feeding and constipation, by swallowing hard substances, or otherwise offending the said gut, or the pylorus orifice of the stomach, as de$\mathrm{N} \boldsymbol{\mathcal { Z }}$ 
scribed at pages 120,123 . Its situation may also be seen depicted in the plate of a skeleton at the intersection of $\mathrm{K} 26$. At that place I did not choose to speak of negatives, and therefore omitted to notice the fact, that the bile or gall secreted in the liver of this animal proceeds at once, as soon as it is formed, into the gut, without being detained in a sac, or gall bladder, as is the case with all other animals, except deer; so that, upon any revulsion or hindrance to its free entry to the bowels, the gall must at once return to the numerous cavities that pervade the whole liver, and its reabsorption by the blood is no longer problematical.

Symptoms.-A dusky yellowness of the eyes, bars of the mouth, and tongue. The dung scanty and pale, generally hard, and covered with slime; but in some few cases the horse scours; that is, when slight inflammation of the bowels also attacks an ill-conditioned horse. The pulse is that of low fever, and the same kind of drooping inactivity, with loss of appetite, noticed under that head at page 178; differing from it only in respect to the seat of disorder, the low fever being general, or of the whole system, jaundice of the circulation only. Sometimes, however, yellowness comes on without the other symptoms, after an inflammatory fever; an occurrence that cannot fail to be foreknown. Genuine jaundice may further be discriminated by the yellow lips, yellow saliva, and dark urine. From this latter appearance we may draw these 
curious inferences-viz. that the colouring of the bile which has ceased to impart its property to the dung, having gone with the blood to the kidneys, there leaves its darkest or more earthy particles-the lighter or brighter ascending to the heart, and passing through the vascular system, there imparts its yelloroness. By this providency of nature we see how it is that malevolent particles in the blood are cleansed at the kidneys, and pass off by urine. Thus it is that grease and other tumours are cured by judiciously stimulating the kidneys. The urine voided, as above described, which is ever done with evident pain and difficulty, leaves on the ground an appearance of blood.

Cure.-Young horses and fat ones are easily cured: they have indulged too freely in good living, on hard meat, and require no more treatment than a good physicking. Give the purgative ball (page 172), or the alterative ball, No.1, prescribed in page 266. Give bran mashes, green food, and succulents, according to the season. Bleeding is seldom necessary, or proper, which the state of the pulse will show.

The Liver is alşo frequently affected with tum mours on its fine surface, as well as with ulcers or schirrus, which are all the effects of an evil state of the blood, of over action, and probably of accidents from external injuries, communicated by the kidneys.

We can easily conceive that the thin parts of this large viscus may be diseased, and even in- 
flamed, without causing derangement of the biliary function, further than increasing its action, and by thinning the blood over much, it obtains more bile. The animal then waxeth thin, though devouring his food as usual for a while; and we may. ascertain when this evil has begun by the state of his dung, principally as to colour, which will then be of a much deeper hue. As pale dung is a symptom of suppressed bile, so is deep colour an indication of a superabundance, that is caused by over action, which is itself occasioned by the heat of the liver, from some cause or other. One of these may be " inflammation of the kidneys" or it may be occasioned by ulcer, and we set about ascertaining which, according to the instructions set down at page 265 ; and in the latter case give the alterative balls, the same as for inflamed liver, at page 266, according to the circumstances there discriminated; but it never happens that a scouring is of a dark colour, and No. 2 would in this case seldom be required, a strong purgative never, though the bowels should be kept moderately open. When there is reason to apprehend that the adhesion of the ulcer to the intestines has taken place, as described at page 136, the animal should not be worked hard, though moderate exercise is desirable, and so is

Change of physic, as in all cases that require alteratives. The following balls may take place of the preceding, particularly when the coat is staring. 


\section{Alterative Balls.}

Emetic tartar, 3 drachms,

Aloes, 9 drachms,

Hard soap, 1 ounce,

Ginger, 1 scruple.

Mix, and divide into three balls; one to be given on successive nights, unless two have operated.

\section{INFLAMMATION OF THE KIDNEYS.}

This being one of those diseases which bears resemblance to another, and as the mistaking and treating the one for the other generally proves fatal, reference should be had to what is said under the head "Inflammation of the neck of the bladder." Such a mistake of the disorder in the present instance is very likely to be made by the common observer, inasmuch as the kidneys, as soon as they become inflamed, secrete much more urine than in a state of health, and any one noticing this, and subsequently its defalcation, as the disease goes on, may easily imagine the bladder itself is affected at the neck. It is worthy of remark, that mares are more liable to affections of the kidneys than horses, particularly brood mares; while, on the contrary, they are less liable than the male to inflammation of the neck of the bladder, in consequence of the shortness of the vagina: its straightness, too, affords easy proof of the real seat of the disorder, - that essential prelude to effecting a cure. See page 145 . 
Causes.-Too constant use of the diuretic powders and balls, or "pissing balls" of the shops, commonly bring on inflammation of the kidneys, by the irritation and over-action of the glands which are thereby occasioned. When one kidney only is affected, though in a mild degree, if suffered to continue, it soon communicates to the other, and sometimes proceeds with such rapid strides as to affect the intestines, when mortification and death ensue; but we have no means of ascertaining when this last incurable mischief has taken place until after the animal is dead-nor would the knowledge be made available for any present purpose, though finely instructive as to future cases : then it is the kidneys present an enlarged and rotten appearance and feel, their texture yielding to the slightest impression of the finger nails, which shows in what degree and how long they have been affected.

A hard blow across the loins will injure the kidiney on the side so struck, and, as is said before, soon affect the other also. Sudden transition from an open airy situation to a stable that is close and hot, violent riding or driving, or an illcured affection of the bowels, whether inflammatory or spasmodic, will affect the kidneys in more or less degree. Those causes all together combine to affect these parts more frequently than is generally supposed, the reason for which misconceit is nevertheless most apparent to me: it is owing to the neglect of all the milder symptoms; 
some persons imagining that unless bloody urine be produced, the defective staling is caused by something less remote than the kidneys, though in all obstructions of the liver, as we have seen above (page 268), the quantity of blood these send to the kidneys leaves some of its colouring property to the water. This class of unreflecting people generally fix upon the bladder as the seat of disorders that so affect the quantity of water. They almost invariably give stimulating medicines, that do but increase the disorder and confirm the ruin it is their duty to prevent.

Symptoms.-The most evident of these has been just now alluded to, and was formerly treated as a distinct disease, under the coarse title of "BLOODY URINE:" it is, however, considered as happening more frequently to horned cattle than horses, and to the female rather than the male.

When this symptom appears, it is accompanied by a corresponding symptom, viz. great tension and soreness of the part; which may be ascertained by passing your hand along the small of the back, over the kidneys, when the animal shrinks from the touch. No doubt can then exist that this bloody urine indicates genuine inflammation of the kidneys; and of course that we should treat it as such, and nothing else-nor by any other name. If the pain and tension cannot thus be ascertained, then "bloody urine" is caused by obstruction in the liver. Another symptom that may be relied upon is a stifiness of the hind leg on 
that side which may be attacked first; afterwards, when both kidneys are affected, the animal becomes stiff of both legss. This symptom does not occur in "inflammation of the bladder," and is a good distinctive mark to go by, when we may be labouring under doubt in some other point of resemblance between the two diseases. In all.stages of this disorder, the horse stands as if he wanted to stale; straddling, and making the most exertion when he voids the least urine (then always bloody), which shows the destructive tendency of these efforts on the gland itself. The consequences are, that the kidneys waste away, and the disease communicates to the bladder, until the final ruinmortification ensues. The practitioner, in this case, will not fail to look at what I have thought proper to say respecting "stone and other calculus," a few pages farther onward.

"Suppression of urine" is also a sure indication of the genuine inflammation of the kidneys; that is to say, the capacity of secreting it is nearly extinct, or it is performed with exceeding great difficulty, pain, and danger. Whereas, in affections of the bladder, the secretory function is not lost by the kidneys (or suppressed); but, when the urine has been sent into the bladder, this latter has not the power to expel its contents. How this happens, see above, at page 145 , \&c.

But the most prolific source of diseased affections of the kidneys, and the least perceptible of any, are ill-cured pains of the intestines and of 
the liver. These leave behind them certain morbid effects that are not immediately felt nor easily discoverable, but nevertheless work their ruin imperceptibly; for, as previously observed, when the kidneys lose their function of secreting urine, they enlarge, and after death scarcely bear the pressure of a finger point.

Cure._-Seeing that strongdiuretics are reckoned with truth, among the causes of diseased kidneys, no man in his senses would think of administering any such, after he has ascertained that this organ is disordered in any way whatever. Such, however, is too often the practice of unskilful persons who, after noticing the defective quantity of urine produced, think of restoring the animal's capacity for producing more by medicines that stimulate the parts, which already labour under a disease of too much stimulation. "As in all other cases of inflammation or fever [how often have I not repeated the same words!] when the pulse is high, let the animal be bled according to the amount of the attack." See general observations at the head of this chapter, pages 159 to 169 . Give warm clysters frequently as there prescribed; and with a similar view give him a loose stall, if the paroxysms are so acute as to cause him to lie down and get up again. Immediately after bleeding, give castor oil 18 ounces, provided the animal has not dunged during the last twenty-four hours, as commonly happens; less may suffice in general; but a horse that has been much addicted to diu- 
retics (pissing balls, \&c.), though his bowels may be in a tolerable state, will not suffer aught from a small proportion of aloes :

\section{Mild Purgative Ball.}

Aloes, 4. drachms,

Castile soap, 4 drachms,

Emetic tartar, 2 drachms.

Mix, with mucilage enough for one ball.

Should the symptoms abate nothing in consequence of this treatment, the bleeding must be repeated and the purgative too. Rub over his loins with a stimulant

\section{Embrocation.}

Spirits of wine, 2 ounces,

Soap, 2 ounces,

Camphor, 1 ounce.

Mix, and apply it with the palm of the hand to the loins; cover the animal up well, and be careful how it is subsequently exposed to the air. The mustard embrocation is equally efficacious : being rubbed on soft sheep-skin, cover the loins therewith. Give the cooling decoction in large quantities, as at page 188; and if the animal is disposed to eat the sodden seeds, it may be permitted to indulge: they are little nutritious when the saccharine has been drawn out by the hot water.

The food should consist of bran mashes, green food, and the cooling regimen already recommended in all cases of inflammation at pages 165 , 
188 , to which the reader is respectfully referred for some general directions for his rule and conduct, equally applicable in all such cases.

\section{DISEASES OF THE BLADDER.}

These are really much fewer than are commonly ascribed to it, the bladder being but the vehicle or outlet for several evils that take their rise higher up; and among these I have already denounced the alarming appearance of "bloody urine" as a disorder of the kidneys and liver, page 273. Neither is the "suppression of urine," nor its obverse "diabetes" ascribable to the bladder, but to the kidneys; for, if these secrete none or imperfectly, little or none can be sent into or escape out of the bladder; but "retertion of urine" may be a fault of the bladder, or collapsion of its neck; and the means of procuring its escape was before recommended at page 1,45 , \&c.

INFLAMMATION OF THE BLADDER, and consequent "Incontinence of urine," are the same disorder; the latter being the irritating effects of the inflammation only, and this I shall consider separately, referring those other disorders that are commonly ascribed to the bladder, to consideration under the head of "Diseases of the urinary organs, generally."

Cause.-Heat and inflammation of the kidneys communicate this effect to the ureters and bladder. 
It may be inflamed also by the irritation of stones or gravel concreted within it; or the excessive labour imposed upon it by the great access of diabetes, after these have ceased.

Symptoms.-Frequent desire to stale; the bladder contracting upon every drop of water, almost, that finds its way into it. A quick, sharp pulse, and small, accompanies, if it has not preceded inflammation of the bladder; yet bleeding would not be proper in this case, as it is the poorness of the blood which brought on the diabetes that caused the intammation. When, however, this symptom has not preceded inflammation, the pulse will be more full, and bleeding to an amount proportioned to the state of the pulse (see page 167), would then be necessary.

Remedy.-A slightly purgative ball should of course follow the bleeding, but employ neither in the extreme. Give the cooling decoclion recommended in general fever, at page 188; administer clysters of the same, two or three times in the day. Should great heat of the bladder continue, notwithstanding these remedies, give the fever powder, No. 2, at page 17\%, and afterwards No. 2, made into a ball, daily.

DISEASES OF THE URINARY ORGANS, GENERALLY.

Besides the foregoing main diseases of the kidneys and bladder, there are several other conjoint 
affections of the same organs, or parts dependent thereon, which require notice, and demand attention, while we examine the distinctions that ought to be drawn between the one set and the other. Mistakes as to the actual seat of disorders are more dangerous than the unskilful administering of medicines, for these might do good by accident, the former never can be applied properly: the better the "receipt" may be, the worse for the horse. Few of these lesser diseases are original, but arise from some defect or ill-cured disorder in the other parts of the animal's system. They may be considered under the heads-1. Diabetes, or excessive discharge of urine. 2. Bloody urine. 3. Calculi, or stone. 4. Stranguary. 5. Suppression of urine. I am aware that the ingenuity of some doctors has subdivided these, and added to the number of diseases incident to the kidneys, ureters, and bladder; but, omitting those which attach to the organs of generation in breeding animals, and also those seated higher up -the communication of acute pains to the more vital parts, by means of the emulgent and vena cava, to the heart itself. This last, however, is so immediately the precursor of dissolution, that no other benefit can arise from the doctor's skill in this respect, than bidding him to cease his efforts, to forbear to torture the expiring patient, and to preserve his medicines for a less forlorn purpose: the pulse, by its extreme languor, tells when hope itself must resign its place. 


\section{DIABETES, or EXCESSIVE STALING.}

The carse of animals discharging great quantities of urine cannot in every case be traced to its right source; but one thing always happens, namely, irritability of the bladder, by reason of the absence of the mucous secretion that is to protect it against the saline effects of the urine: see page 146. A defect in the mucous secretion of the whole system succeeds the disorder termed molten grease, and the irritation just spoken of soon communicates to the kidneys, which are thus compelled to secrete urine to the utmost extent of their power, and to send it forward to the bladder. To an impoverished state of the blood, arising mostly from the use of strong medicines-for the cure of inflammatory diseases leaves more of lymph than of serum in the vital fluid, with an accelerated tendency to increase that baleful difference-may be ascribed the chief cause of this obstinate disease. Bad dry provender, with illusage, and the denial of green food, in season, have a similarly evil effect on the blood.

Symptoms.-Of course, the most obvious is the discharge whence the disorder derives its name, being frequent and in very large quantities. At first, the water is colourless, but occasionally comes off like puddle. Constant craving after water, a staring coat, evident weakness, and weak quickened pulse, succeed each other, and in- 
crease as the disorder is suffered to proceed unchecked.

Cure.-Change the animal's diet, whatever that may have been. If the horse be labouring under the remains of some ill-cured disorder, attend to that first, and by removing it, the excessive staling, which in that case is but an effect thereof, will also cease. Give vetches, grass, sodden corn, water in small quantities and often. If the pulse be higher than ordinary, give the fever powders, pages 176, 17\%; and when the number of strokes per minute is reduced, let the corn be given dry, and resort to bracing medicines. In slight attacks, as well as for the less robust animals, the various preparations of bark will be found sufficiently tonic:

Tonic Ball.-No. 1.

Cascarilla,

$\left.\begin{array}{l}\text { Gentian root, } \\ \text { Powdered caraways, }\end{array}\right\}$ of eac

with treacle sufficient to form the ball for one dose. Give morning and evening.

In the more formidable cases, where greater strength or more tedious symptoms require to be combated, give the

$$
\text { Tonic Ball.-No. } 2 .
$$

Venice turpentine, 1 scruple, Sulphate of copper, $\quad\}$ of each 1 drachm.
Ginger, 
Mix, with liquorice powder sufficient for one dose, and give twice a day for two or three days. After this, a return to the use of No. 1. would be desirable, until the disorder is subdued. Should costiveness ensue, give a clyster, which will also relieve the irritation of the parts; castor oil, one pint, must also be administered, if the costiveness appear obstinate.

Above all things, the horse-owner should avoid the use of such excessively ignorant prescriptions as are recommended, in this disorder most particularly, by every village quack: they are mostly the horses of hard-working people that are attacked with this disorder, and those people more than any other lie open to this kind of advice.

Incontinence of urine is of the same nature as the last-mentioned, only differing in the discharge being involuntary, and the amount, or quantity produced. The disposition to stale frequently, or the urine coming away with scarcely an effort, proves that great irmitability of the bladder is the proximate cause, and we may infer that the quantity would be greater if the animal had more in his system. For this feature of the diabetes attacks only old worn-up horses, in whom the quantity of blood is small, and its course slow. Diabetes of the younger animals sometimes terminates in this mode of producing water by driblets and in small quantities, but to which the moderns have given a distinct term, though both are the same 
disease; a small degree of inflammation prevails when the animal is greatly affected with incontinence. See page 279 .

The treatment should be the same, nearly, as directed at page 281 . Give occasionally the tonic ball, No. 2, page 187, for two or three days. A run at grass for a week, and generous feeding afterwards, generally complete the cure, no other obstacle intervening.

\section{BLOODY URINE,}

I have already said, is but one feature among many other symptoms of inflamed kidneys; and the only reason why $I$ deem it worthy of separate notice is, that real "inflammation of the kidneys" is not always present when bloody urine appears, especially when no other symptom thereof accompanies this single demonstration of disorder. Its causes may be traced to excessive labour, as drawing in a cart or waggon, whilst a slight cold of the kidneys may obstruct their proper action: the office of separating the blood from the water is in this event performed with much difficulty, and of course imperfectly; and small portions of the former, instead of ascending towards the heart, descend to the bladder with the urine, while the animal is straining every nerve and vein.

Rest and a cooling diet are the best remedies for this apparent affliction. Should tenderness of 
the kidneys be evinced upon the touch, or other symptoms of augmented pain appear, give the Tonic Ball, No. 2, page 187, occasionally employing No. 1 instead: the alternation will be found beneficial. If these symptoms increase (which I should not apprehend), then of course the attack must be met with strong appropriate remedies. But I have never known one case of bloody urine out of several score, where the appearance thereof ceases with the day of rest, and comes on again with hard labour, that did ever terminate in genuine inflammation of the kidneys : it will return at intervals (upon hard work) during the animal's whole life probably, without any further ailment attending it.

\section{CALCULUS; OR STONE IN THE COECUM,} KIDNEYS, URETER, AND BLADDER.

When we consider for a moment the vast circulation that passes the (liver and) kidneys, there to undergo separation, as before fully described in the first book; and recollect, that hard extraneous substances pass through these organs, and find their way even into the blood, our astonishment ought to cease at discovering earthy particles, often hardened into stone, in some one or other of those parts.

Cause.-The first particle that is deposited or left behind is no doubt very trivial, as the bisection. of many such stones most amply proves. Want 
of vigour at the time of its access, and the consequent inability to expel the intrusion, appear to be the immediate cause of this otherwise inscrutable disorder. Subsequently, other congenial materials reach the original evil, mostly in the liquid form, and thus add to its size, increase the number of striata, and heighten the danger. The water that is drank by quadrupeds is abundantly impregnated with fit materials for generating calculi : soft river water, and that of turbid pools, convey the softer or earthy particles into the animal's system, whilst that drawn from springs contains the elements for forming stone, as perfect as any geologists find in the strata of our earth. The softer kind of these concretions are found in the blind gut, or cocum; the harder, or stony kind, in the other viscera above-named.

Heat is the power that separates these elements, and hardens each additional lamina that has accrued, or grown over the preceding, from time to time, as the animal may have been exposed to drink so impregnated. This is visible on the section of those stones which have been found in horses and other animals, and preserved by the curious, and cut in two by the lapidary. Every such concretion so found, of whatever nature it may be, exhibits in the centre the nucleus or commencement of the evil, which proves itself to have been either originally stone, or some soft substance, as a bit of chaff, hardened by the heat; but much oftener it presents a perfect pebble, that 
must have been borne along by force of the current, and in the cleansing function of the kidneys got detained and deposited there. If not entangled, as it were, in the cellular membrane of this gland, such a pebble will detach itself occasionally and descend through one of the ureters into the bladder. For full information as to the structure and functions of these several viscera, the reader is again referred to the second chapter of book the first, which treats alone of such matters; as regards the cœcum, at page 12J; the kidneys at page 139; the bladder at page 145 .

One original cause of such concretions has been ascertained beyond contradiction, and as the information may prevent its recurrence among a numerous class of horse proprietors, I quote my authority much at large, by way of preventive advice, seeing that a cure is at present beyond the reach of art: remedies worse than useless. Let us hope, notwithstanding, that the mite which is here contributed may not be thrown away, but incite some future close observer of nature and her ways to add hereto the result of his own inquiries, and so increase the sphere of his utility in one respect, since imperious circumstances have contracted it in another and more obvious line of his profession - the desire of gain.

Millers' horses are most liable to contract this disorder, and for obvious reasons: being large heavy animals for the most part, their owners opulent if not rich, and grain and pulse ever at hand, 
dry food is invariably given to them with a liberal hand. To render these substances more agreeable, to hasten digestion, and thus produce a fine coat with a well-filled carcass, their corn is passed through the mill, the beans also are usually broken; and, thus pampered, they eagerly devour the ready feed, and with it whatever extraneous substances it may have acquired in the process of grinding. These are not few in quantity, it seems; for such articles are invariably ground between stones of a soft nature, that easily part with their rough surface, and these stony particles all find their way into the stomach and intestines; some, here and there, pass on through the circulation, by means that are neither uncertain nor inscrutable in the minds of those who have studied such subjects, and will refresh their memory by turning to what I have said thereon in the second chapter of the first book.

Dr. Withers, of Newbury, Berks, having many years before given to Dr. Hunter a large intestinal stone, which proved fatal to the horse whence it had been taken, communicates to the Medical Society of Crane Court, London, a similar circumstance which had come under his observation -both being cases of millers' horses. He then describes "the case of a very valuable horse belonging to $\mathrm{Mr}$. Andrews, another miller, which lay ill of the colic," as the owner supposed. "I told him (says Dr. Withers) that if he would examine the intestines after death, he would most probably find a large stone, which was the cause of 
the horse's illness." This, the miller, of course, neglected to do; but his dogs made the discovery for him: it was a large round stone, broken, from which circumstance, $I$ infer that it had been at first a soft or earthy concretion, and proceeded from the cœcum. Four such instances all together were remembered at the same mill, besides many others elsewhere; but, with characteristic negligence, the millers in no case thought proper to furnish the doctor with the wohen and the rohere found, nor does the doctor say why. If beans, \&zc. are to be given to horses broken, I may add that a hand steel mill would be found to obviate the objection just raised against the miller's' stone grinding. Such mills may be purchased for three pounds ten shillings of any iron millwright or vender in London.

The symptoms of calculous deposite throughout apparently resemble colic to the view of common observers, as in the case of Mr. Andrews' horse, just quoted; the animal looking at his flanks, straddling when a kidney is affected, as if he would stale, which he does with great difficulty, and sometimes a little bloody. This last appearance also occurs when the bladder has been affected for any length of time, so that the anguish or acute pain had communicated to the kidneys by means of the ureters, in which manner alone blood could possibly have been produced in the celebrated case cited by two cotemporary writers from M. La. Fosse, the elder. When stone resides in a kidney, 
it may be ascertained by pressure of the hand thereon: I will not exactly say you can feel the stone, for it lodgeth underneath, but the greater tension and enlargement of one kidney beyond the other, leaves that notion on the mind; besides which, the animal will shrink, or rather start, a little quicker than in case of "inflammation of the kidneys"- the symptoms whereof, as set down in a preceding page (273), the reader should consult in order to shape his practice accordingly.

Calculous or earthy deposits of substances in the cacum may be ascertained and distinguished from simple colic or gripes, by passing the hand along the lower part of the belly, as described in the first book, at page 126. While such an obstruction remains deposited near the blind part of that gut, no immediate danger or inconvenience is to be apprehended; but when the lump, by any means whatever, moves to the orifice, and obstructs its only passage, the most distressing consequences ensue. One of the causes hereof is the exhibition of hot, strong, or drastic medicines, which are usually given in cases of genuine spasmodic culic; and as the symptoms that attend both are alike almost throughout, with the exception just made, no mistake is more general, probably, than people treating this disorder as they would colic, which course endangers life.

The ureters, it will be seen, are but of small capacity, and in its descent from the kidney, whence it has been detached, the stone sometimes 
meets with an insurmountable obstacle; the irritation it thus occasions communicates to the adjacent parts ; entire suppression of the urinary secretion is the immediate consequence, and mortification of the intestines and death ensues, without the possibility of relief. Indeed, the remedies that seem most proper do but accelerate the catastrophe *.

Much perspiration attends the first hours of the suppression, and it affords evident relief; but painful efforts to void urine, which comes off in very small quantity, and ultimately ceases altogether ; and then cold ears, cold legs, tremor, and an alarming irregularity of pulse, precede but a short time the dissolution of the functions of animal life. This is the most dangerous species of disorder, arising from calculous deposit, that I know of.

In the kidney, however, little danger to life is to be apprehended from the stone, unless the animal is put to severe work, so as to produce the symptom of bloody urine before described. They are mostly fat horses that die with stone in the kidney; in fact, all that $I$ have ever seen or heard of, and these have been numerous; for I have long made a point of inquiring after such cases of calculus, where they seldom escape notice, viz. the

* I say seem, for none can say precisely what is taking place. He whose judgment brings him nearest the real cause of pain being most likely to apply the proper remedy. 
horse-slaughterers' yards, of which it is proverbially and truly said, that not a hair enters but is turned to profit. The probability is, that when the stone detaches itself and descends into the ureter, the fat which partly enveloped it and the residue of the kidney had been withdrawn, through disease or poor living, and the membrane which supported both had divided. I once thought I had made some observations on this part of my subject which would be worthy of public perusal; but these are not sufficiently mature to find place in this little volume, devoted as its pages are to matter of fact, and fair deductions therefrom, and wholly exclusive of theoretic speculation. Nevertheless, in aid of what others may think fit to say in any other place (out of a spirit of controversy), I would just add, that only one kidney is affected at a time, or one ureter; that the calculi found in either of these is invariably of the hardest kind, whilst those of the bladder are softer, and those of the intestines softer still, or little more than concrete eartl. Lastly, that none of those horses which I have found troubled with either kind of calculous disorder suffered under a second at one and the same time. 


\section{CHAPTER II.}

EXTERNAL DISORDERS.

\section{Abscess and Tumours.}

Swelling, with inflammation of the solids, the glands, or simply pustules on the skin, are all tumours, have been divided into eight classes, and when lying deep, are termed abscess, to denote recession from the sight. Poll evil, fistula in the withers, quittor, warbles, range under this head; as do farcy, strangles, grease, and perhaps glanders, owe their origin to the same cause, viz. an ill state of the blood, its vessels, and the means of carrying on the circulation, as happens to all animals that gorge too much. A few general observations on the remote causes hereof seem necessary to a right understanding of each particular complaint.

All those disordersin common, together with several others, I have no hesitation in attributing their remote cause to constitutional defectiveness at least, or incapacity in the function of circulation, better known by the homely expression, "a bad state of the humours," as before insisted upon, principally at pages 159-166. Both series are referable 
to the same predisposing cause. That species of inflammation of the whole system which we have agreed to term fever frequently terminates by concentrating its latent humours, and depositing the same critically in some fleshy part of the carcass or limbs, producing matter (or pus, which, with heat, constitutes the disease) that is corroding, sharp, acrid, and extremely offensive to the senses when brought forth, as it certainly is while yet confined in its cell. Whether abscess or tumour supervene, both have immediate connexion with blood-vessels of no small consideration, though the disorder may have commenced with the finer vessels (capillaries), as insisted upon at the pages above referred to; and hath been repeatedly proved. First, as regards tumours, these being probed, the patients have bled to death, woith arterial blood. And secondly, in every case of abscess, in proportion as they increase in size, so does the patient's strength and quantity invariably diminish. When nature makes an opening to the surface, after long-protracted illness, the patient is usually so exhausted, and the parts adjacent rendered so unfit to re-unite, that the constitution runs off at the orifice; life is seldom preserved, health never completely restored.

Tumours sometimes appear of tolerable large size, that become indolent, without feeling, and are moveable under the skin. These are caused by the same evil state of the blood, or its vessels, and the inflammation or irritation having ceased at 
some time or other, the enlargement remains, though the connexion with the system of animal life has long ceased. Although very unsightly, the animal feels little inconvenience from those protuberances: they receive the name of wen, and might be taken off by dividing the skin, and pressing out the wen: it is then to be drawn forth with the forceps, and the healing of the wound is effected by strapping down the skin with adhesive plaster; the cure is thus said to be effected by the first intention. The usual precautions of taking away the hair, and afterwards keeping the patient's head up for a few days, would of course be adopted.

The genuine tumour is soft and tender, and is contained in a membranous case, or costus, that has been likened to the finger of a glove, or to many of them, when it acquires the distinctive name of fistula. The case, or castus, having been formed by the disorder, and matured by heat, acquires strength the longer it is suffered to continue unopposed, seeking its way inwards, until the knife alone can afford relief. At the shoulderbone the fibrous and membranous construction is exceedingly strong. Look at page 28. Generally speaking, all swellings of a circumscribed nature are tumours.

Some objections which have been raised against the view I have taken of the origin of this whole series of diseases must not go quite unnoticed here, though I dislike controversy as much as any writer who has gone before me on either side the 
question. At the very commencement of this book (page 160), and without adverting to either set, or indeed thinking at all of the controversy, I assigned a reason why the apparently triumphant proof of $\mathrm{Mr}$. White, at page 81 , is no proof at all, but the contrary, as to the thickness or viscidity of the blood increasing with the continuance of inflammatory fever. Every writer on this subject allows that the swelling and discharge of matter that frequently occurs after a fever, or inflammation of the whole system, denotes the crisis or termination of that disorder; and insists that it must be considered as but an effort of nature to throw off something that is offensive to the wellbeing of the animal. The same happens often after " inflammation of the liver" has been reduced; but this kind of occurrence, though it adds nothing material by way of argument, leads us directly to the point at issue. General inflammation (fever), it is allowed on all hands, begets something offersive, and so does partial or local inflammation of any organ through which the blood passes, particularly of the liver and kidneys, through which the whole mass gets filtered, as it were; and nature's efforts to get rid of this offence against her rules are evinced in swelling of the external parts, in the inflammation thereof, and subsequent escape of the offensive something, whereby a cure is effected.

All this is agreed upon by those who deny the necessary pre-existence of a general ill state of 
health, as well as by those who already know, or have yet to learn, that the liver, that acknowledged cleanser, permits much grosser materials to pass through it than those offensive matters, or gross humours, which we contend reside in the blood, and constitute disorder of one kind or other on the surface, or at least predispose the animal to acquire such, according as circumstances may determine one way or the other. Seeing that such gross substances as bits of straw, chaff, \&c. have issued from a vein on blood-letting, is it too much to concede the ultimate point that the feculent humours which constitute tumours, farcy, \&c. may not in like manner escape into the circulation, and be detained at that particular part which is rendered by some accident less capable of continuing the harmful matter in a fluid state? A blow, a gall, a ligature, or bruise, are known to occasion this disability, and bring on disease in one of its varied shapes. So does "a cold" produce fever in some animals sooner than in others, according as the circulation may be more languid, grosser in its particles, more predisposed to inflammation, or otherwise unfitted for its purposes; whilst some again acquire inflammation without any such accident or cold, the fever being lighted up occasionally by zoarm stabling alone, though the air they breathe may be perfectly innoxious.

How it is that those external diseases, enumerated at the head of this chapter, are generated, I shall not here repeat: the reader may consult the 
principles upon which my opinions are founded in the twenty-ninth section of book the first, page 81: to which I will here merely add, that the tumours we perceive on the body that are not of a nature to break and discharge their contents-as farcy, grease, \&c-are usually, if not always, accompanied by corresponding tumours on some vital organ, as the lungs, liver, \&c. But single tumours, containing matter, as the whole tribe of fistula, \&c. are designed to counteract and carry off obstructions and all baleful affections incident to the organs just mentioned, and of all others: an owner ought therefore to deem himself happy, when some inscrutable long illness of the inside terminates in this manner. The appearance of these latter on the surface may be taken as a good assurance that none then exist internally; nor, indeed, any other disorder whatever, the natural strength of the animal system enabling it thus to cleanse itself. Again, we may remark in general, that as it is the better bred animals that are most liable to affections of these organs, so is it the "country-bred cattle," without any breeding in them, that mostly suffer those external attacks. 'To the reflection of every man of experience I refer this material point of dissonance between the two varieties of horse, which serves to prove that those having great lumps of muscle at the parts liable to. such attacks are most disposed to contract local inflammation, and that puffing up of gland or lymphatic which we call tumour of various kinds.

0. 5 
Local inflammation alone, however, could not effect the evil, without some corresponding cause; else, how comes it to pass that none but aged horses, that are heavy in the hand and slow in blood, contract fistula or abscess; young and lively horses, and those with some breeding in them, never? Once more, -if the disorder reside not in the blood, how does it come to pass, that a horse having contracted one species of tumour, he is never known to undergo an attack of any other species-and there are a dozen at the least? For example, give a horse the poll-evil, and see how little he will be disposed to contract the glanders.

Fleshy horses, those of the cart breed and of indolent habit of body, are most liable to contract poll-evil, fistula, \&c.; indeed, I might say, the ready disposition thereto is confined to that breed, though either could be inflicted upon higher bred cattle, which might not be so predisposed by a bad habit of body, or by the gross humours before noticed. When the animals are young, and feed ravenously, the strangles carry off those humours; when youth leaves them, and more doltish habits come on, these humours appear in some other varied shapes: besides those diseases just named, the farcy, grease, and anticor, all come on from the same indolent habit of body. They are always ravenous eaters, gross feeders, and consequently lethargic in their movements, that acquire poll-evil; for they demand harsh treatment to keep them at their work, which frequently de- 
volves into ill-usage, unless the carter possess the patience of Job.

Hence the duty of attending to the general health of such horses, as much as may be consistent with the avocations of the owner; of avoiding the infliction that is often the immediate cause of either species of ailment; and, these being discovered, of applying the necessary remedies for their instant dispersion-if the symptoms are mild, and thus promise success, a low regimen follows of course. But delay too often confirms the disease; it approaches towards maturity, and will not be repressed: then does the duty of "bringing it forward" to suppuration present itself as the only means of obtaining a radical cure; and I may add, that this is always the safest, the best, and the most certain means, when the disease yields not to the first efforts at dispersion. In ordinary cases of saddle gall, the swelling and heat will bend before an assiduous and early application of the lotion; not so easily, however, in case of "fistula in the withers," which lies deeper and is more obstinate. Least of all will confirmed poll-evil give way before the strongest repellents; or, if the resolution be apparently effected, the least external injury, or none whatever, will subsequently reproduce the disorder with more than its original virulence. Perhaps, in no part of the farrier's art has he the opportunity of evincing his judgment more, than in choosing the precise period when he will quit all attempts at suppressing 
the abscess or tumour, and set about bringing it forward to suppuration and a radical cure; when he will also quit the low regimen which was proper in the first attempt, and adopt a more generous diet, that is better adapted to the painful discharge his patient will now be compelled to undergo, either by dint of medicinal applications or the knife.

Abscess in the more fleshy parts of the body, or under the belly, are far less dangerous or troublesome situations than on the parts just named; they also prove to be symptomatic of the actual evil state of the blood, of which they then form the crisis or point of cure, and therefore the repression of such (as recommended in other cases) should not be attempted; neither should the animal system be lowered, but the contrary. If, however, the tumour appears near a joint, or just above it, as the hock, so as to impede its action, in which case it would soon assume an ulcerous appearance, by reason of the movement of the long muscles of the limb in going, repression should then be resorted to with assiduity and skill. Artificial inflammation, excited upon the skin and cellular membrane, near the part, by means of blistering, or rowelling higher up, has the good effect of drawing off the heat and tension from the more important joint; nor does the animal by this application undergo so much pain as he would were the tendon affected, whereby the limb would become irremediably stiff and useless. 


\section{CRITICAL ABSCESS}

Is that swelling or tumour which is occasionally thrown out on the body or limbs from no apparent accident, but what may be traced to that derangement of the system we call fever, and is sometimes attendant upon protracted inflammation of the liver, when the disease appears on the fascia of the muscles of the belly, on the jowt, or other glandulous parts.

The cause and the effect thus become manifest together; and when great tenderness is evinced upon touching the parts, in ordinary cases, nothing more is required than to make an opening in the lowest edge of the swelling, and expressing the contents; the cure is effected by means of the common " digestive ointment," which is prescribed under the article "Poll-evil," farther down. But the proper time at which the opening is to be thus made requires close observation. In general, this may be ascertained by a change in the animal's manner: he will eat more heartily as the matter increases; which proves that the disease of his habit has accumulated at this precise spot. He should not be allowed long to remain in this state, lest the offensive matter should penetrate inwardly or laterally. If the disease is thus distinctly known to proceed from the remains of illcured fever or inflammation, poultices should be applied to bring it forward to the surface, and the animal receive increased feeds of dry corn, of 
beans, or sodden corn, according to his former habits, in order to encourage the access of matter: for nature, exhausted by the violence or the continuance of the disorder, is incapable of expelling this last remains of the enemy, and stands in need of support. Should the horse have been lately laiu up with fever, or for some time past shown languor in his gait, and heaviness about the eyes, or it may be concluded from his recent liard labour and hard mode of living, that he has been long ailing inwardly: in this case the abscess being evidently a critical symptom of the general evil state of his blood, nature must be assisted in getting rid of the offensive matter; and for that purpose bring the tumour to a head by means of a poultice. 'The head is most commonly the seat of swelled glands.

\section{Drazing Poultice.}

White bread, the crum of a $4 \mathrm{lb}$. Ioaf,

Onions, chopped, $2 \mathrm{lb}$.

Boil the onions in water, and pour the whole on the bread: mix to a tolerable consistency, and whilst blood-warm apply copiously to the parts in a cloth. Support the application by means of a bandage of stout linen cloth, with ligatures tying over the forehead and across the poll thrice, as described in the annexed sketch. Some persons have recommended the use of a solution of gum, to render the cloth impervious to liquids, and cahoutchouc is with some a great favourite. See page 212. 


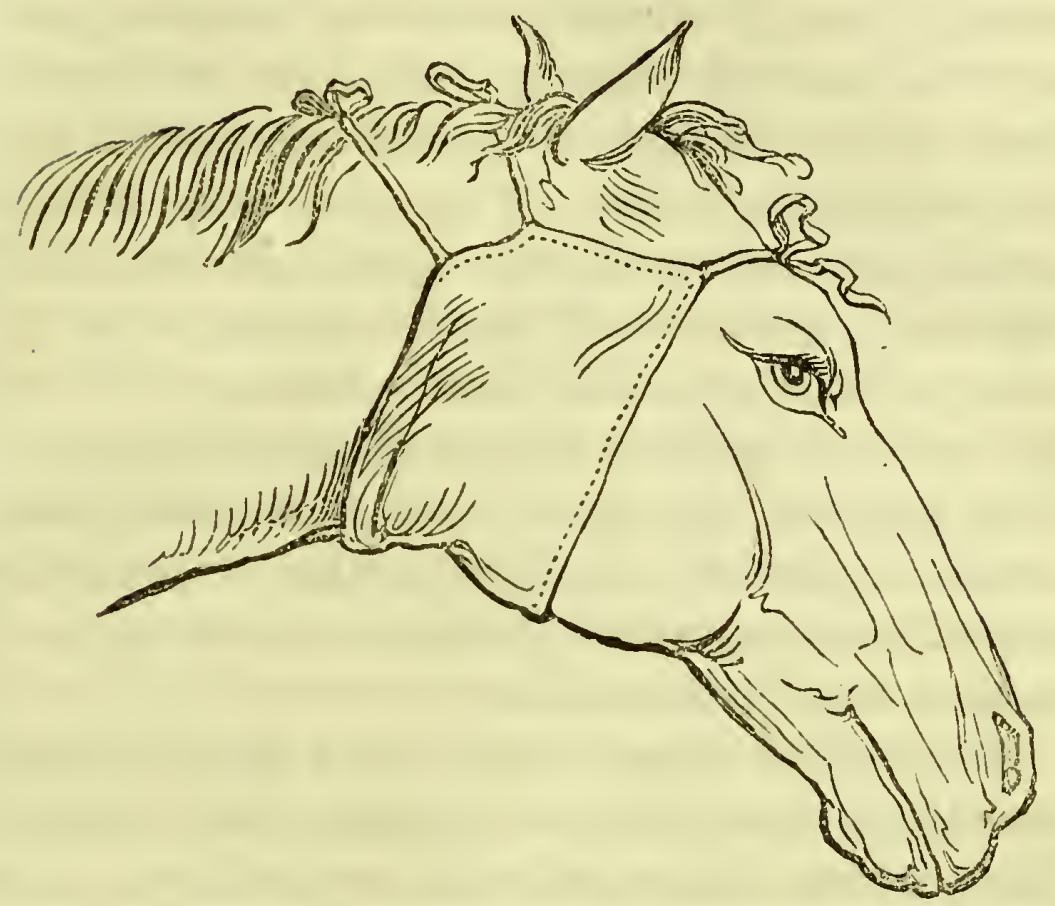

Should circumstances require a more extended application, or that the patient's restlessness might $\mathrm{rub}$ off the bandage, let a more extended bandage be employed. For such an one, and as to further particulars, the reader may consult page 212, where a bandage for sore throat is depicted.

By those means the swelling will come to a head and give signs of being about to burst, but which I have reason to believe never happens spontaneously by reason of the thickness of the skin. Apply the knife, or bistoury, as directed much at large in the case of poll-evil; give the like purgative on the same day, and lower diet is to take place of the abovementioned. When it so happens that the opening has been made too soon, before it has accumulated sufficiently, the orifice may be kept open by means of a seton 
passing through it to the lowest or most depending side, and the running continued for several days, until it assume a healthy appearance and the swelling subsides. 'This plan must always be adopted with the slow or sordid tumour, which will not come forward, though heated with the onion poultice, and even with a blister: then let the seton be applied, without cutting, changing it daily and soaking the tape in the irritating mixture, as in case of poll-evil, page 315. That other critical abscess, called strangles, comes under a distinct head farther down.

Deep-seated abicess, under the fascia of the muscles of the belly, is scarcely ever curable, being seldom discovered to the eye until too late to render assistance in bringing it to the surface by means of strong drawing poultices, as in case of obstinate poll-eril. On passing the hand over the part, the animal may be observed to Hinch from the touch; but this symptom is seldom attended to, and it makes its way inwards, bursts in the cavity of the abdomen, and kills the patient.

\section{POLL-EVIL.}

Causes.-Next to a diseased habit of body, as just above noticed, which predispose a certain description of horses to contract tumours in various parts of the body, the poll-evil is frequently occasioned by a blow, or gall, of a very trivial nature, if it do not come on without this kind of excitement. The action of the head is very great 
with some horses, arising probably from an itching in the upper part of the cervical ligament, where it is attached to the vertebræ of the neck; and this causing irritation, we need not hesitate long in accounting for the inflammation that affects the muscle which interposes between it and the knoll-bone, in a cavity that is greater with some breeds of horses than others. This variance in conformation is exemplified in the whole-length portrait of a skeleton which is prefixed to chapter I, wherein the cavity that should form the seat of this disease is scarcely perceptible; whilst the small figure, inserted at section xvi. of that chapter, to illustrate the uses of the cervical ligament, has this cavity of the usual extent. Of course, this latter would be still more predisposed to contract poll-evil than the former, which was a peculiarly formed horse in another respect also; and it is more than probable, that, if the two were to fall into an equally bad habit of body, whilst the latter might acquire poll-evil thereby, the constitution of the former might throw off any offensive matters that might accrue by some other means *. The reader will do well to turn back to the section referred to (p. 53), as well as to the skeleton [at A 5].

* These might appear in shape of grease or farcy; but it has been generally observed that a disposition to farcy abates, if it do not subside entireiy, upon the appearance of poll-evil. Again, horses that are most liable to contract "the grease" are precisely of the same disposition as those which are afflicted with tumours, \&c. viz. of indolent habit, heavy in the hand, and slow of blood, fleshy and dull. 
The wheelers, in a set of horses, will frequently throw back the head in warm weather, or after brisk work, at feeling the reins that run through their head-harness to the leaders: this action is performed, as the reader will have learnt, by the action of the cervicular ligament, the upper end whereof terminates where the ear-band rests, and perhaps pinches the part. Horses that are given to shy are likely to contract poll-evil when hanging back, and throwing up the head with a jerk.

But the most prolific cause of poll-evil I am inclined to attribute to the low stable door-way, whereby the animal gets many a trivial hit at going in and coming out; next in point of frequency is that brutal mode of attacking restive horses about the head with the butt end of the whip, an evidence of ferociousness on the part of the offending carman that was much more rife in my younger days than at present. Education of the lower classes has effected the abatement of this as well as many other unfeeling practices. Ofttimes, the edges of the ear-band, being sharp, create a painful itching, then soreness and irritation about the part, as does also the showy tip, or " cutting at a fly," practised by our flashy four-in-hand men, who may have discovered that touching up the animal in such a vulnerable part is "sure to make him go along." Stage-coach horses, however, do not now acquire poll-evil, so far as I can learn, like what they did formerly; for the great expedision these vehicles are constrained to compels the 
proprietors to use better bred cattle than their predecessors-those that are less indolent, not so heavy in the hand, nor sluggish, consequently not so liable to contract diseases incident to a bad habit of body, or vitiated state of the blood, like poll-evil and its nauseous train of co-existent evils, that we shall proceed to take into consideration one after another.

Pack-horses composed another great class of horses that formerly fell victims to poll-evil, and afforded of itself extensive practice to some veteran farriers of the old school, among whom, I verily believe, one or two existed who could actually cure this almost hopeless disorder, by some means little more rational than a charm. Of those persons and their practices more anon. Meantime, the improvements in our roads, and the employment of wheel-carriages instead of packhorses, with bells on their ears (which were supposed to cause the evil), have contributed to reduce the number of sufferers by this particular disorder; but the extreme triviality of this attributed cause of poll-evil, which I cannot doubt is valid, tends to prove what I before stated, viz. that abscess or tumour might accrue without any external cause whatever. Most certainly, "a violent blow" is not necessary to bring on the disease, as James White would have us believe.

Symptoms.-At first the animal appears restless, throwing his head back and returning it to the former position, as if the effort had occasioned 
pain. Soon after, it droops the head, holding it now on one side, now on the other; appears dull about the eyes, and becomes sluggish in its movements. In this state it continues a longer or shorter time (even weeks) as the violence may have been greater or less that brought about the evil; the time depending also in some measure on the height of the pulse-a languid system making of course the slowest advances towards bringing the abscess to maturity. This uneasiness of manner is accompanied by heat, swelling, and shortly by tension of the part, and increase in the pulsation. As it goes on, a disposition to flinch from the touch is evinced whenever the part is approached with the hand: if the evil be deep-seated, the swelling is wide, but not so high; but when nearer the surface, it presents a point, is circumscribed within a well-marked circle, and ultimately tells how necessary it is that the contents should escape, by a throbbing which may be felt at this point. Again, to ascertain that the matter is near the surface, apply two fingers alternately on the sides of the tumour, and the matter will recede from side to side. Let it out.

Cure.-At first, this may be attempted, in the earliest stages of the disorder, by repression or dispersion, provided the disorder be not deep-seated near the bone; which will be the case if it has been brought on by violent means, or it be a second attack, when endeavours to repress it would be vain indeed. On the contrary, if we 
can trace the cause to a hurt of no long standing, or of trivial import, and we know the horse was in good health before the swelling took place, then our duty is to put back the evil into the animal's system, and work off its bad effects by physic. Foment the part well with bran and water, warm; rub it dry with cloths, and apply the

\section{Embrocation.}

Spirits of wine, half a pint,

Camphor, 2 drachms,

Goulard's extract of lead, 1 drachm.

Mix, and apply the same two or three times a day, gently rubbing the part as much as the animal can bear. Give also at the same time the

\section{Alterative Ball.}
Aloes, 4 drachms,
Castile soap, 2 drachms,
Calomel, half a drachm.

Mix with mucilage, and give one each third day, provided the embrocation is applied so long.

During these applications, a cooling regimen should be observed, the feeds being reduced to half the usual quantity of oats, and ultimately discontinued altogether. There will be no propriety in clothing up the patient, nor need he be exposed to cold air, if it prevails. When the disorder has been brought on by simple compression of the ear-band, and is recent, I have never 
known the foregoing treatment to fail; and in cases of vigorous constitutions, the swelling, heat, and tension have been reduced so quickly (i. e. in four or five days), as to leare certain careless observers in doubt whether the animal liad really laboured under a genuine attack of poll-evil.

Remove the halter, and if the animal be put to work, contrive to keep back the ear-band. A good and valuable embrocation will be found in simple vinegar three or four times a day, or that kind termed alegar in the north, or the sediment of very stale beer. Old verjuice answers the same end; and all this kind of embrocation must be laid on warm, by means of cloths soaked and applied repeatedly.

* * The same treatment and observations will apply to all the other species of abscess in its milder state, viz. fistula, warbles, quittor; but of these I shall speak more particularly under their respective heads of information.

Second method of cure.-Very few cases present themselves to recollection of even recent poll-evil, that would admit of being completely dispersed, and a radical cure effected, by any means whatever; and it is due to candour to acknowledge, that some of the more stubborn attacks were found to have relapsed after a while, which proved that the cure so effected to all appearance was not radically good, but had left a violent predisposition to renew its ravages afresh. Probably, the time 
of inflicting the injury had not been accurately marked, nor its degree ingenuously reported to the owners in those cases of relapse.

However this be, when the disorder is found to baffle the endeavours employed to disperse it, the whole course of proceedings must be changed, as before hinted in the concluding sentence of my general observations on this topic. Instead of putting back the swelling by those means, let us pursue a direct contrary course, in order to bring it forward: the mode of feeding must be changed along with the medicines that now become proper to procure suppuration, or a discharge of the offensive matter; a full habit being mainly conducive thereto, and proving how closely connected is this disease with a gross habit of body, which in all fleshy animals superinduces a diseased habit, vulgarly but accurately termed "full of humours." After having found useless your efforts to disperse the tumour, or, mayhap, finding at the first-view of it, or by the first touch, certain symptoms 'that prove it ought never to be dispersed, the practitioner will of course seriously set about permitting, or forcing, the offensive matter to escape. Every hour's delay in putting this resolve into practice serves but to render the ultimate cure still more difficult and hazardous; for the evil is all this while extending its baleful effects inwards and sidewise, and forming around it, in every direction, the fistulous case or cæstus before spoken of, which is a film, or skin-like substance, formed of the $\mathrm{cel}$ - 
lular membrane, thickened by the heat of the disorder. (See Book I. Sect. 2\%, page \%6). In this event, the tumour has become decidedly fistulous, and is to be treated as such, when the great length of time it may have been suffered to make head, and its now extended surface, warrant that conclusion. The knife is almost the only remedy, notwithstanding the superficial tumour will in some cases break and discharge matter of itself; this, however, never happens with the deep-seated abscess, which lies close to the bone, and destroys not only it, but the muscular substance of the poll, and the end of the cervical ligament also. In these series of abscess or fistulous tumour, nothing but the knife can ever reach the disorder, and it must be employed fearlessly, but with a commensurate share of skill, after the skin has been prepared with fomentations, \&c. Let the parts be softened and draron with poultice of oatmeal, put on lukewarm, twice a day; and if the effect be not visible to the eye and touch, as before described, increase the powers of the poultice by the addition of onion chopped and mixed with the poultice whilst warm. Or, a mere change may be adopted, and a bread poultice applied instead; for, notwithstanding oatmeal is stronger, yet I have occasionally found the milder have more effect when the former had not succeeded entirely according to my wish. The poultice should be provided in sufficient quantity to cover the whole swelling two inches thick at least, having a small quantity of sweet oil; hog's 
lard, or oil of turpentine mixed therewith. Fix it on by means of a contrivance that is sufficiently explained by the annexed cut, in which it will be seen that the girth is to have a roeb breasting, to which the lateral corners of the cloth are to be attached by broad tapes, as was explained in another similar case at pages 212 and 302.

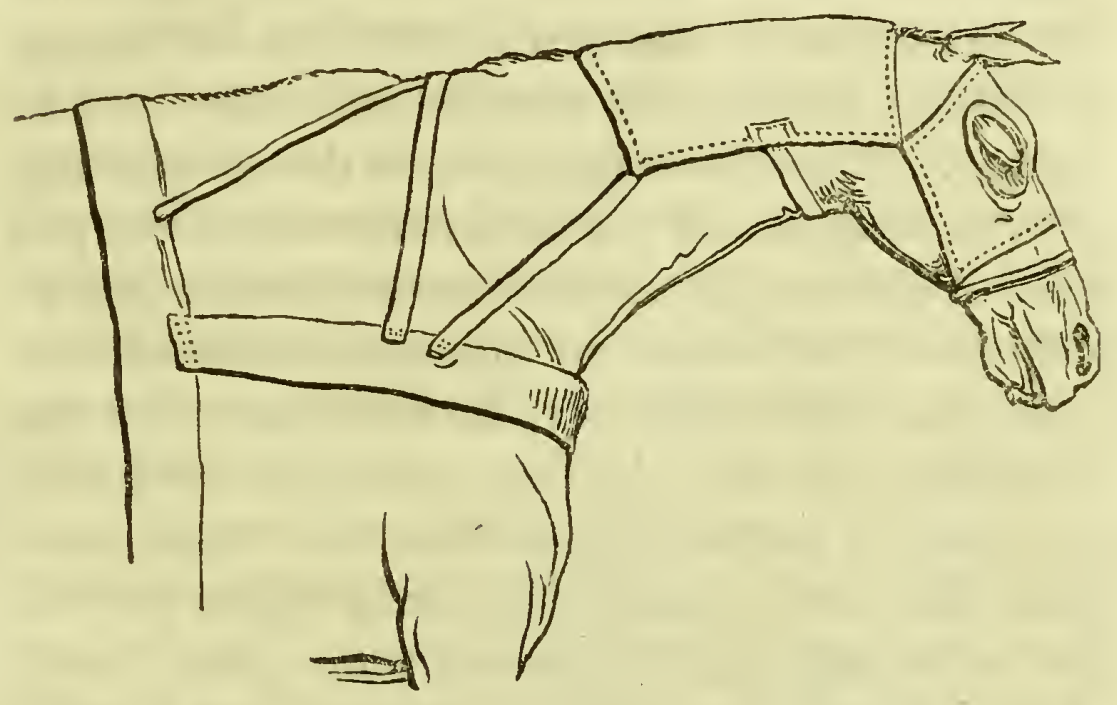

I have here represented the bandage rather longer than requisite, under the presumption that it may occasionally be applied to other affections farther back; a prolongation of the bandage may be affixed at either end, either plain or plaited, according to the amount of the swelling.

When the symptoms above stated inform our senses that the matter ought, to be so "let out," an opening is to be made the whole length of the abscess, a little below its centre; taking especial care that the knife do not pass cross-wise, lest the 
attachment of the cervicular ligament to the first (vertebræ) bone should be severed; in which case the animal would droop its head ever after, as may be learnt by consulting its construction at p. 53, of Book I. On the escape of the matter, after ascertaining by a probe whether it runs in pipes, or sinuses, this way and that, or with small bits of diseased fibre or membrane stretching across the cavity, so as nearly to divide it into unequal parts-let each be just touched with the knife or scalpel. There is no propriety in the old practice of squeezing out all the offensive matter from this kind of abscess, although it be very proper in that detp-seated sort where no pipes, nor the small cavities just spoken of, are to be felt or seen, for the following reasons: the first mentioned kind have the case or castus before described, which contains the matter, and if laid open before the eril be sufficiently ripe, it does not come away freely. This, however, the operation effects in two or three days, if kept running by means of a seton, or other contrivance placed at the orifice; but the application of tow, or any other substance, that obstructs the escape of this matter, is ever to be avoided. On the contrary, when the abscess is very deep, reaching to the bone, which may be felt, and presenting but one large cavity, then the matter should be expelled by pressing gently on two sides of it at once. Let the lips of the opening be dressed the first time, and as long as it may be found necessary to keep open the wound, with 
any ointment hereafter mentioned, on which has been strewed sulphate of copper, powdered. Should the lips adhere together, or appear much diseased, wash with muriate of ammonia, taking care it does not run upon the sound parts, nor into the cavity. In either case, wash off the dead parts with warm water, before each new dressing is laid, sponge it well and dry, after inserting the probe on every side into the fistulous sinuses, and continue this mode of treatment until the parts assume a healthy appearance.

The seton should never be neglected in bad cases of either description, but be introduced at the lowest or most depending side of the abscess, after being wetted with the following

\section{Irritating Mixture.}

Spirits of wine, 2 ounces, Corrosive sublimate, 1 scruple;

Mix and saturate the tape therewith daily. This will keep open the orifice until the offensive matter has run off, and is succeeded by the more healthy issue of a thicker consistency, and nearly white. On this appearance the seton is to be withdrawn, and the parts dressed with the digestive ointment, the animal physicked once or twice with a moderate purging ball of six or seven drachms of aloes, and the cure will complete itself with the usual dressings, viz. 


\section{Digestive Ointment.-No. 1.}

Yellow wax,

Rosin,
Burgundy Pitch, of each 1 pound.

Turpentine (common) 4 ounces.

Linseed oil, 20 ounces.

Dissolve over a slow fire and spread upon leather or stout linen cloth, sufficiently large to come over the undiseased region of the evil, after the wound has been well cleansed. Fresh dressings hereof should go on daily, but in no case until the matter assume a healthy appearance, which it never can be brought to, unless the whole recess has been reached with the knife, or by the operation of "the scalding mixture" of the old school of farriery. This remedy, so applied, though at variance with our modern notions of pathology, has been adopted by the collegians of St. Pancras, and with good reason, for it never fails to effect a cure, by effectually cleansing away the diseased parts. Three several mixtures are adopted in different parts of the country-the Hertfordshire and midland county farriers employing No. 1; No. 2 is that recommended by Gibson; and No. 3 is Ryding's.

\section{Scalding Mixture.-No. 1.}

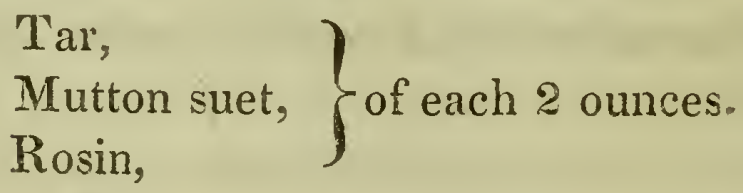


Bees wax, 1 ounce.-Melt slowly, and mix in Spirits of turpentine, 2 ounces.

Verdigris, 6 drachms.

Mix and pour into the orifice hot, and close it with stitches. The next two have the recommendation of being more scientific, and are withal better adapted for penetrating into the sinuses.

$$
\text { Scalding Mixture.-No.2. }
$$

Corrosive sublimate,

Verdigris,

Blue vitriol,

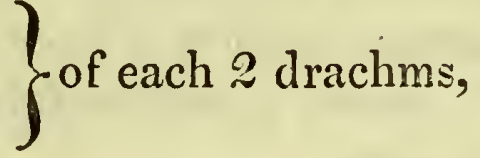

Green copperas, $\frac{1}{2}$ an ounce,

Honey, or Egyptiacum, 2 ounces,

Oil of turpentine,

Train oil,

$$
\} \text { of each } 8 \text { ounces, }
$$

Rectified spirit of wine, 4 ounces.

Mix, and apply as before directed. The difficulty of retaining this last in its proper place, is its only defect; but Gibson appears to have prescribed a quantity sufficient to allow for spilling a good portion. Since writing the above, however, I have inserted the sketch of bandaging for poll-evil remedies at page 313 , to which the reader will refer, when requisite, and introduce such modifications as the nature of the applications may demand to prevent the loss of any part.

Scalding Mixture.-No. 3.

Oil of turpentine, 2 ounces,

Verdigris, 1 ounce,

Ointment of yellow resin, 6 ounces, 
Mix and apply as above. In using any of those hot mixtures, a piece of tow should be so placed as to surround the orifice and prevent its running over the sound parts-which would be injured thereby, as would the operator's fingers, \&c. if he neglect the proper precautions. These he should not fail to take as regards the acrimonious discharge from the abscess, as absorption thereof might take place at the root of his nails; so, if the discharge be allowed to rest upon the sound parts of the horse, it will be found to corrode and produce ulcers.

Frequently it happens-and I believe the old farriers alivays " repeated the dose," that a second application of the "scalding mixture" beconres necessary, for their cases were always very bad ones. In this event, opportunity is afforded of employing. both prescriptions in succession; but whichsoever is first adopted, let it remain undisturbed from sixty to seventy hours, if the stitching do not sooner burst. Sponge out the parts with warm water ; cleanse away the adjacent filth, and either repeat the same or proceed at once to the curea determination the doctor will come to, according as the rottenness may have sloughed off, and the inside of the abscess may present a healthy appearance, or otherwise. If it be quite clean, the adhesion of the parts will follow with very little further care than applying the digestive ointment according to the receipt in page 316 -or the following 
Digestive Ointment.-No. 2.

Common turpentine, 4 ounces,

The yolks of two eggs.-Mix these well, and add

Myrrh, in powder, 4 drachms,

Mastich, 2 drachms,

Tincture of myrrh sufficient to bring the whole to a proper consistence.

Should the cure of the wound proceed too fast, the over-luxuriant granulations of new or proud flesh must be touched with caustic.

But, notwithstanding all that has been said above, it sometimes happens that a totally different course becomes necessary, when abscess in the poll is connected with another disease arising from the same vitiated state of the animal's system, and the remedy for one of these will cure the other. Farcy is the correspondent disease to which I allude, or rather I should say a tendency to farcy, visible in certain scanty lumps or tumours on the body and legs: these will run off sometimes by means of a copious discharge at the poll. More frequently, however, the farcy is of too inveterate a description, and proves that the whole mass of the animal's system requires correction, and that it must be treated with medicines proper for the farcy, as well as the local affection of the poll.

People in general like to be borne out in their 
most novel opinions by those of longer standing in society, and I confess myself one of those sort of people as regards the doctrine of a vitiated or a corrupted state of the animal's system, which it is absolutely necessary to correct by medicine before the cure of some disorders can be effected. I strongly touched upon this topic in the first book, and at page 160 , to which probably the inquiring reader will turn; and become convinced with me that poll-evil may be no other than the critical abscess of farcy; which farcy is a disease of the system, and is correspondent with glanders, as poll-evil is with quittor, warbles, vives, \&c. The writer I shall quote as agreeing with me, mainly, in this view of the subject, is Richard Lawrence. He says, "the poll-evil is sometimes connected with a disposition in the habit of body to farcy; this may be known by the animal appearing universally [i.c. generally] unhealthy in his coat, the tightness of his skin, and also by small lumps or swellings in different parts of his body, and particularly on the insides of his legs. When it is ascertained, therefore, that the poll-evil arises chiefly from a disposition to farcy, the mere operation of opening the abscess, and using the dressings usually recommended, will not prove sufficient, without the aid of medicine given internally; because the abscess, not being then a local affection arising simply from partial injury, it will be necessary to correct the general habit of body, before a cure can be effected." The 
medicines best adapted for this purpose will of course be found under the head of "Farcy," a few pages farther down.

\section{FISTULA IN THE WITHERS.}

Cause.-Although closely resembling poll-evil in so many respects as to seem the self-same disorder arising from precisely the same causes, but differing in situation only, I must here premise that some other distinctions are proper to be taken, which it will be necessary to keep in mind. We have seen, a few pages higher up, that pollevil may be produced without external violence; this never happens with fistula in the withers, which is always brought on by external injurynamely, the galling of the saddle: in the first case the tumour fiequently turns out a simple abscess, in the present case never, but becomes fistulous at its very earliest stages. This arises from the quantity and great strength of the membrane which is found in the shoulder and whole forehand of the horse, in the cellular structure whereof the offensive matter finds an easy receptacle, and spreads its ravages from side to side and inwards. How this operation of nature is performed, the reader is instructed in the first book, at sections 26, 2\%. I have also descanted somewhat at large, in the general introductory observations on this whole series of disorders, as to the distinctions proper to be kept in mind between one kind of 
tumour and another, how they are formed, and what description of horses are mostly liable to this or that species of the disorder. At page 292 will this information be found, and which the reader would do well to consult once more before he sets about treating his horse for fistula in the withers. The symptoms are most obvious to the touch, as in all inflammatory tumours, the animal shrinking when the hand is passed over the shoulder from the mane downwards. But the ill-formed saddle, or one that fits the particular animal like nothing, or one that is so badly girtled in, that the poor beast may be perceived going in great pain, shall be set down as the symptom of all symptoms that the animal is destined to contract this particular disorder of the parts so injured. Sometimes he tumbles down, or seems to trip frequently, which should admonish its inconsiderate rider or driver, that his carelessness is very likely to cost him a broken neck.

Cure.-As soon as the journey can be brought to a close, which has been thus improperly pursued, remove the cause and bathe the part well with the cold saturnine lotion, and when the saddle has undergone the proper alterations, the journey may be pursued, if necessity demand such an exertion.

\section{Cold Lotion.}

Subacetate of lead (gonlard), 2 ounces,

White vinegar, 4 ounces,

Water,3 quarts.-Mix; and apply with a sponge. 
Should not this prevail, and the horse evince pain at the touch, with increased heat and tension, and swelling of the part commence, the disorder is confirmed, and if not repressed in its very earliest stages, suppuration must ensue. Let it be taken in time, however-that is to say, in the course of a day or two, or a week, with healthy active horses, is not too long-and the heat and inflammation will be reduced by employing the cmbrocation, recommended in incipient attack of poll-evil, at page 309, and giving at the same time the alterative ball there set down. Success more generally attends this first method in the present kind of tumour than in that to which I have just referred, viz. poll-evil; but this method of curing both is so exactly similar, that it would be a waste of words to go over the same grounds again, or make the same observations which I thought proper to set down under that head of information. At page 309, the reader will perceive, that when he is attempting to repress the tumour and allay the inflammation in its earliest stages, he is to employ a cooling regimen; that when the disorder has been brought on by a trivial cause, this method of cure seldom fails, if taken in time; and also that fistula is easier prevented hereby than is poll-evil. "However this be, when the disorder is found to baffle the endeavours employed to disperse it (as I before observed), the whole course of proceedings must be altered ;" the regimen, or feeding must be higher, 
the parts encouraged to collect matter and come to the surface, instead of making inroads upon the adjacent muscle and bone, which it will effect more hideously as the animal may be afflicted with a gross habit of body.

"After having found all your efforts useless," said I at page 311 , the practitioner will change his plan, and force the matter to escape as soon as may be; for the disorder is every hour extending its baleful influence. For this purpose the knife, or common bistoury, is to be employed when the tumour is sufficiently ripe, which is a state it may be brought to, by means of the poultice application. Of these, I prescribed two or three kinds, with the method of fastening them on, but in this latter respect, a material difference arises in consequence of the different shape of the parts. The bandage in this case must be allowed to come farther back, and be there detained by tying the tapes short behind and lengthening the front ones. See figure at page 313.

Fomentations of warm water, in which cloths have been steeped, slightly wrung out and applied to the parts, will be found highly serviceable, and may precede the application of poultice. When by these means the tumour appears ripe and ready, open the most prominent part with lancet or bistoury, and insert a whalebone probe to ascertain the direction that the fistulous sinuses or pipes extend, in order that these may be laid open, and the whole matter suffered to escape. In some 
cases a stiffer and larger probe may be employed, and when a sinus lies favourable, introduce the probe, and cut down upon it. But as to the lowermost sinus, when it tends towards the shoulder, so as to interfere with the action thereof, the knife is not to pass through it, but a seton is to be inserted in its lowest or most depending part, so that the matter may escape through.

As directed in the previous case of poll-evil at page 314 , the knife should be fearlessly applied in severing any small bits of muscle that may appear to grow across the cavity; a touch of the knife will be sufficient for any purpose, as by keeping open the lips of the wound, all that belongs to this diseased part will slough off, and should be wiped away, as before directed, every time new dressings are applied. Let the seton be soaked in the mixture of corrosive sublimate and alcohol as directed at the page just referred to; and in the worst cases apply either of the scalding mixtures in the manner mentioned at page 316 , and repeat the same if the first does not accomplish all that is desired.

The operator in this case will not fail to use the proper precautions as regards the application of those scald-hot remedies, nor neglect to remove the matter that is discharged from the wound, in the manner set forth at page 318. Most frequently, the lips or edges of the sore are thickened by the heat and acrimonious nature of the discharge, and assume a very inflamed and ulce- 
rous appearance; this should be reduced by the knife or caustic, or it becomes so luxuriant at times as to close the orifice, and to cause a renewal of the fistula, in which case you have all your trouble to go over again. At Alfort, they have a very neat method of cleaning out fistulous ulcers, by rolling up pledgets of linen cloth, the edges whereof have been scraped out thin, so that when introduced dry to the bottom of each sinus or pipe, and being twisted round, it brings forth the offensive matter and any residue of blood which may have got into them during the operation. They also employ gentian root to keep down the swelling or thickening of the lips of the sore. The healing is not to be suffered to go on too fast, nor until all the offensive matter has been expulsed, and a more healthy discharge, whilst it manifests the change that has taken place, and warrants your closing the sore. Blue stone spread on any plaster of digestive ointment will effect this; or take

Ointment of nitrated quicksilver, 3 ounces, Oil of turpentine, half an ounce.

Mix, and apply as long as it may be found proper to keep the orifice from closing, to which it will be ever too much disposed.

Something was formerly said about scraping the bone when the long continuance of the disorder, its virulence, or the bad state of the horse's general health, hath been such as to affect the fine 
enamel of its surface; but this part of the opera. tion is rather showy than useful, as the rottenness so occasioned will come away as the discharge is kept up, there being a constant disposition throughout the whole system to throw off all such offensive matters.

\section{SADDLE GALLS; vIz. WARBLES, SITFASTS.}

The first of these partake of the nature of the disorder just above treated of, viz. fistula, and are caused by the same means, bruise of the saddle : but being situated farther back, less scope is allowed for the spreading of the original tumour. Consequently, the smallness of the affliction renders it much less formidable, though, if suffered to suppurate, they become most troublesome sores. The means to be adopted for the cure of warbles are similar to those recommended for other tumours, viz. at first try to prevent the accumulation of matter by repellants, such as the embrocation prescribed at page 309, the domestic remedies in the next page, as verjuice, or alegar, made hot and applied by means of cloths soaked therein, and repeatedly changed. Or apply, in the same manner, the following

\section{Cold Lotion.}

$\left.\begin{array}{l}\text { White vinegar, } \\ \text { Spirits of wine, }\end{array}\right\}$ of each 3 ounces,

Super-acetate of lead, 2 ounces,

Water, 6 ounces. Mix. 
Should not these succeed, change your treatment, adopt the direct contrary mode, and bring the tumour forward to suppuration by means of poultices, Sc. as before recommended; and finally, when ripe, open the tumour with a lancet, promote the escape of the offensive matter, and then proceed to healing the sore, as in the former case of poll-evil and fistula in the withers.

Sitfast is an indurated tumour, one that has neither matter nor motion in it, and may arise from either of two causes. The first is simply a gall or brụise, which has produced no inflammation, and consequently no matter has been engendered; the second comes of an ill-cured warble, that has closed, leaving a hard insensible swelling behind. Blistering is the favourite remedy with most farriers, though fomentations and poultices will frequently achieve as much good in very little more time. When suppuration has taken place, the cure is to be completed by dressings of detersive ointment, taking care that the sore does not heal too fast. Should this be the case, put blue stone, powdered, upon the plaister, once or twice, or merely touch it with lunar caustic as often. Sometimes the callosity does not come off of itself, though the edges rise up; it is then to be taken away by force, separating it from the living parts with the knife. The small portion of blood that comes away does no harm, but the contrary. If, however, any one objects to the use of the 
knife, or doubts his skill in this operation, mercurial ointment will effect the same end, as follows:

\section{Ointment for Sitfast.}

Oil of turpentine, 10 ounces,

Blue ointment, 8 ounces,

Gum ammoniacum, 4 ounces;

Mix and apply to these and all hard tumours.

\section{QUITTOR}

Is a disease of the foot, at the coronet, but is so decidedly fistulous, that $I$ choose to treat of it in this place, rather than in the chapter devoted to the foot in general, that the student may more readily remember the general observations I thought necessary to prefix to this whole class of diseases, at page 292, \&c.

Cause.-A tiead which the horse inflicts on itself, for the most part, seeing that it generally occurs on the inside of the foot. This tread or bruise may either be inflicted upon the coronet, or lower down, by over-reaching, or even at the sole; by taking up a stone or other hard substance; also by a prick or blow in shoeing. According to my view of the construction of the foot, and the manner in which the hoof is renovated by a supply of a glutinous secretion from below, ascending to the coronet for that purpose, it will be seen that the injury, however trivial 
originally, would occasion some of the finer vessels engaged in carrying on this supply to suspend their functions awhile; the detention of this secretion would of course cause a morbid affection at that place, and when at length it ascended to the coronet for the supply of new hoof, it would be unfit for that purpose. It remains there, and occasions inflammation, the formation of matter, and the whole train of fistulous symptoms, with a sore towards the hind part of the coronet.

Cure.-The sore is always very small, but admits of a probe being introduced, by which the extent of the evil may be ascertained, and this is generally very extensive and ruinous, according to the time it may have been allowed to make head. The probe will pass readily forward and backward to the whole course of the disease, and sometimes it will be found to have penetrated to the coffin bone, every where forming sinuses or pipes, as in fistula of the withers before described. But in this case situation makes considerable difference : unlike the former, poultices are rendered inapplicable, whilst the employment of the knife or lancet is dangerous in the extreme. Besides which, the diseased part is already open, and seems to invite the only species of remedy yet known, in the shape of escharutics, that by irritating the case or cæstus, which forms the sinuses, shall cause it to slough off. In slight cases, those which are found not to have penetrated deep, the simple application of a wash will prove sufficient; 
and may be employed in this manner. Dissolve blue vitriol in water, and charge a syringe therewith; this is to be discharged into the orifice, and suffered to remain, as much as can be retained. A poultice of bread or oatmeal is to cover the part, and the cure will be completed after two or three days. But unfortunately for the owner and the animal, the disease is seldom taken in hand thus early, but is suffered to proceed until much stronger means become necessary. For this purpose take a long narrow slip of thin paper, and moisten it with muriate of antimony; over this strew powdered corrosize sublimate, and roll up the paper, so that it may not be too big for the pipe which it is intended for. Generally it happens that the opening requires to be enlarged before this pledget so charged with the escharotic can be fairly introduced. Take especial care that the pledget reach the bottom of the pipe, cut it off close, and pass a similar one into as many sinuses as may have been ascertained forms the disease. As considerable irritation of the part will quickly ensue, a poultice sufficient to cover the foot should be previously got ready, and applied immediately.

In three or four days, the bandage being removed, the diseased parts will slough off, a considerable opening presents itself, leaving a healthy looking sore. Let this be sponged off with warm water, and when dry apply tincture of Benjamin, which will effect a cure. A solution of white vitriol is used with advantage, especially when a 
disposition to secrete unhealthy matter is at any time perceptible. Physic the patient after the operation, according to the actual state of his bowels, the motion whereof will alleviate the pain necessarily attending the escharotic quality of the pledgets applied to the foot. If the horse's bowels be found in the ordinary state, give two balls on successive days, thus:

\section{First Alterative Ball.}
Aloes,
Hard soap, $\}$ of each 2 to 3 drachms,
Oil of cloves, 6 drops,
Calomel, 1 drachm;

Mix, with mucilage sufficient to form the ball for the dose.

Second Alterative Ball.

Aloes, 4 to 5 drachms,

Soap, 6 drachms,

Oil of anise-seed, 10 drops;

Mix, and give one dose the day following the first ball.

\section{VIVES*.}

This is the term given to swellings of the glands just under the ear, towards the angle of the jaw,

* From the French " avives," and the verb aviver, to be brisk and lively, as if it were conferred ironically upon the animal in its dullest state. 
that mostly attack young animals. 'The tumour is easily repressed or driven back into the system, and by more simple means than those employed in more inveterate complaints of a similar nature, showing themselves in other parts of the body. In some respects this disorder bears near affinity to the strangles.

The Cause of Vives may be distinctly pronounced "a cold," that prolific source of so many other disorders incident to man and horse. The vives usually comes on after hard work and sweating, by being then exposed to a current of air, or cold rain. The season of shedding the teeth, when the contiguous parts are unusually tender, is that in which swellings similar to vives pervade animals of any species. Nevertheless it sometimes attacks horses at an advanced age, notwithstanding they may have previously got over the most healthful form of strangles, when we might reasonably suppose nature had ridded itself of a disposition to secrete any more such pestilent matter. Want of the usual head-clothing is then the immediate cause of vives. The violence deemed necessary in breaking coits also causes the vives, when the pressure on these parotid glands, at reining up the animal, irritates the parts.

Symptoms.-Swellings under both ears, generally, that occasions manifest pain when touched: the animal coughs more than one which has the strangles, and a difficulty of swallowing soon becomes evident. Stiffness or aridity of the neck 
follows, and the patient makes frequent efforts to swallow the saliva, which it is the proper function of these glands to secrete, but which they are soon disabled from performing, by reason of the cold checking or chilling those functions. Of glands generally, their construction and uses, the reader will find many instructive particulars in the first book, at page 78 ; these of which we now speak being called "the parotid glands," from their situation; and as they now refuse to perform the office of secretion, the watery humours flow from out the animal's eyes, which it partly closes, as if he were about to sleep. For want of the same supply of saliva, inflammation of the mouth and gums takes place, producing what is vulgarly called "the lampers," or swelling of the roof of the mouth near the front teetl, which I shall speak of separately a little further down. Sometimes the swelling of these glands, if not assiduously subdued, continues a fortnight or longer, becoming more troublesome every day, and evidently occasioning very much pain ; all this while the horse loses condition, is feverish, and at length so weak as to totter when he moves, even in his stall. Spreading downwards under the throat, they at length terminate in strangles, and are then to be treated as such.

The cure of the vives that arises from simple cold is very easy, but not so that which is connected with a general bad habit of body; for then the swelling and subsequent suppuration of the abscess must be considered as an effort of nature to relieve 
itself from something that is offensive to it, and must be treated as a disease of the whole system, nature having adopted this or that particular spot for demonstrating its offence. But I have already explained my opinion on this interesting point of veterinary pathology, much at large, when treating of other tumours and abscesses. Vide page $292, \& c$. Oftentimes it happens that the vives depend upon glanders or farcy, of which they are then a correspondent symptom, and will only subside (or "go back") when the virulence of these are reduced. However, no harm can come of fomenting the part with warm water at least; and after it has been well dried, clothe the head so as to keep off the air, upon the principle of " remove the cause, and the effect ceases of course." The application of the bandage described at page 303 , will sufficiently clothe the part.

Much of the pain and tension of the tumour will be alleviated even by this treatment, and a slight attack will be removed by following it up with fomentations of marshmallows; or, anoint the parts with ointment of marshmallows, and cover the head as before. A bread poultice affords relief, and bleeding in stubborn cases of simple vives is often necessary, with purgatives. Indeed, the body should be opened, whether we bleed or no: always leave open the main road for such humours to escape by. This alone will carry off a recent attack, provided the head clothing be kept on at the same time, nature per- 
forming the remainder by absorption. To assist nature, howsoever, employ the following

\section{Lotion.}

Sal ammoniac, half an ounce,

White vinegar, 6 ounces,

Goulard's extract, 1 ounce;

Mix, and rub the part well twice a day.

Low diet, a plentiful supply of water gruel, and bran mashes, to which an ounce of nitre may be added daily, will reduce that thickened state of the blood which ever attends this species of tumour. But, as in the preceding cases of tumour (pollevil and fistula), it is sometimes found impossible to remove the vives by those means or any other; matter is formed, the tension and inflammation continue upon the increase, and plainly indicate that suppuration must ensue, and all our labour is rendered vain, if it ought never to have been so employed. In this event, apply a meal poultice, restore the animal to his ordinary diet, and promote suppuration, which effects the cure in the same manner as all other abscess mentioned before. See page 303, \&c.

Falsc vires, or imperfect ones, that are hard and insensible, sometimes cause a good deal of needless trouble. They neither come forward nor recede, do not seem to cause any particular pain, but still continue an eye-sore, and give reason to apprehend disagreeable consequences, and always prevent an advantageous sale of the animal. 
Stimulating embrocations are well calculated for reducing these hard tumours, and the blistering liniment, made of cantharides and oil, never fails.

\section{LAMPERS, OR LAMPAS.}

Cause.-As just said, lampas is occasioned by inflammation in the mouth. This is brought on by inability in the parotid glands to secrete the saliva necessary for lubricating the throat and gums. These glands, though liable to the disorder we term vives, yet the derangement of their secretory function does not always show itself by the vives : it may. continue to flow, though not in sufficient quantity to meet the increased heat of the animal, as it grows towards maturity, and fills up the juices of its system inordinately. Idle or ill-worked young horses are most liable to lampas.

Symptoms.-A swelling of the bars of the mouth follows the rising vigour and heat of the animal; they then project below the surface of the teeth, and interfere between them while feeding. 'The pain is necessarily very great on feeding, and the animal ceases to chew of a surlden; it afterwards commences anew, with greater caution; but as the disorder becomes worse, it refuses food entirely, and starvation would be the consequence if something did not intervene which is always sure to happen.

The cure would be effected of itself, if the horse lived in a state of nature, or more probably in that state he never would have contracted the pain. 
Over-gorging and consequent fulness of habit having occasioned the blood to flow luxuriantly towards the region of the head and throat, or the gorge, so that disorder is thereby produced, the reduction of that full habit follows this compulsory abstemiousness which the afflicted animal practises much against his will, and might teach man himself a monitory lesson he is usually slow in attending to, until too late. Reducing the system is the neatest method of removing lampas, and purgatives should be employed; bran mashes, in which an ounce of nitre daily has been introduced, may also be given until the pulse becomes more natural. If the lampas be not lessened by these means, the projecting part is to be seared with a hot iron; but some people commence operations with the searing iron, as the readiest way, and give physic afterwards. This application never fails.

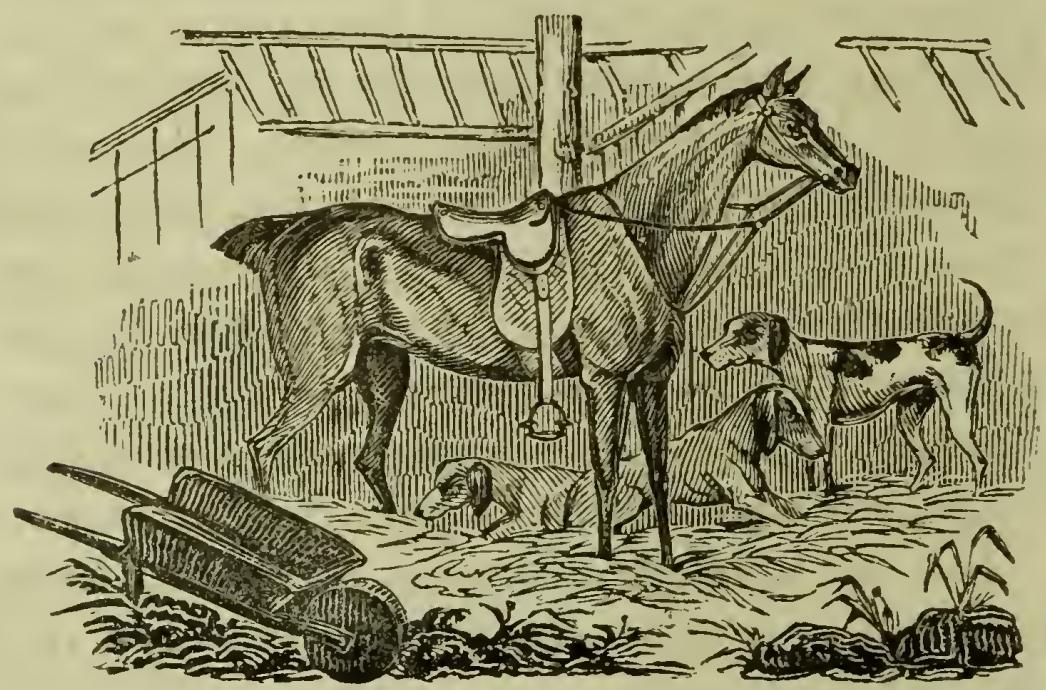




\section{CHAP'TER III.}

EXTERNAL DISORDERS.

\section{Purulent Tumours: Diseases of the Glands.}

Strangles, Glanders, Farcy,'Grease, as they owe their origin to the same predisposing cause so evidently, that the appearance of either is good assurance that no other disorder is then to be apprehended-neither of the above nor those treated of in the preceding chapter, that a few preliminary observations should occupy attention, before we treat of any one in detail. Both series of diseases are in like manner constitutional, or residing in the blood; and the whole class agree together so nearly in cause, symptoms, and effect, that the situation of each on the various parts of the body constitutes the main distinction between them; as this does also affect the appearance and consistency of the matter produced.

What I most strenuously maintain is, that the latent cause of all tumour, inflamed glands, and spontaneous discharge of matter by skin or membrane, is entirely attributable to the actual state of blood of the individual animal. Whence. I

Q 2 
infer, that some horses are more liable to incur contagious diseases than others, and this in a degree proportioned to the state of the blood at the time of communication; so that some might escape with impunity, whilst others meet with certain death from the self-same cause. This accounts for the greater virulence with which some horses incur glanders, for example, compared to what others suffer, which catch the disorder at the same moment of time; as was proved on a largish sort of a scale, and that pretty well known among practitioners, during the late war on the continent. The case was briefly this-A transport with cavalry horses on board, on its way to the Low Countries, met with bad weather, so that the hatches were battened down, and in this manner were part of the horses suffocated. Of those which survived, amounting to some twentytwo, or more, scarcely one escaped the glanders; but, notwithstanding, we may conclude that they infected and re-infected each other at the same moment and under precisely the same circumstances as to heat, respiration, and privations, yet the symptoms varied greatly, and some few recovered so readily as to leave great doubt whether they really had received the glanders or not, whilst others exhibited real glanders in the highest degree of virulence. Between these extremes, we are informed, the remainder were variously affected: all which circumstances prove incontestably how much depended upon the pre- 
vious health of each individual, the vitiation of its blood and its co-fitness or adaptation to receive the infection. I imagine this to be conclusive of the doctrine I have all along laid down. But I will adduce another authority - a veterinary writer of France, who carries the principle even farther than I have adventured to push it.

With that specious ingenuity which attends all affairs of research in that country, an author named Dupuy, who also quotes the rapport of another, called Gilbert, deduces the disposition to contract such disorders from the progenitors of the afflicted, or, as I should have said, from the blood or breed, and he recommends a corrective kind of regimen for brood mares and stallions; that is to say, in other words, an airy situation for the breeding stud, with pastures rather elevated, where they will have sufficient nourriture during the period of gestation, and can find occasional shelter from the weather. " $\mathrm{By}$. these means (says M. Dupuy) the disorder may be prevented in great measure." The disorder he here speaks of he calls "scrophulous tubercle;" to which " all cattle whatever, bred in marshy situations with scanty allowance to the parents, are very liable." This disorder of the blood or breed, according to M. Dupuy, "predisposes the horse to contract those diseases that are known to us under the terms strangles, bastard strangles, farcy, and defluxions from the eyes;" which latter, it will be seen, at page 334, is a corresponding symptom 
and never failing attendant upon the vives, as it is of all other glandular swellings about the jaws. The Frenchman thus converts a single symptom into a disorder!

In England, moreover, we do not talk or write of scrophula in horses, or a disposition thereto, this being a symptom of a vitiated system in carnivorous animals. For the mange in dogs, scurvical or scrophulous eruptions in mankind, and the farcy or grease in the horse, although appearing very similar to the eye of a common observer, and all originating in a depravation of humours; yet the immediate cause of each of these differs greatly, by reason of the manifest difference in the structure of the capillary vessels or tubes that deposit the offensive matter of either kind, demand a very different treatment at our hands, and we reject the anomaly of $M$. Dupuy as inapplicable to horse-medicine. But when this gentleman represents the general predisposing cause as a "tuberculous or fistulous affection, that is capable of being alleviated, prevented, and in some cases cured," he brings his arguments quite within the range of our conceptions; and I, for my part, take all that he subsequently adduces, as being in perfect consonance with my own doctrine respecting the predisposing cause of diseases. As to ancestry, and breeding from a good stock, in favourable situations, of which this writer appears to entertain correct notions, I had already anticipated him, as the reader may perceive at pages 
$47-50$, which is a part of my book that appeared in the Annals of Sporting for 1822.

\section{THE STRANGLES.}

The Strangles, as the name imports, is first indicated by a coughing and difficulty of swallowing, as if the animal would die of strangulation. It is a disorder of youth (like our hooping cough), is inherent to the nature of the animal (as is our small-pox) once only, and its virulence may be abated by inoculation, whereby we choose a favourable period for meeting the inevitable attack, after duly preparing the patient.

Cause.-Repletion of the system of life, and the deposite of blood in the glands under the jaw; which failing to be taken up and reconveyed back again into the system (called absorption-see book the first, p. 57), the glands become inflamed, swell, and burst, the discharge of the offensive matter being the cure. I have always considered it a critical disease, and treated it as such, encouraging the formation of matter, and assisting nature in throwing off a something that is evidently obnoxious to the constitution. Indeed, I have never heard of any other practice; the impertinent attempts at repression, so frequently adopted at the request of proprietors in other cases of tumour, never having extended itself to this. Strangles, strictly speaking, are incident to the young animal 
only-that is, from two years old, until five or near six; when the circulation (as the bloud is called) has attained its fulness, and, perhaps, slight cold has first detained any portion thereof in the glands, whereby the inflammation is engendered that constitutes the disease. When these glands swell and discharge at a more mature age, the strangles must then be considered as the effect of constitutional depravation, and would as properly come under the general description of critical abscess, treated of at a former page, 301.

Symptoms.-A swelling commences between the upper part of the two jaw-bones, or a little lower down towards the chin, and directly underneath the tongue. A cough, and the discharge of a white thick matter from the nostrils, follow; with great heat, pain, and tension of the tumours, and of all the adjacent membranes, to such a degree that the animal can scarcely swallow. The eyes send forth a watery humour, and the animal nearly closes the lid: this is mostly the case when it happens that the two larger glands under the ear are affected also, which frequently happens; but when these latter are disordered without the animal having the strangles, we then say he has the vives. The swelling increases and usually bursts of itself, sometimes without any medical aid whatever, and even without being perceived by any one. This last happens to colts and fillies at grass, when their wants are little attended to, and they never fail of doing well. Consequently, it 
follows, that those attacks which take place in the open air are of a milder nature than those more obstinate cases we so frequently meet with among in-door cattle, which serves to prove, once more, my doctrine as to the cause of all tumours or "tuberculous affections," as M. Dupuy has it. The horses that are kept in-doors accumulate gross humours, by this mode of living on dry food and lying on soft beds, the exercise they take not being sufficient to carry off the effects of either. Enervation generally accompanies this mode of treatment; the glands and membrane suffer relaxation; the pampered animal is not exposed to the air sufficiently to occasion that check, or slight cold, which is generally the immediate cause of strangles, and the accumulation of depraved humours proceeds, until they overcome the capacity of these organs, and the strangles then become a formidable disease.

When this is the case, the feverish symptoms run high, loss of appetite follows with constipation of the bowels, the horse can neither drink nor eat, and the pulse increases. The tumours in these bad cases will be found to have raised nearer the jawbone than they do in a mild attack, and are longer in coming to maturity than those which begin more towards the middle. The disorder is seldom fatal; but when this does happen, the animal dies of suffocation; in which case it stands with the nose thrust out, the nostrils distended; 
the breathing is then exceedingly laborious and difficult, and accompanied by rattling in the throat.

Cure.-For this last mentioned extreme case, no other remedy is found than making an opening in the windpipe, through which the animal may breathe. For this spirited operation, I must refer to Mr. Field, the veterinary surgeon, who has performed it frequently, and says his practice was to cut an aperture the size of a guinea, which nature afterwards supplies in due time. With this exception, perhaps, I might be justified in saying that we have little or no business to meddle with the strangles; unless, indeed, unfavourable symptoms arise, and the previous habits of the horse, his present fleshy or gross liabit of body, with the unfavourable situation of the tumours near the bone, give good reason for believing that the disease will turn out a tedious or dangerous case. And yet I should be very loth to recommend purging or bleeding for strangles, as I have seen done with no good effect; for, although the symptoms are thereby lowered, yet the continuance of the disorder is protracted to an unmeasurable length, and I have heard of the strangles devolving into glanders by this course of proceeding - the subject of this case being a five year old, off, cart mare.

On the contrary, the disorder being constitutional, that is to say, an effort of nature to relieve itself of some noxious matters, the strength of the 
animal system should be sustained in some degree proportioned to what it may obviously require. Therefore, horses that may be in good condition at the time of the attack, and withal highly feverish and full of corn, will only require opening medicine; whilst a brisk purgative might do harm by lessening the access of matter to the tumour, and the system would still retain a portion of the offensive cause of disease, which would break forth at a future period in some one or other of the correspondent diseases dependent on tubercular affection. In this case give the following

\section{Laxative Ball.}

$\left.\begin{array}{l}\text { Aloes, } \\ \text { Castile soap, }\end{array}\right\}$ of each 3 drachms,

Ginger, 1 scruple. Mix for one dose.

If difficulty of swallowing is already perceivable, a drench would be found the more desirable form of arriving at the same end. Then give the

\section{Laxative Drench.}

Castor oil, 6 ounces, Water gruel, 1 quart, Salts, 6 ounces. Mix.

Meantime, at the first appearance of the disorder, let the hair be clipped off close at the part affected, and a little way round, to allow of greater effect from any application that may be deemed necessary. The head being clothed, will restore as much warmth as hath hereby been abridged. Mild cases will require no more than this, proba- 
bly, and the assistance of a poultice and fomentation of marsh-mallows daily to the throat, to bring the swelling to a proper state for opening. This will be shown by its pointing, or becoming soft and peaked in the middle. But a premature employment of the lancet is to be avoided, for the reason before assigned, viz. to give time for the whole matter to collect; when this period arrives, the whole swelling will be soft and yielding to pressure, unless the animal be a very thick-skinned one, with a great chuckle head. In these cases, the part should be rubbed with a stimulating liniment, and if the tumour is working its way inwards so as to threaten suffocation, blistering ointment may be applied. After each and either of these applications, the poultice is to be again put on with care; and as much of its efficacy depends upon its remaining in contact with the throat, the adjusting of it properly requires great pains and some adroitness for the thing.

Much difficulty being experienced in making serviceable bandages, I have annexed a descriptive sketch of such an one as would be proper to keep on the applications. It needs no further explanation than is given in cases of sore throat at page 212 , and of absress, at page 303.

\section{Stimuluting Liniment.}

Mustard, powdered, 1 ounce,

Liquid ammonia, 3 drachms.

Mix, and apply assiduously to the part. 


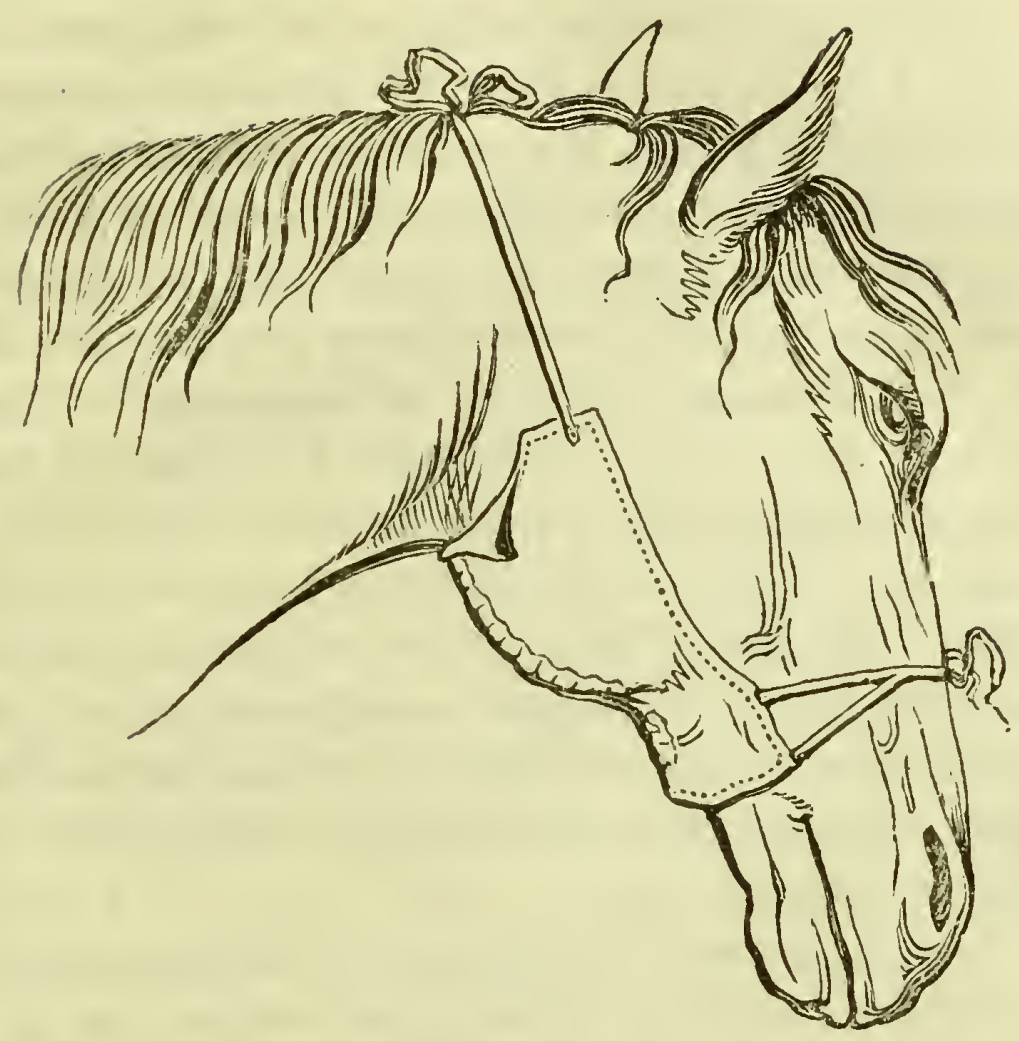

'The suppuration may be further promoted by steaming the head over warm water, or fumigating it as follows: give him bran mashes frequently, placing the vessel that contains this, well secured, in another vessel larger than the first, into which much hotter water can be introduced, so that the vapour may rise up all round the mash, and consequently envelop the head. When the tumour is ascertained to be ripe, and not before, an opening is to be made at its most depending part, and the matter expressed gently; wash it off clean with warm water, and if the sore appear healthy, it will heal spontaneously, or with the application of adhesive plaster. 
Inoculation for the strangles has been recommended above, and was partially practised. About 1802, M. La Fosse, the younger, mentioned the affair in his Manuel d' Hippiatrique, which book I translated into English the following year, and we hear that two or three country practitioners in England afterwards adopted the suggestion. The method was merely to scratch the inside of the nostril, and then smearing the sore with matter from the abscess of a diseased horse-it never failed. In careful hands the practice was feasible enough; but great danger would accompany this imitation of variolous inoculation, inasmuch as the matier might likewise convey a disposition to farcy or glanders.

Strangles of the Gullet. Sometimes we find those symptoms of strangles reduced to one only, viz. an obstinate running at the nose, which usually lasts a long while, and occasionally ends fatally, by the animal wasting away in pulmonary consumption, as I am informed from good authority, but never witnessed such a termination of this species of strangles, which La Fosse calls "strangles of the gullet." Many people mistake this disorder for glanders, but it may be distinguished from that contagion by a rattling in the gullet, whence its French name; also by the quality of the running, which is neither so white nor of so much consistency as the true sort, but watery and curdled. The animal scarcely ever is troubled with a cough, and then it is very feeble; but to 
make up for this, exhibits frequent contractions of the larynx, or "throat apple."

After the tumour is opened, give gentle physic, for which purpose the laxative ball recommended in page $\mathbf{3} 47$ will answer every desirable purpose; or you may add thereto one drachm of emetic tartar, and give another ball after an interval of one day, unless the pulse is low.

Bastard Strangles is a favourite term with some owners, who would soften down the real fact of their horses having the glanders, which it really is, and not strangles. But bastard or not bastard, it is always infectious, and the animal either dies of strangulation, or the disorder becomes the glanders, producing watery blackish matter at the nose when the cough ceases. Apply a

\section{Fumigation.}

Take the leaves and root of marsh-mallows, an arm-full,

Water, 6 quarts.

Boil them, and put the whole into a nose bag, and hang it round the head of the animal to make him inhale the steam. The bag may be made of stout cloth, but hung with the upper part quite open, to avoid suffocation. Leave the bag at the animal's nose until no more steam will arise.' This will be found a very proper remedy in all cases of strangles, the first stage of glanders, and obstinate colds. 


\section{GLANDERS.}

For about twenty years I apprehended that we had arrived within a short space of finding the true cause of glanders, and that we should then soon ascertain the means of preventing our horses from engendering the malady, if we could not avoid their catching it, nor discover a specific remedy. But, lo! we were not yet agreed even as to the symptoms of true glanders; as to that which was communicable and dangerous, compared with another affection of the glands and pituitary membrane, which was but a temporary disease, not easily communicated, and was asserted to come within reach of the curative art. Most small proprietors, unwilling to destroy their afflicted horses, maintained that they belonged to the latter description, and in this they were frequently supported by the cupidity of practising farriers, who administered medicines and performed operations with a confidence which never could belong to any department of science - and least of all to that of medicine *, which is, alas! ever uncertain.

* Much inhumanity was shown by the country practitioners in their mode of treatment: they scraped the bone after slitting the nostril; and also seared the swelled gland with a hot iron. A late writer applauds the practice of searing ulcers and abscesses, generally, "whereby (adds he triumphantly) they are reduced to common scalds:" he was then speaking of the doctors in Morocco! mere Turks. The gentleman, probably, did not distinguish between abscess and indolent tuniour.

It is related by La Fosse, that in 1801 several regiments in Al. 
During this state of the question, we turned to the French veterinarians, who up to a certain period enjoyed the reputation of being superior to all Europe besides in this and a few other pursuits [war and chemistry, videlicet], and found one of their most respected names had arranged the boundaries and distinguishing qualities of the two into three divisions. Nor was this all. M. $L a$ Fosse, the younger, who enjoyed the post of "principal farrier to the French army," and was withal a member of the Institute, insisted with much energy that "glanders of the first species, the real glanders, glanders properly so called, absolutely consists of nothing more than the loss of the sense of smelling," and is "a curable disorder, if treated early, but incurable when confirmed." His treatment was very simple, and worthy of calm consideration, as are also the means he proposes for ascertaining by the symptoms when it is a horse is afflicted with communicable glanders, and ought to be destroyed. It is in this latter respect that I reprint here the substance of La Fosse's researches on this highly interesting subject; for, since none of us can offer a remedy that ought to

sace and Loraine employed the actual cautery as a cure for glandered horses. Some " applied fire to the jugular gland in three lines; others cauterised the bones of the forehead and nose; but the most ridiculous affair of all was, to see forty horses together which had fire applied round their eyelids to cure the running," that is common to all glandular affections about the head! 
be relied upon-unless the animal be submitted to our measures earlier than is: usual-I think an useful particle may be added to the new study of medical jurisprudence, by showing the line of demarcation that divides healthi and contagion-the point at which destruction ought to commence, by authority, or, in common humanity, to prevent the thoughtless from immolating the property of others, who are usually little proprietors.

I am the more determined in this course of proceeding, because all my inquiries on the subject are already in print, and these coincide so nearly with the speculations and reasonings of two or three respectable writers now before the public, that I could add but a small portion of novelty to what has been so elaborately discussed by others. On all those points on which I differ from them, I shall offer a few practical observations, in the hope of being serviceable, whilst I shall sedulously avoid the "debateable land," which some contend for a little unamiably.

"So great has been the destruction of horses which have either really been, or reputed to be glandered, through the prejudice of ignorant persons, that it has been said, whoever can point out the distinction between the communicable disease and those which bear some affinity to it, will confer a benefit on society, and serve the cause of humanity. Much labour had been bestowed on this subject by the elder La Fosse, who threw a 
great deal of light on a disease, which, of all others that attack the horse, is least known, and therefore most misrepresented."

What M. La Fosse proposes to show is, 1. "That it is easy to confound this disorder with others that resemble it, in some particulars. 2. That among the different sorts of glanders (so reputed), some are infectious, whilst there are others that are not so; and 3. That some of these are curable, and others incurable.

"There are few veterinary practitioners who do not know that strangles, bastard strangles, pursiveness, or asthma, and other pulmonary complaints, exhibit the same external appearance as the glanders, properly so called; consequently it is easy to be deceived on the subject, and the farrier will fail in his endeavours at a cure if he has not previously ascertained the distinguishing symptoms of the disorder. What then ought he to do in order not to be led into error, and to ascertain with precision that species of the disorder with which the animal is affected?

"After much experience on the subject of the diseases of horses, we are convinced that it is necessary to distinguish three sorts of glanders, viz. The first sort, which is the glanders, the real glanders, the glanders properly so called; the second is nothing more than some disorder circulating in the mass of blood; and the third may be denominated the farcy glanders. Glanders of the first kind is not infectious, except it be compli- 
cated with other disorders; but this is seldom the case, though we may daily witness horses thus attacked abandoned as incurable, or with little more humanity put to death. On the contrary, glanders of the second species is communicable, because the horse, besides running at the nose, and becoming glanderous, has likewise chancres, and these chancres appear to be the only proximate cause of contagion.

"The third species of glanders is in like manner contagious, because it not only occasions a running of the nose, but the tumefied glands and the cartilage of the nose are chancred, and likewise certain parts of the body are covered with lumps and chancres, which latter characterise the farcy glanders, the most dangerous disorder of the three, but not the most common. These two latter species of glanders are infectious, because the disease resides principally in the blood; but the glanders of the first species, the real glanders, the glanders properly so called, is not in anywise contagious, although it most frequently occurs.

"The second and third species are incurable, but the last only is mortal. But as to glanders of the first sort, it is neither incurable nor mortal. In the first place, we repeat, this disease is not mortal in any case, and a horse attacked by it is in the same situation as a man who has lost the sense of smelling; it is the loss of a sense, and the loss of a sense prevents neither the man nor the horse from fulfilling all the animal functions; for, 
ENLARGED GLANDS, A CURABLE DISORDER. 357

as we daily observe men affected with ulcerated noses preserve an otherwise sound constitution, and even look jolly, so we may observe a glandered horse preserve his strength and health.

"Secondly; it is incurable only when inveterately confirmed; but when taken in an early stage, its progress may be stopped with very little trouble.

"Thus we find that glanders of the first species, the real glanders, glanders properly so called, absolutely consists of nothing more than the loss of the sense of smelling. Its cure may be readily effected by frequent bleedings and fumigations. Hence may be estimated the little necessity there is for killing horses attacked by this disorder; and what important services may be rendered to society or to a regiment, for instance, by an intelligent farrier making a proper distinction between this species of glanders and all other affections and diseases resembling it."

So far M. La Fosse : his table, prefixed to the translation, "Veterinarian's Pocket Manual," is sold separately by the booksellers, and may be consulted with profit by those who would push further their inquiries respecting "true glanders."

Cause.-The glanders is a contagious disease only when it has lasted for some time. Original glanders may be acquired by horses being shut up close together, in hot, damp stables, in swampy situations-as in thecase of the twenty-two cavalry 
hor'ses adduced higher up (page 340), which were confined damp, under hatches, but were variously affected, according to the predisposing cause in the constitution of each individual. Those animals were improperly condemned, because the disorder had not continued long enough to render it contagious, and they might have recovered if treated as for a simple cold.

A sudden transition from cold air to a hot stable, as well as from heat to cold, will occasion a running at the nose; or a blow there, as well as a drench clumsily administered: either of those causes being foreknown, should render us chary of pronouncing the running contagious, and thus subject the property to destruction, as proposed. Almost any running, from whatever cause proceeding, or however healthy the previous state of the animal's system, causes the glands to enlarge and inflame; after a while, remaining uncured, they usually adhere to the bone, when alone we should pronounce the glanders confirmed and incurable. This is "the second species of La Fosse, which may be communicated by contact, or by respiring the same air-in the stable; though it does not appear until eight or ten days after the infection, in the enlargement of the gland, accompanied by running. The third species is caused by farcy being in the system, or by inoculation, in which way the glanders is often communicated by experimentalists : the running at the nose and swelling 
of the glands are then symptomatic of farcy, and must be treated as such.

What inference is to be drawn from all those premises, but that we should endeavour to ascertain the length of time the patient has been afflicted; whether he has received any external injury to cause it, or, has he been brought in contact with infected horses, and when? and out of the answers hereto we form the resolution of condemning the animal to solitary keeping, at the least; and setting about the remedies that are likely to restore him to health. Crowded towns, posting stables and barracks, are most subject to contain glandered horses, on account of their closeness, and the frequent succession of inmates to which they are liable; for some horses will bear it for a good number of years, the discharge almost subsiding (though the swelling of the glands remains) upon changing to country quarters, or to a succession of regular living and regular work.

Symptoms.-No cough accompanies real glanders in any of its stages; and this, though a negative piece of information, shall be taken as a good and positive criterion that must not be neglected: a running may make its appearance, as it does at the left nostril usually, in the glanders, and the glands under the jaw may adhere to the bone, as they do in real glanders, but no cough accompanies these symptoms of glanders. When cough supervenes, the disease may be a catarrh, or a consumption, the asthma, or strangles, but these 
are not contagious, unless they last a long time, and adhesion of the glands takes place: in these last mentioned disorders the discharge commonly proceeds from both nostrils alike; whereas, the running in incipient glanders is chiefly confined to the left $*$, and the gland of one side only is then affected. Mind that.

As the disorder proceeds, it affects botll sides alike; chancres appear all over the pituitary membrane, occasioned by the corrosive nature of the discharge. This assumes a different appearance as the constitution of the individual may have been more or less gross or vitiated; the appearance or quality of the discharge differs also, according to the manner in which the disease may have been acquired; i. e. whether it has been engendered or caught by infectioir. If it come of the first-mentioned, through a depraved system, the glands are harder, often smaller, and always adhere closer, than in those cases which are derived from infection, at a time when the animal is otherwise in comparatively good health. Again, with the infected horse, the matter comes off copiously; it is curdled, and may be rubbed to powder between the fingers when dried. It subsequently hardens, and becomes chalky when submitted to acids; whereas the animal that engenders the disease without receiving infection sends forth matter that is party-coloured,

* Of eight hundred cases of glanders that came under the notice of $M$. Dupuy, only one horse was affected in the right nostril. 
less in quantity, blackish, watery, and mixed with bloody and white mucus. Finally, if the animal that receives the disorder by infection be previously in a bad state of health, those symptoms are complicated and more intense, the chancres are more numerous, the cartilages of the nose become rotten, and the bones likewise, in a short time: the creature seems to have combined together the evils of its own system with that of the sufferer from whom he has received it. In both cases the swelled glands are simply hard tumours without any matter in them.

In addition to the preceding tokens for discovering at an early period the true glanders from another semblable disorder, let the nostrils of the animal be examined, and the left or running nostril will be found of a deeper colour than ordinary, whilst the other or dry nostril is of a paler colour than ordinary, or almost white. At this period the discharge is a white glary fluid, and the maxillary gland of that side is but just perceptible to the touch; but these being symptoms that belong: equally to a catarrh, it is best to be guided by the varied colour of the two nostrils, remembering that in catarrh, or cold, вотH NOSTRILS RUN.

Well worthy of remark is the fact, that when horses in a tolerable state of health first receize infection, they show mettle, and are full of freaks theretofore not experienced; as the disorder proceeds in its ravages, this mettlesomeness goes off: 
other acquired diseases have the same effects on all animals --the venereal, for example, on man.

A great stench accompanies the discharge in confirmed glanders, which increases during the latter stages of the disorder; and that stable-man who has once scented it in perfection, may presently ascertain whether glandered horses have been recently kept in any stable he may examine for the purpose of detection.

The Remedies that liave been applied to the afflicted animal in this forlorn disease are found of no avail, unless taken at an early period. As hath been said higher up, infection is not to be apprehended at first, and therefore the precaution some use to prevent its spreading, by bleeding and purging all the rest of the horses in that stable, is super-necessary, unless the animals require that process in other respects; but some practitioners must be doing something, and some owners will not rest satisfied unless preventive measures be undertaken.

As soon as the horse is suspected of glanders, it should be kept separate from all others, and the fumigation of marsh-mallows applied, as prescribed at page 351 , repeatedly; a purgative or an alterative ball may be given, according to the state of his body, and the usual remedies as for a catarrh, continued for a week or ten days. If the disorder does not lessen in this time, but the symptoms increase in virulence, the horse should be 
destroyed; but unfortunately for healthy animals, this measure is not compulsory, no statute existing upon the subject*. Besides which, disputes might arise as to the precise nature of the symp. toms, and the executioner subject himself to heavy damages for his temerity. Something of this sort happened near Woburn, in Bedfordshire, early in the present century, to a lately deceased statesman. A neighbouring farmer having a horse in a state of confirmed glanders (in my opinion), persisted in keeping it in an old shed on the roadside: his obstinacy was highly provoking, and Mr. W. the gentleman alluded to, went with his servant and shot the animal; at which the venal part of the periodical press set up a great clamour, from which none defended him, for the transaction was at variance with his public professions.

Stables that have been occupied by glandered horses retain a long time the taint, and the means of communicating the disorder, which nothing will remove but washing with soap and sand, and scraping with sharp instruments, every part of the rack, manger, and all other parts that may have come in contact with the diseased horses. After examining the cases reported by various writers, particularly St. Bel, I have come to the conclusion

* The common law, however, is fully sufficient to prevent improper exposure of animals afflicted with a contagious disease in horse-markets, fairs, and other assemblages of cattle. $\Lambda$ case of this sort was adjudged at Guildhall, London, the facts whereof were detailed in the Annals of Sporting for March, 1826. 
that there is no analogy between glanders and the venereal disease, but the inoculation of sound animals; and that the exhibition of mercury in any form is utterly fallacious. One case, in which this mineral was employed with asserted success, at the Pancras College, is proved unworthy of credit, by the failure of the same medicine in every succeeding attempt.

\section{FARCY.}

Cause.-General ill state of the blood, vulgarly, but most appropriately, termed " corruption of all the humours of the body ;" and, by prevalence of the farcy buds in the course that the veins run, all over the surface of the body, no doubt can exist that it resides in the blood. In fine, the original cause has been already defined at the head of this class of diseases, to which the reader who is fond of research would do well to turn back for a few minutes, at pages $339, \& c$. However, infection is frequently the immediate cause, and (as observed of the glanders) the animal will be afflicted more or less severely as his constitutional health may be sound or otherwise at the time of receiving the infection. When this disease is engendered or created-which is easily supposed to have happened at first, and capable of being so produced at the present day, the blood being overcharged with offensive matters unfit for its 
proper purpose, it becomes stagnated at the lymphatics which follow the course of the veins (see book I. page 81), and these corrode the parts, inflame, and appear on the surface in the form of "buds." And I should feel surprise if they do not also pervade the large glands of the viscera, though I have had no opportunity of examining: such tumours on the skin of mankind have been found similarly seated on the inner surfaces, on dissection. "I feel all over as if pins were running into me, observed a patient; and so, poor fellow, he might, for on dissection I found the same sort of tumours even on the heart," said Mr. Abernethy in one of his lectures. As regards the horse, I take this upon credit, and by analogy for a while, purposing to satisfy myself more closely upon the first favourable opportunity that offers.

A predisposition to farcy must exist in the system, for it is cured by means of correctives of the blood; and its connexion with glanders has been proved, for the one will produce the other by inoculation, and without it running at the nose is one of the symptoms of farcy. A certain inability to perform its office, termed "debility," that leaves the finer vessels filled with the vital fluid, which exercise might have carried off-is one main cause of farcy; and a sudden check by cold after exercise stops at once the perspiration, and the blood that would otherwise be taken up, or absorbed into the circulation, remains in those fine vessels, as afore- 
said. Hot and crowded stables relax the vessels, and indeed the whole system, when sudden exposure to the air inflicts the same evil I have just now contemplated. The reader may recollect, that I referred the cause of fever to the same want of ventilation, to the same exposure to cold air, and made the remark, that the state of the animal's bodily health at the period of the attack would determine whether it should acquire this or that particular disease: the quantity and kind of cold, or chill, would also determine whether the horse should be afflicted with inflammation of a certain part of his inside, or or his whole system, which we term fever.

Symptoms. - Though too well known to be mistaken, we yet may describe them, as, in the first place-skin tight and dry, for want of perspiration, as just said, when some swelling is perceivable about the hind legs, and on the insides particularly. This symptom increases to an extremely large size in the course of a night, when the genial heat of the animal's system, and of the stable, appear to have matured the disease. The lymphatic vessels, and the more perfect glands, that run in the same direction as the veins, rise above the surface; and it is easy to be seen that they are sore when touched, the glands in particular, which feel hot, light, and hard at first, similarly to the glands of the throat, as described in the glanders. A few hours confirm the exact nature of the mischief: the inflammation of those glands proceeds; 
they become softer, and each throws out an ichorous, unliealthy discharge. They are then termed farcy buds. The edges have a chancrous appearance, which it is found impossible to heal with ointments. As the disease advances, a glanderous running at the nose takes place, with swellings about the nose, lips, and all over the body nearly.

According to the constitution of the horse at the time of receiving the infection, so will the progress of the disease be rapid and disastrous, or unaccountably slow and uncertain as to the result. In this latter case it retains its appetite, and bears up its strength for a considerable time.

Cure.-Three stages of the disorder present as many methods of cure: first, when the effects are slight or partial; second, when it resolves itself into large tumours, and a more copious discharge from a smaller number of ulcers carries off the disease; third, when it is confirmed, general, and diffused over the whole system.

In the first instance, when the glands only are affected, it may be treated as a local disorder, which has not yet found its way into the animal's system; and if appearing on one limb only, the natural inference is, that the system is indisposed to carry on the threatened evil. This happens mostly to animals in good condition, that are strong and vigorous, and of good habit of body; with such the farcy is not brought on spontaneously, or by being engendered in the animal, but has been acquired by infection. The limb affected is 
generully so to a good extent, and the corded veins scarcely visible; this happens mostly to a fore-leg (not always), and has been considered of a dropsical nature, in a slight degree, or rather lymphatic, the glands still continuing their functions. In this case give a purgative ball, and repeat it in three days after; but should the animal be a very fleshy one, and full of condition, with full pulse, this may be preceded by bleeding to the amount of three quarts, or four.

\section{Purgative Ball.}

Aloes, 8 drachms,

Castile soap, 1 drachm,

Liquorice powder sufficient to form the ball for one dose.

Prepare the animal with bran-mashes; let his drink be chilled, and he may be moved about, under shelter, with body clothing on that covers the affected limb. The limb should be fomented with warm water, or the chamomile decoction, taking care to rub the part dry, and wrap it up warm. This course usually prevails against an ordinary attack of farcy, and the cure is aided when it affects the fore-leg only, by a rowel inserted under the chest. But the absorption or taking up of the disorder into the system, and carrying it off by stool, is by far the neatest manner of managing the cure; for this purpose give the following ball, after the animal has been reduced by the foregoing treatment. 


\section{Alterative Ball.}

Camphor,

Emetic tartar,

Asafotida,

Ginger,

With mucilage sufficient to form the ball for one dose. Give one of these for three successive nights; then stop one night between each dose, until the disease is removed.

If these efforts to absorb the disease prove insufficient to conquer it, recourse must be had to the use of mercury, as recommended for the third or most virulent stage of the disease, which is also the most common of the three. Meantime, we come to consider of that particular kind of farcy which is the least common of all three; and this is wherein the tumours are larger than usually happens, and smaller in number. The disease then partakes very much of the nature of critical abscess (page 301), and of the strangles (page $343)$; both of which, the reader will perceive, are but the efforts of nature to relieve itself of an accumulation of offensive matter; and, this escaping, the cure is effected. In this second kind, or stage of farcy (as I call it), nothing more is requisite than to promote suppuration, as directed in the diseases just referred to, and follow it with the physic prescribed for the strangles.

The third, most common and virulent kind of farcy, that which comes on quickest, lasts the longest, and requires the most powerful means for 
its removal, is that which is spread minutely all over the body and limbs, and has penetrated the whole system. In whichever manner the animal may have acquired the disorder, we may safely presume that the mass of humours is lideously depraved, and mercury, in one or other of its varied forms, is the only anticlote to be relied upon for its extinction. Previously, however, the farcy buds and chancres must be reduced to the state of common sores, by means of the actual cautery freely applied to each. When these slough off; and the sores assume a healthy appearance, less of the mercurial preparation will be required; but if these retain a livid and therefore unhealthy hue, accompanied by a poisonous discharge that ulcerates the adjacent parts, a thorough course of mercury is the only certain remedy, and this must be managed with caution.

Mercurial Ball.-No. 1.

Ethiop's mineral, 2 drachms,

Opium, 10 grains,

Liquorice powder and mucilage to form the ball for one dose.

Give twice a day, until the patient's breath smells very offensive, and then discontinue the medicine a day or two, as you should also when the animal is found to stale inordinately, or the bowels be very much disordered. But, when the bowels are only slightly affected, increase the quantity of opium to 20 or 30 grains. 


\section{Mercurial Ball.-No. 2.}

Corrosive sublimate, 10 grains, Emetic tartar, half a drachm,

Opium, 6 drachms.

Mix, with liquorice powder and mucilage sufficient to form the ball for one dose. Give as before, at night and morning.

Feed the patient generously during the operation of this strong medicine, watch its progress closely, and lessen the quantity, or discontinue it altogether a day or two when he is agitated greatly within, particularly if a kind of sickness or gurgling be discernible, and the horse is off his appetite. Let him be clothed completely. Malt mashes, sodden corn, and coarse sugar mixed with his corn, dry, are good assistants to the proper operation of mercury. That is a mistaken notion, which induced some farriers to give the edible roots, as turnips, carrots, \&c. to the horse under a course of mercury. They war with its operation, and cause that very commotion in the bowels we should most sedulously avoid.

In recommending the free application of the actual cautery to the farcy buds, in the last page, I do but follow the common practice, being altogether the safest means in ordinary hands, who apply fire in many other cases, with much less reason than is done in that of farcy. Butter of antimony, or sulphate of copper, effects the same end, and has the recommendation of being used 
exclusively by the French veterinarians. What La Fosse says on this point is emphatic, and shows his opinion of the predisposing cause of farcy: "Do not apply fire in any manner to lumps produced by farcy, under an idea of stopping the disorder. 'The disease being in the blood, treat it accordingly, and as for the lumps, cut them off: apply blue stone, dissolved in water." When he forefends the "idea of stopping the disorder," doubtless in saying this he only allows that to be the true farcy, which I have considered as the third stage, or confirmed kind. But the earlier or milder stages, which would ultimately end in the third or most virulent kind, if not stopped, being occasioned by the cessation of the lymphatic function-when the attendant glands refuse to communicate with the system (the blood), cannot have yet carried the consequence of that stoppage into the blood. In making this remark, I have not overlooked what was said of the practice in Morocco at a preceding page, 352, note.

\section{ANTICOR}

Is more prevalent in France than in this country, and is so named from its position, anti against, and cor the heart. The French words ante-coeur have the same meaning, and are derived from the same origin. It consists in an inflamed swelling of the breast near the heart, and the name is extended to any other swelling from this part 
back under the belly, even unto the sheath, which also swells: in this event anticor is decidedly dropsical.

Cause.-Full feeding without sufficient exercise, similarly to this whole train of disorders which I have been just above considering. Hard riding or driving, and subsequent exposure to the elements, or giving cold water to animals that are very fleshy in the forehand, as is the case with the greater part of French horses; these, combined with a vitiated state of the blood, which is then sizy, produce those extended swellings that partake somewhat of the nature of swelled limb in grease, and yet terminate in abscess when the case is a bad one.

Symptoms.-An enlargement of the breast, which sometimes extends upwards to the throat, and threatens suffocation. The animal appears stiff about the neck, looks dull and drooping, refuses his food, and trembles or shivers with the inflammation, which may be felt. Pulse dull and uneven. By pressing two or more fingers alternately, the existence of matter, or a disposition to suppurate, may be ascertained (as in poll-evil) by its receding from side to side as the pressure is withdrawn. On the other hand, if the disease owes its origin to dropsy, each pressure of the finger will remain pitted a few seconds after the finger is withdrawn. Consult "Poll-evil" in its two stages.

Cure.-As in other cases of tumour, that do not 
partake of critical abscess after fever, \&c., this disorder admits of being repressed, readily, by the means before prescribed, or of being otherwise cured, as it may be allied to some disorder of the constitution. To repress the swelling, bleed the patient copiously: give purgatives and clyster him; give bran mashes, and let the chill be taken off his water. Foment the throat and breast with bran-mash or marshmallows, every four or five hours; and when these have reduced the symptoms, give an

\section{Alterative Ball.}

Emetic tartar, 2 drachms,

Venice turpentine, $\frac{1}{2}$ an ounce.

Mix with liquorice powder enough to make the ball for one dose. Give one every eight-and-forty hours. On the contrary, if the swelling depend upon dropsy, as aforesaid, let a fleam or horse lancet be struck into the skin at four or five places distant from each other, and in the lowest or most depending part of the swelling. From these punctures a watery discharge will take place, that relieves the patient of his affliction hourly, and the issue of matter is to be promoted by keeping open the sores as directed in the case of fistula, \&c. at page 315: again, when the swelling indicates the collection of morbid matter, let it be fomented, poulticed, and opened as directed in cases of critical abscess, in poll-evil, fistula, \&c.: the whole series of these diseases are of the same 
nature, but differing principally as to situation, which sometimes affects the disease mainly. In this case, for example, the swelling sometimes ascends along the throat, and goes nigh to choke the patient: recourse must be had immediately to poultices, and let these be changed twice a day. The modes of bandaging may be learnt by consulting those I have given sketches of, in other cases, at pages 212 , sic.

\section{GREASE.}

Causes.-This is another of the diseases that take their rise in a tardy circulation of the blood, and consequent indisposition to take up and carry back again to the heart that which has been sent into the extremities for their nourishment and renovation. In Book I. at bottom of section 44, this process of taking up, or absorption, is spoken of, whilst the few pages that are there bestowed on the manner in which the circulation is carried on, show the importance of this function, and point out the principles that should guide us in promoting it, when aught has occurred to retard its action. When great age and consequent lethargic habits cause the blood to circulate slowly, our art can but ill supply the remedy, though the evil may certainly be alleviated by stimulants. A small portion of beans given to aged horses admirably assist the heat of the circulation of old horses, especially towards the heels, whilst this 
very species of food given to young horses will promote humours of the hind legs in particular, where grease is mostly situate, and in the right hind foot oftener than in the left. That is to say, at the part of the animal that is remotest from the heart is the effect of a slow circulation most frequently recurring, and to heavy fleshy cart horses oftener than to those that are lighter and freer from meat about the heels.

Trimming the heels of the hair, which was intended to keep them warm in winter, is a very prolific source of grease. Thorough-bred horses never incur this disorder, so far as I can learn; and the chances in favour of those which are produced by crosses from blood stock, is in proportion to the amount of their breeding:

A cold in the heels is caught by walking the horses through water whilst they are hot: or being put into the stable with wet feet at nights; or lying in a stable that imperfectly keeps out the wind; all conduce to that stagnation of the blood, or tardy performance of its function, that causes the animal to generate this disease. They term it debility, but I think we had better say "want of ability," or of vigour to drive on the circulation of the blood; so that if the blood that is left behind in the fine capillary vessels be ever so good and proper for its purpose at first, yet the very circumstance of its remaining idle causes an inflammatory heat, that attracts towards itself all such congenial particles of the blood which may 
have been sent through the arteries to the part for the propagation of new horn, or the supply of marrow-of the nature whereof the matter partakes. Indeed, I have very little doubt that the marrow is concerned in the production of grease; for I have successively examined twenty legs which were affected with grease at the time life was extinguished, and the marrow was invariably confined to the lower part only, as if it were fallen down there for want of vigour, whilst the upper part of the bone was hollow, in every instance: healthy leg bones are always full to the top of each, and $I$ have reason for thinking that this is the case with all debilitated horses. Again, the glutinous substance that pervades the surface of the coffin, and to which I have attributed the formation of new horny matter of the hoof, is always found scanty in greasy-heeled subjects. See my observations on the foot in the next chapter.

One of those legs parted from the knee, having the skin removed, but otherwise untouched, was hung up in the yard whilst the sun was at 70 degrees (July 1825). In three or four days the grease might be seen to give a colour to the lower part at the fetlock joint, and every day the greasy nature of the colour was evident to touch and smell, whilst the articulation of the large pastern and sesamoid bones remained unaffected in either way. Upon breaking the bones nine months afterwards, the marrow had all escaped without a puncture, i. e. through the bone. 
The following ingenious suggestion I find among much voluminous Veterinary Memoranda, but whether it be my own, or I owe it to some friend, I have no means at hand for ascertaining, nor does my recollection serve me sufficiently to say who. "Horses with one or two white feet are more liable to the grease in the feet that are white than in the others; and if the proposition be true that white feet are weak ones, we come to the same conclusion, that the want of colour having occurred through want of vigour in the parts, then weakness and grease have the same cause."

Symptoms.-First perceptible by a swelling at the heels, mostly of the hind legs, and right oftener than left; but sometimes both heels are affected. This is occasioned by local inflammation, and is soon followed by a slight issue of greasy matter, whence the name; but it is sometimes more watery, ichorous, and offensive, which will depend principally on the constitutional health of the patient. The swelling sometimes extends much higher than the fetlock joint, even towards the hough, and occasions stiffness of the limb and indisposition to move. He cannot lie down, by reason of the unbending nature of his joints, and therefore stands to sleep, which renders the disorder more virulent by the accession of fresh matter to the part; the skin cracks at various places, and ulceration ensues. The hair sticks out like furze, the discharge is darker than originally, is thin, acrid, corroding, and stinking. 
Remedy.-The grease is one of those disorders about which we should employ our ingenuity in prevention rather than the cure; and this indeed is the case with nearly all the diseases that depend upon constitutional defectiveness, or rather inability of some of the organs of life to perform aright the functions of nature. How these ought to act I have spoken at large in the second chapter of book the first; and pointed out the free circulation of the blood as the principal cause of health, as would also the want of a good circulation prove the harbinger of disease. Now this affair of grease being produced entirely by such inactivity, it seems clear that exercise would be the best preventive of it; and the horse-keeper should also keep the heels dry after work is over, and handrub him a little with as much industry as he can afford, according to his wages. He should also let the hair remain on the heels of his heavy. horses, and give to the large ones sufficient depth of stall and bed, so as to prevent such from throwing their long legs half way out in the stable (as too often happens) upon the cold stones, of winter nights.

In slight attacks, a Wash made of a solution of alum, as under, will correct the disposition to grease, and a dose of physic set all to rights in a short time: both, however, regulated according to circumstances. When considering these, we should inquire into the preceding habits of the patient, as to his usual evacuations, and whether 
these have been stopped; for it frequently happens that grease is caused by the suspension of the pissing balls, to which many proprietors are so very much addicted, that they give them without reason, or suspend the giving through the same whimsicality. In this latter case give the diuretic powder, and the horse will require very little more physic. Again, if the animal require opening physic, give him the purging ball as under, and in-door exercise; but should his debility be then very great, the commotion this would occasion might reduce him too much, and therefore the alterative ball will do better, with the same attention to in-door exercise, if he can bear it. Sometimes, however, the heels are so cracked and chapped, that every step the animal takes only makes the matter worse; we should then assiduously apply ourselves to keeping the heels clean, with water of which the chill has been taken off, and with a brush get rid of as much of the running as possible; and after drying it well with cloths, use the alum rash of the stronger preparation; provided always that the inflammation be not. too high at the time, but which the warm water without the alum wash has a tendency to alleviate.

I will now set down the several articles just recommended above, premising this much as an apology for the numerous recipes here prescribed, that the grease requires we should be always doing a something for the animal, either of topical 
application, or in devising the means of carrying off the cause of the disorder by stool, by urine, or by perspiration. For, by keeping one or other of these evacuations agoing, we enable the animal's system to take up or absorb (as before described) the watery particles of the lymphatics, which remaining indolent constitute the disease.

$$
\begin{aligned}
& \text { Alum Wash.-No. 1.* } \\
& \text { Alum, } 2 \text { ounces, } \\
& \text { Blue stone, } 2 \text { drachms, } \\
& \text { Water, I pint. }
\end{aligned}
$$

Mix, and wash the part two or three times a day.

$$
\text { Strong Alum Wash.-No. } 2 .
$$

Alum, Vinegar,

Water, 1 pint. Mix, and use as before.

Strongest, or Mercurial Wash.-No. 3.

Corrosive sublimate, 2 drachms,

Muriatic acid, 4 drachms,

Water, 1 pint.

Mix, and apply to inveterate cases.

* Instead of this, the following is preferred by some persons, and those good judges too.

$$
\begin{aligned}
& \left.\begin{array}{l}
\text { Goulard's extract, } \\
\text { White vitriol, }
\end{array}\right\} \text { of each } 1 \text { drachm, } \\
& \text { Water, I quart. Mix. }
\end{aligned}
$$


Diuretic Alterative Poroder.

$\left.\begin{array}{l}\text { Nitre, } \\ \text { Powdered resin, }\end{array}\right\}$ of each 2 ounces.

Mix, and give in four doses; of mornings. To be continued until its effects are visible.

$$
\text { Purging Ball. }
$$

Aloes, 9 drachms,

Hard soap, 3 drachms,

Ginger, 1 drachm.

Mix with mucilage sufficient to form the ball for one dose.

The Alterative Balls.

Aloes, 6 drachms,

Hard soap, 8 drachms,

Ginger, 3 drachms.

Mix with mucilage sufficient to form the mass, and divide it into four balls. Give one every morning until the bowels are opened sufficiently.

The perspiration must be promoted by the following

\section{Diaphoretic Ball.}

Emetic tartar, 2 drachms, Venice turpentine, 4 drachms.

Mix well, with liquorice powder sufficient to form the ball for one dose; and give every other night for a week or ten days, taking care to clothe the patient, or put a rug on his body at least, regu- 
lating his sweats according to the weather. Some persons do not think it too much trouble to divide the foregoing ball into two parts, and give one every night for the periods just mentioned, which would bring the whole quantity of emetic tartar to the same amount in the end. Be careful to buy it genuine; and if the horse be taken care of while in his sweats, it will mainly contribute to his getting well. The patient is not to have this sweating ball whilst he has other physic in him; but it may be given alternately with the foregoing powder of nitre and resin; and is better administered thus, when it happens that the individual requires to be set a staling, and we think best to sweat him at the same time. If the medicine make his guts to grumble, add to the ball

\section{Opium, $\frac{1}{2}$ a drachm,}

which some do put into the prescription, whether or no. But then the opium having a tendency to bind the body, why, it counteracts our labour in this respect, and is not desirable in case the animal requires opening physic:

Regimen.-A good generous feeding should be allowed, with a few beans for the elder patients only; and in all cases where the disorder has lasted a long while and the cure is effected with difficulty, a run at grass is greatly conducive to complete recovery; especially if the convalescent can be allowed the option of a linhay, or covered 
shed, lying high and dry, or the advantages of the homestead, with an allowance of corn and hay. This change of regimen is greatly assistant of absorption when the physicking has ceased, especially where the disorder has terminated with a tedious ulceration which causes lameness, on which event he should not be exercised; but let the parts be poulticed with a turnip poultice, or it may be made of oatmeal and the grounds of stale beer, or both may be employed alternately; and then the parts, if luxuriant or thick, may be washed with a solution of blue vitriol in water, or the wash, No. 3. Dress the cracks with the following

\section{Ointment.}

Oil of turpentine, 3 drachms,

Hog's lard, 6 ounces,

Litharge water, half an ounce. Mix.

This may be varied by substituting Venice turpentine, half the quantity of the oil. In these inveterate cases we have now under consideration, a change of medicine is desirable, if but for the change which it occasions in the animal's digestive powers; for this purpose the blue pill has been given as an alterative, as well as that other preparation of mercury, the well-known calomel. Both act upon the kidneys, and set them in motion for the production of urine: and calomel chiefly effects this, by previously stimulating the liver, which again is very desirable by way of change. 


\section{Alterative Balls.}

Calomel, ] $\frac{1}{2}$ drachms,

Aloes, 3 drachms,

Castile soap, 6 drachms,

Oil of juniper, 40 drops.

Mix; make into three balls and give one daily for a week ; but should it gripe the animal, discontinue it, or add opium from half a drachm to a drachm.

\section{SURFEIT-MANGE.}

Both of these are diseases of the animal's system, and the first-mentioned proves its connexion with the second by sometimes ending in the mange. Over-feeding, or too much of it, or gross feeding, as it is the cause of these twin diseases, so are the two appellations it receives in the different stages of the attack descriptive of the cause : both are of French origin, as I apprehend ; sur-fait, or overdone, being tantamount to mange in its imperfect tenses, the effect of eating too much, which has brought on the disease. The manger, as every one knows, is the place for a horse to dine at, which is again derived of manger, to eat ${ }^{*}$, the

* Laroyers are not horses, nor ought they to resemble each other in the remotest degree; but I cannot resist mentioning the fact, that during term time, the Benchers of the Temple are called to their refection with a "Manger, manger, manger!" pronounced aloud and authoritatively at the door of their hall. 
noun from the verb. A surfeit, or sur-fait, is not an uncommon disease with reasonable man, and is alike caused by eating improperly, if not too much, and sometimes from the preparation of viands that are over-luxurious for the stomach that is to receive it, and is in fact incapable of digesting it. This is a state of the stomach that is by no means uncommon, and up to a certain extent happens every day to the full feeders of every genus of created beings. If, during this full and overreplenished state of the alimentary canal, and its then active state of lactification (or making of new blood), a sudden check be put upon the said process, by drinking cold water for example, what happens but the rapid propulsion of some part of the blood through the arteries, whilst the mouths of the offended lacteals close up for a period, and the blood, already filling the capillary vessels of the surface, becomes extremely irritable? Perspiration ceases; the lymphatics refuse to perform their office of absorption, and the blood so deposited in a due course of nature, forms innumerable small tumours under the skin, or become scabby, and throw off a dry scurf. The first has received the appropriate name of surfeit, the second is the more loathed mange, both having but one common origin. They are of the class of tubercular diseases, spoken of by.M. Dupuy, quoted higher up (as partaking of glanders, \&c.), are akin to grease, and to other accessions of matter on the surface, differing only as to situation, and like the grease, 
require that we should promote absorption and the application of repellants.

The cause of surfeit is thus distinctly met by the means of cure. The symptoms, however, frequently announce the disorder that has taken place within but a few minutes ere they subside again, to the utter surprise of all beholders. On such occasions mischief is supposed to lie in wait, and it is generally understood that the pustules, or tumours, only retreat from the skin to infest some more vital internal organ; but I always considered that such an attack had subsided through its own weakness, for nothing ever came of it after thus retreating spontaneously. Like surfeit in man, these tumours are attended with a pricking pain, the animal appearing restless, flinching from the touch, and looking round sharp at his legs and sides as if he were spurred trivially. Whenever he can bring the parts to bear against the stall, the bail, or the wall, the animal will rub violently, until the hair comes off, and the skin is raw. Instead of tumours that emit a sharp, acrid, and stinking humour, like grease, a dry scurf appears, resembling scabs, and this is mange in some animals; whilst other subjects exhibit no eruption whatever, though every hair is affected in a small degree, the skin becomes dry, and he is then Ride-bound.

Cure.-Surfeit is casily removed by a cooling purgative; but if the pulse be high, he should be bled also. Promote perspiration by means of the diaphoretic ball recommended at page 382 , with 
the same precautions as are there set down. If the animal be fat, he must be reduced; give bran mashes, sodden oats, and good exercise; and should moisture be found to discharge from the skin, wash it with the

\section{Surfeit Wash.}

Blue vitriol, 1 ounce,

Camphor, half an ounce,

Spirits of wine, 2 ounces.

Mix in a quart bottle, and fill it with water. Wash with soapy water warm (as in gréase), rub dry, and apply the above wash once a day, and at the same time give one of the diaphoretic balls as above. Let the diet be cool and opening, as scalded bran, sodden oats, or barley; and if the horse is low in flesh, mix an ounce of fenugreek seeds with his corn daily for a fortnight at least.

\section{THE MANGE}

Sometimes succeeds an ill-cured surfeit; and is moreover an original disease, arising from beastliness, hard living, ill-usage, and the consequent depravation of the humours. It partakes of the nature of itch in man, is communicable by means of the touch, by using the same harness, clothing, \&cc. and probably by standing in the same stall as a diseased horse may have left.

The symptoms are stated in the preceding pages, 
and from its cause we may rest assured never attacks horses in condition. As in surfeit, the horse is' constantly rubbing and biting himself; great patches of the coat are thus rubbed away, and ulceration frequently supplies the places. Scabs appear at the roots of the hair of mane and tail, large portions whereof fall away. When eruptions appear, they form a scurf, which peels off, and it is succeeded by fresh eruptions.

The cure is to be effected by topical applications of sulphur, and giving the same internally as an alterative; but mercurials are mostly preferred by our moderns; and there is not such a variety of opinions and prescriptions at this moment in practice for the most momentous diseases, as for this loathsome malady of the poor man's shed: neglect and ignorance having brought on the evil, ignorance and stupidity engage to effect the cure. I shall subjoin a few forms of those which are in most repute, and have been found effectual: even alteration is frequently found beneficial, though it may not at first seem to have been for the best.

\section{Mange Ointment.}

Prepared hog's lard, 2 pounds, Sulphur vivum, 1 pound,

White hellebore, in powder, 6 ounces.

Mix with oil of turpentine sufficient to make a soft ointment; rub the animal wherever the eruption and scurf appear, with hair cloths, or a new besom, so as to get rid of the loose filth before 
applying the ointment. Rub it in well every other day, and give the following

Alterative for the Mange.-No. 1.

Tartarised antimony, 1 ounce,

Muriate of quicksilver, 2 drachms,

Ginger and

Anise seeds, $\}$ powdered, of each 3ounces.

Mix, with mucilage sufficient to form the mass; divide it into six balls, and give one every morning until the eruptions disappear.

Allcrative for Mange.-No. 2.

Antimony in fine powder, 8 ounces,

Grains of Paradise, 3 ounces.

Mix, and add Venice turpentine to form the mass, which divide into twelve balls. Give one daily whilst the rubbing is continued.

\section{HIDE-BOUND.}

The cause of hide-bound is commonly the same as that which produced the last-mentioned disease, viz. poverty, only that the particular animals may not both be in the same state of general health, and the more depraved would incur mange, whilst another would became simply hide-bound. This is less of an original disease than the effect of some other, and of bad digestion and consequent defective perspiration beyond all others, as 
may be inferred from what I have said concerning the intimacy that exists between those two operations of the animal system in my second chapter of book I. at pages $64-6 \%$. The justness of this view of the cause of hide-bound was further proved by a series of dissections of this particular malady undertaken by me in May 1820. I invariably found tumours had formed upon the larger lacteal vesse!s of the peritonæum, on the gut, or the like kind of attack on the pleura that covers the lungs. The formation of those tumours was no doubt the mediate cause of hide-bound, and had been brought on (I have every reason for believing) by the inordinate use of diaphoretics, the stimulating nature whereof, as is usual in all such cases, had thus defeated itself.

Horses that are so affected with tumours, are they which become distressed easily, though in good apparent health, upon being pushed on a journey, or at a heavy drag, particularly when the belly is distended. Thus the cause of hidebound exists long before we can perceive it, and is the reason why I recommend the arsenical preparation hereafter prescribed, as a tonic, previous to administering the sweating remedies. The appearance of hide-bound is frequently ascribed to the roorms, botts, \&c. ; but in all those subjects examined by me, amounting to half a score or more (for I kept no notes), no worms were to be found of any consequence, for it would be ridiculous to talk of two or three such stray 
insects occasioning such an extensive disorder, so remote from the seat of their supposed ravages. What is very well worth remarking (though such a thing is not very singular), is, that the writer who has most lustily cried out "Worms, worms !" upon every occasion of disordered skin and staring coat, has recently suggested that after all, worms are necessary to the horse's digestion; and the gentleman seems to think that these insects act upon the horse's stomach much in the same manner as pepper on that of mankind! Thus he blows hot and cold with the same breath, or rather worms and pepper with the same pen; for, whilst the worms are so lauded in one volume of his works, the malediction remains uncorrected in the other.

Symptoms.-As the word implies, the hide or skin seems bound or glued to the bones; the animal is always very low in flesh, or we might aver that the skin adhered to the flesh. 'The pulse is low, and great weakness is manifest in every step the patient takes. As the tightness is first observable at the sides of the animal's body, before it reaches the limbs, and every hide-bound subject examined by me proves the fact, I have no hesitation in ascribing hide-bound to disordered digestion, which includes the negation of wherewithal to digest, or starvation and hard work. Again, one of two extremes attend the bowels: they are either relaxed greatly, or much constipated-usually the former; which may be the 
effect of a long fit of illness from inflammation or fever, and the use of strong medicine, or much of it.

Cure the animal by the direct contrary conduct to that which brought on the illness. If its stomach be empty, as commonly happens, fill it nearly with food that is easy of digestion; if it be too full, empty it; give alterative laxatives and tonic alteratives afterwards; restore the perspiration by the diaphoretic ball recommended at page 382 , and let the curry-comb and brush be assiduously applied to his coat. He may then be exercised, but notbefore, as it is nearly impossible without inflicting great pain. Besides which, forced exercise, or sweating, as hath been strongly recommended, would in this case only aggravate the disease; for if the animal did sweat, it would be caused by internal pain; probably the tubercles which had formed upon the membrane would suppurate and burst, and thus confirm the disorder internally by the inflammation of the particular viscus where the disorder began.

\section{Alterative Laxative.}

- Aloes, 9 drachms, Hard soap, 7 drachms, Anise seeds, powdered, $1 \mathrm{oz}$.

Mix with mucilage sufficient to form the mass into four balls. Give day after day until they effect the purpose of bringing away a good stool. Then 
give the arsenical tonic alterative, thus proportioned for a large horse, with care.

$$
\text { Tonic.-No. } 1 .
$$

Prepared arsenic, 10 grains, Ginger, powdered, 1 drachm, Anise seeds, powdered, 4 drachms, Compound powder of tragacanth, $2 \mathrm{dr}$. Mix with mucilage sufficient for one dose. Give daily for a week, preceded and followed by mashes, and then give the bark, thus:

\section{Tonic.-No. 2.}

Cascarilla, powdered, 4 ounces,

Ginger, 8 drachms,

Salt of tartar, 10 grains.

Mix with mucilage sufficient to form the mass into four balls; give them daily. If the preparation of arsenic in No. 1 is disliked, substitute the alterative ball at page 385 for it, and follow it up with the bark as above (No. 2).

The following ball is calculated to improve the coat, and will be found beneficial when the animal is recovering, if given in these proportions for ten days or a fortnight.

\section{Alterative Balls.}

Tartarised antimony, 3 ounces,

Powdered ginger, 2 ounces,

Opium, 5 drachms.

Mix with mucilage sufficient to form the mass, to be divided into ten balls. 


\section{WORMS.}

As remarked in a preceding page, 392, so many other disorders, external as well as internal, have been charged to the existence of worms in the intestinal canal by veterinary writers, that we find much difficulty in persuading ourselves that this is not the precise ailment which afflicts the animal when his coat becomes staring, and his skin sticks to his ribs. Most frequently, however, that ugly appearance which denotes hide-bound, and other similar symptoms that depend upon suspended perspiration, arise from tubercular diseases of the mesenteric canal (see page 12\%), and not within the gut or stomach; for the excess or the suspension of perspirable matter must alike depend upon somewhat of a more general affection than torms, that fasten on this or that part of the stomach or intestine (as we are told), and can only influence the part they immediately occupy. Unfortunately, we know of no specific cure for worms, the remedies that are usually prescribed being of a hot, burning, and destructive nature, that are as likely to injure the intestine as the worm; it becomes our primary duty, therefore, to ascertain when the disorder be really the worms, so as to prescribe the proper remedy when we have asceltained that the fact is so. It is very easy to say a horse "has the worms;" and to give him worm 
medicine; but much more difficult to ascertain the real fact, than to remove it when well authenticated. Our inquiries, then, should be directed towards this point as much as. to any other unsettled question-the existence and quality of true glanders, for example; and yet more fine learning has been bestowed upon the uncertain knowledge of botts and other worms, than has attracted the attention of our veterinary writers to any other portion of their labours.

Causes.-Indigestion, and consequent stoppage of the aliment in the stomach and cocum; which again may be occasioned by bad corn, musty hay, or hay made from rank grasses, -if all hoy whatever does not contain the means of generating insects, when used without sufficient water; also, when either substance be swallowed, as often happens, without being properly masticated, through wearing away of the teeth (see page 46), the lampers, \&c. Much pampering of the appetite, by dealers and others, to produce fine coats by means of stimulants, as eggs, wine, ale, bread, diapente, linseed, \&c.; when the effects thereof are worn away, these leave the lacteals (see page 127), impaired or offended at being deprived of a short-lived energy. The articles just enumerated form indigestible crudities that become the appropriate niclus for generating worms in the canal, so deprived of its natural functions by artificial means. Consult again what is said at the conclusion of the first book, at page 147, \&c. Irregular feed- 
ing also tends to the lodgement of crudities in the cæcum, or second stomach.

Symptoms.-A staring coat, with emaciation and weakness, were formerly deemed sufficient indications of the existence of worms to warrant the doctor in pouring into the animal his monstrous mixtures; for a worm case was esteemed by the professor like a little annuity, pro tem. Those symptoms, however, are at first rather the presage than the concomitants of worms; since they are also symptomatic of several other internal diseases, some of them producing worms in the sequel, whilst other some are found still more rapidly destructive of life than worms are, and therefore demand more immediate consideration. Slight affections of the lungs, as well as of the liver, being of long continuance, occasion partial roughness of the hair, and slight hide-bound of the integuments nearest the seat of disorder, that spreads progressively all over. The cough which accompanies severe attacks of the worms differs from cold in the organs of respiration; the first being more deep and cavernous, leaving a shake or vibrating heave of the flanks, whilst the former comes off with a wheeze, as if not fetched from so deep a recess.

As the disorder proceeds, and the roorms may be supposed to extend their ravages; the patient's appetite is subject to extreme variation; he being sometimes ravenous after food, at others not caring to eat at all; which shows that the stomach is af. 
fected, and is frequently succeeded by vertigo, or staggers. A horse with worms that give him uneasiness in the bowels will leave off eating sometimes for two or three minutes, when a cavernous rattle maly be heard coming from his inside, and he resumes his feeding. If he endeavours to kick his belly, it has been construed by the roorm advocates into the pain occasioned by worms gnawing . his bowels; but neither symptom is an invariable indication of worms, for he does the same when attacked by any other pain of the beliy-whether colic, tight girth, injury of the sheath, \&c. When the worms appear coming away spontaneously, with successive stools, no matter of which kind, it affords proof that the animal has taken grass or hay that contains grasses of an anthelmintic property, and points out the propriety of continuing him on the same food.

A yellowish ordure appearing about the fundament something like flour of sulphur, shows the death of a good number of small worms (ascarides) has been occasioned by some such natural means as the preceding. Some worms come away as soon as generated in the aliment, but if no other sign of their existence is manifest, the solitary fact should occasion no uneasiness. When botts, having been detached by similar natural means, leave the stomach - where they do not always cause inconvenience, we find them adhering to the large intestines and final gut, to which they adhere and canse the animal to rub his breech 
against the wall or upright of the stall. Should those symptoms continue, and the generating of worms remain unchecked, the horse falls into profuse sweats on the least exertion, and when these cease, he exhibits a weak and languishing condition, scarcely notices a brisk application of the whip, his skin adheres to his ribs and flankshide-bound has commenced. Cough, more or less hectic according to his remaining strength, accompanies him to his end; for, as to a cure being practicable when hide-bound arising from such a cause has fairly laid hold of him, 'tis clean out of. the question.

Regimen.-As the commencement of this disorder is mainly attributable to the coarseness of the animal's food, and consequent incapacity of its guts to expel the hardened materials, so will an entire change in the mode of feeding him do more towards effecting a cure than all the medicine we can prescribe, and all that the most liberal hand would bestow. I think it would be too much to expect that generous treatment alone should effect a cure of itself, but I certainly have known worms voided after a few days' casual good keep ; and in these cases I apprehend we may attribute the coming away to the change or alteration that was so effected in the state of the patient's bowels. Hence the propriety of any change of his usual diet, as well as the advantages of alterative medicines. In the first place, try a run at grass, or give green food in-doors, or succulent and a greeable 
vegetables. If poor living has not been the original cause, sume defect in conformation has; and the above change, with plenty of water-gruel, bran mashes, boiled potatoes, bruised corn, and the like, by lubricating the parts, may detach the worm, or at least assist the medicine, which ought to have the same tendency.

Cure.-Since the worms are not always to be killed even by strong poisons, nor brought away by brisk purgatives, for a certainty, but are frequently discharged in a few days by an alteratize regimen, reason dictates and nature beckons us to follow her course, in affording to the horse which cannot be spared from work, or a run at grass be obtained, to adopt the means nearest thereto that lie within our reach. Laxative alterative medicines then obtrude themselves upon our notice, and in all cases are found to do good, more or less as they may be addressed to the actual seat of the disorder: in pills, if the worms lie in the intestines; in powders or liquid, if they occupy the stomach-in all forms alternately when we are uncertain. The various preparations of mercury, and of antimony, with Barbadoes aloes, as being more drastic in operation; also common salt, box, sulphur, savin (a vegetable poison), and sal Indicus, offer a sufficient variety for the bases of as many varied prescriptions; and variation is here most desirable, inasmuch as some kind of worms which resist the effects of one substance may be detached and hurried off by another. 
Water-gruel, as it relaxes the parts, and prepares them and the worm for receiving the antidote, should precede every other remedy, particularly the mercurials; a course of which should be followed by a purgative, but not be given together, as is commonly practised. For ascarides, which usually infest the large' guts, I have found great service in calomel to the amount of a drachm or mure, given over night twice, followed by a purgative ball next morning after the second.

No. 1.-Mercurial Bolus.

Calomel, $1 \frac{1}{2}$ drachms, Anise seeds, 5 drachms.

Mix with treacle for two doses.

No. 2.-Purgative Ball.

Barbadoes aloes, 4 drachms,

Gamboge, $1 \frac{1}{2}$ drachms,

Prepared kali, 2 drachms,

Ginger, 1 drachm,

Oil of amber, a tea-spoon full,

Syrup of buckthorn sufficient to form the ball for one dose.

No particular care need be taken of the horse, but he should not take any gruel for the two days that the mercury is in him, as directed by White, but give him bruised corn or other dry food with little water, the calomel not having entered the system. Neither does he require any of the exercises usually forced upon patients " in 
physic." Let a week elapse ere the same bolus and purge are repeated as before, when they seldom fail to bring away whatever worms he may have in him. Instead of the foregoing, sume persist in the following old method, by way of laxative mercurial, which, however, I must premise, seems much too strong, notwithstanding the high character some bestow on it.

No.3.-Laxative Alterative Balls.

Quicksilver, 1 ounce, and

Venice turpentine, 2 ounces.

These being well rubbed together in a mortar, add

\section{Aloes in powder, 2 ounces, Ginger, 1 ounce.}

Mix with syrup of buckthorn, and form the compost into four balls, one to be given with intervals of five or six days. Water-gruel or a bran mash to precede each ball, as before, and give the same when the physic may be working off.

Some horses, however, cannot bear the bolus No. 1, calomel having a tendency to gripe; in that case the quantity should be divided into three balls and given on three successive nights, followed by No. 2. on the fourth morning. In like manner, if the horse be not a very strong one, the above quantity of No. 3. may be divided into six or eight balls, and given at intervals of two days each until purging is produced. Indeed, neither of these medicines should be given, least of all continued, when the animal dungs loosely. 
From those precautions, it is manifest that my opinion, so often expressed regarding the misuse of strong medicines, remains unaltered; and if I have been successful in impressing the reader with the same wholesome and humane truths, he will at once perceive the absolute necessity of attending to the symptoms, to assure himself that the patient really has the worms, and not some other affection of the liver, kidneys, coecum, \&c. as remarked by me at the head of this article. Mistakes in these respects often prove fatal, or at least affect the animal's future health.

If worms do actually exist, they cannot fail to come away with the foregoing course of medicine; and the patient, though a little weak at first, will come out of hand with a good appetite, brisk in his manner, and bright as a ruby. These considerations, however, should not influence us to neglect a trial of the milder medicines, before enumerated, as containing anthelmintic properties, less powerful indeed than the foregoing, but not therefore less likely to prove serviceable in ordinary cases. Of these, the Indian salt (sal Indicus) deserves the first consideration, though denounced as differing very little from common salt, with a small portion of sulphur, both of which are known to be goodly anthelmintic. Be its virtues what they may, the following substitute will be found to contain all the properties of the genuine salt, and may be employed when this cannot be readily procured. 
404 WORMS; VARIED REMEDIES, NOT STRONG,

\section{Laxative Porvder.-No. 1.}

Sublimated sulphur, 4 ounces,

Emetic tartar, 4 drachms,

Liver of sulphur, 1 ounce,

Bay salt, 4 ounces.

Mix for six doses, one to be given daily in the corn, which should be previously moistened with water-gruel. As soon as the bowels are tolerably opened, desist for a week at least; but should it fail to produce this effect, give the following

\section{Laxative Balls.}

Barbadoes aloes, 4 drachms,

Gamboge, 1 drachm,

Hard suap, s drachms,

Anise seeds powdered, 4 drachms,

Oil of clover, 6 drops.

Mix with syrup of buckthorn enough to form the mass, and divide into two balls. Give them on two successive mornings, unless the first prove effectual. I have found these balls, without any other aid, produce worms, a few, by repeating as often as five or six times. Another preparation of antimony may be substituted for the first mentioned powder, viz.

\section{Laxative Poroder.-No. 2.}

Liver of antimony, 3 ounces,

Cream of tartar, 4 ounces. 
SUCCEED. - \$TAGGERS, ITS VARIETIES. 405

Mix for six doses, one to be given daily until the body is opened. But should not this happen, the laxative ball just advised should be given.

Savin (the leaves) pounded, and a spoonful given twice a day in the horse's oats for ten days, and then the laxative balls above, brings away slimy matter with the dung, if not worms alive.

Arsenic has been tried, to the amount of ten grains a day, for a week, but its powers are tonic only: it is a dangerous remedy in unskilful hands. All bitters are anthelmintic and tonic; thus to wormwood, rue, and chamomile flowers, have been attributed the faculty of killing the worms; but the fact is not exactly so: those effects are proluced by bracing the stomach, and restoring its tone, and thus disposing the parts to throw off the intruders.

\section{STAGGERS, APOPLEXY, MEGRIMS, VERTIGO, FITS.}

STAGGERS is the common or vulgar name given to all those disorders of the head which consist in vertigo or "swimming of the head." Drowsiness attending this symptom confers the distinction of sleepy staggers upon this kind of attack, whilst mad staggers is that affection of the brain which causes the animal to kick, to tumble, and plunge about: both are occasioned by diseased stomach, brought on by inflammation of that organ, or simply by the retention of a great mass 
of indigestible food there and in the intestines: constipation attends every species of staggers, and in some cases the hardened dung may be felt or observed by applying the senses to the proper parts. The breath is offensive, the respiration impeded, and the pulse high and sharp in mad slaggers, whilst in the slecpy it is slow, heavy, and full, without vibration [see page 167]. When these latter symptoms continue a long time, the blood determines towards the head, and the pulse increases, if the animal be one in good condition; and unless blecting and purging be employed effectually, sooner or later ends in apoplexy, or one paroyxsm only, which terminates fatally. Highbred cattle, stallions, and brood mares, which are pampered in their food with stimulants, frequently fall victims to this kind of attack, as do their progeny whilst under training, sometimes. In some cases the animal makes one effort, in others it drops instantaneously; so the reader may perceive that he does not stagger at all: and $I$ infer that a manifest difference exists between the two, although both arising from the same cause; for, the one we may aftord some assistance to, and usually succeed in performing a cure ; in case of apoplexy, the only symptom is remedyless-death. To prescribe for such an event would be utterly useless.

Under the head of "costiveness" I have already considered the origin of staggers, and prescribed the remedy at page 183 ; because that is the dis- 
ease, whilst staggers, \&c. are but the accompanying symptoms.

The megrims is an occasional attack on the sensorium or brain, in which the animal drops down as if shot, lies motionless awhile, recovers slowly, and is next day fit to go and do the same thing again, if pushed in his work. This disorder originated in a foul stomach, in one case that came under my care, and was at first a fit of the sleepy kind, which afterwards degenerated into megrims; the morbid state of the head, I apprehend, continued in a trivial degree, which any great exertion brought into activity. Sometimes these megrims are preceded by a short warning, when the animal rears up before it falls, or rambles like a drunkard; it then tumbles and plunges about with considerable danger to those who may collect around it. The muscles of the eye are usually affected, much in the way of horses in locked jaw, or the human subject in a "falling fit;" but all those symptoms disappear upon employing the proper remedies, some of them so quickly and by such means as to appear the effect of a simple mechanical operation.

The cause of staggers, and the symptoms that distinguish the one kind from the others, being thus settled, without distracting the inquirer with the needless distinctions of agriculturists or the fanciful reveries of the doctors, let us proceed to the 
Remedies.-Farm horses that live much in the straw-yard, and work hard on bad hay, \&c. will sometimes stand still at once, as if struck motionless in the midst of their work, which is a sure sign that some great leading function has been suspended for the moment by reason of the great exertion. The driver has nothing more to do in this case than to let the tired creature rest for the space of a minute or two, and then proceed in his work a little more leisurely. Prevention is better than cure.

In all ordinary cases of staggers, simply opening the bowels will effect a cure nine times out of ten; and when the animal shows symptoms of a disordered stomach, the coming disorder may be warded off by a dose of physic. In violent attacks, let a clyster be first employed, of warm water, in which common salt has been dissolved, and the hardened dung brought away by manual assistance-as more fully detailed elsewhere-see the mode of doing this effectually, at page 186 . I have known violent cases of staggers cease by this remedy alone, and the cure was completed with a purgative ball, as prescribed at page $\mathbf{1 7 2}$.

The fits that constitute megrim, or the more genuine staggers, will require the lancet; and let the quantity of blood taken be commensurate with the violence of the animal, his bulk and fleshiness. From four to six quarts will thus reduce his powers, and aided by the back-raking and purgative just recommended, a cure is soon effected. 


\section{LOCKED JAW}

Is rather the effect of other diseases, of the acute kind, than an original attack, and is symptomatic of approaching death. A prick in the foot and docking the tail, are fruitful causes of locked jare. Hot weather is most conducive to this manner of dissolution, which is brought about by great excitation of the nerves, and accompanied by imperfect digestion. The remedy would of course be found in restoring the tone of the former, and opening the main outlet of nature. I have seen a case of locked jaw proceeding from inflammation of the intestines, of a very aggravated nature.

Symptoms.-The case to which I allude was that of an old horse, from twelve to fourteen year's of age, just off from hard work, which seemed to have lived badly and suffered severely the ills of a protracted life. Date, May 14, 1820, when the weather was prematurely hot. As usual, it began by the animal thrusting out its nose and eating with some difficulty, which increased as the stiffness of the neck became worse. The ears stuck up, and the sufferer could scarcely move a foot, and this with the greatest pain. Thus, every hour the malady is found to extend itself towards the more vital parts, until reaching the heart, life is then extinguished. The brain appears to be affected at the very earliest period of the attack, when the animal evinces unusual apprehension, and will 
neigh and prick up its ears at the approach of any one, as the last effort of nature to obtain the notice of man. The pulse is then increased to about 50 ; but in the future stages of the disorder it falls again below 40, and lower still until its final extinction.

In a few hours, the balls of the eyes of the animal just alluded to were turned back, showing the nerve which retained the ball in position in a very disgusting manner; he appeared to suffer much pain, respiration had ceased, the abdomen was drawn together, and immediate dissolution was expected momentarily. When the subject was opened, I was struck with the inflamed state of the mesentery, and all the lacteals assumed a bloody appearance. Previously to this catastrophe, I hit the animal hard on the forehead with my fist, once; the blow shook his whole frame, which before was as stiff as if made of wood; its eyes immediately returned full one-half way back again towards the proper situation, and I was not mistaken when I imagined that its jaws, which had been knit together, seemed to relax somewhat, and the rigidity of the neck gave way.

Remedies have been prescribed, and $\mathrm{Mr}$.Wilkinson of Newcastle reports several cases of successful practice upon young horses which had acquired locked jaw by being nicked, or docked, or pricked in shoeing. The chief obstacle to the administering of any medicine being the closeness of the teeth, which defies the introduction of a horn, it 
may not be amiss to observe, that profiting by the foregoing experiment, I have in several cases caused a little relaxation in this respect, by placing a piece of wood upon the forehead and striking a smart blow upon it with another piece or a small mallet. Some substance might then be placed between the teeth to prevent their return to the original closeness, whereby the remedies recommended by Mr. Wilkinson may be employed with much prospect of success, for he only failed in four cases in which the jaws were inmoveable by any means which he then knew of ; and as he has treated this particular subject more happily than any veterinarian of our time, I think I cannot do better than follow the example of copying his account of a well-marked case successfully treated.

When called in, he observes, "I found the symptoms were a spasmodic affection of the muscles of the jaws, head, neck, back, hinder ex-. tremities, and abdomen, which occasioned them to become rigidly contracted, and the abdomen was much drawn in ; the pulse was about fifty, with some irregularity, the breathing a little quickened, the jaws were considerably shut, but not so close but medicine might be administered as a drench with a small horn; the appetite not diminished, but she could not masticate hay; the head somewhat raised, and on elevating it a little more, the haws covered great part of the ball of the eye, the nose was thrown out from the chest, the nostrils expanded, the ears erect or perched up, a great stiff- 
ness of the neck and back, the tail a little elevated, and, upon a little fatigue, a shaking of it, a straddling of the hinder extremities: the animal was very costive, and the urine was somewhat diminished. The mare had been shoed about three weeks before, and the farrier had driven a nail into the sensible part of the foot while shoeing her. The lameness thus produced was soon removed, and the disease came on after performing a journey; that is about three weeks after the injury in the foot had been inflicted. Two quarts of blood were taken off; a purgative drench and an emollient clyster were given; considerable friction was used over the inuscles of the jaws, head, neck, and back, particularly where they were found most rigid; a stimulating liniment of turpentine, hartshorn, mustard and oil, was well rubbed over those parts, which were afterwards covered with sheep-skins, as recently taken off' the sheep as they could be procured, which soon brought on sensible perspiration. The diet was principally thin bran-mashes and oatmeal-gruel, of which she frequently took a little. The next day, pulse the same, breathing a little quicker, jaws not more locked; a constant perspiration had been kept up by the sheep-skins; the purgative drench not operating, anothér clyster was administered, which promoted its action : the liniment was repeated. Next day (the ninth), symptoms nearly the same, perspiration copious: the purging having subsided, the anti-spasmodic me- 
dicine, composed of opium, camphor, and asafœtida, was given with a small horn morning and evening, and a similar mixture, with the addition of three pints of a decoction of rue, was administered as a clyster, morning and evening. The drench and clysters were repeated morning and evening till the 14th day ; and during this, the quantity of opium, viz. 1 drachm, was increased or diminished according to the violence of the spasms, which at times were very severe. It was always administered in such a manner as to have its effects constantly in the system, without producing much restlessness; during this time, there was also a most copious perspiration going on under the sheep-skins. The bowels becoming costive again, another purgative drench and an emollient clyster were administered. On the $15 \mathrm{th}$, the drench not operating, a clyster was given, which produced the desired effect. Pulse and breathing a little hurried and irregular, jaws not more locked, still perspires under the sheep-skins, appetite good, but cannot masticate hay. 16th, Pulse more regular, breathing more calm, perspires freely under the skins: the purging having subsided, the opium, \&c. were administered as before, and continued until the 21st, when another purgative drench and emollient clyster were given. The jaws were now more open, and the mare could masticate hay: the muscles of the head, neck, back, and hinder extremities, became considerably relaxed, and on raising the head, the haws did not cover much of 
the eye. On the $23 \mathrm{~d}$ day, the purging having subsided, the anti-spasmodic medicine was again employed until the 10 th of A pril, when another purge was administered. On the 12 th, the purging subsided; the anti-spasmodic medicine was again used a few days longer, when she was completely cured of the complaint. After this, tonics were given, which, with a nourishing diet and suitable exercise, soon restored the tone of the muscles, and the animal became as useful as ever." his to edreny

Of the twenty-four cases described, nine came on after docking or cutting off the tail, from ten days to a month after the operation. In such cases, the tail was fomented with warm water, and the sore dressed with detersive ointment. It should be remarked, that in all the successful cases the jaws were not so completely closed but medicine could be given with a small horn, or introduced as a bolus, by means of a cane. In some instances, there appears to have been considerable difficulty in giving medicine at first; but by persevering carefully, both medicine and food were introduced in sufficient quantity. With respect to cold application, Mr. Wilkinson says, he has only tried it once, when the whole of a mare's body affected with locked jaw, except the nostrils, was immersed in snow for some time, witlout producing any relaxation of the muscles : on the contrary, the symptoms afterwards gradually in creased, and she died on the third day. In four cases that terminated fatally, the jaws were so 
completely closed, that neither food nor medicine could be given by the mouth On examining these horses after death, there was some degree of inflammation in the lungs, stomach, and bowels. It was generally found on opening the spinal canal, that the membrane covering the marrow exhibited a very inflamed appearance, and the marrow itself was tinged of a still darker colour, whilst the membranes of the brain exhibited some marks of inflammation.

\section{HYDROPHOBIA.}

No notice whatever would have been taken of this dreadful malady, but for some additions to the stock of information already before the public as to the means of discriminating the true from the false rabies, which $\mathrm{I}$ am enabled to furnish from authentic sources. A disease confessedly incurable requires no more to be said of it; but this having been, at one time or other, the case with several other subjects treated of in this volume, I must not, consistently with the duty I have im posed upon myself, pass it by in silence. Even the names of authors who have written on canine madness would be serviceable to such of my readers as may be desirous of extending farther their inquiries concerning this melancholy and appalling disease. Preceding anthors have all confined their information to the dog itself, with mere casual notices of his attacks upon other ani- 
mals, and on man. Their researches extended not to the horse, or but trivially so. But, inasmuch as the symptoms of madness discoverable in dogs so affected are good to be known to those who would keep their horses out of danger, $I$ ain thus further induced to bestow a page or two on the distinguishing character of the true symptons, and add a hint or two as to prevention, since cure is nearly hopeless at present.

Causes.-The bite of a rabid animal--universally of the dog, and in every case that I hear of, on the lip. The bull-dog, the lurcher, the mongrel, the Danish dog, and the shepherd $\log _{\text {g }}$ are the kinds most disposed to run at horses, especially when so affected (the first-mentioned, on other occasions, usually fighting at the throat) jumping repeatedly at the horse until they get hold, and the two first pertinaciously holding fast a long time, even until killed off, as we hear and believe*. This will happen mostly with horses tight-reined, or which we bear up in harness, whilst those having the head loose rear and paw off the offender, or being at large, evade or trample upon him; but however slight the bite, the mischief is already

* On the morning of September 9, 1826, as Mr. Hawkerford, of Bilston, Staffordshire, was driving two ladies from Willow-hall, a bull.dog, which was with its master in the road, seized the horse by the nose, and retained its hold, though the horse ran away, overturned the gig, and threw the party into a hedge. Still the ferocious brute retained its hold until its throat was cut on the spot. Vide Annals of Sporting, No. 58, page 238. 
committed; so that avoidance by flight is the only preventive of an irremediable evil, unless we are prepared to shoot the caitiff, or to run him through. We hear the free use of horse-flesh for keeping dogs in England charged as one main cause for engendering rabies, or at least quarrelsomeness *; add to this, the denial of water to which some of them are subjected at a season when dilution is most required - "what time the dog-star reigns," and we think the suggestion of the writer named in the margin is not very far removed from the fact. At least, he informs us that this appalling disorder is comparatively small in other parts of the world, where horse-flesh is less plentiful, or water, the antidote, is found in abundance, and adduces Lisbon in proof, where dogs perform the office of scavengers, and further are supplied with water by individual housekeepers $\uparrow$. Our own towns, too, in which water is easily obtained, are much seldomer subject to epidemic visitations of rabies than others more arid, yet lying open to an access of carrion in abundance. Degs invariably take water with much eagerness in every stage of the disorder, so far as I have seen, or heard of, orally; some printed accounts differ. Man dreads

* The " combattiveness" of butchers' dogs, and of butchers' boys, has been referred to the inordinate use of butchers' meat by our friend Jon Bee, Esq., who seems to think, that "to them is alse. denied sufficient quantities of roater, for which the latter kind of beings substitute extracts of malt and its maddening compounds."

$\dagger$ In "Annals of Sporting," No. 46, page 217, signed J. P. $_{\text {. }}$ 
it ; but when he can get it down, which has been done within a day or two of his dissolution, he finds the raging heat of his stomach alleviated by the effort.

Symiptoms of liydrophobia.-In the dog its approach may be known by a marked deviation from the general habits of his kind, amounting to dislike of former friends, a symptom which ought to be particularly regarded. They have been seen to eat their own excrement, and lap their own: urine, besides other marks of depraved appetite; though at this early stage of the complaint they are: less likely to attack a horse than to resent an affront, or be guilty of treachery towards friends. But as the disorder increases, he shors an inordinate desire to gnaw any substance whatever, and evinces augmented antipathy to cats. Even the dog called Danish, though mostly kept witl, and very fond of horses, would, as soon as affected, be the most likely to snap at his old companions? noses. As the malady increases, his eyes become inflamed, and are affected with a blearing from the lids. He howls horridly when the throat is inflamed at the larynx, or part where the voice (barking) proceeds from; the which sound, whoeverhas once heard, he can never afterwards forget or mistake, unless he himself be bit, or become deaf. The confirmed mad dog now usually sits upon his rump to howl his obstructed bark, through very pain from apparent intestinal inflammation. If suffered to range about as the last stages ap- 
proach, he seems bewildered and de void of sight, and shiould be either avoided or attacked with clubs and other weapons to extirpation feeble opposition is obviously dangerous.

ef The symptoms of hydrophobia coming on upon the horse are direct and positive; blood on the lip, and other marks of violence, convey the first intelligence that the mischief has been inflicted; for neither horses, sheep, nor neat cattle inicur wabies without inoculation. We are further sold, by M. Huzart, that they do not possess the power of communicating the disease by bite to other animals, even though labouring under the highest degree of hydrophobia at the time; a fact I do not further vouch for, but which, when proven by well-marked cases, would go far towards inspiring confidence and certainty in applying any of the alleged remedies. What man is bold enough to administer $a$ ball, for example, whose own life is at stake, ingloriously, by the feat? Increased pulsation, inflamed throat, and evident thickening of the membrane that lines it; soon after, the stomach being also inflamed, rejects food, or the patient is at least indifferent to it, which may occur about the eighteenth day after the inoculation; four or five earlier if the animal be in good condition, so still sooner if high fed and full of blood. Shortly after, i. e. from five to eight days, the bitten parts enlarge, and difficulty of swallowing, evidently prove that the disorder is making progress; the patient rubs the part against the 
manger, stall, or wall, increasing in vehemence from the twentieth or twenty-third day. He does. not drink water freely, as usual, though this is by no means a certain criterion, for his power of swallowing is already imperfect : he does not flinch from water when sprinkled over his face, but will even drink to the amount of a pailful, when occasionally he can find free passage for it, and the whim may be said to seize him. Some rabid horses will take to water, and one in a very high state of excitement was known to have run into a river. Suppression of urine next proves that the inflammation has reached the region of the kidneys, which is effected by way of the stomach; perspiration and excessive exacerbation ensue, with inflammation of the parts of generation, accompanied by contraction in the male-yet a gelding was found to have protruded its sheath, and staled with much pain to the amount of half a pint, about the twenty-fourth day.

Weakness of the back and loins sometimes is observable at any period of the disease; some quadrupeds being thus attacked, and falling down mad without previous indication of rabies.

The eyes glassy, fiery or red-loss of vision; tongue sometimes shoved out, and then gnashing of the teeth. The raging symptoms increase from the twenty-second or twenty-fourth day to the twenty-eighth or thirtieth day after being bitten, when the animal will beat itself to death, unless the owner more humanely puts it out of pain with 
a musket; for "tis dangerous to approach within reach: the interposition of a strong gate across the stable, and the application of a beast rope well fastened, are good preventives of accident during this final operation, or a cart that will bear some kicking might be employed.

-3oginien.-None will afford any permanent relief, though it has been usual to place before it weater as a test of its madness-though now known to be a fallacious one in any state of the disorder with any animal whatever. All horses continue to feed up to a certain period-until the stomach is attacked-and some eat voraciously in the intervals of the fits, and drink too, but no good can be expected from either, unless made the vehicles for the introduction of some nostrum. If a cure be attempted, certainly nutritious food, easy of digestion, and cooling, must assist it. The stomach being very much inflamed in this disorder, points out the propriety of bran mashes, marshmallows; and of water gruel, given cold, which will afford the means of alleviating the anguish of that organ, to the coats whereof the last food taken by the expiring patient has been found to adhere after death; that is to say, the fibrous coat of the stomach of the subject alluded to identified itself with the food so intimately, that it stripped off, whilst the insensible coat still adhered.

Remedy.-Every possible remedy, some of them of opposite tendency, has been tried on the $d o g$, and on man. Sea-bathing, the Ormskirk medi- 
cine, copious bleeding, excision of the part, the actual cautery, and cupping the parts, have been each employed-successfully, we are told; but no reliance can be placed on either, since they oftener fail, though there is no reason why the horse should not undergo bleeding and cutting off the laceration as soon after the accident as possible. When we consider that the part bitten is ever observed to enlarge previous to the horse showing other signs of confirmed hydrophobia, it seems clear that the cutting off the immediate cause of incipient rabies presses itself upon our notice as the most efficacious measure for warding off the disease. Six months is no unusual time for dogs to conceal rabid infection, a quarrelsome disposition being for a long time the only indication perceptible; but the horse seldom goes beyond the twentieth day in developing all the symptoms before enumerated; which shows that the peculiarly rapid circulation of the blood, noticed elsewhere (page 159) as the harbinger of inflammatory complaints of every kind in the horse, naturally demands early and copious bleeding as a good accessary remedy for this particular one. In this case alone we should not be solely guided as to the quartity of blood proper to be taken by the quicliness of the pulse, or actual inflammatory indication, but its fulness, and habit of the patient's body: empty his body subsequently, as directed in cases of fever, with a brisk purgative, as follows : 


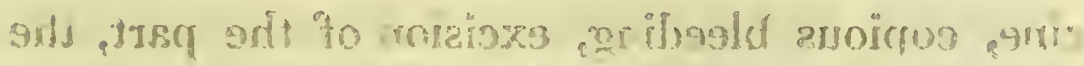

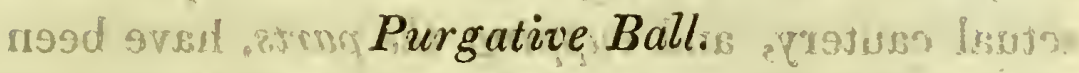

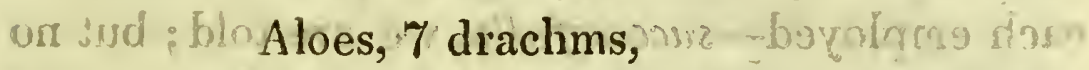

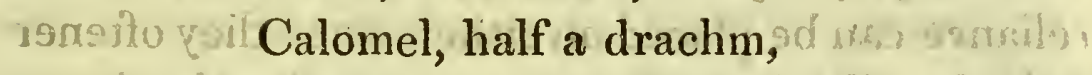
gerort ail Hard soap, 3 drachms, idf the Oil of caraways, 12 drops.

Mix with mucilage sufficient for one dose. If the animal seem not otherwise to require purging physic, omit the calomel, and omit it also if the bleeding has been trivial on account of the previous low state of the animal's system.

ef The application of the plant Scutelleria laterifolia is lately reported from North America to have succeeded in several cases; but the symptoms do not accompany the report made to us, and we rest in doubt as to its efficacy. However, let it be tried. So we say of " any mineral acid," which a certain medical gentleman recommends may be applied-a few drops on tow to the wound whilst fresh. This may be tried in the form of oxygenated muriatic acid, which has the property of being destructively detersive; it decomposes the virus, and acts as a styptic. Salt water bathing has been employed upon a large scale, and has been loudly commended; then, let common salt be also tried to the amount of two or three ounces a day mixed with the patient's corn. It is but fair to add, that sea-bathing failed of effecting any good, when tried upon the canine under the best auspices. The king's stag-hounds, in 1823, being more than suspected of rabies, were taken to 
Brighton, and the ablution well performed under the directions of $\mathrm{Mr}$. Sharpe, the huntsman, but to no good effect; they were all destroyed. $D r$. Fayerman, of Norwich, published a case in the spring of 1825, of the cure of hydrophobia in a man of forty-two years, by giving him superacetate of lead (Goulard's extract) in doses of from fifty to ten drops on lumps of sugar. He also bled the patient, who was at one time raging mad. Strong soap-boilers' lye, or solution of potash, in either of its varieties, has been used frequently as efficaciously detersive of the virus left by the bite or bites inflicted by a rabid enemy; besides which, the seat of all the wounds may thus be discovered, as they usually lie concealed by the hair; and thus, if excision be deemed necessary, every injured part may be similarly treated : let the eyes be guarded against the lye, and the wounds should be quickly pressed and assiduously washed. An eschar forms and completes the cure. The once celebrated "Ormskirk Medicine" is unworthy of reliance.

The subject of canine madness has been well handled by Mr. Gillman, in his "Dissertation on the Bite of Rabid Animals," 8vo.-Mr. Daniel, in his "Rural Sports," has made some good, sensible, practical observations on this subject. Mr. Thomas, in his "Shooter's Guide," is more pithy than communicative; he recommends immediate death being visited upon the victims of the disease ; a very effectual mode of preventing commu- 
nication, truly, but he seems not aware that premature judgments would be very likely to consign to death many good animals afflicted with other disorders than rabies. Subsequently, Mr.Johnson,- in his "Shooter's Companion," has printed some interesting details of occurrences within his ówn proper sphere. Dr. John Pinckard's "Cases of persons who have fallen victims to the bite" are well marked. But the labours of none are so much in point, as regards the horse, as the researches of my friend, Mr. John Surr, Surgeon, communicated to me, subsequently to 1810 ; in which year he published the result of his dissection of several horses which had died of hydrophobia, partly under his own inspection*. The substance of all my friend's observations is embodied in the foregoing pages. A writer, who adopts the signature of H. C. in addressing the publisher of the $A n$ nals of Sportingt, has communicated much practical information on the subject of canine madness, that is well worthy the perusal of all persons interested in this order of created beings.

* Those papers appeared in the "Medical and Physical Journal," No. 131, and several successive numbers ; $M r$. Surr being accompanied on one occasion by $D r$. Adams and $M r$. Pettigrer.

$\uparrow$ First in No. 34, p. 226 ; in No. 35, p. 259, No. 40, p. 224, and No. 44, p. 77. These papers should be read by every one having aught to do with dog or horse ; indeed much real good might be done by printing a cheap edition by "the Tract Society," for distribution. They should be preceded by the very nervous appeal that called them forth; which appeared in the Annals, No. 33, p. 191, from the pen of my friend Jon Bee, and also gave the impulse to "T." on the same subject in No. $44, \mathrm{p} .75$. 


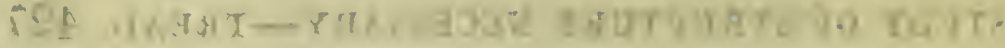

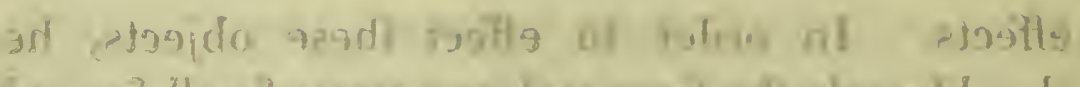

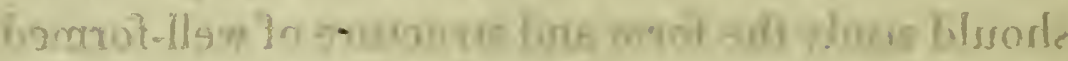

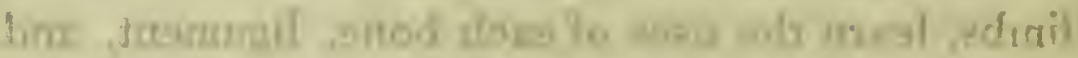 BOOK III. \\ OF THF LEG AND FOOT OF THE HORSE; OR SHOEING}

SMITH'S GUIDE.

\section{CHAPTER I.}

Structure and Physiology of the Foot; Mode of studying it advantageously.

Certain disorders of the foot owe their origin to bad structure of the limb, and the manner it is attached to the body, which influences the tread, or bearing, that the foot has upon a plane surfaced ground; others arise from accident or hard work, and a good number from the errors shoeing-. smiths fall into when they neglect to adapt their work to the circumstances peculiar to each kind of horse. Furthermore, almost every individual hor'se has its peculiar tread, and the scientific workman should place himself in a situation to ascertain whether this be owing to such original defectiveness, or to the evil accumulations of age and hard usage : he must not pretend to counteract, but to follow the first mentioned; the second he may endeavour to correct, to amend, and prevent its evil 
STUDY OF STRUCTURE NECESSARY-TREAD. 427

effects. In order to effect these objects, he should study the form and structure of well-formed limbs, learn the uses of each bone, ligament, and tendon, and ascertain how it happens that deviations from symmetry in the limb always affect the sole of the foot, sooner or later. For he may rest assured, that at the sole the horn is prepared in its liquid form which afterwards ascends to the coronet, as I shall show presently; and that hence arise many of the evils of mis-shapen hoofs, of illsecreted horn (whether brittle or soft), and the occurrence of several other diseases there that frequently depend upon constitutional ill-health, but which never would appear on the foot at all (it is presumed) were it not for such contractions of the horn, which further obstructs the entire sensible part of the foot; whilst again, obstructed function also occasions a defective supply of horn, and consequently distorted hoof.

11. But so much space has been already occupied in the anatomical description of the leg, that it might properly be considered a waste of time to enter into new details to the same purpose. The reader will therefore turn back to the early: sections of the first book (page 13, \&c.) and he will readily perceive in what manner an originally. defective limb; or the ill-adaptation of the parts to each other, or its awkward attachment to the body, may become the harbinger of one or other of the many diseases of the foot, which we come shortly to take into consideration. He will know, 
also, that besides this error of birth, as I call it, there are others of mismanagement: as, the employment of horses in work that is beyond their powers, or of that kind for which nature never designed them; either of which is as likely to bring on distortion of the foot, and its train of disorders, as any accident of birth to which $I$ before alluded. Natural defects go much farther than shape or make, and the distinction between these and the inflicted, or acquired, may be aptly illustrated by the fact, that white-legged horses, whatever be their shape, are more disposed to contract "grease" than those of any other colour. This is therefore a natural predisposition to that disease ; whilst the animal which is suffered to contract the "grease" eritirely through mismanagement suffers an infliction as much as another, which, being put upon hard services, throws out splents, spavin, curb, \&c. in consequence.

Furthermore, the shoeing-smith who should inform himself of the primary causes of badlyformed feet would carry on his business with the greatest emolument to himself, and with most satisfaction to his employers ; for he would adapt his shoes to the natural defects, whilst the acquired ones he would amend by degrees until he could control the horses' heels to a heaithy shape, and thus promote the regeneration of healthy horn. He should also accustom himself to reflect on the various breeds of horses that are brought under his care, their limbs and hoofs, produced 
in certain situations, climates, or countries, as we hear them denominated, each of which requires some peculiar contrivance or adaptation. Thus, horses bred in swampy situations have long, flabby limbs and large fiat hoofs, to say nothing more of their long washy carçasses, that predispose them to contract certain ills which come shortly to be erumerated. All those "countries" where ague prevails among mankind are unfit for breeding good horses, as is proved by the thick spongy heel and soft foot. It was to this peculiar climate I objected some years ago, when I first printed the advice given at page $4 \%$, which has since been corroborated by the opinion of Mr. Dupuy, as quoted before at page 341. Brittle hoof is produced by a hot, sandy breeding country, as much as by the heat and dryness of the animals' constitution. But, to whichever extreme the individual belongs that may come under consideration, misshapen hoof is visible from the earliest years. This increases as the animal is roorked, and disease of one description or another follows, which requires the care of the shoeing-smith to modify, or of the doctor to cure. Thus the combination of ferrier (or iron-worker) and veterinary surgeon in the same person is not so very incongruous as at first sight may be imagined.

In the anatomical treatise that occupies the first chapter in this volume, the reader will obscrve (at page 30) how strenuously $I$ insisted on the 
proper shape or elevation of the hoof; and he will not overlook the great service our shoeingsmith, or ferrier proper, may derive from duly considering this shape and external form, and of adapting lis shoe to each deviation from the true form, as I shall show presently in detail. For that attendant upon and assistant to nature, who is neglectful of her deviations, or ignorant of the causes which produce them, is ill calculated for his office, whether that be ferrier or doctor; in fact, he is ever the most prizable workman of either class who is best acquainted with those deviations, accidents, or errors that, for the most part, are inflicted we know not how. The boot and shoe maker, for example, who can best suit the bumble-footed man, is a more ingenious mechanic than he who is wholly employed in making his cordovans for perfect-footed persons only. But then, the "shoe-maker" of either genus should not be ignorant of well-turned feet, and the symmetry of the horse's foot should form an especial part in the education of an intelligent shoeingsmith; else, how is he to work for the preservation of the proper shape, of its restoration when time or circumstances may have effected those alterations we deplore, and strive to amend if we cannot fully restore?

Let him examine nature itself in its fastnesses; let him investigate the minute parts that constitute the whole foot, to which his operations are calculated to afford support, or to effect alterations in its form. To aid him in his inquiries, I have an- 
nexed hereto the section of a foot of nearly perfect shape, prepared by myself, and published sonie time before these sheets, in order to meet and correct the blunders intelligent shoeing-smiths were every day led into by relying upon the misrepresentation of the subject contained in certain publications of the present day. I lamented this the more, because it is impossible to withhold approbation from the leading parts of the work in which the ill-conceived picture appeared, and therefore is it very likely to have diffised error more extensively than a less popular author could possibly inflict. As an antidote to all mistakes on this interesting topic, I would recommend every one who has occasion to meddle with horses' feet, as owner, groom, or shoeing-smith, to obtain a fresh hoof of a horse which has died in comparative health, and having softened it in warm water, proceed to make a section thereof, in the same manner as I have here done.

FIG. I. SECTION OF THE FOOT.

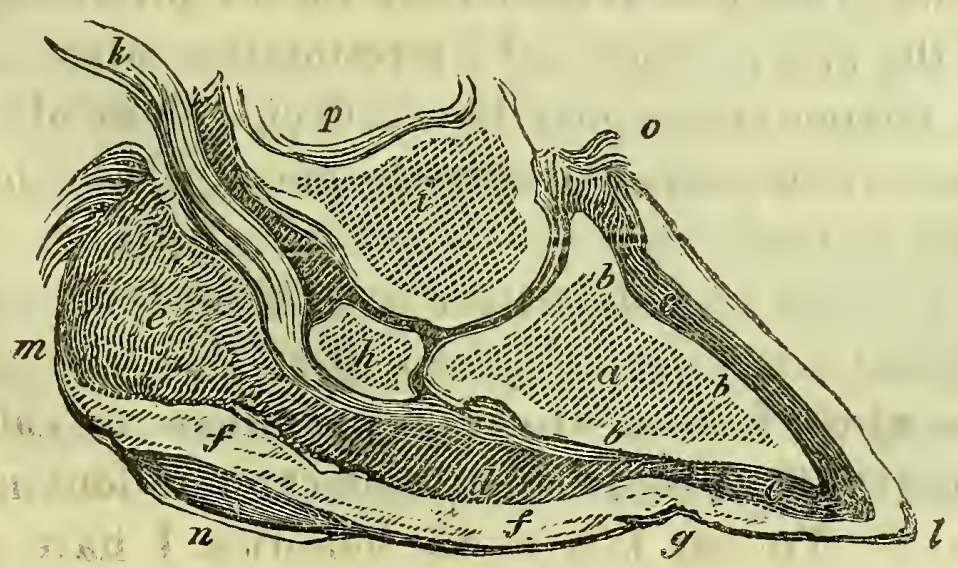


This portrait of a section of the healthy hoof was taken from a freshly severed foot of a fiveyear old horse, recently killed in full health. This latter remark veterinary readers will know how to appreciate, when comparing this with their own preparations, which may have been derived (as generally happens) from the anatomy of diseased subjects, after the juice which should have supplied fresh secretory matter has been long turned aside, or converted to increase deformity.

To the general observer, the foot of a horse inclosed in its hoof would, indeed, seem like a corpse shut up in its coffin: and there is, certainly, no mode of arriving at a knowledge how these act upon, and with, each other, than by dissecting the hoof. By this means the whole arcana of its construction are laid open, but in no manner so intelligibly as by the section straight up and down from the toe up to the coronet, and throughout between the clefts of the frog and heel. This being done, the vessels which supply the juices for renovating the wear and tear of the whole exterior are plainly bared to the view : the ligaments, bones, and tendons, show their means and manner of action; and, above all, the back sinero laid flat behind the smaller pastern-bone, and quite so at passing underneath the navicula, and at its insertion in the bottom of the coffin-bone. On entering the hoof it acquires the term tendo palmaris among the learned, but this course only serves to puzzle the general reader. 
At $(a)$ on the coffin-bone, the general porosity thereof is much greater than at any other part, being the avenue or receptacle for the blood which is diffused throughout it, except on the surface, or border, at $(b b b)$. The shape of this bone at the toe ( $(l)$ is worthy of note, as being that which is best calculated to give firmness of tread, fitting with the greatest nicety to the shape of the hoof; or rather, perhaps, we should say, that the shape of the hoof of a healthy animal should ever partake of that which we have before us, and is evidently instructive to the shoeing-smith in his final raspings, to keep clear at the toe. Deviations from this rule, brings the coffin-bone nearer the surface of the hoof, as is shown in fig. 3, plate 3 , where the coffin-bone $(c)$ and the wall of the hoof $(g)$ are in contact; and even this representation, the picture of the college* shows that the toe

* Is it not strange! but no less true is it, that since the foregoing ' section and description' was published_in the Annals of Sporting, for June, 1825, Mr. Goodwin, the "late veterinary surgeon to his majesty," retains the following passage in his "New system of shoeing," page 181, viz. "Mr. Bracy Clark remarks, that the French method of shoeing is more conformable to the natural form of the foot, and that it harmonizes with the shape of the coffin-bone, which he illustrates by stating [what is not true] that if a coffir-bone be placed flat on a table, it will be seen that there is a considerable space between the toe and the table. This is certainly correct," adds Mr. Goodwin, complacently aiding the assertion of his preceptor; but it is, nevertheless, a - $\longrightarrow$ sad blunder ; as any one not blind may perceive at a single glance at the foregoing cut, or the college repre. sentation, plate 3, fig. 3. The actual bone is now before me, 
of the bone is much sharper than the horn, which they rasp away so much at $(l)$, that the new shod animals go a little groggy for a short time.

Between the hoof and the coffin-bone interpose an aggregation of secretory vessels, forming a juicy elastic substance, that prevents concussion, as would necessarily happen at every step but for this providence of nature. I have marked it $(c c)$; but this substance, in like manner, pervades the concurrence of all other bones of the foot, only differing much in quality, and in structure a little : between the shuttle and coffin-bones it is more vascular, and the blood is still decidedly arterial. Underneath the coffin-bone at $(d)$, it becomes more elastic, thicker, and striated, resembling pale India rubber, which qualities increase towards the heel at $(e)$. These latter rest upon the frog ( $f f$ ), which is horny, or perforable with a point-knife, so far as $\left(g^{\prime}\right)$, where it joins the toe of the hoof, more abruptly as the horse is most worked, or otherwise.

but no light is perceivable under the toc-as, indeed, how should it? and I conclude that friend Bracy having fallen into error, inadvertently, Goodwin would needs keep him in countenance, and talks courteously how they "harmonize," in the shape of a horse's toe! Who ever heard, before this, of shape hammonising? By the way, these two author-practitioners do not harmonize professionally, I hear from good authority, though the pupil seems to clap his former preceptor upon the back, uncandidly, when he allows that Bracy Clark's jointed shoe may hereafter prove a "Basis for the repose of the profession." This and that is real stuff. 
The navicula $(h)$, or shuttle-bone, as it has been called, moves in the midst of much elastic substance, resting upon and pressing the back sinew flat upon the strongest part of that substance, above the centre of the frog. This little bone, it will be seen, is well adapted, by its shape, to traverse the lower surface of the small pastern $(i)$, and the lateral edge of the coffin bone $(a)$, whenever the back sinew $(k)$ is drawn up to lift the foot, as it does, from off the ground, always returning into its place as the foot comes down. At $(l)$ is the toe, $(m)$ is the heel of the foot, and at $(n)$ is the near side cleft of the insensible frog. At $(o)$ is the coronet, or coronary ring, as at $(p)$, the lowest end of the large pastern bone.

At $(a)$, when the bone is recently cut through, no difference of structure is perceivable, though upon stricter examination, it will be found at the central part more porous, than that which is adjacent to the other bones; the hardness increases towards the whole surface $(b b b)$, where the cutting presents a perfect enamel. But the contents of the receptacle at $(a)$, I have proved by experiment to be unequivocally the same glutinous substance (in a state of preparation) as the hoof itself. This process of nature is well explained by the old aphorism that, "arteries entering bone engender bone, those of muscle create muscle," and so on; and the blood deposited in the coffin-bone, and being dispersed over the internal part of the foot, partakes of all the qua. 
lities of bone, membrane, muscle, and skin-the whole combined becomes horn.

If my advice be worth any thing-if my earnest exhortations to investigate the subject effect their object, every man who reads these pages, whatever may be his station in or about the stable or the smithy, will not fail to make a section, or cut down the middle of a hoof at the earliest oppor-s tunity. To effect this purpose, the now industrious operator needs little more preparation than to furnish himself with a cordwainer's knife, and a butcher's saw with fine teeth: if he can add to these the use of a carpenter's vice, in which to fix his subject, he will much accelerate his labour. Having secured the foot upside downwards, he will cut down between the cleft at the heel until he comes to the bone at $(b)$, and the wall, or horny part of the hoof (at $g$ ), where the labour of sawing is to begin. The shuttle bone $(h)$ he will feel and hear rattle forward and backward at every stroke-the horn yields easily. As he proceeds, he will find his trouble lessened, and his views of the matter in hand much enlarged by driving into the chasm his exertions have made some two or three wedges of wood, whereby he will ascertain that the stiffest part of the horn is elastic, even though he should not have adopted the precaution of soaking his preparation, as recommended. He will thus be convinced, that the application of Bracy Clark's jointed shoe is not without its uses. But if our inquirer has soaked his horn, as directed, 
he will find that the warm water renders it more elastic, and he will conclude that the practice of permitting their horses to stand in the kennels during the issue of hot water from breweries, dyehouses, rectifiers' premises, \&c., must soften the hoofs, and indispose them for immediate concussion over the rough stones of our paved streets.

He will also thus discern why $I$ advise, in certain cases, the enveloping the rohole foot whenever the application of a poultice becomes necessary to any part of it.

On completing the section, he will discover two branch arteries which descend into the foot at the coronet near the quarters have supplied the coffin-bone $(a)$, that occupies the cavity of the horny hoof, with fine blood for its fructification. In other words, the formation of new horn is derived from the blood, which is sent hither in good. quantity, and pervades the internal part of the coffin-bone in particular. In this bone the operator will perceive a cavity, or rather three hollows communicating with each other, in which the horny matter is generated. Or, probably, this is the reservoir for such particles of blood as are suited to the formation of hoof, as it may be required and called for by the process of nature, and the demands of wear and tear, of rasping and drawing inordinately, all which must subtract from its quantity, and leave the bone comparatively hollow, and less fit for resisting the hard concussions to which it is liable at every step. 
This fact may be ascertained by keeping a bisected foot for a few months, when the moisture having left it in great measure, in the cavity of the coffinbone will be found a yellorvish glutinous substance precisely of the same nature and colour as that which fills the space between the hoof and coffinbone at $c c$, in the section at page 431 : without odour and nearly tasteless, its uses are evidently the supply of new hoof.

Seeing this curious construction of the foot, we are compelled to allow that numerous accidents may also occur to prevent the supply of blood to the parts, to say nothing of its unfitness at times to carry on its proper purposes. The two vessels before noticed that bring this supply of new blood descend into the foot behind the small pastern bone, and pass with the back sinew $(k)$ underneath the shuttle bone $(h)$, as may be noticed in the section, at page 43l. Here it enters the coffinbone at the sole, by an indentation of the bone designed for the protection of the vessels passing in and out. From the receptacle in the coffinbone, after concoction, the blood issues forthpart of it to lubricate and nourish the shuttlebone and its adjacent ligaments, the remainder to effect similar purposes elsewhere; but the greater part is attracted, by heat and action of the foot, to supply the horny material of the hoof in the manner I propose to show how it is brought about: Along the whole length of the shuttle-bone, on that side which is next to the coffin-bone, is a 
groove serving as a protection to certain small blood-vessels that terminate there, and as a central receptacle for the blood that is destined for dispersion. When dried, it is equally inodorous and clammy, with less colour in it, than the deposite found within the coffin-bone. Now, seeing that it is at the seat of the shuttle-bone that this elastic substance is more juicy and plentiful than at any other part, and there is no other means of its escaping the constant concussion of the animal's tread; but by forcing its way along underneath the coffin-bone, and upwards, between the wall or crust of the hoof and the coffin-bone at $c c$, and making its way to the coronary ring at $o$, no doubt remains that the supply of new hoof is thus carried on, and completed by its descending as it may be required. At $b$, fig. 2, of plate 3 , the coronary ring may be further seen at whole length, its uses being therein exposed by the removal of the horn, laying bare the front of the coffin-bone.

Those "concussions" at every step, before spoken of, as affecting the action of the shuttlebone upon the posterior point of the coffin-bone, occasion trivial injury at every step in quick motion; more harm arises as the animal is much pushed in his work; then heat and fever of the foot supervene, contractions follow, with a train of evils that have acquired different names, thirty in number, but which I have reduced by threefourths, with a view to simplifying the subject: 
most of these differ only in situation. Very hard concussions, or a single injury of sufficient magnitude, produce lameness at once, which most unaccountably received the name of "strain of the coffin-joint," and under which general misconception I shall shortly give it a moment's consideration. Poor old Jeremiah Bridges prefers to call it "numbness of the foot," or stunning; and he is quite as correct as those who talk of a joint being strained, where there is no possibility of straining it: he who could talk seriously of his six discoveries, and thirty-two diseases of the bottom of the foot, was yet as correct, in all the essential points, as many of our modern discoverers and patentees.

The student who would push his inquiries farther will next turn his attention to the muscles, ligaments, and tendons, that guide the foot; that lift it up, and suffer it again to meet the ground; that may perform these offices firm and effectively, or being relaxed, diseased, or ill-formed, they and their functions agree not with the well-being of the foot. Probably he will find it convenient to lay open this part of the arcana of progression by the horse's leg (the lower part of it) previous to severing the foot itself, seeing that the subject will then be quite fresh, and that one part may intelligibly illustrate the other. This is more particularly the case with the flexor tendon, or 
back sinew, which he will ascertain is of great length, descending all the way from the hock, or back of the knee, behind both pastern bones, under the shuttle-bone, and is fastened to the bottom of the coffin-bone.

With the following "description" before him, he will study the figures 2 and 3 of plate 3 ; and after removing the remainder of the integuments, and cleansing the bones, he will then perceive the articulations of these, the manner of their working in and upon each other; and as he proceeds to repeat the investigation, he will note the difference that exists in the shape of a leg taken from a thorough-bred horse and that of a cart-horse; the one small and flat-sided, or sharp before, as best calculated for speed, the other round and heavy, as being made for heavy draught, and to support a large, muscular, and boney frame. In giving this advice, I presume he has already examined the superior part of the limb, though the lower bones and their covering come more immediately under notice in this place.

Description of Plates 2 and 3, of Anatomy of the Horse's Foot.

These figures were not designed or corrected by me, with one exception, viz. fig. 2 , of plate 3 ; they are, however, very fair representations of the subjects studied, and depicted by members of the College. I have here a small objection to make to 
their mode of enlarging the coffin-bone, which they invariably draw much too big in proportion; why, I never could learn. In fig. 4 of plate 2 , for example, where the whole of the integuments are supposed to be removed, the coffin-bone projects inordinately beyond the small pastern, which is not the case at all when viewed in front, or at the back. In other respects these figures speak intelligibly without further explanation.

Plate 2, fig. 1. Front view of a colt's foot, hoof, skin removed and $(a)$, the sesamoid bone, $(b)$ the large pastern, $(c)$ the coffin-bone, $(d)$ the toe.

Fig. 2. Back view of the same-a a the back sinew, or flexor tendon, as it appears above its ligamentary sheath and below it, descending flat into the foot underneath the coffin-bone at $(e)$; $d$ the coffin-bone, having the sensible sole still adhering to it; $c c$, the lateral cartilage; $b$ is the sheath in which the back sinew is enclosed, and moves at every step, but part of the sheath has been removed in order to show the course of the sinew.

Fig. 3. The whole of the ligaments is here laid open by the removal of the flexor tendon, whereby is seen (at $a$ ) the smooth surface of the sesamoid bone over which the tendon is ordained to pass; at $b b$, part of the sheath is turned back, at $c$ is the hollow part of the sheath; at $d d$ the ligament that connects the small pastern to the bone above is shown, with its insertion below at $e$, whereby the large pastern is kept in position; $f f$ the lateral 
cartilages; $g$ the bottom of the coffin-bone, $h$ the toe.

Fig. 4 is a front view of the same, but with all the integuments removed; $a a$ the sesamoids; 6 the large pastern; $c$ the small pastern; $d$ the coffin-bone, but represented rather wider than ordinary.

Plate 3, fig. 1, back view of the bones, in which $a$, the shuttle-bone, is seen that works loosely behind the conjunction of the small pastern, $c$, and - coffin-bone, $d$; but the small pastern (c) has been lifted or strained upwards inordinately, as the lower part of it lies concealed, as far as the mark $(c)$ in the healthy subject, behind the shuttle-bone. This shuttle-bone may be seen at its middle or thickest part, in the "section of a healthy foot," at page 431 ; and by turning the cut sideways, the perspective will be found sacrificed to no useful purpose.

Fig. 2. View of the foot, with the hoof only removed, showing the front of the coffin-bone at $b$, and the coronary ring just above it at $c$, in which the substance is treasured up that constantly supplies the material for new horn to the foot below. At a a the sesamoid bones, freshly severed at the knee joint.

Fig. 3. A section of a foot, agreeing essentially with my subject, at page 431 , but evidently drawn from a diseased foot; the elastic process marked $c c$ in that picture being wanting in this, and the shuttle-bone, $d$, having lost its function; neither 
do we perceive the descent of the back sinere ( $k$ in the preceding) to its insertion at the coffin-bone. Yet is this a fac-simile of the college members? mode of teaching pupils the mystery of the hoof's construction. At $a$ is the lower end of the large pastern, $b$ is the small pastern, $c$ the coffin, $d$ the shuttle-bone, $e$ the cleft of the frog, $g$ the wall or hoof, $h$ the situation of the sinew, $i$ the sensible sole.

Fig. 4. Transverse section of the foot, from the coronet $a$ to the point of the frog $b$, having the wall $c e$ on each side, and showing the divided edge of the sensible sole $d$.

\section{CHAPTER II.}

\section{Disorders of the Foot and Leg.}

Introductory Observations.-ALL those derangements of the limbs which we come next to consider, I shall divide, for the reader's more ready comprehension, into-1st, those of the leg, and $2 \mathrm{~d}$, diseases of the foot; for it does not always happen that affections of the leg alone can be properly denominated diseases, whilst those of the foot are invariably so. I before observed, that both, or either, may be occasioned by accident, derived from ancestry, or be the fault of misconstruction and consequent misapplication of the individual's powers. They may be also considered, 
as, 1st, those of the bones, $2 \mathrm{~d}$, of the ligaments, tendons, and muscles. But I shall not so subdivide the heads of my treatises on the several diseases, since each will appear under the respective heads of information; besides which (as will be seen further down), whenever the bones suffer derangement, original or acquired, the integuments follow the same evil course. Enough, however, has been said on these points in the first chapter of this volume.

id Rest is the primal remedy for all acquired disorders of the limbs, whether those of hard work or of accident; but employing the animal whilst yet too young is an universal error, which is but seldom remedied by allowing it rest when lameness once lays hold of him, much less is it capable of being cured. The impolicy of this practice, the fruitful source of so many evils, is demonstrable by the custom of the Arabs, who never mount a lame horse, even in the desert, nor propagate from horse or mare which is permanently marked with the effects of over-work. One remote consequence whereof is, that the foal is not entaited with a predisposition to contract readily such disorders as I come shortly to treat of; whence the superiority of the Arab breed in this respect. At least, the fact is to be deplored, that most of our stallions of the roaggon-horse breed are worked at plough and in the team at two and three years old, too much for their tender years, and permitted to cover mares at this very early age; the 
result of this lamentable cupidity of orenership is, that their get are impregnated with one or other of the various maladies that I come shortly to enumerate, ere they reach maturity; but the causes and symptoms whereof I have shown are so similar, or proceed so naturally out of each other, that they differ but in name for situation, in treatment nothing. Higher bred cattle are subjected to the same disadvantages in most breeding studs, in which the breeders prefer to derive their stock from parents which may have been successful at winning three-year old stakes, or probably strained every muscle, bone, and tendon whilst yet yearlings. We owe to the late Sir T.C.Bunbury, of Bildeston, the introduction of this practice on a large scale, which is so evidently harmful to the rising generation-of horses.

Lameness is universally the symptom that denotes disordered limb; it is the only one perceptible for some time, until its continuance throws out some appearance on the surface; and that inquirer who can ascertain its true seat is most likely to find the cause, and to effect a cure. For instance, lameness occasioned by disordered bone, as in ring-bone and bone-spavin, is almost universaily ascribed by the stable-men and humble practitioners to strain in the stifle, in the shoulder, or the zehirlbone; whereby so much valuable time 
is lost in applying the proposed remedies at the wrong place, that those two disorders in particular make head almost irremediably before the true seat of ailment is ascertained.' The same species of blunder is propagated when a disease happens to the foot, and the precise cause thereof, even when well known to those employed about the stable, is kept a secret from the owner and the doctor. "Let them find it out," is sometimes heard muttered in the distance; and in order to comply with the unfeeling permission, we pass the hand down over the whole leg and foot from the top to the sole, compare the size of the lame limb with the corresponding sound one, and move the animal about. For without this examination it would be next to impossible to ascertain the precise seat of the disorder, and quite so to apply even the right remedy at the proper place. As an illustration of this position by its reverse, I may adduce the coming on of bone-spavin as that kind of attack which we can ascertain with the greatest precision of all those which lie concealed from our view and touch. It happens, too, that this is one of the few disorders of the leg that admits of cure by early applications, as it is also that which, being neglected, renders the animal wholly useless. When a horse becomes lame of a hind leg occasionally, and that after rest only, the complaint going off on taking a short exercise, we may be quite sure he labours under incipient bone-spavin, provided no other distinct cause can be adduced 
for his lameness; but should the lameness increase with exercise, then it does not depend upon bonespavin, but some other malady. Further consideration of the causes, symptoms, and cure of this disorder will be found a few pages lower down.

** When lameness occurs to his horse unaccountably, and the inquiring reader turns to these pages for information, he had better run over once more the whole of the next six or seven heads of information; their great similarity in many respects dictates the propriety of this additional trouble, as most of the series will be found referrible to the same causes, and require much the same treatment, though differently situated.

Throughout the whole of this chapter, the reader will find great help to understanding the details, by carefully consulting the delineations of the leg and foot on plates 2 and 3 , and the cut at page 431, with the description of each, References are not always made in zoords at length, it being presumed that he is already acquainted with the preceding pages, to which he is now referred.

\section{QUITTOR.}

Under the class of fistulous affections, I spoke of this disease at page 329. To what is there said I may 
here add, that as quittor is caused by sand crack, by a tread, or the prick of a nail, so will its situation be determined by the precise cause, on the inside of the coronet, or the outside, near the heel, or otherwise, as the cause may have been inflicted; and also, that the cure being effected by harsh means, or burning remedies, these leave the foot disposed to contract other disorders at this region, as ringbone, \&c. Hence it follows, that the more moderate the means employed to get rid of this disorder, the less probability is there of the patient's contracting some other. Therefore is it advisable to try the milder remedies first, unless the quittor is of long standing, and of a very bad sort. The extent of each sinus, and the course it pursues, is denoted by the colour of the soft parts of the foot, being black or livid, or else scarcely tinged, according to its virulence. In order to pursue this examination more accurately, it will be necessary to stop the circulation of the blood above, by tying a ligature tight round the fetlock joint, whereby the skin of the healthy parts below will appear white, and thus more distinctly expose the nature of the sinuses. The pledgets that are to be introduced for the destruction of the pipes may thus be selected of a larger or smaller size, as the calibre of the sinus is greater or less; as also may the quality of the caustic application be made stronger or weaker, as the virulence may require.

Some hastily use the knife, and lay open the pipes 
freely along their whole course; and if it approach near the bottom of the foot, the coffin-bone is usually affected with rottenness (caries): This they hesitate not to scrape off, though, if the patient be of strong and vigorous constitution, exfoliation will take place without extending the operation so far. Indeed, it seldom happens that more is required than to give the disorder free vent at the coronet, whereby the necessity of operating underneath is superseded; for it will be seen that the ascent of the hoof-making particles from the sole will bring away to the orifice of the ulcer any offensive matters from below; and this process of nature effects the cure. Whenever a sinus leads towards the back tendon, or the joint, much care should be taken not to injure either with knife or caustic, for a bad-looking seam is then left behind, with lameness that terminates in anchylosis, or stiffening of the tendon, or growing together of the small pastern and the coffin-joint (a) and the shuttle-bone $(h)$, in the cut at p. 431.

\section{RINGBONE.}

Causes.-At times a badly-cured quittor, at others ill-shapen foot; which occasions that concussion of the hoof and small pastern bone at their conjunction which causes the latter to swell at the coronet. Cart and waggon horses with short upright hoofs, that do not sufficiently secure 
the articulation of the coffin and pastern bones against injury, are most liable to this disease.

Symptoms.-Lameness is sometimes the first intimation we have of the existence of ringbone, which is at first neglected, and only ascertained by passing the hand down over the part. As usual with.most diseases of the foot, the attendant commonly ascribes the lameness to a strain higher up-of the shoulder generally, as ringbones afflict the fore foot oftener than the hinder one. It consists in the ossification of the cartilage in front of the foot, which extends in time to the lateral parts also.

Remedies. - These may be applied to relieve, but no cure is to be found for ringbone. As high heel usually accompanies the short upright hoof, the concussions of the foot may be lessened by lowering the heels. Apply blistering ointment to the seat of the disease, and firing may also be employed with advantage.

\section{WINDGALLS.}

Like ringbone, these appear mostly on the foreleg, or a little above the fetlock, on each side of the back sinerws, and consist of small puffy swellings, that occasion no immediate inconvenience, but prove that the animal has been strained in his work, unless it has been occasioned by his having been put to it too early in life. They might be 
occasioned by the sinus of a tumour, pointing towards the pastern joint, having been cured too harshly, whereby the joint oil issues forth upon their being pricked.

Blistering, and a run in the straw-yard, are the only remedies, though experiments are often tried (when it is found necessary to sell the animal) with preparations of muriatic acid, and muriate of ammonia diluted in water. Saturate a roller bandage herewith frequently, and partial absorption takes place.

\section{THOROUGHPIN}

Is of the same nature as the foregoing, arises from the same cause, and is equally devoid of immediate consequence to the animal's going. It consists of a soft flexible swelling on the inside of the hock-joint, as well as the outside, immediately opposite each other; whence it obtains the name of thorough-pin, being supposed to go through the joint. When one of those tumours is pressed it yields, and the fluid it contains is thereby forced into that on the other side; when the pressure is removed it immediately returns to the same state as before.

This disorder has no other effect upon the animal's going, or value, than its appearance amounts to, as it conveys the information of its having been worked too hard, and too early in 
life, as do all these minor evils we are now considering. How this is effected, I have shown in the fifteenth and sixteenth sections of the first book, at pages 48-52. Like unto the other disorders of this class, blisters and rest are the only remedies : apply the blistering liniment composed of cantharides and spirits of wine.

\section{SPAVIN.}

Bog spavin is the more common, blood spavin but rare. Both varieties, as well as bone spavin, owe their origin to hard work in early life, in the same manner as just adduced in cases of windgall, and thoroughpin. Bog spavin is caused by the joint oil of the hough issuing into the membrane that surrounds it, and stagnating under the vein causes this to swell. The old remedy of taking up the vein by ligature should be abandoned as a long and tedious mode of cure : the circulation has then to force a new channel, in doing which irritation of the parts adjacent is the means of cure, by promoting absorption; whereas the same effect might be produced by blistering, as in the two correspondent disorders just named above.

\section{BONE SPAVIN.}

This disorder consists in a bony enlargement at the upper end of the shank-bone, inside of the 
hock-joint, or a little below it. It belongs to the hind leg only; and if not undertaken in time becomes incurable.

Caused by the same kind of cupidity as the last mentioned diseases; and like these is generally mistaken for some strain at the superior part, as the hip-joint, until by delay all our endeavours are rendered hopeless. At the seat of this disorder the leg is composed of three bones, which fit together into one common cavity at the hock; and notwithstanding they appear as close together as one bone, yet possess separate motion to give elasticity to the animal's tread, and assist him in the act of progression, as may be observed in the working of his haunches when the horse is going at full speed, or making a standing leap. By mounting the colt whilst too young to bear the incumbent weight, by pushing him hard in his work, as well as by working young cattle at plough, a practice some breeders of heavy horses injudiciously adopt, these bones get strained asunder, as 'twere, and inflammation takes place.

As almost every one knows, by misusing young colts in the manner just described, they become cathammed, if they do not derive that particular mal-conformation from parentage, as before hinted (p. 432), and is more scientifically accounted for in the first chapter of Book. I. Generally it happens that horses so formed are good, easy goers, brisk and active; but though well adapted for light weights, are utterly incapacitated from 
undertaking horsemen's weight at speed, until they are full mouthed. If heavily mounted, or hard driven earlier in life, they invariably throw out a curb or spavin. The shoeing-smith frequently contributes to the contraction of bonespavin without knowing it, by turning up the heels of his shoes in frosty weather unerenly. In the same manner, when the inside heel preserves its roughness longer than the outer heel, it is clear that this last must bear lowest, and further contribute to the evil strain that cathammed horses are ever liable to, about the hock. Cow-houghed is but another name for the same mal-conformation.

Symptoms.-Inflammation is scarcely perceptible at first, or any other symptom; and as it is vitally necessary that we should apply the remedy thus early, we must employ the discriminating test described at page $44 \%$. If the existence of adhesion, which constitutes bone-spavin, be not discovered in the manner proposed, the disorder proceeds until it may be perceived upon comparing the hocks together. At first, the inflammation is but trivial, when the horse is also lamest; but when time has been allowed to unite the bone, the heat and enlargement increase, and the sparin is incurable, but the lameness is less.

Cure.-At the commencement only it may be effected easily, by simply blistering the part all round the hough, in such a manner as to raise the blister to a good extent. Generally, in bad cases 
it would be advisable to repeat the blister; in which event let the former one be first well cleansed away with Goulard's extract, diluted with water. But should the duration of lameness and degree of swelling give reason for apprehending that the adhesion is uncommonly extensive, let the part be fired previously to blistering. Be careful to keep the horse's head up whilst the blister is operating, and subsequently dress with hog's lard; but do not use any greasy applications previously to blistering, as these only tend to harden the skin, and so obstruct the perspiration and absorption which promote the cure.

Making the shoe thin on the outside at the heel relieves the pressure when the horse is worked: the contrary form of shoe is conducive to all diseases of the leg bones.

\section{CURB.}

Cause.-Inflammation in the sheath of the back sinew ( $b$, fig. 2 , plate 2$)$, a little below the point of the hock, where the sheath is attached to the muscle. Like spavin, curb mostly affects young horses of the cow-hocked built,-whose legs stand too much under the body, and which have been worked prematurely hard, as in cases of bonespavin. Indeed, the two diseases bear so much resemblance to each other, in cause and symptoms, except only as to situation, that I feel no difficulty in referring the reader to the preceding page for 
my description of these, only premising that he cannot discover the coming of a curb, by any other means than lameness, and comparing the two legs to each other sidewise, when a diffused swelling may be seen, but very little heat felt, by reason of the disorder being deep-seated.

Cure.-It may be effectually removed at first, by blistering, as in cases of bone spavin; but when the disease has lasted a long time, firing must be resorted to with the same precautions as those before recommended. Ease may be afforded by adding to the thickness of the heels of the shoe.

\section{SPLENT}

May be looked upon as a disorder of the foreleg $s$, though occurring on the hind ones, at times.

Cause.-Working of young horses before they have acquired sufficient stamina, or on labour which is much beyond their strength, as in case of spavin, curb, \&c. to which the reader is referred, and the concussion which the leg receives at every step upon hard ground, stones, \&c.

Symploms.-Frequent lameness, that goes off and returns without apparent cause for either, before the splent shows itself upon the shankbone, which it does above the knee, inside. Similarly hereto, it affects the bone of the hind leg, and then acquires the name of bone spavin. In- 
flammation of the skin is soon felt, and the horse goes lame until the splent is completely thrown, and afterwards he does as well as ever, except retaining the splent mark, perhaps; but severe cases occur, that do not terminate so favourably. Such happens when the shank bone has received the concussion, that causes the enlargement and rupture, which constitutes the disease, at the hinder part of the leg, where it meets with tendons or the suspensor ligament-(See back view, plate 2, fig. 2, 3.) The lameness and the inflammation are then greatest, and the splent requires our careful attention.

Remedy. - But should not the horse throw out the splent on this last mentioned dangerous part, and become lame, he will yet suffer much in all ordinary cases; for the enlargement of the bone strains the membrane which covers it tightly, as described in book 1, sect. 1\%. p. 54. For this purpose apply a warm stimulating embrocation, which affords relief in the more favourable cases; but when the splent rises under the ligament or tendon, blistering or firing must be resorted to. The latter, however, is proper only in extreme cases, and only to be adopted when blistering is found inadequate to the purpose : if the swelling is hot and tender, firing would have the effect of enlarging the whole bone of the leg, and even the blistering liquid is improper when this symptom is highly prevalent. Rather let the heat subside, or 
assist it in doing so by means of Goulard's extract, diluted with water, frequently applied. When this has reduced the heat, employ the following

\section{Liquid Blister.}

Cantharides pulverised, 4 drachms.

Mix with sweet oil to the consistence of treacle, and apply the same twice during the day; thus, - Let the hair be clipped off close from the part, and all round the leg, and the blister well rubbed with the hand (covered), for five or ten minutes. If this does not cause further swelling and the discharge of a clammy nature, a third application of the liquid blister becomes necessary. After a day has elapsed, dress two or three days with hog's lard, and the patient may be walked about, to get rid of the stiffness. It may be proper, after this, farther to reduce the heat by more applications of the Goulard's extract, as above.

Shoeing is supposed to occasion splents sometimes, it being the practice with most smiths to make the inner heel of their shoes thinner than the outer; and the inner heel being also lower than the outer, occasions the splent bone to receive the concussion more sharply than the outer one; for, as I before observed, splents oftener occur on the inside of the leg than on any other part of it. 


\section{MALLENDERS AND SALLENDERS.}

Scurvy eruptions on the bend of the kneejoints, or on the corresponding bend in the hock joint; the first mentioned term being applied to those eruptions that appear upon the fore leg, the second, sallender, is confined to those of the hinder leg. A crack, with much soreness, accompanies both. - The cause may be found in the gross habit of body, attended by suppression of some evacuation, as stool, urine, or perspiration; therefore, to

Cure the patient, restore the defective evacuation by giving the purging-ball prescribed at page 231 , or that at page 232, according to circumstances; or a urine-ball, or the emetic tartar, at page 176 , or $\mathbf{3 7 4}$, in smaller doses, and the scurf decreases until it wholly disappears.

Let the hair be cut off close from the part affected, and the scurf well washed with strong soap-suds, and then rub over it daily, of the

\section{Ointment for Scurvy Eruption.}

Red precipitate powder, half an ounce.

Hog's lard, 2 ounces. Mixed well together.

Sometimes, a poultice, in which is introduced acetated litharge, becomes necessary when the eruption is divided by a gaping crack, which the ointment may have occasioned. The blue ointment of the shops is employed by some instead of the above ointment. 


\section{STRAINS.-LAMENESS.}

These are the most deceptious class of ailments attributed to the foot of the horse; for many such are spokien of in the most confident manner which do not exist in reality, whilst others could not possibly happen to the parts indicated by the names they commonly bear; yet shall I fall into this old method of titling the various affections of the limbs, in order to make myself more generally understood. Our neighbours, and rival veterinarians, the French, in the instructions issued to their smiths of the army, went a little farther in their complaisance to error: "All swellings of the tendons from the knee to the coronet, or from the hock to the heel, show an extension or strain of the integument. Take off the shoe and pare the foot." In fact, their practice of giving rest in all cases of strain, which often effects a cure with very little further assistance, could not be more assuredly complied with than by thus taking off the shoes; for the Marechallerie were ill able to retain their sick horses in quarters upon urgent accasions of active service, unless they could demonstrate the fact upon the view to their superiors. By this general mode of forming their judgment as to the cause of all swellings before or behind, we may perceive they included all "extensions". of the bone in their notions of a strain, and treated spavin, splent, curb, strain of the tendons and 
ligaments, all in the same manner at first. Of these latter-mentioned we come next to consider the distinguishing symptoms and most appropriate methods of cure; and I will here candidly allow, at setting out, that our neighbours took a correct view of the general cause of all lameness: those strains which occasion inflammation of the ligar ments, tendons, and muscles, always communicate fever to the foot*, whence arise thrush, canker; sand-crack, \&c. \&c. We very improperly, so far as precision is concerned, term all lameriess of the tendons, \&c. a strain, though it may arise from any other cause, as frequently happens, viz. a blow given by the toe of the hind foot, in hunting over heavy lands, when the fore foot is detained too long in the ground, coming in contact with rolling stones in leaping, the kick of another horse, \&c.

\section{STRAIN OF THE BACK SINEW AND} LIGAMENTS.

Cause.-Back sinew is the vulgar name for the tendon, which the reader will find depicted, in a section of the foot at page 431, and marked (k). It ascends behind the small pastern (i) and large. pastern, up to the knee-bend of the fore leg, or the hock joint of the hind one, respectively. In plate 
2 , fig. 2 , at $(a)$, this sinew is again shown, where it emerges out of the heel, and enters its sheath (b), to which it is attached in a certain degree, by means of very fine membrane, adhering from side to side, and capable of distension or relaxation. 'The sheath itself is attached to the two pasterns, of which it thus becomes the tendon or support; whence the back sinew and its sheath, or flexor, together obtain the plural-tendons. Within the sheath is secreted a milky fluid, intended for lubricating and defending the parts during the very great action to which they are liable in every effort of progression. As happens in all other secretions, this one sometimes fails to produce enough for the intended purpose, when the sinew and its sheath adhere together, or at least do not act with freedom; the consequence whereof is lanieness in a greater or less degree, which may be temporary only, or become permanent, according to circumstances. If the dryness and adhesion be trivial, as happens after hard work and a night's rest, the horse, upon getting warm, loses the lameness this deficiency has occasioned, for the secretion has been thereby renewed, and the lubrication is now supplied in sufficient quantity; but the horse falls lame again next day, probably, and if he cannot be allowed rest? 'tis 7 to 1 that he becomes permanently lame. In this respect the French beat us hollow (as just before remarked), though they do not profess humanity so sensitively as the English; and even 
the Ir Arabs, though robbers by profession, by habit, and inclination, are too sensible of what is due to a faithful animal in distress, to travel on lame horses. anhe same fact was before adverted

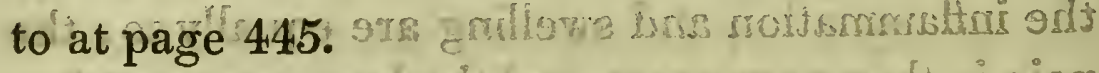
Symptoms. - That sort of strain which consists of relaxation of the back sinew shows itself by the horse going low upon his pasterns, in consequence of its "carrying high," or being trotted constantly in harness. Occasional lameness sometimes ensues in that fore foot which beats, or has the lead at setting out-generally the off one; inflammation of the whole foot may be felt by comparison with the heat of its fellow, which is aptly enough termed "fever of the foot" by the old farriers. This is a very puzzling kind of lameness, no other symptom than those presenting itself for us to ascertain the exact cause; and of course the less observant persons ${ }^{\text {are }}$ very likely to apply the wrong medicine, and render the horse a disservice instead of doing hiin good. The lameness sometimes goes off without any treatment whatever but rest; it is, however, more frequently accompanied, or followed, by some dis. ease of the sole, in consequence of the secretion of horn in the foot being obstructed. Sand-crack, frush, corns, are among these evils, arising from supernatural heat.

Whenever it so happens, that the secretion does not restore to the entire tendons their birginal motion, it follows that some part adheres to 
another, inflammation is the consequence, and the horse becomes worse and worse every day he is put to work, the lameness never leaving him altogether. When the adhesion begins extensively, the inflammation and swelling are equally so; the pain is then very great, and the lameness complete and permanent. This denotes the disorder called "strain of the back sinews," otherwise "strain of the sheath of the tendon," the sheath being technically termed flexor tendon. In very bad cases, or where a slight attack has continued some time; the ligament that passes between the back sinew and the pastern bones becomes greatly diseased; and conducts the inflammation to the foot, affecting alike the sole, the coffin-bone, and the hoof, with heat.

"Fever in the foot" is that low state of the symptoms which arises from a slight attack which has been neglected; the more virulent attack must come under separate notice.

Cure - Rest is indispensable; foment the entire foot with warm bran-water, or make the whole into a poultice sufficient to envelope the foot all over, as high as the inflammation may extend, which is sometimes as far up as the fetlock. When the heat is greatest at the sole, and the fever extends no higher than the coronet, a stuffing of cot'-dung will reduce the heat considerably; it may be secured by thin splinters of wood, and clanged twice the first day or two-once a day afterwards. Introduce a strong solution of nitre 
and let it be strong, as you cannot employ much of it. Both legs should be stuffed at the sole, though the sound one (if one only be affected) does not require changing. Let the animal have a loose stall during any stage of strain, or disorder of the limbs. Look after his evacuations, and cause them to be regular; a simple fever (or inflammation) of the foot depending very often upon. nothing more than one or other of these being stopped, which affects the whole animal system sometimes, to say nothing of a single limb.

Violent strains ${ }^{*}$, and swelling above the fetlock joint, when the lameness is very great, require strong physic; and the inflammatory symptoms, when running very high, with a quick and irregular pulse, should be lowered by bleeding. Apply fomentations of bran, or a poultice of the same, or of oatmeal, in which saturnine lotion has been introduced, as much as it will bear. When the great heat of the part has caused dryness of the poultice, saturate it externally with the saturnine lotion, either by soaking cloths in it, and spreading these all over the part affected, or in a poultice as above. This latter mode is an affair that is generally very ill performed among us, and

* The word strain, as here employed, is evidently used in the wrong sense: it should be sprain, i.e. bent or twisted out of its proper position. To strain, or stretch any thing long to a greater length, as when the back sinew is strained or elongated so as to permit the pasterns to slope or bend down, as in mild cases of "'breal. ing down would be more accurate." 
he among the attendants upon sick horses who is most expert at making bandages ought to 1 be looked upon as a valuable servant.rio?

After this treatment has reduced the inflammatory symptoms, but not the swelling and lameness, apply opodeldoc, which may be made as under, viz. No. 1. Embrocations. If this does not fully succeed in the course of three or four days, recourse must be had to No. 2; and if this does not prove sufficiently stimulating, apply the mild blister No.3.

Embrocations for Strains.-No. 1.

Spirits of wine, 6 ounces,

Camphor, half an ounce, Soap, 2 ounces.

Dissolve the camphor in half the spirits; mix the remainder with the soap, and then put both together. Rub the parts assiduously twice or three times during the day.

$$
\text { No. } 2 .
$$

(160tin will Crude sal ammoniac, 2 ounces,

Vinegar, one quart.

Mix in a bottle, and rub the parts twice daily. Let a long vandage, dipped in the embrocation just prescribed, be passed tightly round the parts, beginning at the bottom and making it fast above the knee, or the hock, as the case may be. Moisten the bandage after it is on. 
alorivy ant grios?d" No. 3.

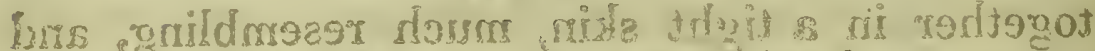
bodrs Cantharides, in powder, $\mathbf{1}$ drachm, Spirits of wine, 2 ounces.

Mix, and rub it on the part. Although this acts as a yery mild blister, the horse's head must be tied up for a few hours while it is operating.

A course of treatment that has been followed in] this manner steadily, and with due caution, seldom fails to restore the animal to a comparative soundness, if not completely so: though the swelling may remain after the lameness has ceased, it generally subsides when the convalescent animal can be permitted to walk out for a little exercise, which should take place gradually, and the use of a loose stall allowed, than which there is not in the whole catalogue of remedies a more certain ad junct to be found. Going out too early after apparent recovery is very likely to bring on a re lapse, and a relapse, as every one knows, is always more difficult to remove than the original disorder. Time is required for the injured parts to recover their former posture and strength, if that event ever arrive Fi,ing may be employed after a while, but is very often resorted to prematurely, before the tendons and ligaments have recovered position, or absorption has reduced the musculay parts to their former size, and restored their action. When three, or four, or five months of moderate labour give reason for believing that these events have taken place, firing is likely to 
prove highly serviceable by bracing the whole together in a tight skin, much resembling, and greatly excelling the long bandage prescribed with the embrocation No. 2 in p. 467 . The reader of discernment will please to note, that if the said artificial bracing be found to lessen the lameness in that early stage of the disorder, no less will the bracing of the natural skin by firing be found beneficial when healthy action is restored, but not perhaps the former strength.

but not perhaps the former strength.

\section{BREAKING DOWN.}

More ruinous than any preceding kind of strain, this accident is moreover remediless, and happens mostly to the better description of horses; to young racers in training, at their trials, or in the actual race; to hunters in leaping, or during a hard run over a heavy country.

Tause. Simply relaxation of the tendons and ligaments that support and keep together the pastern bones. Grooming overmuch by handrubbing the heels until the tendon is divested of most of its muscular covering, and it becomes naturatly cool and elastic*. That race, or breed, of the horse which has low pasterns, and high goers. are most liable to break down upon being pushed.

Symptom. None precedes the actual breaking

- This hand-rubbing causes lymphatic absorption of muscle, until tendinous substance supplies its place, and as the former state had been too fleshy and warm, so is the latter too cold and elastic. 
down, or falling of the animal, though it sometimes runs many yards with the large pastern protruding through the skin upon the ground, in which state we have it upon record the courageous animal has come in and won the stakes, to obtain which it has thus paid for with its life: in this case the suspensor ligament has been ruptured or torn from its true position*. Not always proceeding to this frightful extremity, however, the animal is ascertained to have broke down by the fetlock joint nearly touching the ground: in this case the back sinew and ligaments under it are found to have relaxed or given roay.

Cure there is none, though ineffectual attempts are usually made to doctor up the ruined animal for sale. Apply the same remedies as those recommended for strain of the back sinere in pages 467 , of all which, firing promises the least benefit of any. Yet does heat, atmospheric and animal heat, possess a tendency to brace or contract the tendons, whilst coolness preserves the juices, and with it the elasticity of this particular integument, when the remainder of the coverings are least incommoded with muscle.

* At the Lancaster races, 1825, Sir P. Musgrave's Walton colt broke down in the third heat. Soon afterwards the Tiresias colt of general Byng also broke down in a similar manner. 


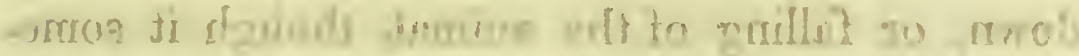
CHAPTER III.

\section{SHOEING.}

TERMs and phrases, in all matters connected with the arts of life, should convey a good and distinct notion of the thing spoken of. This does not always happen in our day, formerly never, and proved a vast stumbling-block to the advance of science; but whoever termed the horse-shoe an "iron defence" was a happy fellow, and deserves well at our hands, inasmuch as his appellation is goodly descriptive of the thing intended, and tells plainly what a shoe ought to be in reality. If not made of sufficient quantity, and of a proper material, it proves inadequate to defend the hoof from injury; if made too heavy, or ill-shaped, the shoe becomes the cause of grievous offence, of pain, heat, and contraction of the horn, with its train of evils. Any workman may learn by practice, and therefore every one ought to know, at least, when too much or too little is applied. Sume feet have the wall very thick, and the shoe will require a good bearing; if very thin, it cannot carry a heavy shoe, though it stand most in need of defence. Again, the horn of some horses' feet is so well- 
tempered and stout, that they might be permitted to go without shoes without danger, if not worked 16 upon stony roads. Time, however, and hard work, and the heat of the blood, occasion brittle sl hoof, and distortions, with numerous disorders that attach to the foot generally, or belong to the sole only.

When these ailments begin to show their effects, of the actual shoe-maker, or "fire-man," as he is if called, must adapt his work according to the new pattern thus cut out for him, and here begins his ingenuity : in some cases he will even have to 10 adopt a differently shaped defence for the same d set of feet; but in all cases, and under every cir-? cumstance, he must fasten them on firmly to the horny wall of the foot by nailing and clenching; is he who performs this office being termed the "door-man" in London, where labour of every kind is very much subdivided. Both will find, in the ensuing pages, that $I$ have not been unmindful of the duties they have to perform. To the latter of these men falls the task of preparing the hoof to receive the shoe, by removing the superabundant horn; but if horn do not so abound, he should cut away scarcely any, lest the defence come off for want of sufficient attachment. What is worse, by paring the sole inordinately, the bones within are pressed out of position, and the wall having now no resistance in the horny sole to keep it expanded, it contracts and becomes shaperogs less and diseased. Partial parings overmuch pro 
duce partial accidents from without, and engender diseases within, which have received a great number of names according to the situation, but all having their origin in this or some such injury, and all producing contracted hoof and sole. The importance of avoiding this baleful practice may be deduced from the great anxiety of our ancestors to particularise, by so many different names, this single disease of the sole arising from contracted hoof. For whenever constitutional diseases fall into the foot, they never affect the sole, or any part of the bottom, unless attracted thither by accidents or contraction of the hoof, by reason of this paring and rasping away of the natural deferice. For example, inflammation of the lungs affects the fore feet with fever and chest-founder, whilst the like attack upon the urinary organs affects the hind feet with thrush. Those diseases are constitutional, or residing in the blood, and may originate sand-crack, fever in the feet, quittor, and the like, but produce no curb, canker, surbating, corn, or those other twenty alleged disorders of the bottom of the foot before alluded to.

Under each of those heads of information, $I$ shall presently place before the operative reader a few plain and intelligent precepts, accompanied by some fatherly admonitions ; for most assuredly, that teacher who contents himself with telling the learner what is necessary to be done has but half performed his duty, if he leave uncorrected certain long-standing errors, which he knows to 
exist, and to have received the sanction of ages that were confessedly working in the dark, as regards horse-shoeing above all other operations. But the method of performing this operation is avowedly not to be taught in its rudiments, upon paper. Practice is indispensable, manual labour requisite; and much of it, conducted by an intelligent mind well versed in books, is necessary to wards forming the proficient shoeing-smith. $\mathrm{Hi}^{-}$ therto, however, from the nature of the blacksmith's trade, its laboriousness, and the deficiency of general education down to a late period, most of the operatives in this branch of mechanical labour were precluded from acquiring the additional information that books contain, after they had once adopted their future calling. Error and prejudice laid fast hold of our ancestors for ages; but the prevailing national desire of acquiring the minor school endowments promise a different result at the present day, and on this occasion, when Science has been disrobed of her cloak, and the niceties of Art are sought in language that all can comprehend.

The shoes affixed to the feet of their horses by the continental farriers differ materially from our own and from each other; which proves that no fixed principle is acknowledged by either of them; though the English and the French assimilate together the nearest of any, and are those, I apprehend, that approach nearest to perfection; notwithstanding the controversies and bold as- 
sumptions of superior wisdom, and the "patents," that enabled a few persons here to give themselves airs, and to set up pretensions they have miserably failed to substantiate. The jointed shoe, for instance, of Goldfinch, of B. Clark, and of Rotch, which is the best modification of the old semi-oval defence for healthy feet, was pre. ceded a whole century by the French author of "Le Cheval," a folio French work, noticed by Mr. Bee in the Annals of Sporting, for 1823.

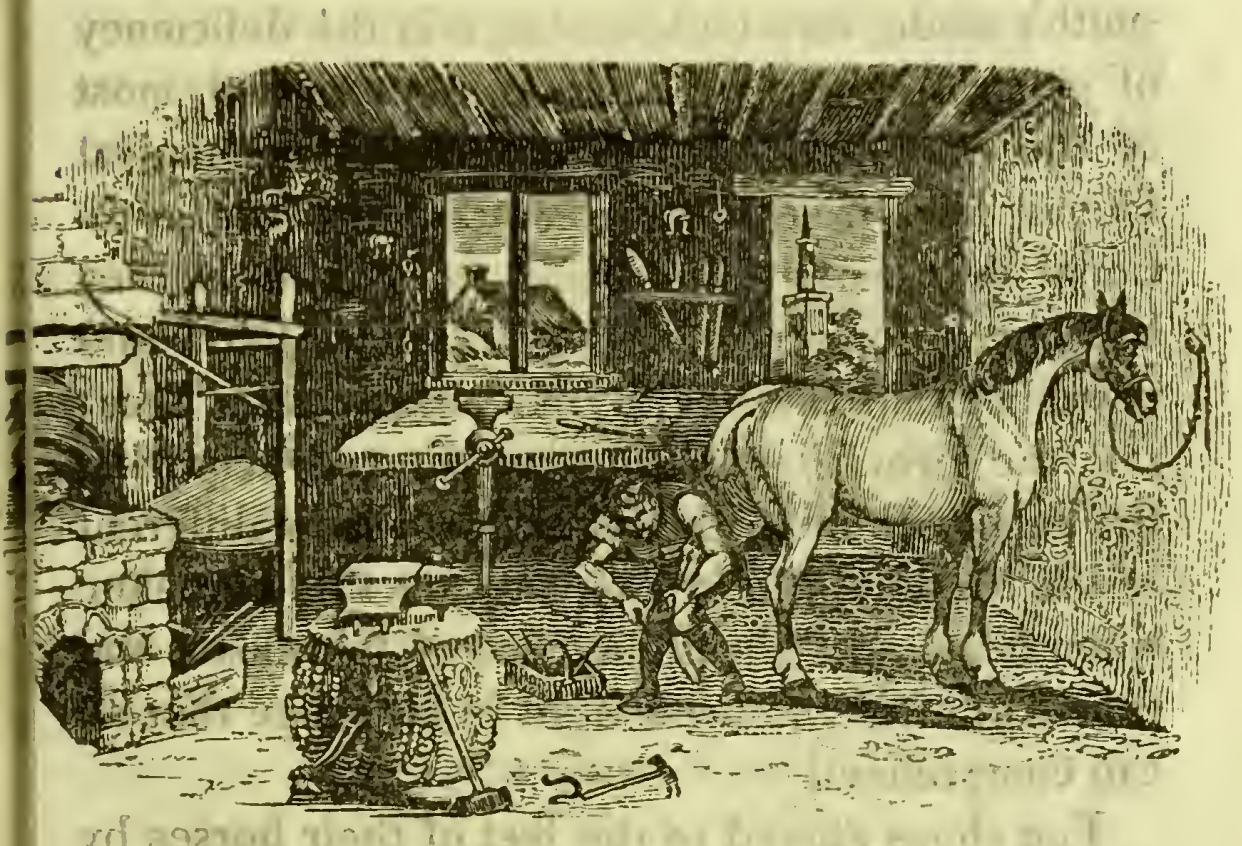

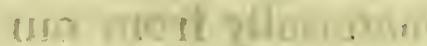

Practical Precepts.

16)

ury zints eavi:?

The shoe. In quantity or size, the common defence of the full-grown horse's foot is made half an inch thick at the toe, but near the heel one

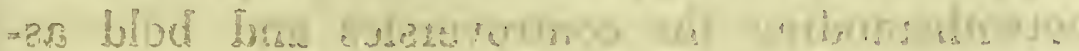


fourth less; here, also, it must be made narrower by the half than at the toe where it is an inch wide, and so continues round to the quarters, lessening away towards the heel, where it is but half an inch wide. Very near the outer edge a groove is made, not too deep, but sloping from the side next the rim, in order to throw the heads of the nails slanting, when the final hammering down takes place. A practice prevails with us of making this groove, called fullering, much too close to the edge ; and to so great an extent does this mistaken notion prevail, that he who could so make it nearest to the edge without cracking the rim was long considered the best workman. This, however, is not the most approved method of our times; for the nail-holes that are to be punctured. in this groove are thus brought too near the edge of the horn, so that the nails do not hold fast, unless driven and clenched high up on the hoof, which also is an exploded part of practice. Neither should the fullering be continued round the toe; nor to the quarters, lest you weaken the defence where its protection is most required.

Iron is the only material proper, and the toughest is the best defence, as it affords a small degree of elasticity in action, is least likely to crack, and is capable of being hardened at the wearing points, at will. The toe alone is usually hardened at the time of making, unless in winter; when it may be found necessary to turn down the 
heels, termed frosting, when these may also be hardened, or steeled.

Some persons frost all their shoes in winter, by fullering them all over the ground surface; but this rough soon wears away, or is of little serrice from the first. On turning the heel down, a crippling gait is produced if the rough be long, especially with heavy horses, having tow hoofs, which may be counteracted, so long as the roughing lasts, by turning down the toe also, and steeling both. But then the necessity of frequently removing the shoe, and thus impairing the wall or crust, may be remedied by making screw-holes in the ground surface of the heels, and providing a suitable supply of screws with steel heads, that may be applied and screwed on fresh every day, if need be. Sizes of course would vary according to that of the horse and shoe.

Shape. For sound feet, both surfaces of the English shoe are made perfectly flat, the inner rim being thinner than the outer. The shoe extends all round the edge of the wall or crust, which it is desirable to deferid, and terminates where the bar and crust join at the heel. A curve upwards, at the toe, to prevent tripping, though sanctioned by authority, and carried to an extreme by Goodwin, and others, is seldom desirable, even with heavy horses, or those which go close to the ground, and is well met by a modification of the German and French method, of forming the shoe wider than ours, and consequently less pointed at 
the toe. The toe being then rasped close to the shoe, no tripping takes place on that account.

The French form, or shape, differs from our English shoe, in being made wider and approaching nearer to a semicircle, and instead of being flat next to the hoof, is hammered hollow, which renders the ground surface convex; a mode of proceeding that suits admirably with their coarse footed horses, and comparatively harmless roads [meaning their petit chemin, and the sides of their grands chemins], but is inadmissible in England, excepting perhaps with our agriculturist owners of the like ordinary cattle. They also make their shoes as thick at the heel as at the toe, which is a transgression against the general precept, at page 472 , that I cannot reconcile with propriety : what is more against the French, they take little heed of hardening either toe or heel. An adjusting curve upwards, which they give to the toe, could add nothing to the security of a horse's going along safe on our roads, whatever it might do on theirs; but their system of punching and nailing is altogether so excellent as to deserve imitation more extensively than it has hitherto been honoured with, and is described with due discrimination lower down. The horn at the toe would of course be made of a fit shape to receive such a form of shoe as the French; and I have reason to believe that it affects the toe of the coffin-bone in process of time, which also becomes curved upwards, precisely after the form thus 
factitiously given to the horn, and doubtless gave rise to the discrepant representations adverted to at page 433.

On finishing off fine work, let the inside of the edge or rim of the hinder shoes be well bevelled off towards the ground, and rounded, to prevent the possibility of coming in contact with the fore foot: with horses that are apt to forge, the necessity of keeping the fore-shoe heel short, so that it may not project beyond the natural heel, should never be lost sight of. So, of the inside of the fore shoes to prevent cutting : let these also be filed off, sloping, towards the ground, though not so far as the heels.

An improved form of shoe, preferable to both the foregoing, has been recently introduced, which is an assimilation of the French and English shoes. Instead of allhering to the old practice of fullering the ground surface of the common English shoe, to admit of punching the nail holes therein, it is the improved practice to hollow that surface, and leave a shoulder towards the outer rim as a protection to the nail heads. This is performed by a tool resembling the head of a hammer, one face whereof is well represented by the annexed figure; the lower part at $(a)$ being placed on the work, as is usual in fullering, but nearly a quarter of an inch from the edge; the hammer is applied at $(b)$, which leaves at $(a)$ the desired shoulder, and 
along that surface so far as nailing is necessary, a hollowness equal to the inner slope of the tool. This hollow is not in fact any more than a wider fuller, extending the width of the shoe, excepting the width of the rim left at the outer edge; though some do further prolong the hollowing all round the toe, and to within half an inch of the heel, whereby they leave a slight caulking that never incommodes the animal, but which may be increased in quantity and hardness towards winter. The operation of hollowing the ground surface just described produces a slight convexity upon the foot surface three-fourths of the shoe's width, leaving the outer fourth still flat to receive the bearing of the horn. Hereby the distance between the sole and the inner rim is increased, and is moreover less likely to retain stones, gravel, or filth, than is the usual flat surfaced shoe, and possesses all the advantages of the seated shoe of old Osmer, that has been claimed by some of our moderns. Moorcroft took great pains to recommend the seated shoe, but finding some difficulty in getting them manufactured, he set up a machine for puncturing out the hollows, that quite failed of success, because the power employed was only equal to cutting soft iron, and this was found inadequate to the required wear, we are told. Why he did not subsequently harden, or "steel" the toe and heels seems surprising. 
Healthy feet are those alone which I have kept in view hitherto; the bar-shoe, concave and seated shoes being contrivances for ill-formed and diseased feet, require separate notice. But the idea of giving elasticity to the hoof by means of the jointed shoe, being a preventive remedy, calculated for the preservation of health by giving lateral action to the internal sensible parts of the foot, I shall very briefly describe the contrivances of several inventors and patentees, whether philanthropic or sordid, with this previous intimation, viz. that it becomes " any and every" slioeing" smith whatever to make "any or either" of such jointed shoes, notwithstanding certain "letters patent," letters of puff, or volumes of stuff, whereby those so-called patentees, and others, arrogate to themselves the merit of being inventors, for the reasons set down higher up, page 475. Their patents are not worth a straw, unless for cutting into slips for tailors' measures. I must also here add the assurance of my belief, that this contrivance for affording expansion at the heels, by means of the joint, is the best antidote yet made known for correcting the evils arising from the application of a rigid iron defence to the horse's foot.

Objections have certainly been raised against this mode of forming shoes, that seem plausible enough at first glance: not so fast, however; for upon cool examination they vanish. The objectors aver, that because we cannot impart the 
desired freedom of expansion to the relole of the foot, forsooth, we are not to allow it at any part : if we cannot get all we want, we are to reject what is within our reach; all or none, say they, like froward children. One of these, who is likewise the last, tells us, "In order to admit of expansion and relaxcation of the hoof by a joint, it would be necessary to make the nail-holes wide enough to allow sufficient play between the shoe and the nails [!], thus producing an effect similar to the end play of carriage springs. But even supposing (says he) this provision were made, the shoe would soon tear out the nails."

To be sure it would, Mr. Goodwin ( $\mathrm{p} .187$ ); but supposing (even or not even) that your shoes do not so "make play," no one would imagine that you were making game at your readers. Why, he sets up a bug-aboo, ard then knocks it down, with "I have often proved the truth of the preceding observations." But the observations being unjust, because applied to an unfounded suggestion, proof was not necessary.

The jointed shoe. A form of shoe was propounded for cutting the shoe into three or more several parts; then lining the foot surface with leather, and fastening on the shoe in the usual manner, with nails that were inserted into each part. But this contrivance, though plausible, did not answer, inasmuch as the leather had not sufficient strength to stand the wear and tear. Mr. 
Rotch was the inventor of this notable affair, and took out a patent that, I may venture to affirm, will never be invaded.

Mr. Bracy Clark may have been the real inventor of the jointed shoe that bears his name, for aught I know, but he labours under the disadvantage of being preceded by about a century, by a French author; so that his battered saying, that his great discovery! forms "a basis for the repose of the profession," however elegant in expression, becomes nonsense to our ears, who concede nothing to simple gentility, and less than that to self-complaisant egotism. "Clark's shoe," in its various modifications, differs nothing from the generality of shoes, except in being divided at the toe, and fastened again by means of a pin, screw, or rivet. The toe would require to be made thicker than usual, let me suggest, to prevent the rivet's parting, and to secure each head of it in a counter sink; one half the thickness of the toe is to be cut away on one side at the ground surface, and from the foot surface of the other half, resembling what is termed in carpentry a mitre; and these being brought close together, a hole should be drilled or punched through both, and let the rivet employed be the size of the hole. Whatever degree of rigidity the workman might restore to the entire shoe, it is plain that the great weight of the horse would very soon strain the rivet, so as to cause it to relax therefrom, and allow the beels to expand byso much. That this mightextend 
over a larger part of the front of the hoof, $\mathrm{Ml}^{2}$. Clark preferred nailing the shoe pretty far back towards the quarters, which I reckon among the mistaken notions of the whole class of improvers. But, mark the dissonance of Fig. 3. our teachers! the next inventor or improver ran into the other extreme, erroneously punching and nailing up intolerably near to his rivets or pins, for he has two of them, as per marginal cut.

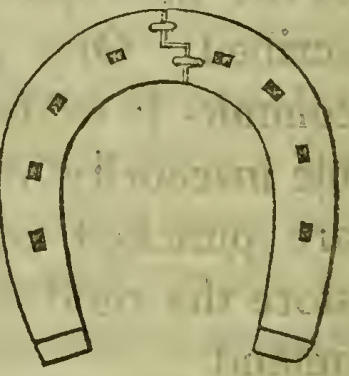

This representation of the shoe invented by Lieutenant-Colonel Goldfinch exhibits a modification of "Clark's patent." Like it, the necessity of making the shoe thicker at the toe than usual with the ordinary shoes is evident. The patent was enrolled in October 1821, granting to Lieutenant-Colonel Henry Goldfinch, of Hythe in Kent, an exclusive right for fourteen years; and his specification of its advantages and novelty, and the manner of making it, appears to be as follows: "The separation is to be made in any inclented form, and the two parts fastened together with pins. It is further proposed to attach the shoe to the horse's hoof by driving the nails obliquely, as in the French manner of shoeing. With this view, the nail-holes are to be punched about one-third to half the width of the shoe dis stant from the outer edge, and tending in a slanting direction outwards." In this latter recommendation I cordially join the colonel: he was the 
first writer who noticed it, and is the mode of punching and nailing before alluded to, and hereafter described as the only wise course. Since 1821 it was adopted by the more intelligent smiths of the metropolis, and is hereafter minutely described. One main blunder which the colonel commits is evidently intended to correct the visible insecurity of his shoe at the joint: his holes are punched so near his patent joint as to restore the rigid immobility the patent pretends to amend.

Coleman's patent shoe for giving pressure to the frog continues in use (though in a very limited degree), notwithstanding the demonstrability of its inapplication to frogs already diseased. But, in the hands of the professor himself, and any practitioner tolerably habile in his profession, I was free to allow, from the very first, it might be rendered available-but not in ordinary hands *: with these it has failed of success -in some cases from the want of an assortment adapted to the various kinds of feet; a defect that may be now remedied in some measure by the cheapness of the malleable invention of $\mathrm{Mr}$. Dudley, as sold at a cheap rate by Mr. Long, of High Holborn.

Under these new circumstances, and seeing that Mr. Coleman's opinions as to pressure, and the diseases consequent upon the absence of it, are embodied in his specification, drawn up to ob-

* The subject received lengthened notice, in the Annals of Sporting for April, 1822, p. 246. 
tain this patent (for the professor has several), he may be allowed to speak for himself on this ever-interesting subject. He says, "the improvement proposed in this patent is to prevent contraction, and to relieve contracted feet, contracted frogs, flat soles, corns, "sand-cracks, thrushes, canker, and quittors, and also to prevent cutting.

The patentee observes, that "the fore feet of horses in their natural state are nearly circular, but from the ordinary shoe worn in this country, which keeps the frogs from off the ground, the hoofs of horses with light fore-quarters are generally found to be more or less contracted, and this in proportion as the frogs are more elevated, and support little weight;" whence the cause of those diseases. To remedy this defect, and to afford the necessary expansion to the hoof, the patentee proposed the annexed forms, ob-. serving that no specific form of shoe can be suited to all horses under all circumstances, and to every sort of road; it being necessary to alter the shoes of the same horse at difierent periods.

The construction of the professor's shoe will be seen in figures $4,5,6$.
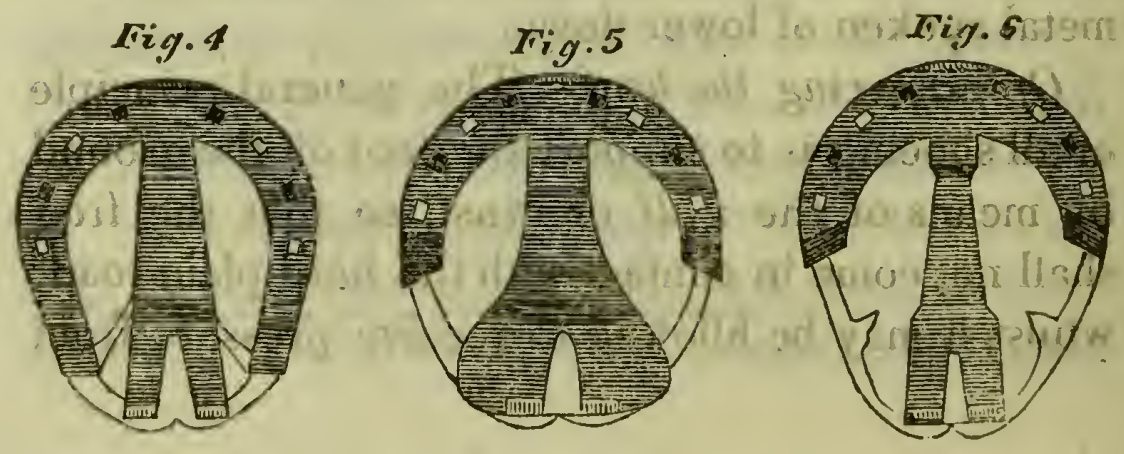
"The bar of iron down the middle of the shoe, called the frog-bar, is made broader than the frog, and welded to the shoe. This bar, when the cleft of the frog is diseased, is slit open in the middle." But all that I have seen in use are without the slit represented in the margin; and the zoelding on of the bar is greatly objectionable, inasmuch as the chief strain is at the junction of the bar with the shoe or tip, and I have often seen the bar break off here, or else draw the nails, and throw the patent shoe altogether.

"When the ground is dry, the crust and sole strong, and the heels of the hoof high, the shoe should be made about an inch shorter than the ordinary shoe, as fig. 5, or shorter still, as fig. 6, with the hinder parts bevelled, but the heels of the frog-bar for contracted hoofs should not exceed the level of the heels of the crust or shoe." The patentee promised himself and the public great advantages from his contrivance, which $I$ could never perceive it possessed; notwithstanding the public, or the military service, are said to approve of Mr. Coleman's patent, for they purchase good numbers, so 'tis said, of those which are cast by Dudley, and sold by Long, of the new malleable metal spoken of lower down.

of preparing the hoof.-The general principle of all shoeing is to support the foot off the ground by means of the wall or crust, so that the frog. shall not come in contact with the hard plain road, whilst it may be allowed to receive pressure from 
soft ground: the first prevents injuries and resists wear and tear, the latter promotes the secretion of healthy horn; the proper degree of pressure being received by the heel, frog; and bars. Whatever is here said, the fore foot is still kept in view, unless the hinder foot is particularly mentioned; and occasion will present itself for the cistinction, as there is great difference between the two, as regards heavy draught cattle. Greater heat, fever, and affections of the lungs also cause the fore feet to contract disorders unknown at the hind feet; whilst a tardy circulation of the blood, and the consequent relaxation of the animal system, to say nothing of the evils incurred by heavy drags against the collar, produce affections peculiar to the hind feet. Something more is said of this kind of variation at page 32, book 1 .

When very much flaky or rotten horn presents itself, the sole should then be pared the least, for this is a proof that great heat, or inflammation, affects the whole sensible foot, and that the hoof is then too brittle. When the flakiness is trivial, run over the whole surface with the butteris, or knife, but go no deeper than the removal of the loose flakes. La Fosse and Moorcroft were both in the right when they told us that paring the sole inconsiderately is "the chief cause of contraction;" for the sole is thus rendered less capable of resisting the pressure of the wall on all sides, and of the coffin-bone within, insomuch, that were the paring carried to an extreme; this bone would pros 
trude at the sole, and come upon the ground for want of sufficient resistance. Whenever a smith applies his thumb to the sole, and then cuts again until he causes it to bend under the pressure, let him be admonished that he contributes his aid towards contraction of the foot, and some one or other disease of the sole. He has but to cut away a little more to arrive at the sensible sole, which would produce blood, and ruin the horse by a quicker mode than thumbing and cutting, and cutting and thumbing.

The frog seldom requires the knife ; never after the removal of a shoe which has allowed it to come upon unpaved ground; for then the wearing away is carried on naturally; but if not so, the rough and rotten outside must be taken away, which some smiths effect by first tearing away the slips, or exfoliation, and then paring the mealy-looking part underneath. Hereupon the well recognised healthy horny frog makes its appearance, but is by no nieans to be meddled with. The cleft is to be cleared out by means of a knife having a sharp return, at the extremity; but it must be evident that if the cleft has incurred no foulness, nor the frog grown luxuriantly, neither the one nor the other will require the least reduction. I will not say a word on the necessity of removing the rotten overgrown horn at the toe, and round to the quarters, so as to obtain a proper seat or bearing upon the shoe, this being an afrair within every one's compass; but the rasping should always proceed Y 5 
with the shoesbefore the workman's eyes, unless when he may find it necessary to take it to the fire for the purpose of making alterations. The habit of doing this to a nicety with a single heat may be acquired without going to the fire half a dozen times, as $I$ have seen done; least of all should the shoe be tried on hot, that the most ignorant of workmen may see where it bear's most, or the least industrious lessen his labour by softening the horn. Ruinous consequences attend the application of fire to the feet, and yet I remember the period when it was the common practice to place a shovel of hot coals on brittle hoof to ease the workman's labour!

- When a foot is fitted to receive the shoe, the bottom resembles somewhat the hollow and rim of an oval dish. On being placed on a plane surface, the frog and heels bear equally; but when the shoe is applied, the frog is raised by as much as the thickness of the shoe may be at the heel. At the heels, for about an inch of its length; the rim of the shoe is to project beyond the outside of the hoof, lest the growing state of the horn should cause the shoe to imbed itself at this part, where the substance is soft and the wear is very little. Take good heed that the inner edge of the shoe-heel bear not on the ground more than the iouter, but the contrary. Expansion of the heel may be promoted by making the heels thicker at the inner edge than at the outer, though this be but $1-32 d$ of an inch. 
Nailing, a very important operation, requires much previous study of the formation and functions of the internal sensible parts of the foot, many injuries being inflicted by penetrating those parts to the quick, and thereby occasioning them to fester, as we shall see presently, when treating of the diseases incident to the sole. A good aphorism has it thus-" "If it were possible to keep the shoe in position without nailing, we should then have arrived at perfection in the art of shoeing; it follows that the less number of nails that are driven consistent with safety, is the most commendable practice." I believe it was Mr. Bracy Clark, in the plenitude of his many inventions, who once proposed to fasten on the shoe by/enveloping the whole hoof in an iron defence, and fastening it by screws; but the scheme failed for a most obvious reason-its zweight increased the offence adverted to elsewhere (page 471). But I will not speculate on novelties, nor further object, simply contenting myself with taking the evil of puncturation as one that is inevitable, though capable of alleviation. All hands agree that the less nailing we could suffice with, the less chance there would be of driving into the quick-hence the firmer each nail is driven, the less liable is the shoe of loosening, and this good never can be effected unless the nails fit the holes so nearly as to prevent shifting, and also pass through a good portion of the hurne Doubtless, a couple of nails on each side would be sufficient to retain a light 
shoe for a short time, if the work be not heavy, and allow that desirable expansion of the heel which all agree promotes the secretion of new horn, and the health of the foot; but we enploy double the number in common work, and seven altogether in the "improved shoe."

As before remarked, the fullering usually practised upon the common shoe is so near the edge, that the rim sometimes breaks off of high-tempered iron; whilst, if it be soft, the punching inevitably drives out a bulge that the smith seeks to reduce by hammering, which again contracts the size of the nail-holes: the latter error occasions the nails to break off in driving; the former leaves the heads exposed to be knocked off, or readily worn away; and by either the security of the shoe is diminished greatly and dangerously. Besides which objection to the old method of fullering, there is a corresponding necessity imposed upon the workman of clenching high up on the hoof, which increases the danger of puncturing the sensible internal parts of the foot. This entire objection to the narrow fuller, or groove, is fully remedied by adopting the proposed manner of punching the nail-holes farther in from the edge, thus taking firm hold of the whole thickness of the horn, and driving out sooner and clenching lower than is ordinarily practised-say, within $\frac{3}{4}$ of an inch of the shoe in all cases.

The vail commonly used is much too long in the shank for any kind of shoe, and too thin near 
the head, but should be of the same thiekness throughout from the head so far as the pointing takes place. The material must be of the toughest quality, equal to Swedish, insomuch as the nail may bear bending forward and backward half a score times without breaking; it should have a counter-sink head to match with the second punchholes, and the hammering which the head receives before, at, and after driving, sufficiently hardens it to resist the immediate effects of wear. Do not point the nails too much, lest they splinter in the driving, nor make two or three punctures before you drive home each nail : both these practices proclaim the clumsy workman.

Puncling.-As before intimated, the nail-holes should be punched as far from the outer edge of the shoe as the roull is thick. A small punch of the size of the nail's shank is to be first driven smartly and visibly through, but not so deep as to raise a burr on the hoof side. Then, open the hole with a pritchel; and a larger counter-sink punch, the size of the nail-head, is then to be employed, but not driven so deep as the small punch; the first being of the size of the nail shank, the second is to receive a small part of the head. This mode is, of course, best adapted to the "improved shoe" recommended at page 479 , where a shoulder and groove supply the place of fullering. But, in every form of shoe, and every modification of nailing, the manifest advantage of admitting the nail-head to a rest or protection 
from rude concussions against the ground, must be evident, when the counter-sink part of the head is allowed to lie deep in the shoe.

The number of nail-holes has hitherto been eight, but a better practice prevails in some forges of driving seren nails only, three on the inside, four outside; whereby the fourth nail outside is thrown so much farther back than the third nail inside. More play is thus allowed for expansion at the quarters; and if the punching and driving be performed effectively, the hold thus obtained will be found fully adequate to any service to which the greater number of nails is applied. The safety of the shoe depends more upon the nails' passing through good sound horn, and filling up the punch-holes in the shoe, than upon their number. A good workman can hear when the nails thus tell, by the sound of driving. After punching, the smith must not apply heat, or a hammer to the shoe, with a view to reduce any bulge, or burr, which the punch may have occasioned; for this exploded practice spoils the shape and size of the holes, upon the fitness whereof wholly depends the security of the shoe. Indeed, good and proper iron does not readily incur either of those objectionable forms, nor will it break or chip off at the fuller-edge (when such a plan is adopted) like ordinary metal.

Driving the nails home properly includes no small share of skill. Formerly, he who could drive highest into the crust without occasioning 
lameness was reckoned the best workman, whilst the french method of driving both into sole and crust is an error in the contrary extreme, and argues no little slovenliness and disregard of the construction of the sensible part of the foot. As may be seen and accounted for by reference to the section at page 431 , immediate lameness is not always likely to succeed the pricking of the sensible part at $c c$, but matter may form underneath, and lameness ensue at a future day, unless upon removal of the shoe it issue forth at once in the shape of blood. The hoof, which may have lost the elastic substance of this scnsible part through age or infirmities, as represented at $(\mathrm{g})$, fig. 3 , plate 3 , is usually "pricked to the quick" at once, and flinches, or goes crippling away from the smithy.

According to the most improved modern mode of punching and nailing, the nail should enter at the conjunction, nearly, of the sole and crust, so as to penetrate almost the whole thickness of the crust*, and be driven slanting outwards, so that the clinch be little more than half the usual distance above the shoe. If the nail-holes be punched too near each other, and the driving be performed by a workman who drives and draws his nails, and then peers into the punch-holes, then points his nail and drives again-however well his work may appear when put out of hand,

* As shown in the figure of Goldfinch's shoe at page 484. : 
he will but have prepared the hoof for fresh injuries at the next shoeing: after this treatment, portions of the hoof are apt to come away, and the smith is thus compelled to fasten on his defence by the toe, or at the quarters, and so produce fresh offence and incurable lameness.

Do not nick the hoof, as is too commonly practised, previous to turning the clenches; as most feet cannot afford to lose so much of their natural support, and even the stoutest foot ought not to be subjected to the loss of so much of its main strength. Neither rasp off the clinch, by way of finish, for the same reason, but hammer it down like the head of a rivet.

Diseased feet stand in need of various modifications and alterations of the foregoing shoes, of which the form most opposed in principle is the

Bar-shoe, which is well calculated to prevent that elastic healthy aciion so much insisted upon as necessary to the secretion of new horn. As elasticity is desirable in health, so is it injurious when disease has once commenced: then it is the bar-shoe keeps the sensible parts at rest.

Concave-seated shoe, for convex soles, when these cannot be reduced. This is nearly the same shoe as recommended above, with a different name, and the making whereof has been undertaken only by the best workmen, or with much 
reluctance. To obviate this difficulty, a very neat cast iron shoe (let not the reader smile) has been manufactured, as well as those of most other forms for diseased feet, which may be obtained of Mr. Long, the veterinary surgeons' instrumentmaker in High Holborn, and of the "patentee," Mr. Dudley, of Soho Square.

Cast iron shoes, however, have been at length made of a metal that admits of being heated and altered to the deviations which the feet of every individual horse assumes, according to circumstances. The mode of accomplishing this, and the manner of hardening the toe, \&c. are taught in a printed paper distributed by the vendors. Great quantities of the casted shoes have been supplied to the army; and may be made available to the service in times of great exigency-for, what evils do we not endure when warfare adds to our sufferings! But the well-known rigidity of this material; being at entire variance with all our notions and experience of elastic hoof, seems a bar to its general introduction for healthy feet. Again, for hard-working horses that require frequent shoeing, but do not secrete a sufficiency of new horn, the evident fact that the nail-holes will constantly occur always at the same spot, affording no fresh hold for the nailing in sound horn, must operate as a great objection to the general employment of cast iron shoes for working cattle. 
Mr. R. B. Teast recommends a construction of the foot, surface, that seems very well calculated to attain his object, the preventing contraction and amending the several evils arising therefrom, by raising a ridge along the whole extent of the shoe so far as the heels, exclusively, thus making an inclined plane outwards of the thickness of the wall or crust of the hoof. The punching and nailing takes place at this ridge, thus affording secure driving for the nails, and a safe hold upon the iron. Withinside; the shoe is convex on both surfacès, but admits of modification, at will, on the ground surface. The hoof must be prepared to receive this form by paring away the horn lower on the inner part than on the outer side, or external edge of the wall; in fine, so as to correspond with the form of the shoe. At least, this is what I understand in the course of reading a series of very obscurely written "Practical Observations" on the subject; for, although the plan seems admirable, none of my connexions have seen it in actual use, notwithstanding I called at his forge for that purpose. This was in 1821, soon after the promulgation of $\mathrm{Mr}$. Teast's plan.

By the means proposed, the hoof is spread outwards at every step, so as to afford expansion to the heels, and avoid pressure upon the sole; an advantage for such horses as are weak or thinsoled that is at once obvious and gratifying. His idea of giving pressure to the convex sole, lby 
making his shoe with the whole foot surface incliving outroards, is more vague, since all that is requisite is attained by the first method.

Notwithstanding the French method of punching has been spoken of in terms of approbation, and their-mode of driving and clenching low is recommended to imitation, let it not be supposed that in other respects they make the best shoeing smiths in the world, but the contrary. Their finest shoeing is sad, slovenly work to look at; and this very exceilence of theirs is more attributable to laziness than to design or plan. As one instance of this undesirable quality, they assign two men to placing the shoe, a lacquey holding the foot and bringing the tools, whilst le marechal himself hammers it on with much pomp. In Portugal they employ three, which includes the gallegios, or porter.

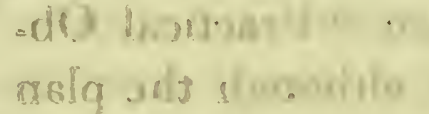

\section{arser arojis.mon.}

$\overline{10}$

\section{I: holligi}

\section{CHAPTER IV.}

\section{Diseases of the Foot.}

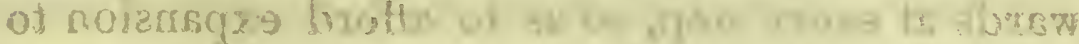

IISWEN these cannot be traced distinctly to any specific cause, they are fairly attributable to ailment of the whole system dropping into the legs, and "fever in the feet" decidedly so, in my opinion, when both are so afflicted. Therefore it was that 
I noticed this disease along with "strain of the tendons," to which I attribute its origin, as much as to other causes of general heat of the foot. Indeed the whole structure of the foot of the horse is so peculiarly curious that it almost deserves a separate study; but we must always keep in mind, whilst considering its ailments, that the great irritation kept up by its extreme action is readily communicable from the one to the other, so that we cannot intelligibly. separate the leg from the foot, when speaking of the ailments of either, notwithstanding I have thought proper to begin this chapier with the disorders that are situated higher up, and mean to close it with such as only make their appearance below.

But there remains still another distinction that may as well be drawn here, before I enter into other particulars, as to fore foot and hind foot. In all the little dissertations which I have ventured upon in this book, and elsewhere, as to the structure of the foot, and all the dissections I have made from time to time, I have taken the fore leg and foot only, with one unimportant exception. I know not why this preference was first made; I believe it to be general, but is of very little importance. For the hind foot, though a little smaller, and somewhat more upright in form, corresponds exactly in all its parts with the foreone, until age and deformity comes on; the back sinew descending from the hough behind the pastern bones, until its insertion underneath the 
coffin-bone of the hind leg, in the same manner as before described, as pertaining to the knee and bones of the fore leg. Further, I believe the name given by the learned to this sinew in the hind leg differs from that given to it in the foreleg, that being tendo plantaris, this one the tendo palmaris; a distinction that became necessary, perhaps, that they might be enabled to make themselves understood by each other, when speaking of this important tendon as belonging to the one or the other leg.

When we reflect upon this strict accordance between the structure of the fore foot and the hind, and then look over and lament the numerous disorders that the first is liable to, whilst the hinder one is comparatively free, it gives us reason to pause. But without entering upon an elaborate investigation of this difference as to health, I come to the conclusion that we ought to attribute diseases of the feet, as I have already those of the body, to excessive heat of the vascular system, promoted by the great exertions the animal is put to, and the rude concussions the fore feet in particuiar endure at every step, thus creating heat and attracting hither any evil humours that may afflict the body generally.

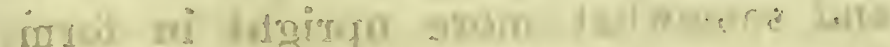

Q $7113,301 ?$

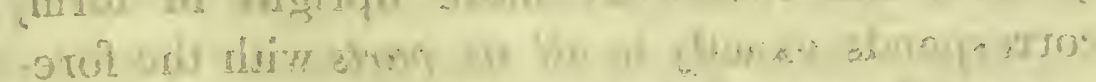

FRUSH, OR THRUSH.

A running of matter at the cleft of the frog 
was formerly called "a running frush ;" the moderns, however, write it "thrush." But, to frush, being old English for to break, to crack, or crush, like the cracking of walnuts, I prefer that term before thrush.

Cause.-Depraved habit of body and disordered pulse always accompanying the appearance of a frush, I have no hesitation in ascribing its origin to that remole cause, especially as it is proved to be a deep-seated morbid accumulation; aided more immediately, perhaps, by an injury received whilst travelling, either by the bruise of a stone, or the insertion of gravel at the parts. 'This latter, however, is not a necessary cause of frush, though the gravel and dirt work into the ulcer as soon as it opens; for the lurking approach of the disease towards this consummate symptom may be ascertained by turning up the hoof and pressing the cleft, which will give pain and occasion the animal to flinch: inflammation has already begun at the insertion of the back sinew in the bottom of the coffin-bone, where the branches of the crural artery also enter the bone, at the bottom whereof is the sensible sole, which separates it from the horny sole. See this structure of the foot described at page 433, \&c. Filthy stables promote frush, and, when the cure may be nearly effected, cause relapse in nine cases out of ten.

Symptoms.-The earliest, as just said, is denoted by tenderness at the cleft, accompanied by sharp, quickened and irregular pulse, as usual in all 
cases of local inflammation, being at the same time both cause and effect. Of course it follows, that as the disorder in the sensible frog proceeds towards maturity, the blood feels and tells of that fact by increased disorder of the pulsation. These timely indications being neglected, as usually happens, if the animal be then put along over stony or newly-dressed roads, the first discovered symptom will then be his tumbling down through acute pain. The cleft opens, and an issue of a most offensive kind presents itself.

Cure.-If not speedily taken in hand, canker will be the consequence of a neglected fiush. But, as scarcely one in ten will take the precaution to ascertain, from the state of his pulse, when the horse is likely to acquire this or any other inflammatory disease, it may be deemed impertinent in me to say, that the preventive of frush in its worst state may be found in purging physic and a cooling regimen, as prescribed for general inflammatory and febrile complaints, set down at the commencement of book 2 , pages $159,1 \% 0$, \&c. ; for this disease frequently depends on some untimely-suppressed evacuatiun, as the urine, stool, or perspiration; then let these be restored by giving the diaphoretic powders, purging or pissing balls, according to circumstances. A very much hurried pulse would of course point out the necessity of immediate bleeding; for the animal so suffering in the vital function must necessarily contract disease of some 
kind or other; and that particular organ or member which may be least able to bear it is sure to feel its effects soonest. This is as likely to happen to a horse with defective frog, as to its size, texture, or shape, as to any other part of him. "Then, let the careful owner examine and find out the least perfect part of his horse, let him watch it closely in all its weakness, and endeavour to detect the first symptoms of illness, that he may aid nature and restore her functions, before these run riot beyond the help of art.

When the frog has been pared away, and the filth of the sore removed, wash it with a solution of vitriolated copper, and apply a pledget dipped in tar or turpentine at the opening. If the case be a bad one, the roash may be made stronger by the addition of a few drops of vitriolic acid to the solution; and the tar may be poured into the opening whilst warm. Place dry tow and keep it in position by means of splints. Repeat this tardressing every other day, until the injured parts slough off. Purging physic will be necessary to complete the cure.

\section{CANKER.}

Evidently a corruption of the word cancer, as applied to a running sore in human ailments, it is yet well silently to permit the innovation, the 
Better to keep the two practices separate, in small as well as more extended affairs.

Causes.-Precisely the same as those which produce the frush, only making its appearance at various parts of the sole, frog, \&c. Sometimes the canker is but an aggravated frush; a very bad or neglected cure becoming in my estimation a canker, and next to incurable; whereas a frush, taken in time, is easily cured. Our French neighbours write of the two under the same head, of cancer, let them be seated wheresoever they may.

The symptoms are those of frush, extended also to the bars of the frog, the heel, the sole, \&c.; and so is the

Cure; with this addition, that the paring must be carried on to the extremity, baring all the diseased parts, though these extend over the whole bottom of the foot. Cut away the proud flesh to the quick, and when it has bled a little, apply

\section{The Poreder.}

Sulphate of copper, 1 ounce,

Corr. sublimate, 4 drachms,

Prepared chalk, 1 ounce.

Mix and sprinkle it over the exposed surface. If the disease makes a hollow between the hoof and the coffin-bone, the powder must be introduced there by means of a spatula, or flat piece of wood, with a bit of tow on it; but do not leave the tow behind, as that might produce a fresh disorder. 
Butter of antimony is preferred by some to the foregoing powder, because it is a liquid and acts more generally; but it operates only for a very short time before its effects cease, being killed by the moisture of the disease it was meant to destroy. Bind up the foot until the following day, when the application must be repeated, after wiping away roughly as much as possible of the diseased parts.

As it is found of some importance to the cure, that the foot should be kept as much as possible from wet and filth, and seeing that the mode of tying on a great bundle of tow in cloth, in the manner now in vogue, often fails, a light shoe, adapted to the present shape of the foot, should be put on, for the purpose of sustaining the dressings, \&c. which may be found necessary to put on. The shoe has another advantage over the tying fastion, inasmuch as it allows of the animal to place his foot fairly on the ground, a position that mainly conduces to the cure by promoting the secretions, especially when at length he can move about. Let the shoe be narrow-webbed, with a groove on the inside edge, so as to admit of a tin slider being shoved in and drawn out, when you desire to examine the under surface of the foot, to change the dressings, \&c. Such a shoe will obviate the complaints usually raised by our stable attendants, that they cannot keep on the dressings, nor preserve the foot from damp, which always retards the cure; for they are 
most of them bunglers at bandaging, owing to the very little practice which falls to the share of any one person among the whole fraternity. Splents of wood may supply the place of tin, when this latter may not be at hand.

Whenever the cankered parts slough off, and leave a more healthy appearance, the powder need no longer be applied at those particular places. Upon these lay on a dressing of tar, in which has been introduced about a tenth part of blue stone, powdered. Let as much pressure be given to the sole as can be contrived, to prevent the granulation of new flesh coming on too luxuriantly, which is otherwise very likely to happen, on the edges of the wound particularly. In this respect, the grooved shoe will be found effectually serviceable. If, notwithstanding all your care, the edges will grow too fast, touch that part with lunar caustic; and in case the horny substance grows over the still cankered parts, it must be again pared away and laid bare. Perhaps the animal is young and vigorous in other respects, and his system probably would promote the secretion of new horn quicker than an older, or less healthy horse; this difference should teach us to employ some digestive for the dressings, which has less tendency to promote the growth of new horn than tar has, which would be found more proper for old horses. For the younger animals, let turpentine be substituted, into which has been mixed a small portion of vitriolated copper. 
From what has been said, the reader will perceive the dressings require changing with some degree of judgment and discrimination, and that they should not be passed over or delayed, as he values the horse; for, upon this marked attention alone dépends the cure, and such a cure as shall prevent a relapse. Of course he will not fail to take care of the evacuations, as in case of frush; nor that the earliest exercise the animal takes be proportioned to the amount of disease he has undergone in an inverse ratio.

Prevention.-As we have seen that inflammation is the immediate cause of all disorders of this class, and seeing that the irritation which produces this has been brought on by distress of the parts for want of due pressure on the frog, any one whose eyes are open may see the necessity of paring down the heels so that the frog may have a bearing, when the horse is walked over field or turf, for example. For hereby it will be seen, on turning to the brief description I thought proper to give at the beginning of this Book, pages $433,441, \& c$. of the internal conformation of the foot, that the healthy action of the parts upon each other is only to be kept up by the pressure of the sensible frog upon the juices, that abound to redundancy at the shuttle-bone, so that these may be dispersed for the general resuscitation of the whole foot, and to make up its losses by wear and tear.

"When the frog is not sufficiently pressed upon, 
(says Mr. Coleman), it becomes soft from the accumulation of the fluid which it naturally secretes in great abundance from the fatty [elastic] substance, which lies immediately under the tendon." This view of the process tallies tolerably well with my own examination of the subject, at' the pages just referred to, and elsewhere.

\section{SAND-CRACK.}

When suffered to continue, the cure is attended with great difficulty, and the disorder may therefore be divided into two stages or degrees, like many other affections of the horse. The name of sand-crack is derived from the worst of these states, when sand, gravel, or dirt, has got into the crack, which constitutes the disease.

Cause.-Brittle hoof will occasion sand-crack of a very bad sort, but the accompanying cause is the cessation of the function of supplying matter for forming new horn in the vessels leading from the coronet. This may arise from an external injury at the coronet, or severe treatment for some other disorder of the foot, as a running frush; but oftener both are indebted to a heated state of the blood for their origin, and the function may be restored by physicking the animal, provided it does not dung at proper intervals. Slight cases have been removed by this means alone. $\Lambda$ s the hoof is always hot, one main cause of sand-crack 
is referred to heated roads, to travelling in deep, hot, sandy countries; scantiness of water, and removal out of a cold to a very hot climate, as from England to India (East or West), are all known to cause the heat and brittleness which accompany sand-crack.

- Symptoms. - A split or crack in the hoof, on the inside quarter of the fore foot, for the most part, but often on the front of it, down towards the toe, and occasionally on the outside, and also near the heel. Sometimes it appears on the hind foot, on the front of it, and prevails with us generally in hot weather. Sand-crack is either superficial and easily remedied, or deep and extensive, requiring much attention, and an operation or two in its different stages.

Cure.-It will be seen, that a slight crack may, by working the animal, become one of the worst species. Pare away the rotten parts, if such be found, and make a transverse incision across the upper part of the crack; wash out the sand or dirt, apply daily tincture of tar, with a pledget of tow, and give the horse rest. Bind round the hoof tight with listing, and stop up the sole with cow-dung, and this treatment will suffice in ordinary cases. But when the crack extends so high, that there is no room left for making this incision across, to stop the progress of the crack, the disorder has assumed its worst aspect: the edges of the crack internally now press upon the sensible part, or ligamentary substance that holds 
the coffin-bone and hoof together, and inflammation succeeds, if blood does not issue forth. If the crack affects the coronet, you may draw one side of it down to the quick about an inch with good effect, but no farther, as that would occasion the hoof to divide more readily. Rest, however, will restore adhesion to the upper part of the crack, and when this has taken place extensively, the operation of cutting across, or of firing it across with one line only, may be performed with every prospect of success; for, as the hoof grows down, which it does from the coronet, this transverse artificial crack you have made intercepts the material for forming horn, on its inside, and thus contributes greatly to fill up the chasm below. To increase this supply of the horny material, let the coronet be anointed with a solution of tar and tallow and hog's lard daily, which should be extended to the horny part of the hoof.

Stopping has been mentioned as necessary to be adopted on the first or mildest attack, being very conducive to recovery of the lost function of secreting the proper horny material. This, of course, will be attended to in every other stage of the disorder, whereby moisture is applied to the dry brittle hoof, and conveyed to its most sensible part internally. On the uses and advantages of this simple remedy I took occasion to say a few words when speaking of frush at page 50, and recommended the application of a web-shoe grooved, as an excellent auxiliary to the cure; by keeping 
on such dressings as might be found necessary; and by allowing of speedy removal, it will also save much time and labour to that description of persons who are seldom inclined to bestow too much of either. A number of other contrivances may-be adopted to apply the same remedy-for affording cool moisture to the hioof, the readiest of which is the leading him forth to a shaded place, and there tethering him up, where he might stand upon the natural sod, grass, clay, or soft ground, without a chance of running about to make the case worse, as would inevitably happen. In default of this convenience, a good substitute is the sponge boot, with bran poultice to cover the whole surface of the foot from toe to heel. In all cases remember to keep out the sand, gravel, or dirt, which is ever likely to insinuate itself and protract the cure, and, if not otherwise come-atable, an opening must be made for that purpose by cutting down one side of the crack, as before recommended. Proud flesh will be found at this part of the opening, which must be dressed with a solution of blue vitriol.

If the crack be near the heel, merely thinning the horn and taking off that part which bears upon the shoe, will assist the cure; and whatever shoe may be put on, care should be taken to prevent the crack from bearing on it: the bar shoe for heavy horses is esteemed indispensable, and some farriers apply it invariably. Others again fire the foot, from the upper half of the hoof, 
above the crack, to the fetlock joint. This is certainly decisive practice, as the hoof is renewed with new horny matter, being so supplied as to thrust off the old one; but all violent remedies should be avoided until the milder ones have been tried and failed, which will not be the case with those means I have recommended above.

The bearing of our English shoe being commonly on the outer surface of the hoof, promotes the cracking and chipping off of the wall. Mr. Teast's shoe (see page 498) is admirably calculated to prevent this disorder, but is nowise calculated to cure it, when once the ruin has fairly commenced.

\section{THE CORN.}

Causes.-An entire series of disorders, as canker, sand-crack, corn, and founder, may be referred to the same original causes; namely, a heated or inflammatory state of the blood, which accident may concur to bring forward in one or other; form, according to circumstances. I shall not repeat what is already said on the two first-mentioned appearances a few pages higher up, but merely add, that distortion and undue pressure on the sensible sole occasions that irritation which brings on inflammation of its edge, where the shuttle-bone, or heel-bone, presses down upon it at every step, and causes the utmost bending 
that the minute elasticity of the hoof allows of; but contraction of the heel, which accompanies hot, brittle, and inelastic hoof, prevents its bending duly and truly, and lateral pressure upon the quarters follows. The sole being thus unduly pent up, the circulation is obstructed in its passage to and from the cavity of the coffin-bone, and a deposite of blood, which soon becomes'offensive matter, is the consequence. Bad shoeing, whereby the heels are pinched, also when the ragged hoof is left, which may have contained particles of sand, will cause irritation, and end in corn, or figg.

Symptoms. - The mischief thus commenced within shows itself between the bar and the crust, or wall of the hoof, in a foxy or dirty-red tumour, with greatly increased heat. Lameness, in a degree proportioned to the badness of the corn, is usually the first symptom that directs our attention to the sole. Figg is but another name for the same kind of corn when situated close to the bar of the frog, a little farther back in the hollow of the sole. Pain, very acute on the touch; or, when the horse treads on a hard substance, he issues a moan, or grunt: it is that sound in which his voice is aptly likened to the complaint of the human sufferer.

Cure.-Although oftentimes very troublesome, returning again and again when the farrier apprehends he has cured it radically, yet no affection is easier of a partial remedy, or effected by more ordinary means. Deceived by the name, perhaps, 
resembling the hard excrescence called a corn, on the human foot, they proceed at once to "pare the corn out to the quick, till the blood starts;" but they heedlessly put on the same shoe upon the same thick heel and hard hoof which first brought about the malady, and the lameness returns. Let the heel of the shoe be cut off on the side that is afflicted, or if both sides have corns, a bar shoe is recommended as giving pressure to the frog. The heels are then to be rasped away free from any contact with the shoe; if they are thick and hard, this will give them play-if thin and tender, they will thus be freed from pressure. The thick heel is most commonly affected, and should be softened by an extensive poultice that is to cover the whole foot, after the corn has been pared and treated with butter of antimony. Tar is then a very desirable application, or Friar's balsam; and if inflammation is again discovered, poultice the foot once more. Fire is applied by some, but the hoof is permanently injured by the actual cautery; and whatever good is achieved is thus counterbalanced by the evil. Vitriolic acid mixed, carefully, with tar, in the proportion of one-tenth of the former to nine-tenths of the latter, will promote the absorption upon which the cure depends.

But in some desperate bad cases, the matter has already formed within, most offensively, and discharges at the coronet by means of that curious process of nature which I described at a preceding 
page, as affording the coronet the material for: forming new horn to supply the wear and tear of the hoof. Upon paring away the horny sole, which now becomes necessary, the offensive mat-' ter will be found to have spread itself underneath the sensible sole, which will ooze forth and give immediate relief to the coronet. Let so much of the horny sole as lies loose from the sensible sole be pared away, and a dressing of tar, or of Friar's balsam, be applied as before directed; and if in. flammation is again discovered, apply. a bread poultice; should the growth of horn be found too luxuriant, discontinue the tar.

\section{CHAP'TER V.}

\section{of Strains generally.}

STRAIN OF THE COFFIN-JOINT.

Cause.-As previously observed, lameness of the foot does not consist in a strain of the joint within the hoof, but is referrable to general concussion of all the parts, and is rather a strain of the back sinew at its conjunction with the bottom of the coffin-bone. Inflammation and accelerated circulation follow, and numbness of the foot succeeds: these, if not remedied betimes, are followed by ossification of the tendon, of the ligament of the small pastern, and the carti- 
laginous process at $(f)$, fig. 3 , plate 2 , also becomes bone. That the joint of the coffin-bone with the pastern-bone may be strained, is very probable; but no injury, blow, or concussion, can affect it, which does not at the same time affect all the component parts of the foot. Thin hoof and sole are most liable to this injury.

Symptoms.-Sudden lameness, that is always increasing, and has scarcely an intermission, with. out any appearance to account for it on the limb; and the persons who permit the horse to incur this disorder by their carelessness seldom have the candour to acknowledge that they know the cause to be a tread, a rolling stone, or a stumble, and the doctor is left to "find it out." Almost every one imagines the lameness to reside higher up, as in the shoulder or the hip joint. Great heat and tenderness of the part soon come on; the latter symptom may be ascertained by striking the hoof in front with a key or small stone, when the animal will flinch considerably more than when the corresponding foot is struck in the same manner. When the horse would stand at ease, he usually does so with his toe pointing forwards, эo as to keep the pastern in a straight line with the leg, and thereby take off the tension or pressure upon the back sinew and ligaments: the inflammation shortly after reaches the upper part of the sinew, as may be ascertained by passing the hand down over it when the patient flinches.

Cure.-Blistering at the coronet and fetlock 
repeatedly will reduce the inflammation within. A poultice covering the whole foot also tends to the same effect, which will be further assisted by paring the sole, if it be not already too thin: reduce the frog also, and do the same for the corresponding foot.

Formerly they pared the toe tolerably close, and bled it there, by making a longitudinal incision: the usual application of tar, \&c. then completed the cure. But this is an operation that is seldom performed with sufficient exactness, the incision being too often made unwisely deep, so that other diseases were thus generated at some future day. Others, again, passed a seton through the heel to the hollow of the frog, taking care not to touch the sensible sole. A third set apply the actual cautery, which comes least recommended of either of the remedies just described; especially when we consider that the actual disease is very often mistaken for some other; a remark that implies how much caution should be used in first ascertaining the exact seat of the lameness, its cause and symptoms, ere we set about the cure by such violent means.

\section{STRAIN OF THE SHOULDER.}

Horses that are weak before, and low footed, with an unsteady tread, are most liable to contract this disorder, which consists in a twist or 
sprain of the strong muscles that attach the shoulder to the body. There being no socket for the shoulder-blade to rest in, as is the case with most other animals, I think the horse is very liable to incur this disaster, in a petty degree, whenever his progression is accelerated to the utmost of his powers; but we must guard ourselves against placing entire reliance upon the hastily-delivered opinions of empyrics, who boldly pronounce when they hope to deceive, and expect belief from the credulous.

Cause.-Much the same as those which occasion concussion, blows, and numbness of the foot, with their consequences, which we consent to call "strain of the coffin-joint," without the most distant possibility of knowing whether this misfortune ever has happened. When the horse is subjected to any rude accident, as a kick, or his load becoming disordered, or being thrown down, or slipping on pavement, ice, \&c., or treading on a loose stone, he is very likely to incur strain of the muscles of the shoulder. See conformation of the shoulder, in chapter 1, p. 26.

Symptoms. - Decided by swelling upon the chest, or at the top of the shoulder; but we think it desirable to ascertain whether the accident has taken place before this symptom becomes apparent. Lameness immediately succeeding any or either of those accidents, which may be distinguished from a strain lower down by the animal's drawing his toe along the ground, from inability 
in the part to lift it off the ground; but when he throws out the foot in a semicircle, described by the segment at page 29, this shows that the hurt is chiefly confined to the lower part of the shoulder near the elbow. Taking up the foot and bending the limb will further prove the existence of strain in the shoulder, if the animal evince pain; whereas, if it lie in the foot, and not in the shoulder, the lame leg can be moved as supple as the sound one. The difficulty of ascertaining the real seat of lameness is sometimes so very. great, being entirely invisible, that the groom seldom hesitates to assert his belief that the horse may be gammoning, or "shamming Abraham:" this uncertainty has put us upon all sorts of expedients to find out the real seat of the disorder. For this purpose, hold up his head high, and after comparing and finding no difference in the shape of his two shoulders, let go the head, when he will be observed to flinch upon bringing it towards the affected side. Let a person rattle some corn in a sieve at a distance behind, now on this side, now on that, and he will be observed to evince pain at turning the neck so as to strain the affected side; not so if the pain be in the foot, of course. As the horse will step short, and also throw out his leg somewhat in a semicircle, when he has received a prick in shoeing, this latter sign is not to be taken as finally indicative of "strain in the shoulder," until the foot has been examined, and the shoeingsmith questioned as to his skill and carefulness. 
Cure. - If the injury be considerable, as when the horse has been thrown down, he should be bled at once, in the plate vein when it is local, but in the neck when the injury has been more general. A laxative ball, or a purgative, must follow, as a matter of course, proportioned to the actual state of his body at the time. A fomentation of camomile flowers, or of scalded bran, should be applied largely and assiduously at the chest and inside the elbow, and these remedies, with rest from all labour and exercise, generally perfect the cure.

When the swelling is great, but not extensive, as in the case of a kick, spirits of wine, in which a fourth of its weight of camphor has been dissolved, should be rubbed in. This will supersede the necessity of walking the horse too early, with the hope of recovering the "use of his limb," by promoting the lymphatic absorption. A rowel is sometimes employed, when the heat and swelling are very high, with good effect; but the old system of previously boring and blowing, and laying on "a charge," is exploded as barbarous and inutile. On the symptoms abating, let the convalescent horse have a loose stall, and in proportion as his action may be free from lameness, so should be regulated his return to walking, to exercise, and to work. Before he can be fit for his former occupation, it generally is found best to give the horse a run at grass; but previously he may try. his powers in a contracted plot of ground in the 
homestead, to prevent his indulging too freely in exercise, seeing that he is very liable to a relapse, which is generally more difficult to overcome than the original attack.

Sroimming the horse "for strain in the shoulder joint," was a favourite remedy formerly, but is deservedly exploded, although we could be certain that the joint intended to be cured were the elbore. This accident, however, does not happen often: I never saw a marked case, and merely deem it possible; yet has the practice still its advocates. And it may be serviceable in other respects, as the muscles are thus brought into play, and the whole limb employed in quite different kind of action to that of walking on terra firma. Some persons submit their horses to bathing, by entire submersion; an operation that was performed most adroitly, about thirty-five years ago, by a stableman named Denis Laweler, in the bay of Dublin. His manner was to ride his horse to a convenient depth of water, and then jumping forward suddenly on the animal's head, thus souse it headforemost to the bottom. The feat caused great marvel at the time; but not so the total disappearance, upon one occasion, of the performer: poor Denis is supposed to have received a kick to the bottom, and his body drifted out to sea, as his Howth friends heard no more of him after that, though "New harbour" underwent thorough repair since Lawler's last kick. 
STRAIN OF THE WHIRL-BONE (HIPJOINT).

A supposititious disorder, that is more frequently found to be a tardy attack of bone spavin, that is slow in coming forward, and upon which M. la Fosse has thought proper to be very facetious: "a horse has the spavin, or he has it not," says he; "it is not like a jack-in-a-box, that waits to make his appearance when you pull the string." Either spavin or strain of the whirlbone, he concludes, must be the disorder of the hind leg, when the animal draws its toe along the road, as described just above as being a symptom of strain in the fore leg. When the animal has received injury in the region of the hip, the camphorated spirits recommended in a preceding page (521), should be applied; but if the heat, swelling, and tension do not abate by this treatment; blister the parts with the mild blister No. 3, at page 468. This application, with rest, is adequate to any ordinary case of hip-joint accident.

\section{STRAIN OF THE STIFLE.}

Simple "lameness" would better designate this so-called strain: The same remedies as those prescribed for whirl-bone strain will apply to this part; also fomentations, physic, and if the case be 
inveterate, a rowel, \&c. \&c. one after another: Camphorated spirits, or ultimately a mild blister, are useful and proper, according to the circumstances just set down.

\section{STRING-HALT'}

A catching up of the hind leg at every step the horse takes, constitutes what is termed stringhalt. It is one of the incurables; but this consideration shall not deter me from observing, that this over-action of the hind leg may be brought about by art, or rather the ingenuity of man operating upon a known function of nature.

The cause, naturally arising, is very obscure; but the horse-exhibitioners, having occasion for much show at their amphitheatric courses, sought to bring on this "high show" by puncturation. To them let the secret belong; it is barbarous and unseemly.

\section{STRAIN OF THE BACK.}

When the immediate covering of the bones, described in Book $I$. at page 51 , become relaxed, and thereby fail to hold the joints together sufficiently firm, the consequence naturally arising from this circumstance is, that they bend a little out of place, at every movement the animal makes, 
and the least accident confirms the strain, or sprain. Merely straining or stretching will effect this evil at times, though that be no greater than an effort to relieve nature by a motion. The very great number of joints in the back-bone, added to its horizontal position, render it more liable to sprain, perhaps, than any other joint connecting longer bones; and this is the reason, I think, that the short-bone joints of the foot are so liable to give way at apparently trivial concussions.

Cause-Mostly affecting draught cattle of the heavy kind, and principally incident to cities and towns, where dray and cart-horses are obliged to turn short upon slippery stones, we may ascribe this disorder to what is called a verench, or twist in the human practice. The steady pull, unattended by a turn, is not likely to occasion hurt of the back, be it never so hollow originally; because the effort that is made to pull a great weight causes the joints to press strait against each other, every capsule being then filled with its next corresponding convex bone.

Symptoms.-A kind of separate motion for the hind quarter, compared to the fore one, of which the exact perceptible division is the seat of the injury. Sometimes it appears as far back as the 29th spine, but when farther forward than the 15th, (at G. 24) on the frontispiece, it affects the respiration, and with it other vital functions, and the animal suffers in his gencral health. It nay be muscular or ligamentary, or compounded 
of both, in which cases the parts adapt themselves to the derangement that has taken place, by thickening their substance, and the first lameness decreases greatly: in this event the horse's condition is not at all affected. While staling, his efforts are somewhat ludicrous; as are also all attempts to make a trot of it when out of harness. These symptoms have deceived some persons into the belief, that the one or the other exertion has caused the strain; whereas it is only the earliest demonstration of it to the observer.

Remedies applied early may assist nature, but the lameness never can be cured completely. If the wrench or sprain has been of a violent sort, as in case of "strain in the shoulder," let the animal be bled to a good extent, i. e. from three to five quarts, according to the quantity or degree of violence the animal has sustained; for it usually happens that it has been strained all over, in various parts. Two dray-horses, which were employed in pulling beer butts from the cellar of a public-house at the corner of Homer Street, being backed too close to the steps, fell in, the weight of the hinder horse dragging in the fore one upon him. Much contusion was the consequence, as well of the accident itself as in dragging them out: they were in fact strained all over, so that they could scarcely stand for a while. Bleeding copiously, however, to the amount of six quarts, reduced the tendency to inflammation; and although they might be pronounced hurt all over, 
and the hind horse in particular, both did well after physicking, and a few days of light work.

I have found a fomentation of hot vinegar of very great service, in a well marked case of recent strain; the plan recommended by White, of administering it by means of a woollen cloth or rug, steeped and loosely wrung out, being followed. A fresh sheep-skin, just flayed, was applied immediately, and the lameness sensibly lessened, after. two days, applying the fomentation four or five times.

\section{FOUNDER}

Is a disorder, or rather a complication of disorders, of the fore feet. Some controversy has crept into our books of farriery latterly, as to what really is founder: and whilst some would confine their consideration of the subject to the foot only, others follow the fashion of grooms, and ascribe the incurable lameness that has no visible specific cause, to an affection of the chest. Hence "chest founder" of the stables, and the "body founder" of White. "Shoulder-shcok" is a provincialism of the smithy, when the farrier can perceive "nothing amiss" with the feet-so far as he can see, feel, or understand. Surbating was another name given to the symptom we now recognise as founder, at a time when it was the practice to divide and subdivide every disorder under many, useless, and unmeaning appellations. 
Cause.-Hard work, bad shoeing, age and ill'usage, either of which produce so many other disorders pertaining to the horse in his domesticated state, precede founder; for, we never meet with it unless the animal has been so treated or kept, and I look upon it rather as a complication or effect of several diseases of the foot. Some of these, we have seen, are liable to be mistaken for others; therefore do they get maltreated, imperfectly cured, or retain the seeds of future disease; and founder is the name given to that which is otherwise inscrutable, has no other origin, and is badly defined by all writers and talkers upon the subject. Out of this dilemma I do not at present attempt to rescue it: I care not for terms, unless insomuch as they can assist us to unravel the character of a disorder. Contracted heel is the slow cause of most cases of founder, whereby the quarters press on the coffin and shuttle bone, and thus prevent the action of the latter, which is very great at every step, and is mainly conducive to the proper secretion of the horny material before spoken of pretty much at large. To "a chill" is generally attributed the immediate cause of founder; and indeed the poor animal which has suffered severely at the hands (or spurs) of his master is most open to acquire any ill which chill or cold may inflict. When this chill takes place, the attack is sudden and usually violent.

Inflammation always attends the first symptom of founder, if it be not an immediate cause thereof, 
arising, I have no doubt, from the waste or destruction of the secretion marked $(c)(c)$ in the . cut at page 431. To this conclusion I am come the more positively, by reason of the absence of those secretory vessels in the feet of old, foundered or otherwise diseased horses; which secretions were designed to furnish the material for forming new horn and giving elasticity to the tread. Fig. 3 , plate 3 , at $(g)$ shows the progress of incipient founder, where those vessels are represented as nearly dried up, and adhesion has begun of the inner surface of the hoof and the coffin-bone. What must follow, but brittle hoof, battered feet, or surbating, want of elasticity in the sensible frog and tendon, accompanied by inflammation, which is a cause, if not caused by founder?

But young horses sometimes, while breaking in, by the violence that is deemed necessary, are, foundered by the rough-rider, through the rupture or forcing asunder of the connexion between, the hoof and coffin-bone, just spoken of. In such cases, the animal being vigorous and the foot replete with juices, the coronet is greatly affected by oozing out there, in its blood and lymph state. If youth and general good health should bring the animal through his sufferings, its feet will ever after bear external marks of the internal injury.

Symptoms. - Curved, wrinkled, or striated hoofs, ever attend those animals which have been so over strained in youth, appearing as if the horn had been carved or indented; which arises from 
the coronet furnishing the horny material too luxuriantly, before it has received sufficient concoction within the coffin-bone, as before described, at p. 43\% Lameness in one or both fore-feet, with evident pain, and great heat in the whole foot, attend founder in every case. At the first attack of acute or violent founder, the horse is observed very restless in his fore feet, which he endearours to ease, by alternately changing position, and lying down when he should be feeding. He brings his hind legs far under his belly for the same purpose, and if he is roused by hunger or mandate he lies down again. Considerable alteration takes place in the pulse, which indicates fever, and the patient breathes short with pain. The progress of those symptoms is very rapid, seldom occupying more than a day or two.

The slower or chronic founder begins with apparently rheumatic pains and awkwardness of going, for which he usually receives the whip. After a while, flattening sometimes appears on the front of the hoof, and the heels contract: the older animals have now short, brittle, shining hoofs, with the small pastern bone deeper sunk than heretofore; the hollow of the sole is converted into the convex, or pumice foot, so that the animal can scarce find foot-hold on the ground, but will slip and slide about. He is then considered groggy, or grawgy, that is to say, " like a drunkard," and may last many years: this is 
chest founder, and indeed the whole limb is usually affected up to the very chest.

Whether the attack be of the acute or the chronic kind, it dies if not relieved; for the coffin-bone becomes rotten, and the hoof is cast off without the possibility of ever being renovated. In some constitutions, nature lends its aid in critically raising a tumor at the coronet, the breaking whereof and the discharge of offensive matter effects a cure. The same sort of critical tumor as denoting the crisis of general fever, or inflammation, was noticed at page 301, "Critical Abscess." to Remedy.-As soon as discovered take off the shoe, note well the condition of the sole, the heat, and other symptoms, for according as these vary, so must the remedies be changed. Draw the soles a little with the buttress if found too thick, not otherwise; rasp the heels and quarters, which will ease the pain occasioned by the binding of the hoof, and give room for the action of the foot; a fact that may be ascertained by bending it at the pastern, forwards and backwards, before the operation, and trying the same experiment afterwards. Apply a bran poultice warm to the whole foot daily, but do not add to it any greasy or oily substances, as is too often practised. The sponge boot may be employed with advantage, made large. After three or four days, that the horn has recovered its former consistency, put on the shoe gently, and walk the patient, to try in how much he is now lame; and if the attack has been a slight one, he may recover with very little 
more treatment than a turn out in a meadow will afford? Otherwise the feet must be stopped, and kept moist and cool, as directéd in case un of Canker, at page 506. adt al and corly anolutan ${ }_{2}$ In all cases, (except where the foot is ${ }^{\dagger}$ pul miced, or the sole is very thin), the jointed shoe of B. Clark, or of H. Goldfinch (page 484), will be found serviceable, as being well calculated for giving play or action to the parts of the foot which produce the secretion that is so salutary to? the renovation of new hoof; but which the disorderf we call "binding of the hoof" has sadly pert verted irito an offensive and harmful matteriry nos

The proper secretion of the juicy elastic substance, for the formation of new hoof, being? essential to the restoration of the horse, and as the lameness will not wholly subside unless this" process goes on healthily, resort must be had to blistering, provided he still goes lame any. This should extend from the coronet and quarters to the knee, and be repeated, taking care to keep the heels open and the sole stopped. The good? effects to the sole that will be found to result from blistering shows the connexion or com panionship that exists between the legs and feet, as I took occasion to observe at a former page.

But, as to drawirg the scle, as before recorin? mended generally, there is one exception: if the 4 lameness and other symptoms come on after and inflammatory fever of the whole system, then wey ought to look ripon it as an effect of the fever seeking to throw off its dregs thus critically; and 
a swelling and discharge at the coronet may be expected soon to take place that should be tencouraged, and treated as simple abscess, not fistulous. When this is the case, the bar-shoe is better adapted to keep the parts in position, that the discharge may proceed temperately.

In default of sending the sick horse to at meadow, he may be allowed to stand on a claymade floor in an outhouse by day, or any slip of soft ground; but by no means adopt the plan of putting the patient upon litter that is damp, and therefore half rotten and heating. A number of contrivances for affording coolness and natural pressure to the sole and frog, besides the foregoing, have been resorted to, and among these the admixture of vinegar, alegar, verjuice, or solution of nitre with the clay, with the stopping, \&c. are well calculated to answer the purposes intended. Rubbing the knees with turpentine is also serviceable.

Physic would not of course be neglected at the earliest stage of lameness, adapted to the previous state of the patient's bodily health, and calculated to lower the access of inflammation, which so much pain must naturally produce. Either of the three evacuations being suppressed, or imperfectly performed, must ke restored, and a purgative, an urine-ball, or a diaphoretic powder be administered as occasion requires, and opportunity presents itself: of course, neither of those would be given while the animal is out of doors. 


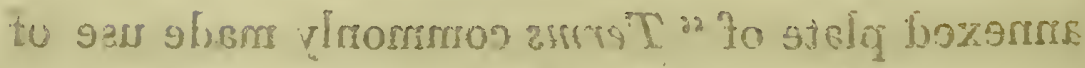

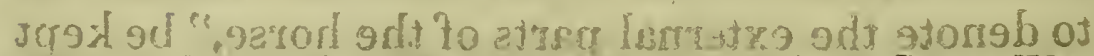
PRECAUTIONS NECESSARY TO BE OBSERYED ON BUYING A HORSE.

Much as hath been said of the make, sliape, and proportion of the various breeds of horses in Book I., some few precautionary hints, still more familiar, seem desirable in this place. Of the several points of inquiry to which purchasers apply themselves, the age of the animal is ever considered the most deserving of attention; the state of its legs, bodily health, and eye-sight, coming next in order, if general appearance does not precede every other. On each of those heads I offer a few words of advice, most of which are tolerably well recognized, though seldom in print, as most of those who deal in horse-flesh acquire their knowledge from experience rather than books. Before all things, the new horse-dealer should guard against imposition, and not "look at a horse" where he has got to withstand two or three masked advisers. To be sure, no one desirous of a nag would submit to the imposition of a cart-horse instead; but, next to this kind of gross attempt, the thorough-paced dealers practise deceit of every species, and throw obstacles in the way of cool examination, especially when we come to investigate the seat of any actual defect.

General appearance : an idea of a good horse.And first, that we may make no blunders, and the younger portion of readers be thinking of one part of him, whilst I am talking of another, let the 
annexed plate of "Terms commonly made use of to denote the external parts of the horse," be kept constantly in sight, so that there be no mistake of that sort.

Previous to stating our own old English notion, it may not be useless to quote the instructions with which the purchasers of cavalry for the French military seivice travelled (as I believe) over that country. Its coincidence with our own opinions and practices is at least curious, though on such a topic no Englishman whatever requires instructions from a foreigner, if his own assertions are to be taken for genuine. "The person sent to purchase horses should not only keep in mind the colour, height, and price of horses for which he is to treat, but also the usual defects of the country, that he may guard against them : these are, faulty sight, flat hoof, too brittle, or too soft, and affections of the lungs. Though he knows already where horse-fairs are held, he should prefer travelling round the adjacent country, a short time previously thereto; as he may be sure that all the good horses are sold before it begins. The age should be between four and five years, and as little above as possible.

"Those things being well thought on, the purchaser will look at the horse sideways at a tolerable distance: he will choose him as nearly as possible one tenth longer than he is high, measuring from the breast to the quarter, and from the withers to the ground, so that if the horse be five 
536 TRENCH MODE OF EAMINING HORSE, AYA

feet high, his length should be fre feet and a

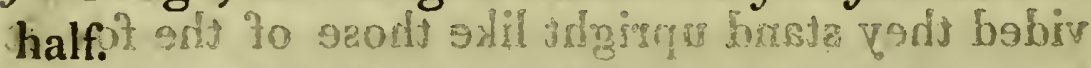
eil " Preserving the same situation, he will see I st; If the horse has a small head, not too fleshy, perfectly free from tumours, and well placed, neither carrying it too low nor too high ; 2nd, If heliasnot an ill-shaped neck, with his windpipe hanging too low, or bending; 3rd, Whether his zoithers be either too sharp or too large, with fleshy shoul ders; 4th, Whether he is not hollow backed ; $5 \mathrm{th}$, Whether his chest be well formed, neither too round nor too flat; 6 th, Whether he be lowbellied, with a small sheath; rth, Whether herber touched in the wind; $8 \mathrm{th}$, If his forelegs are not too slender, or his hock do not bend forwards too much ; 9 th, If the tendons or back sinews be not ailing, i. e. either sore to the touch, or else stiffjointed; 10th, Whether the animal be not either: long-jointed, or short-jointed; 11th, Whether he be strained in the pastern joint, going low ; 12th, Whetherflat-hoofed, withlow heels ; 13th, Whether he be not narrow at the hind quarters; $14 \mathrm{th}$, Whether he has not spavin, windgall, or curb, ring bone, or thorough-pin, or is likely to cut. Examine his sole and heel for thrush, canker, or corn, and if contraction has taken place."

Having thus before us the Frenchman's precautions, we come to the Englishman's long-accepted description of a good horse, and nothing else. His head ought to be lean, of good size, and long; his jowls thin and open; his ears small 
and pricked; or, if they be somewhat long, provided they stand upright like those of the fox, it is usually a sign of mettle and toughness. 9 His forehead dong and broad: not marefaced, but rising in the middle like that of a hare, the feather being placed above the top of his eye, the contrary being thought by some to betoken approaching blindness. His eye full, large, and bright; his nostrils wide, and red within; for an open nostril betokens good wind. His mouth large, deep in the wykes, and hairy. His wind pipe big, unconfined, and straight when he is reingd in by the bridle, for, if it bends like a bow (or cock-throttled), it very much hinders the passage of his wind. His head must be so set upon his neck, that there should be a space felt between the neck and the jozol; for, to be fullnecked is uncomely to sight and prejudicial to the horse's wind. His crest should be firm, thin, and well-risen; his neck long and straight, yet not loose and pliant, which our north countrymen term withy cragged; his breast strong and broad; his chest deep at the girth, his body of good size and close ribbed up to the stifle; his ribs round like unto a barrel, his fillets large, his quarters rather oval than broad, reaching well down to the gaskins. His hock bone upright, not bending; which some do term sickle-houghed, and think it denotes fastness and a laster. His legs should be clean, flat and straight; his joints short, well knit, and upright, especially at the pastern and A $\Lambda 5$ 
hoofs, with but little hair at his fetlock; his hoofs black strong, and hollow, and rather long and narrow than big and flat. His mane and tail should be long and thin rather than very thick, which some think a mark of dullness.

Some do affect a small head at all hazards, thinking none other belongs to a good horse, but much will depend upon how it is set on; if that be upon a crane-neck, as usually happens when very small, he will carry unsteady, with tail up as a counterbalance; and if large head arise from thickness of the jowol, this will also be a real deformity and interfere with his safe going: hard mouthed usually accompanies the great big head at the jowl. Expanded forehead is quite a different thing, and belongs to neither of those objections, but on the contrary is a redeeming sign of good breeding for any kind of faulty head, or long or short, or thick or thin. The crest being slightly curved is always accompanied by distinctly marked roindpipe. No horse with a bad shoulder can carry his rider with ease and pleasure on the road, though a large one be requisite for harness, or a very oblique one belong to a speedy horse; because it is the hind legs that send the animal along, as was eminently the case with Eclipse. See pages 13, 25, 26, of Book I., where many other points to our present purpose are discussed.

As to bodily health, also, the reader will not have far to look to enable himself to judge how 
TEETH DHNOTE AGE. HEAVY CATTLE, ETC. 539

any animal is affected which he may desire to purchase. The whole volume now in his hands is devoted to a perspicacious description of the functions of animal life, and of their derangement.

\section{AGE.}

General appearance bespeaks the age of every animal, to those who have much practice in ascertaining that point, and whose interest may be said to sharpen their judgment: in the horse we are enabled to make a fair estimate of his years from the birth, to nearly twenty, by means of its teeth, but then we should guard ourselves against a number of deceptious tricks that are practised on the unwary.

A certain juvenility of countenance and springiness of action, legs long compared to the carcass, or filling up, large at the knees and other joints, wide jowl, rough coat, and intractability, denote the foal and colt in succession; all which indications vanish gradually as it advances towards maturity, and becomes full mouthed. Heary cattle assume premature age and sometimes deceive us upon the first view; nor do such decay when aged so fast as the more spirited, fretful, and lighter breeds; and as no one would purchase a horse for use before it be fit for his purpose, nor take to one that is worn out, the vendor hesitates not to stretch a year or so, one way or the other, as may best suit his own interest and his customers' wants. To aid their nefarious designs, they are said to file the marks of age in colts' teeth, and to 
bishop the aged, for confirmation of their false hoods. But we never rely wholly upon those marks, but turn our attention to the curve of the tushes in the horse's mouth, and the sloping forward of the corner teeth in both sexes, lo detect the imposture.

When we open the mouth of a full grown, or four year old horse, we perceive twelve nipper teeth in front and twenty-four grinders behind: between the two sets, above and below, a space is seen on the gum, designed by nature to receive the bit, and termed the bars of the upper or lower jaw, as the case may be. About an incli behind the last of the front teeth, the male has tushes at this age, which seldom occur with mares. The tushes coming up in the lower jaw sometimes occasions soreness at the bars, when these are to be lanced and the tushes appear: this the dealers. effect prematurely at times; and having also drawn out the two front sucking teeth, this causes the "horse teeth" to come up soon; so that the animal mày appear four years old before its time. is Pursuing the same species of deception, they proceed to draw the remaining sucking tecth, that the animal may assume the appearance of a five yeur old. Jockies have then a pass word for this operation, which they term " all up!"

In examining the mouth to ascertain the age, we leave entirely out of consideration the grinding teeth, and chiefly rely upon the under jaw; though when deception may be suspected, the buyer should refer to the upper teeth also, as these 
follow the same course of nature the lower, butdo not decayl so fast in old age. all A tofteen days old the fore teeth two above and two below), appear above the gums, the outside shell first, having muscular substance in the middle of the two shells, which fills gradually up, till about the end of the first year, when the surface becomes smooth, and a small ring is observable towards the root of each.

Meantime, when the foal is a month old, the next two teeth (one on each side) above and below, appear in like manner; and at thirteen months the fleshy cavities of these fill up, and a ring is observable as in the former.

silt four months old the corner tecth come up, and the filling up is similarly effected at sixteen or seventeen montlis old. After this period the whole six teeth wear eren, and so cointinue smooth and unmarked until two years and a half, the corner teeth being still the least perfect, the front ones largest.

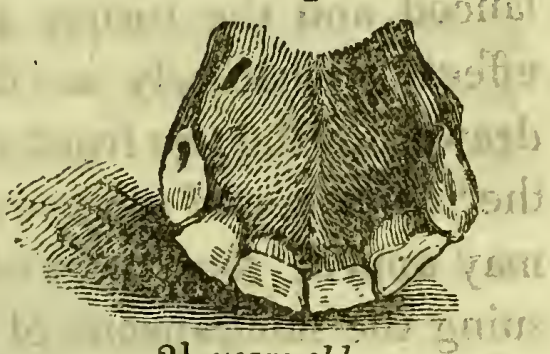

$2 \frac{1}{2}$ years old.

During this state of the mouth, if the unprincipled dealer would give his animal's teeth the mark of three or four years old, he is said to "file" two or four front teeth hollow in the middle; though in fact it is burnt in with an acid that is capable of destroying the hardest substances. But this falsification may be detected, 1st, by comparing the upper with the lower jaw 
which they omit so fole;" 2 nd, by noticing. whether the marked teeth have the ring before? described, as pertaining to the sucking teeth, biit does not belong to the horse teeth-lastly, these latter are larger, of a brownish yellow tinge, and soon acquire tartar, very unlike the fine whiteness of the sucking teeth.

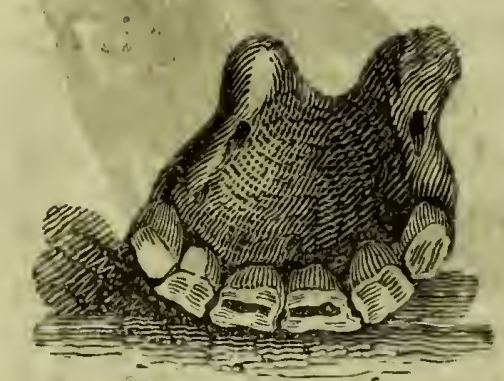

Rising 3 years.

On rising three years old, the two fore teeth (below, and two above) fall out, and are replaced by two horse teeth, hav: ing the hollow mark in the middle, as shown in the annexed cut. As just said, they are also larger and of a darker colour than the sucking teeth. But between the third and fourth years, two further colt's teeth (as well above as below) shed, and are replaced by "horse teeth," $i$. $e$. larger and browner than the sucking teeth, with the black

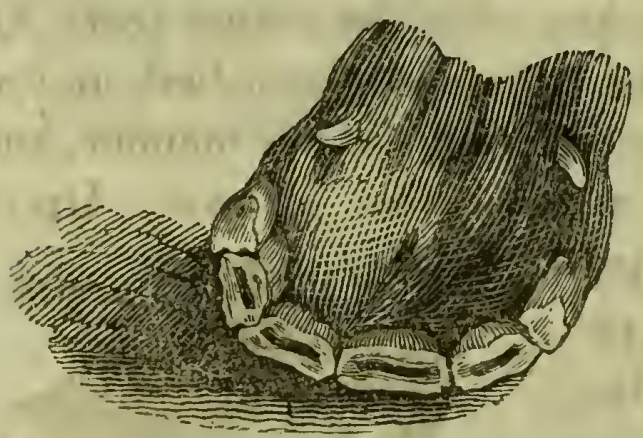

4 years old. mark; the tushes also push forth, and the horse is now full mouthed, as represented by the cut in the margin.

Only the corners now remain unchanged from colts' to horses' teeth. These differ from the others in being shorter, smaller, and of a shelllike appearance, until the middle of the fifth 
year, when these also are displaced by horsetecth, in shape much like the former, and their marks but just perceptible within the upper surface. But, toward the completion of five yecirs of age, they become larger, are more strongly marked, and are grooved on the inside, which groove denotes the age to be five with precision; no deception can be practised on this point, nor as regards the tushes, which are now curved,

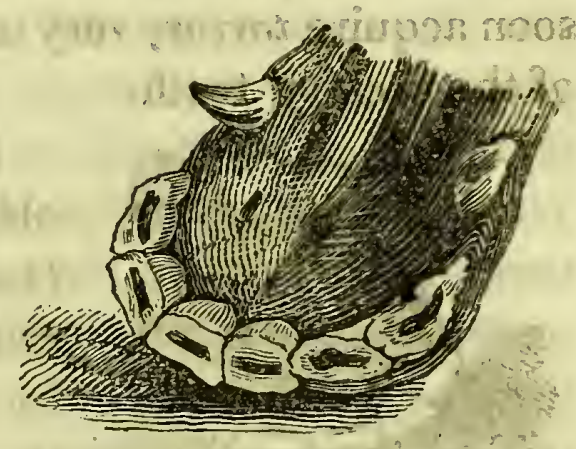

5 years. having grooves inside, that may be felt with the finger, and seen as represented in the figure annexed. At this age the two front teeth give proof of being worn, principally on the outer edge; the wearing away goes on, and at six years the surface is level, or as they say " the mark is gone," whilst the next two teeth also begin to wear. Now, also, the grooves just spoken of in the corner teeth fill up; the curve in the tushes is diminished, and at seven years their grooves fill up in like manner, and become convex in another year or two. Up to this age only the two corner teeth retain the mark, and that but slightly; when the horse acquires the term "aged," and these two likewise soon after become smooth.

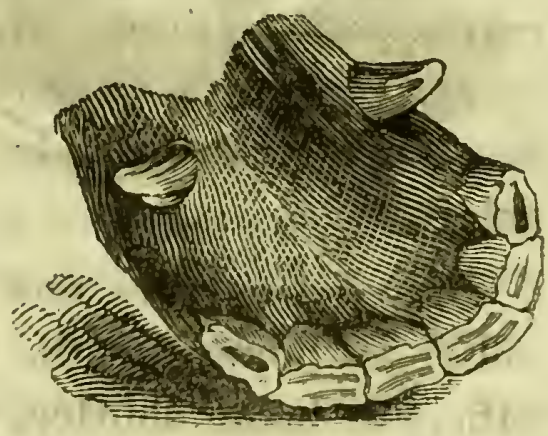

7 years. 
544 UPPEN JAW, " FILLINE UR" SLOW.

- This is the state of the loxler jare at seven years old; but the teeth of the upper jaw do not fill aup / so) fast by two years; so that a tolerably shrewd guess at the age of a horse may be formed untilits is twelve. The marks in the two front teethoft the upper jaw are not obliterated until eight? years old, and the next two become smooth only at the tenth year of its age; being each two years later than happens to the correspondingd teeth of the lower jaw; whilst the two cerney teeth above do not lose their marks until the twelfth year.

"The tushes of old horses, then, have neithev? curve noi groove; they wear away at the points as is if they had been broken off and polished again the corner teeth appear long and leaning fois ward; the upper teeth project over the lowerys and all lose their oblong shape, whilst the gum is recedes and leaves their roots bare, so that the teeth seem as if grown longer. When the teeth do not so meet evenly, certain dealers file awaygr the projecting teeth; for this denotation of old age, which may be attributed to $a_{2}$ strong mouth in sometimes happens prematurely without any other is corresponding sign. In two or three other ress spects we notice similar deviations from the gerne neral rule, that none know how to account for; unless it be that such animals were got byloldiv parents, when the hollowness over the cyes will be found to disfigure young colts of the most tender age. Some, again, lose the mark in all their teeth except the corners, as early as five years old; 
others thave hard moutlis and the bärs almost callous; ibut all these have the hollow justspoken of. This defect dealers endeavour to rectify by punces turing the skin and blowing it up. On the other hand, some horses are so strong in the mouth; or rather healthy, that the marks of five years old are retained by them until six or seven.

Extrene old age may be further ascertained by the mouth, with moderate accuracy. Up to ten or eleven years old, the teeth generally re? tain their oblong figure and touch each other. From this period the teeth contract in size, be-s come roundish, and leave a small space between them; which space increases up to the fourteenth or fifteenth year, when each tooth assumes an angular shape, and projects forward, irregularly. In another year or two the under lip hangs down, the jaw becomes neaped and contracted, the gum recedes considerably from the roots, and the shape of the teeth is then of an oblong, but di-s. rectly contrary to the first.

Moreover, the eyes of a horse approaching twenty years wax yellowish, he winks much, and the inner skin of his mouth turns outward. If naturally of a grey or roan colour, the darker spots turn rusty, and he is then what they term. "flea-bitten:" gradually he turns grey, beginning with the head and finishing with the legs. 


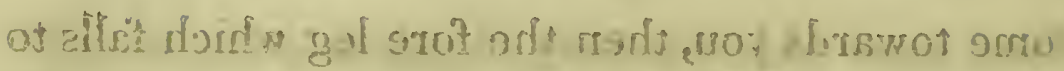

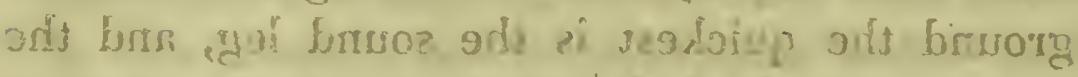

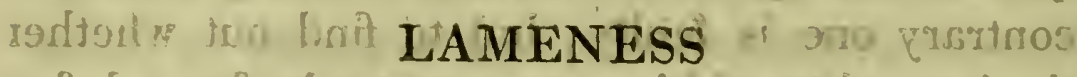

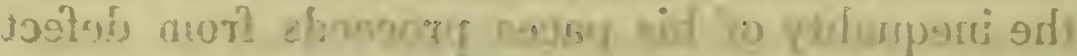

Is not easy of detection, when the horse comes from the hands of a dealer; who of course makes the best of him, and endeavours to inveigle our judgment, and to throw obstacles in the way of examination: Perhaps, when a horse walks queerly, or unaccountably odd, this should be sufficient cause for rejection; but, if he suits the purchaser's purpose in other respects, we are usually induced to look at him a little further, ant this is the reason that the seller always puts his' tit upon the pace he can perform best, commonly the gallop. All paces are natural ones, except backing and cantering, and are all modifications of the walk, trot, and gallop. The roalk is made in four equal steps; the trot in two, and the gallop likewise in two, except at setting off. When the steps are not made in equal time, then is the horse lame. This is observable when he walks, is more apparent when he trots, but is scarcely perceptible when he gallops: therefore to judge whether a horse be lame or not, he should be put upon the short trot, because at the long trot it is more difficult to be discovered by seeing him go, than by hearing, the difference of sound in each alternate step. Hence, it will be seen, we must examine whether a horse be lame by a gentle trot. To judge whether the lameness be before, let him 
come towards you, then the fore leg which falls to ground the quickest is the sound leg, and the contrary one is faulty; but to find out whether the inequality of his paces proceeds from defect in the hind leg, make him trot from you, and that leg which is longest in coming to the ground is affected in some manner or other; and in either case the faulty leg is to be closely examined, according to the instructions before set down, page 447 Even then, unless the person has great experience he is liable to be imposed on, as the poor animal is often lamed of a fore and a hind leg, at the same time: an occurrence that may have been inflicted on one leg in order to counteract the first appearance of actual lameness in the other. To detect this cruel imposition, it becomes necessary to examine every leg, to turn up all the soles, and to ascertain whether the horse has not been pegged between the shoe and the sole, or his "heels opened," by the shoeing smith for the purpose of sale.

\section{EYE-SIGHT.}

Acurte pain affects the eye by contracting it. - tir Thus founder, corn, \&c. occasions one eye to be edéss than the other; and the sympathy that exists between the stomuch and the eyes, has the same sreffect on both when the organs of digestion suffer - Tpain. Small cyes, however, is more frequently in ân original liereditary defect, and are objection- 
able, inasmuch as the horse requires to see before him without turning his head, which he cannot do unless the eye-ball fill the socket; to say nothing? of the known predisposition of such eyes to con-3 tract diseases.

They of the stable term this "buckee," or buck-eyed, though with a very poor taste for natural history; the buck's eye, whether of deer or coney, being large. Very large eyes are equally undesirable; for such horses see too much, are apt to shy, and are also more liable to contract disorders than those of a middling size. A hand. some eye is strong, well placed in its socket, not projecting beyond the eye-lids; the cornea should be transparent, and show distinctly the various humours of which it is composed.

No animal is so subject to blindness as the horse. This arises from the great heat of his blood, and the consiant feverish state in which his great exertions keep him, which occasions inflammation, and thickening of the extremely thin membrane that covers the eye. To discover when this misfortune has commenced, place the horse within the stable door, or under a penthouse, looking outwards; then get behind the head and look sideways through the eye towards the light, whereby you ascertain whether it be clear and transparent as it ought, or whether any spcctis are discoverable, that denote the coming on of a cataract, or perhaps an ill-cured opacity of the vitreous humours. Now bring the horse's 
head to the stable door, and placing yourself opposite him, in that situation exanine all the parts, as well the crystalline lens in the centre, as the urea and the haw of the eye or Whenever any speck, or inequality is perceptible, look "closercto discover precisely what part is affected. The most common defect is one of original construction, and consists of round projections of the ball, chiefly on the lower edge of the uvea or iris. In this situation they are of no actual disservice; but on the other hand become very much so when found on the crystalline lens; for the uvea being capable of expansion and dilatation, these spots appear and disappear before the animal's sight, and cause skittishness.

Blcar eyes, caused by a thickening of the aqueous humour or tears, is termed "moon-eyed," from its increase with the moon;" this however decreases with the changes of the moon, and is capable of cure by treatment as for a cold in the nostril, where the superabundance of this watery secretion naturally escapes by tzeo ducts, that are not lunfrequently mistaken for glandulous chancres. Not so, however, with a thickening of the crystalline humour, which causes cataract and another disorder still more dangerous, which attacks horses that have the best of eyes, and is called gutta serena. When these exist the horse doesinot see well, as may be discovered by his walk; by his lifting his fore legs very high, and

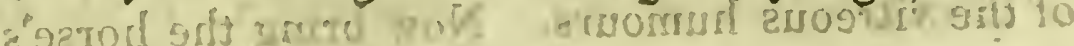


carrying his ears alternately one before and the other behind.

\section{BLOOD-LETTING.}

Every one, almost, can bleed a horse in some way or other, and it is often found extremely desirable that the operation should be performed without delay. But, like many other excellent remedies in the hands of unreflecting persons, this one is frequently employed imperfectly, as well as too often. Each has his peculiar notions, either as to the fit part whence the blood should be taken, the time when it becomes necessary, or the quantity proper to be taken; the latter being the more common error, as it is also the more excusable, inasmuch as they can plead "authority" either way for what they do, is nevertheless demonstrably ruled by wrong principles. The practice of bleeding at given periods, be the quantity taken ever so small, is most injudicious, to say no worse of it; for, why should we employ a curative when there is nothing to cure? especially when we thereby subtract from vitality itself.

"Only bleed in cases of inflammation," say the French farriers, and then they take a large quantity, under the impression that taking a quart, or little more, from a mass of two hundred and twenty quarts, which is fairly calculated to reside in a 
middling-sized horse, "is but trifling with the disorder." The existence of inflammation, or fever, is to be ascertained by the state of the pulse, upon which I was tolerably minute whilst speaking of fever, \&c. (pages $16 \%-1 \% 1$,) the number of beats, and the kind of vibrations, being well considered, previcusly to taking the fleam in hand, when the quantity drawn should be commensurate to the extent of the disorder. Keep in mind, however, the exceeding danger of mistaking one series of febrile symptoms for another, as may be judged of by turning to those of "low fever," at page 180 , when bleeding would destroy the horse. See also pages 184, 5. Without question, if the operator entertains a doubt about the symptoms as indicated by the pulse, the least quantity he takes is likely to perpetrate the smallest amount of harm; whilst, if he be correct in his observations, and has witnessed the good effects of bleeding in strictly similar cases, its inadequacy can effect no good whatever, nor repetition amend the matter one tittle, but the contrary. So that he must be wrong either way.

For, as I proved at the pages before referred to, the disorders for which bleeding is found serviceable depend less upon the quantity of blood that may be in the system at the time of the attack, than upon the construction or "state of the blood*," and the degree of irritation that may exist in the vessels that contain it; both which affec-

* That is to say, the proportions of its then component parts, which is mainly affected by disease. 
tions, or causes of disease, are more frequently to be moved by the manner of taking any given quantity than by the actual weight, or rather the measure thereof. If the blood, for example, be drawn from a small orifice, no matter how rightly judged the quantity may be, however consonant to the proportions I have prescribed at page 171, yet the irritation of the blood-vessels, known by the rigid feel of the artery, will not be reduced, nor the animal recover. "He has been bled," is thrown in the face of the doctor, "and is no better: we have even preserved the blood." But the thing has not been performed with requisite skill. Among other absurdities, the operator will perceive the impropriety of permitting the blood to escape upon the ground, and then guessing at the quantity drawn; than which no practice can be more slovenly and fallacious.

A measure should be provided, marked with graduated circular lines; and numbered from the bottom by pints each. Glass forms the neatest vessel; but percter offers a less brittle material in horse-medicine. The blcod should be preserved awhile in the vesscl, that the form it assumes in coagulating may be noted and remarked upon; as commonly happens most indiscreetly by all bystanders, whether it be caught or not; for very few can pronounce accurately, upon the view, the quantity of disease the blood indicates, particularly when it is on the ground; nor yet when in a ressel, unless it be caught properly. 
Let the vessel be presented so as to catch the blood fairly, and not trickle down the sides, whereby the manner of its coagulation is affected. Blood that is drawn from a healthy horse, soon congeals in nearly one uniform mass, about one fifth of water only remaining at the top; from the residue you may wash away the red or colouring particles, and leave a pale thick coagulum or Jymph. In a pound of such blood will be found these proportions-viz. 8 ounces of thick lymph, 5 ounces of the red or colouring particles, 3 ounces watery. If the operator keeps stirring the blood until it cools, the water does not separate, but the whole forms one homogeneous mass. In cases of great inflammation or fever, the watery proportion is much less, and the blood is then consequently more viscid or thick; which proves that this viscidity is an accompanying symptom of the disorder, as maintained in various parts of this volume; but, as the fever goes on, the animal loses appetite, and he makes no more nerv blood; the blood then becomes thinner in consequence of the deposite of lymph made in its circulation, and the red part predominates. On the contrary, in lire fever and all languishing disorders of a tardy circulation, in cases of cedomatous tumour, the watery part is found in the greatest proportion, and the red part is then almost extinct; in inflammatory fever the red particles predominate, the water is nearly dried up, and the lymph greatly decreases.

Instruments. The fleam and blood stick have 
been attacked as remnants of the old school, but were unjustly stigmatized as a rude method of obtaining blood. In the hands of judicious persons, the fleam has been found equal to every purpose that was required, and when used adroitly no other means of blood letting, probably, ever will supersede it. But during the rage for improvements and new inventions, that prevailed a few years since, they sought to avoid a certain clumsiness of its application by introducing the lancet to general use. True it is, that the awkward method of: making two or three aims with the stick, before striking at the fleam, occasions the horse to shy, especially whilst every vessel of the head was swelling with blood, in consequence of the application of the ligature round the neck; and equally true, that careless operators frequently cut through the vein, so as to cause subsequent disorders; though others, again, dangerously wounded the carotid artery that passes under the vein; yet are there insurmountable obstacles to the general use of the lancet, that can never be overcome.

Of those, I need mention but one objection, viz. the time occupied in making the opening-seldom less than four or five seconds, which causes the animal to move its head, and thus to defeat the intention of making a sufficient orifice, whereby the adipose muscle of fleshy animals is allowed to interpose, and the blood trickles down the neck, and part of it gets underneath the skin. By the way, this happens when the operator does not bleed suf- 
ficiently high up the neck, the skin and muscle being much thicker lower down. Upon large animals, likewise, the lancet is wholly incompetent to its purpose, owing to the very thick teguments it has to pass through, leaving entirely out of consideration the substance of the vein itself. To remedy those objections, the spring fleam is more advisedly employed by less practised hands; and is found to combine the advantages assumed for the lancet, whilst it secures the requisite orifice punctured by the fleam.

Bleeding is now performed without previously applying a ligature, as it became apparent that the blood which was thus detained in both veins, distended also the capillary vessels in the head, which pressed upon the brain. Hence it frequently happened that vertigo came over the animal, filling it with the apprehension of danger. Sometimes it fell down through compression of the brain, and plunged; whereupon the disconcerted operator was known to give it up for a $b a d j o b$, at the moment it became more than ever necessary, charging the fault to account of the horse's restiveness, with an expressed intention of resuming the attempt at some more favourable opportunity. But this was a promise he was seldom able to redeem cleverly; the alarm excited by striking the fleam again and again scarcely ever subsiding, for the tension of the vein would but increase with the continuance of the ligature, and cause it to slip aside more certainly. Apoplexy and death has ensued from the 
same cause, namely; the application of a ligature, and the consequent bursting of the fine blood vessels of the brain.

3. A large vein is more desirable to take blood from, as an evacuation that is to relieve the whole system, than a small one, and the jugular or neck vein, within a hand of the jowl, is ever preferable; because the smaller do not conveniently, admit of making so large an orifice, for the quick escape of the blood, upon which so much benefit depends; nor for the same reason allow of drawing a sufficient quantity at one time, to effect any good upon the spasmodic tendency or irritability of the vessels.

Local bleeding, in the plate vein for example, for a bruise in that region, does not enter exactly into my present view of the subject of blood-letting; though as much service to the part affected may be derived from drawing off from the circulation at the neck vein, as spraying a vein immediately at the seat of the evil. Bleeding in the foot is the only exception I should make; unless the practice of incising the bars of the mouth when the animal will not take his corn, be another, or at least not of importance sufficient to be mentioned at all, even as an exception.

The jugular vein being sought for where it is largest and nearest the surface, this will be found upon pressing it with the finger, a hand's breadth from the setting on of the head, a very little below the place where a branch comes from the 
lower jaw, and joins another from the upper part. The Frenchman instructs his marechal thus pithily on this topic, as on several others- $\$$ Do not bleed your horse in the head, but as near to it as possible." Its situation being thus found, take the fleam between the fore-finger and thumb of the left hand, and pressing gently upor the vein below with the other fingers, the vein will rise; then strike, with stick or spring, as the case may be, and continue the pressure until the proper quantity of blood is drawn off. If this latter necessary attendance is found inconvenient, the ligature may now be applied without danger, but with no additional advantage.

Pinning up the orifice is the final part of bloodletting that is frequently overdone; that is to say, too much of the skin is drawn up over the orifice of the vein, so that the blood will flow underneath the skin, which causes a swelling; and a fistulous tumour is the consequence, that is very troublesome to cure. Where the quantity of blood taken has been small, leaving a redundancy in the system, this latter misfortune is likeliest to happen; but when the quantity taken has been large, and the horse rests quietly after it, the pinning up may be dispensed with, for the blood ceasing to flow of itself, the parts'being brought together will adhere almost naturally, by holding the finger at the oritice for a few seconds. But when you must use a pin, be careful it does not prick the orifice of the brain. 
Is it necessary to add, that the fleam should be clean, and otherwise in good order?

Rules. 1. Always give purging physic after letting blood. 2. Never bleed immediately after a run; nor at the moment pretend to pass judgment on the pulse, as it is then flurried. 3. You may bleed after a fall, or a contused wound; though the pulse be not quick it will then be irregular : incised wounds do not require bleeding, since enough escapes at the wound. 4. If the blood in the measure be very hard, with buff at the top, the animal may be bled again : it indicates high fever. 5. If the blood scarcely coagulates, the poor creature ought not to have been blooded at all.

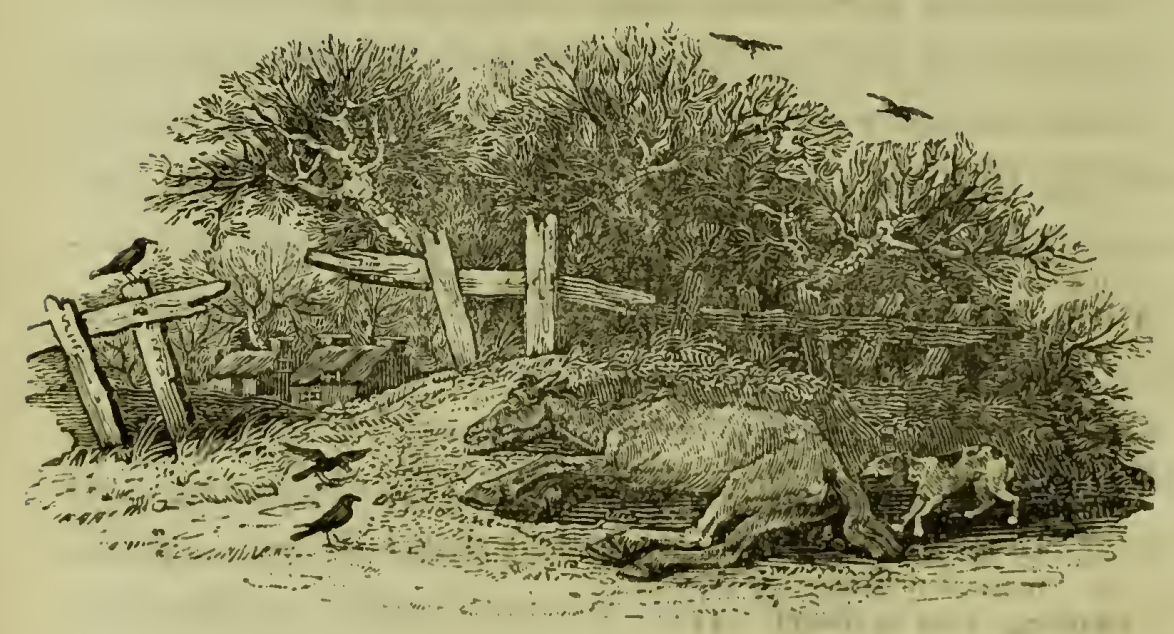




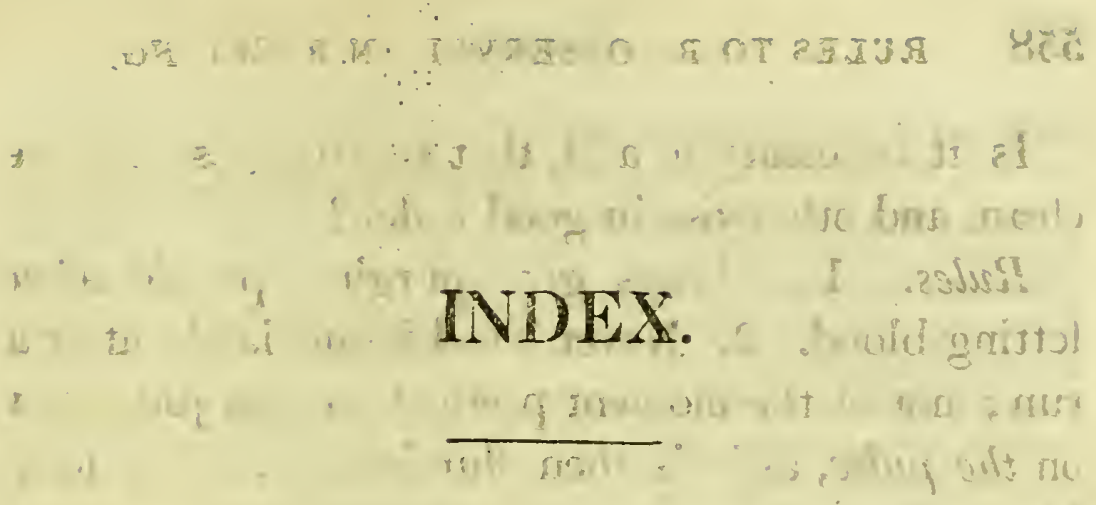

A.

Ascess and tumours, how engendered, 292 critical, treatment of, 301 ,

Re drawing poultice, 302 deep-seated, danger of, 304

Age of horses, how to estimate the, 539

Air, effects of, on the blood, 106

-, confined or noxious, a cause of inflammation, 163

-, the importance of keeping out a draught or current of, in stables, 199

Air cells, controversy concerning, 220

Anatomy of the foot, 441

Animal system, general observations on the, 148

_ definition of the term, 149

—_ how deranged, ibid.

- lesser parts of the, described, 152

Anticor, prevalence of, in France, 372

_- cause, symptoms, and method of curing, 373

Be alterative ball, 374

Arabs, practice of the, in cases of lameness, 445, 464

Arteries and veins, their office, 112

B:

Back, strain of the, cause and symptoms of, 525

- effects of; and remedies for, 526

Back-raking, in cases of costiveness, method of, 186

Bile, excess and deficiency of, 136

Bishoping, how to detect, 541

Bladder, construction of the, 145

_- diseases of the, 147,277

- - , cases of stone found in the, 287 , symptoms and remedy, 278

Blear eyes, cause of, and méthod of treatment, 549

Bleeding, copious, in certain cases recommended, 200, $526^{\circ}$

- - dangerous, after continuance of inflammation, 201

- of the employment of the flcam and blood-stick in, 554

-

- local, remarks on, 556 
Bleeding, modern method of. 555

- , on pinning $u p$ the orifice after the operation of, 557

$\longrightarrow$, rules to be observad in, 558

Blind.gut, its uses, 125

Blindness, why horses so subject to, 548

Blistering, to divert inflammation, considered, 203

Blood, circulation of the, 99

-

, how clearised, 110

, fluidity of the, 115

-, effusion of the, 116

- , the, how made, 128

, healthy, proportions of the component parts of a pound of, 053.3

Blood-letting, remarks on, 550

Blood-vessels of the foot, 437

Bone spavin. See Spavin.

Bones and integuments of the foot and leg, description of the, 44:

Bowels, infammation of the, symptoms of, 239

Breaking-down, cause of, 469

Breeders, advice to, 47

Broken wind, 218. See Organs of Riespiration, $₫ 6$

Brood-mares, treatment of, 49

C.

Calculus, or stone in the bladder, cause of, 284

C., its resemblance to colic, 288

Canine madness, causes of, 416

Canker, causes, symptoms, and method of curing, 505

- treatment in cases of, 506

- how prevented, 508

Cataract, cause of, 549

C'at-hams, how contracted, 35

Circulation of the blood, 99

Cline, Mr., his opinion regarding hereditary roaring, 227

Coffin .joint, strain of the, how caused, 516

Cold, progress of a, 89

mistreatment of a, 96

Cold or Catarrh, causes of a, 205

- remedies in cases of, 210

Colic, a prolific source of inflammation, 238

- - spasmodic or flatulent, symptoms of, 239, 255

- definition and re-production of, $25 \%$

- causes and progress of, 253

$$
\begin{gathered}
\text { B drench, No. } 1.259 \\
\text { sedative Nall, ibid. }
\end{gathered}
$$

Colts, consequences of mounting, too early, 50 
Concretions, cause of, 280 - the cœecum, 125 ; kidneys, 139 ; bladder 145

Coniumption, definition of the term, 217

Contraction caused by paring the sole inconsiderately, $488 \ldots \ldots$

Corns, how caused, 513

Costiveness, causes of, 183

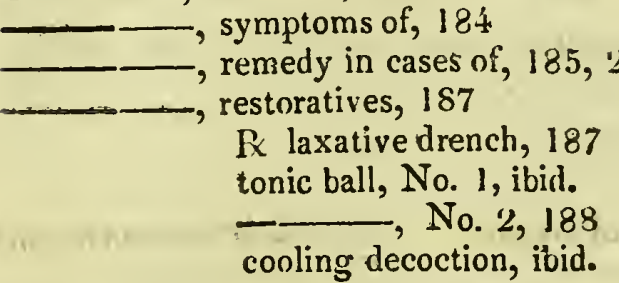

Cough, remedies for, 213

R expectorant ball, No. 1, 215

a laxative ball, 216

a diuretic ball, ibid.

- drench, No. 1, 217

, diet and regimen in cases of, ibid.

Cough, chronic, described, 98

, symptoms of, 229

plethoric, how brought on, 230

remedy in cases of, ibid.

Px purgative ball, 231

periodical, treatment of, 2,32

Re mild purgative ball, ibid.

alterative ball, ibid.

constitutional, 233

Re drench, 234

Curb, description of, and how cured, 456

D.

Dead subjects, duty of examining, 4

Defectireness, constitutional, 292

Diabètes, cause and symptoms of, 280

-_, remedies for, 281

Diet and regimen in cases of cough, 217

Digestion, the process of, 116

Diseases of the lungs, review of, 97

- , origin of constitutional, 130

Disorders, inflammatory, 159

of the foot and leg, introductory observations on, 444

Dissection, how to proceed with, 5

Docking, introduction of the practice of, 153

--, effects of, 414

Dung, an indication of the state of the body, 175 
E.

Ears, the, by their movements, indicate the passions, 156

Eclipse, the race-horse, 13, 25

, weight of the heart of, 101

Englishman's description of a good horse, 536

Eruptions, scurvical, treatment of, 460

Exercise, effects of, 114

Eye, appearance of the, a criterion by which to judge of the constitution, 155 ; and of the age, 545

Eyes, general remarks on the, 547

F.

Farcy and poll-evil, connexion of, 320

$\longrightarrow$, cause of, 304

$\longrightarrow$, symptoms, 366

- treatment and cure of, in its three stages, 367

- mercury, a specific in, 370

Farcy-buds, the free application of the actual cuntery recommended to, 370,371

Px purgative ball, 368

alterative ball, 369

inercurial ball, No. 1, 370

Fever, predisposition to, 161 No. 2, 371

and inflanmation, slight distinction between, ibid.

-, remedies reconmended in cases of, 165

- , high, indications of, 169

, simple, symptoms and treatment of, 170

, danger of relapse, in cases of, $176^{\circ}$

-, low, cause of, 178

-

-

--, typhus or putrid, causes and symptoms of, 189

_-_, epidemic, cause of, 1.91

Fever in the feet, $3.9,462,465$

R purgative ball, 172

clyster, ibid.

fever powder, No. 1, IT

fever drink, ibid.

laxative draught, 181

ligg. See Corns.

diuretic ball, ibid.

Firing, barbarity of the operation of, 154 
Firing, in cases of strains, when proper, 468

Fistula in the withers, cause of, 321

- symptons, 322

, method of cure, ibid.

__ operations necessary in, 325

R cold lotion, $32 \%$

Fleam, the spring, advantages of, 555

Fluidity of the blood, 115

Fomentations, great service of, in strains, 527

Food of the horse, 117

Font, constitutional defects in the form of the, 18

- cutting away the horny part of the sole, reprobated, 154

- a section of the, 431

- structure and pliysiology of the, 426,433

—

_. blood vessels of the, 437

-

, anatomy of the, 441

and leg, description of the bones and integuments of the, 442

, observations on the disorders of the, 444

- remarks on the diseases of the, 499

France, prevalence of anticor in, 372

French method of cleaning sores, 326

notions of strains, 461

military service, instructions to the purchasers of cavalry for the, 535

Founder, causes of, 528

$\longrightarrow$, in young horses, 529

-

_- distinction between acute and chronic, 530

—

- - the effect of inflammatory fever, 532

Frush. See Thrusk.

\section{G.}

Genitals, how nourished, 157

Glanders, how generated, 90

- observations on, 340

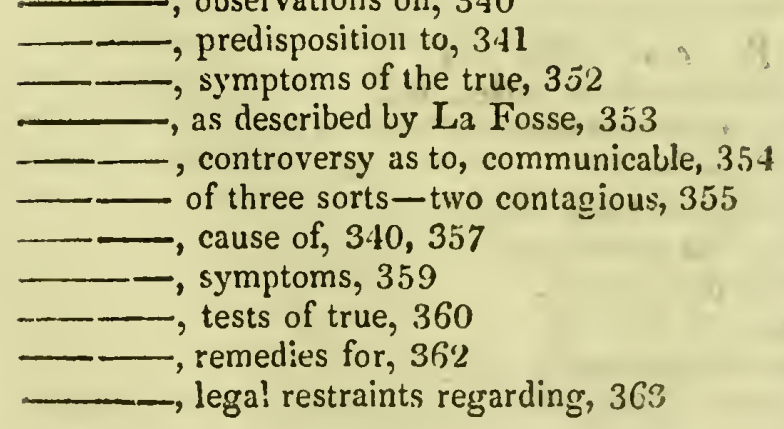


Glands, on the functions and diseases of the, 79, 339

Grease, causes of, 375

_- white feet liable to, 378

, symiptons of, ibid.

-, preventives and remedies, 379

- - , regimen recommended, 383

Bu alum wash, No. 1, 381

strong alum wash, No. 2, ibid.

strongest, or mercurial wash, No. 3, ibid.

diuretic alterative powder, 382

purging ball, ibid.

alterative balls, 382,385

diaphoretic ball, ibid.

ointment, 384

molten, physiology of, 247

, its causes traced, 248

treatment of, 250

Ix sedative clyster, ibid.

Great gut, course of the, 127

Gripes and inflammation of the bowels, distinguishing symptoms between, 239

_- distinguishing symptoms of, 256

Gutta serena, 549

H.

Head, motions of the, indications of pleasure and pain, $3 \%$

- a large, a sign of sluggishness, 45

Heart, structure and functions of the, 7

- organization of the, 100

- , shape of the, 109

, weight of Eclipse's, 101

Hide-bound, caused by internal tumours, 391

, symptoms, 392

, method of curing, 393

$\mathrm{R}_{c}$ alterative laxative, ibid.

tonic, No. 1, 394

- No. 2, ibid.

alterative balls, ibid.

Hip-joirt, treatment in cases of strains of the, 52.3

Hoot, shape and make of the, 30

-, duty of studying deformities of the, 430

bisecting the perfect, 431

- internal structure of the, 43 ?

- component parts of the, 433

- , brittle, a cause of sand-crack, 509

Horse, external structure of the, 12 
Horse, evils resulting from bad make and shape of the, 14

, length of body of the, 41

, hollow back, 43

- food of the, 117

- of the leg and foot of the, 426

- impolicy of working the, too early, 50, 445

, advice to purchasers of a, 534

, Englishman's description of a good, 536

-, criterion by which to ascertain the age of a, 599

, remarks on the eyes of the, $5+7$

, no animal so subject to blindness as the, 548

Hydrophobia, an incurable malady, 415

_- causes of, 416

-

-, in the horse, 419

-_ water no true test of, 420

_—

writers on, 424

R purgative ball, 423 .

\section{I and $\mathrm{J}$.}

Indigestion, diseases of, 124

Inflammation of the stomach, 121, 234

- of the liver, 138

and fever, distinction between, 161

—, causes of, 163,236 , restoratives in cases of, 166

- of the lungs, causes of, 193

-_ symptoms, 194

_- stage horses liable to, 236

- how distinguished from colic, $2: 39$

_ _ of the kidnevs, 139, 240, 271

- _

_

- - liver and kidneys treatment in cases of, 26.5

Iron defence. See Shoeing.

Instructions, French military, for the purchase of horses, 535

Intestines, construction and diseases of the, 121, 234

Jaundice, or vellows, cause of, 267

- symptoms of, 268

K.

Kidneys, functions and diseases of the, 139 
Kidneys, influence of inflamed, 240

- inflammation of the, 271

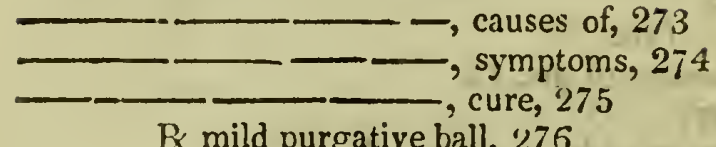

R mild purgative ball, 276

embrocation, ibid.

\section{L.}

Laertes, Mr. Maberly's, a capital leaper, 24

Lameness, test for ascertaining, 447, 547

_- remarks on, 461,546

-

Lampers, or lampas, description, symptoms, and method of curing, 337

Lancet, objections to the, in blood-letting, 555

Lawler, Denis, anecdote of, 522

Leg and foot, on the disorders of the, 444

Legs, mechanical explanation of the form of the, 15

Ligaments and tendons of the foot, 440

Liver, situation of the, 133

- , functions and diseases of the, 135, 262

_- inflammation of the, 138, 262

ulcers and tumours on the, 269

- complaints, and kidneys, discriminative symptoms of, 270

Locked jaw, symptoms, 409

- - , remedies for, 410

-.., treatment of, 411

Lungs, cescription of the, 85

- experiments on the, 90

$\longrightarrow$, review of diseases of the, 97

- ulcer on the, frequently mistaken for worms, 107

- causes of intlammation of the, 193

, symptoms, 194

$\longrightarrow$, restoratives in cases of inflamed, 202

Lymphatics, importance of stimulating the, 81

M.

Madness, canine, causes of, 416

-_ _ - symptoms of, 418

Mallenders and sallenders, cause and cure of, 460

Dange, cure for the, 389. See Surfeit.

Re ointment, 389

alterative for the mange, No. 1, 390

, No. ", ibid. 
Megrims, characteristics of, 407 , remedies, 408

Mrembranes, construction of the, 72

- cellular, diseases of the, 75

Mercury, a specific in farcy, 370

, green food improper under a course of, 371

, precautions necessary in the use of, 401

Midriff, its uses, 72, 92

Millers' hor'ses most liable to stone in bladder, and why, 286

Molten grease. See Grease.

Muscles, their construction, shape, and uses, 76

N.

Nailing, importance of the operation of, 491

-

- improved modern mode of, 495

Nerves, construction and uses of the, 83

O.

Organs, large and small, description of, 57

of respiration liable to several kinds of disease, 96

P.

Pegged, how to ascertain whether a horse has been, 547

Perspiration, 63

Phenomena, the trotting mare, 15,24

Physiology of the stomach, 118

Pinning up the orifice, after bleeding, cautions relative to, 557

Pleurisy, 205

Poll-evil, causes of, 304

-

-

_-, form of bandage for, 313

_ method of operating, in cases of, 314

- , the seton, how applied in, 915

-

- _ and farcy, connexion of, 320

R embrocation, 309

alterative ball, ibid.

irritating mixture, 315

digestive ointment, No. I, 316

scalding mixture, ibid.

- - No. 2, 317

- - No. 3, ibid.

digestive ointment, No. 2, 319 
Pulmonary patients, treatment of, 196

Pulse, observations on the state of the 167,55 !

- a register of the state of the, recommended to be kept, 168

Purchasers of horses, advice to, 534

Q.

Quittor, how caused, 329

- - method of curing, 330

, mild treatment of, recommended, 143

$\mathrm{R}$ first alterative ball, 332

second ——, ibid.

R.

Rabies, incurable, 415

- - means of discriminating the true from the false, ibid.

, prozress of symptoms in, 419

- - nostrums recommended in, 423

Regimen and diet in cases of cold, 217

Relapse, dariger of, in cases of strains, 468

Respiration, its close connexion with the formation of blood, 84

, the organs of, liable to several kinds of diseases, $96^{\circ}$

and exercise, effects of, 114

Ringbone, causes, symptoms, and remedies, 450, 451

Roarers. hereditary, Mr. Cline's opinion respecting, 227

Rules to be observed in bleeding, 558

S.

Saddle galls, how caused, and remedy for, 327

Sand-crack, cause of, 509

- - , symptoms of, 510

-, treatment in cases of, ibid.

--, remedies for, 512

Secretions, uses of, 59 ; redundant and defective, 61

Shoe, shape of the, English, 477

-, French, 478

—, an improved form of, described, 479

- the patent, remarks on, 475,481

—. the jointed, 482; Bracy Clark's, 483; Goldfinch's jointed,

484; Coleman's frog shoe, 485 ; 'Teast's, 498

- , ruinous consequences of trying on the, hot, 490

- importance of the operation of nailing the, 491

Shoes, various, for diseased feet, 496

- 
Shoeing, remarks on, 471,489

, of preparing the hoof for, 487

French method of, 499

Shoulder, conformation of the, 25

-, lameness of the, 39. See Strains.

Sitfasts, how to remove, 328

Skeleton, explanation and practical use of the, 10

Sole, danger of paring the, too much, $47 \%, 488$

Sores. French method of cleaning, $3: 6$

Spavin, varieties of, 453

-

- - symptoms and cure of, 455

Splents, cause and symptoms of, 457

_-, remedies for, 458

___ in sorne instances, occasioned by shoing, 459

By liquid blister, 459

Stables, close, prejudicial to health, 106

- the necessity of ventilation in, 198

Staggers, origin of, 183, 406

___-, varieties of, 405

___ remedics for, 408

-

Staling, excessive, or diabetes, 280

Stallions: on the choice of, 48

Stifle. See Strains.

Stomach, physiology of the, 118

- inflammation of the, 121, 234

Stone, cases of, found in the bladder, 287

Strains, remarks on, $\mathbf{4 6 1}$

- of the back sinew and ligaments, cause of, 462

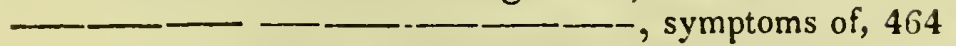

_- danger of relapse in cases of, 468 , method of curing, 465

B embrocation, No. 1, 467

- No. 2, ibid.

blister, No. 3, 468

— of the coffin-joint, cause of, 516 .

____- remedies for, 518

shoulder, cause and symptoms of, 519

__ treatment in cases of, 521

whirl-bone (hip-joint) remedies for, 523

- - stifle, treatment of, ibid.

L_ Lack, cause and symptoms of, 525

Strangles, cause of the, 343

- symptoms of, 344

__ cure of, 346 
Strangles, bandage for, 349

- inoculation for the, 350 of the gullet, ibid. bastard, 351

$R_{K}$ laxative ball, 347

laxative drench, ibid.

stimulating liniment, 348

fumigation, 351

Stringhalt, 19,524

Surfeit, effects of, 38.

- cause, remedy, and cure of, 387

Be wash, 388

T.

Teeth, description of the, 539

Tendons and ligaments of the foot, 440

Thoroughpin, cause of, and remedies for, 452

Throat, sore, remedies in cases of, 210

Thrush or " " frush," cause and symptoms of, 502

__ _ - method of curing, 503

Tongue, state of the, a health-gauge, 155

Tonics requisite after inflammatory diseases, 127

Tumours, internal and external, 132

- on the liver, 269

-_ definition of, 294

—_ how engendered, 295

_-

$\longrightarrow$, the kind of horse most liable to, 298

- on the joints, 300

—_ and abscess, general observations on, 292

\section{U.}

Ulcer on the lungs, frequently mistaken for worms, 107

Urinary organs, diseases of the, 278

Urine, secretion of the, 142

--, chemical analysis of, 144

- a good indication of the state of the body, 175

- -, suppression of the, 273

- balls, evil effects of, 275

-_. incontinence of, 282

_- bloody, causes of, and treatment recommended, 283

V.

Veins and arteries, their co-construction, 112 
Ventilation of stables, the importance of, 198

Veterinary knowledge, the advantages of, 1

Vives, description, cause, and symptoms of, 332

- , its connexion with farcy and glanders, 335

- cure for, 334

-._., false, method of removing, 336

Rx lotion, ibid.

\section{W.}

Warbles. See Saddle galls, and Sitfasts.

Water, no true test of rabies, 420

Whirl-bone, strain of the, remedies for, 523

Wind, broken, how acquired, 218

-

, causes of, 222

, regimen in cases of, 223

Re tonic ball, 224

ball, ibid.

Windgails, causes of, 451

Win , temporary cure of, 452

Windpipe, corsstruction of the, 87

Withers, fistula in the, 321

Worms, general remarks on, 395

_- causes of, 396

—_ distinguishing symptoms of, 397

, regimen recommended in cases of, 399

-

R No. 1, mercurial bolus, 401

No. 2, purgative ball, ibid.

No. 3, laxative alterative balls, 402

laxative powder, No. 1, 404

— balls, ibid.

—- powder, No. 2, ibid.

Y.

Yellows. See Jaundice.

THE END.

LONDON :

PRINTED BY THOMAS DAVISCN; WHITEFRIARS. 


\section{THE}

\section{ANNALS OF SPORTING,}

('Published on the 1st of every Month, price 2s. Gd. each $\boldsymbol{\Lambda}^{\top}$ umber,)

\section{A MAGAZINE,}

ENTIRELT APPROPRIATED TO

\section{SPORTING SUBJECTS;}

Containing every Thing worthy of Remark on

RACING,
HUNTING,
COURSING,
SHOOTING,
FISHING,

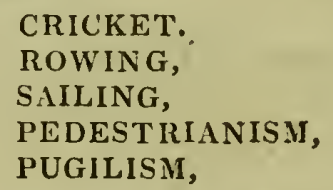

\author{
WRESTLING, \\ SINGLE STICK, \\ BILLIARDS, \\ COCKING. \\ \&c. \&c.
}

Accompanied with Striking Representations of the various Subjects, Drawn and Engraved by emirient Artists.

* * It is intended, by a decided superiority in Paper, Printing, and Illustration, to place the ANNALs of SPortivg far above the reach of competition, and to render it an appropriate ornament to the I ibrary of the Country Gentleman and the Man of Fashion. 'The Drawings are inade from life by the most esteemed Artists; and the Representations of FIELD-SPORTS are either engraved in the line manner, in the first style of excellence, or beautifully coloured after Nature, which, from their very superior execution, have the effect of so many "Animated Pictures." 'The work is further illustrated with numerous Engravings on Wood; and the Subjects include the best breeds of Horses and Dogs used in the Field; also every species of known Game in the habitable world.

Every Six Numbers of this interesting Work form a Volume, price 17s. each, handsomely half-bound; in these is recorded every occurrence and improvement connected with Field-Sports, subsequently to January, 1822, furnishing a complete

\section{REGISTER OF SPORTING SUBJECTS.}

In consequeric 3 of several applications from Country Gentlemen and Collectors of Pictures, to sell the Illustrations to the AN NALS OF Sipontro separately from the Work, and with a view to gratify the wishes of the Sporting World, as also Amateurs and admirers of the Fine Arts, the Publishers have been induced to take off a limited number of Impressions, which may be had for the purpose of Framing, or for the Portfolio. 





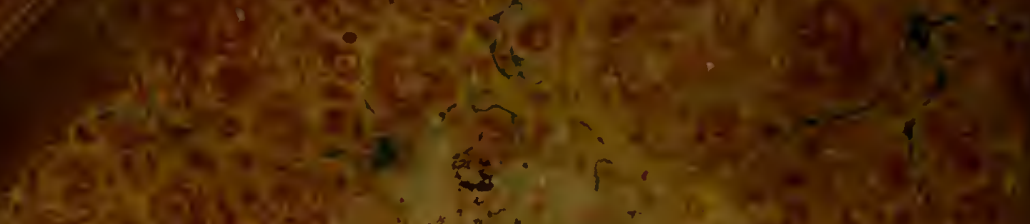

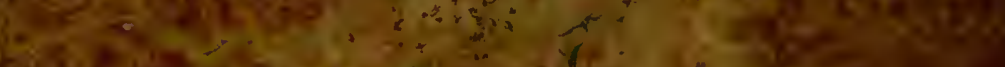

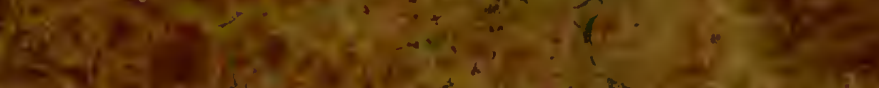

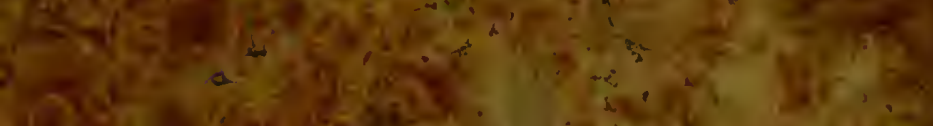

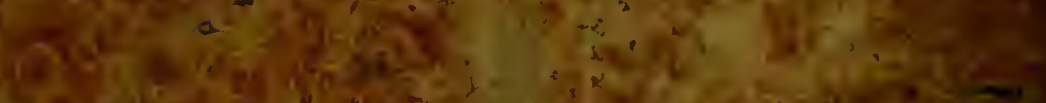

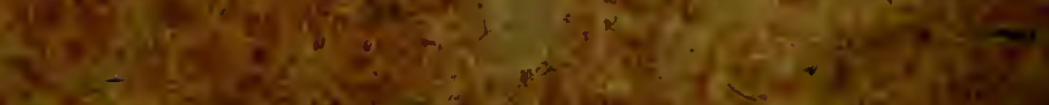

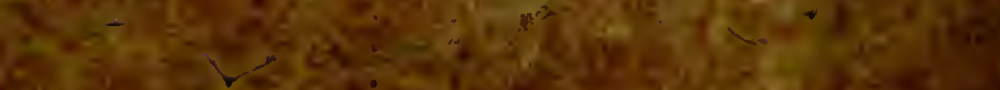

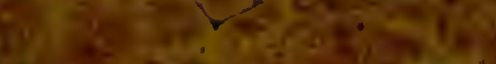

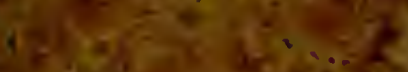

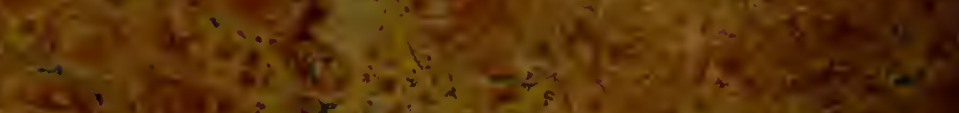

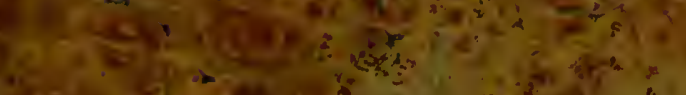

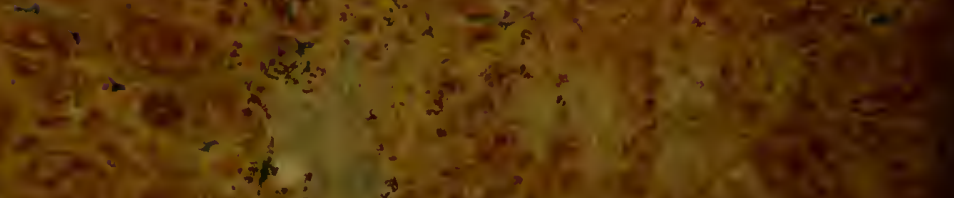
Q9.

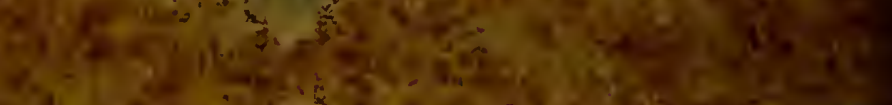

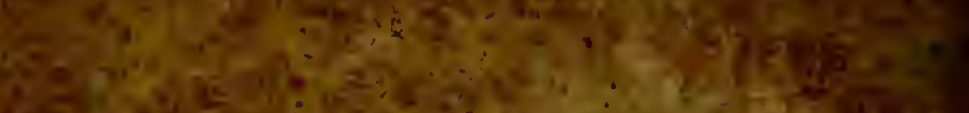

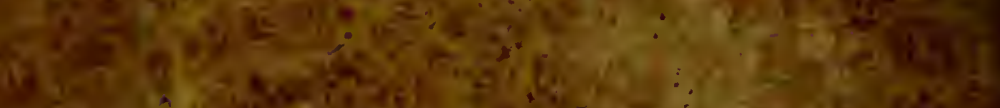

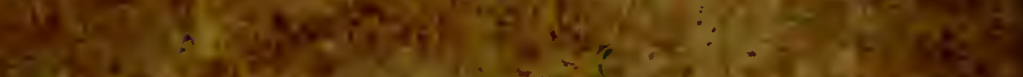

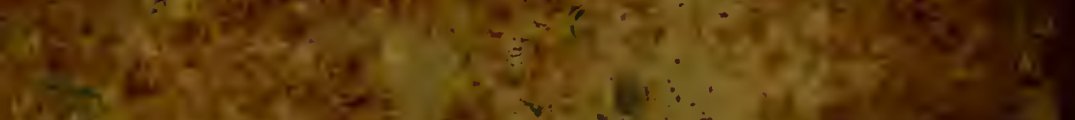

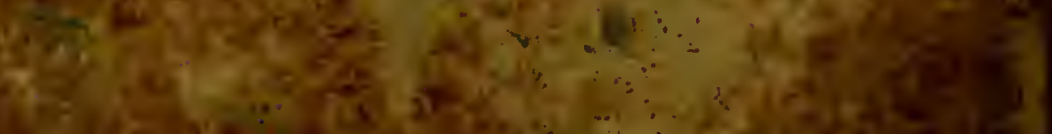

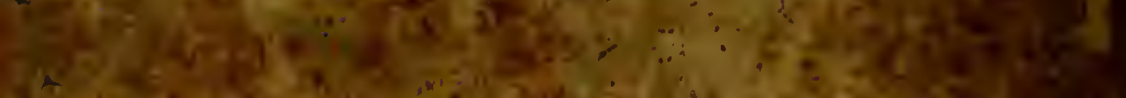

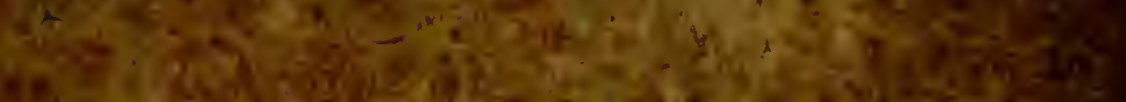

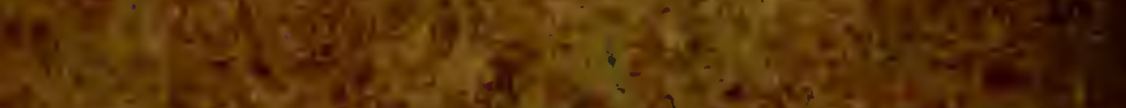

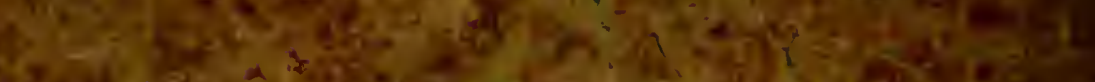

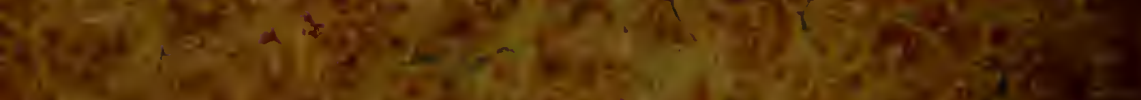
lis

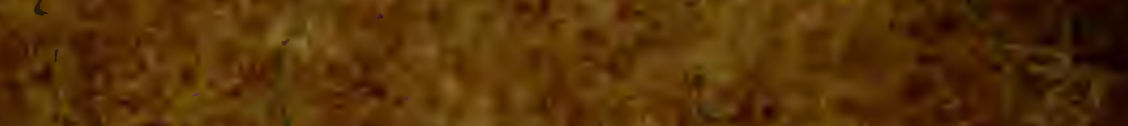

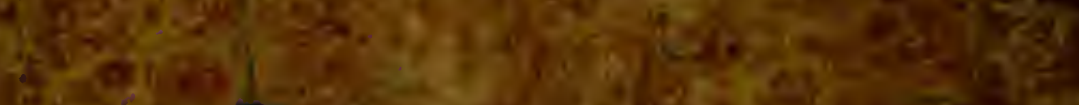

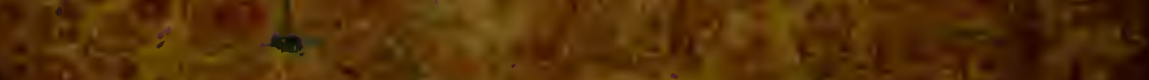
Q

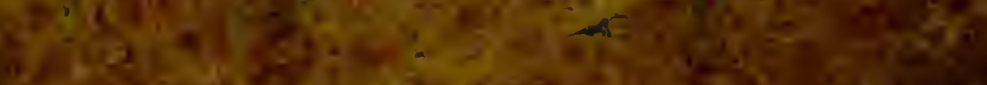

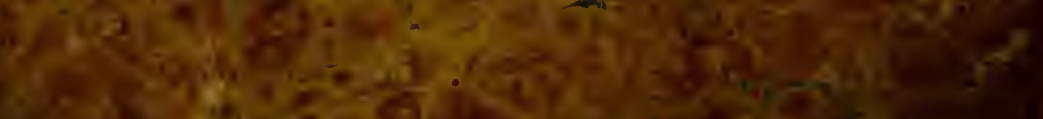

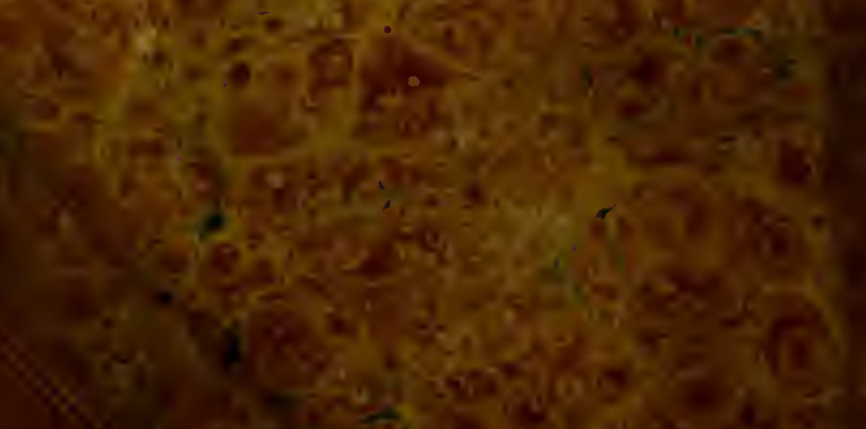

